\title{
Gendering labor: How foreign direct investment affects state behavior towards female labor in South and Southeast Asia
}

Ritu Dhungana

Follow this and additional works at: https://researchrepository.wvu.edu/etd

\section{Recommended Citation}

Dhungana, Ritu, "Gendering labor: How foreign direct investment affects state behavior towards female labor in South and Southeast Asia" (2015). Graduate Theses, Dissertations, and Problem Reports. 5490. https://researchrepository.wvu.edu/etd/5490

This Dissertation is protected by copyright and/or related rights. It has been brought to you by the The Research Repository @ WVU with permission from the rights-holder(s). You are free to use this Dissertation in any way that is permitted by the copyright and related rights legislation that applies to your use. For other uses you must obtain permission from the rights-holder(s) directly, unless additional rights are indicated by a Creative Commons license in the record and/ or on the work itself. This Dissertation has been accepted for inclusion in WVU Graduate Theses, Dissertations, and Problem Reports collection by an authorized administrator of The Research Repository @ WVU.

For more information, please contact researchrepository@mail.wvu.edu. 
GENDERING LABOR: HOW FOREIGN DIRECT INVESTMENT AFFECTS STATE BEHAVIOR TOWARDS FEMALE LABOR IN SOUTH AND SOUTHEAST ASIA

\author{
by \\ Ritu Dhungana \\ Dissertation submitted to the Eberly College of Arts and Sciences \\ at West Virginia University \\ in partial fulfillment of the requirements \\ for the degree of \\ Doctor of Philosophy \\ in \\ Political Science
}

\author{
Approved by \\ Christina Fattore, Ph.D., Chair \\ Scott Crichlow, Ph.D. \\ Ann Oberhauser, Ph.D. \\ Trisha Phillips, Ph.D. \\ Karleen West, Ph.D.
}

\author{
Department of Political Science \\ Morgantown, West Virginia \\ 2015
}

Keywords: foreign direct investment, women's labor, MNCs, developing countries, EPZs

Copyright 2015 Ritu Dhungana 


\section{ABSTRACT \\ Gendering Labor: How Foreign Direct Investment Affects State Behavior towards Female Labor in South and South-east Asia}

\section{Ritu Dhungana}

This study examines the partnership between foreign capital (FDI) and state in manipulating women's labor. In this dissertation I have two research questions: My first research question is to determine whether the interaction between states and FDI renders workers vulnerable and

unprotected. Other scholars have shown that states have been willing to relax labor laws (and offer non labor-related incentives) in order to attract FDI. My hypothesis is that cultural patriarchy intensifies this relationship between states and FDI, and further weakens the labor laws. My second research question is to identify the causal factors that bring about change in the relationship between states and FDI, and minimize the influence of historical patriarchy. My hypothesis is that, in certain environments, cultural patriarchy has been mitigated by the rise of women's civic engagement. I show that grassroots movements and increased civic participation among women leads to states adopting labor laws that will specifically protect all women workers, especially the most vulnerable ones located in FDI industries. Feminist Methodology approach and gender analysis is utilized to examine the labor policies pertaining to women as workers in the global production. The key to my employment of a feminist approach is to challenge the predominant androcentric views and ways that are perpetuated by the global production. 


\section{Acknowledgements}

I would like to express the deepest appreciation to my committee chair Professor Christina Fattore, who has been an outstanding mentor for me. Without her supervision and constant help this dissertation would not have been possible. I would like to thank Professor Ann Oberhauser for encouraging my research and for allowing me to grow as a person. Your advice on both research as well as on my career have been priceless. I am also grateful towards Professor Karleen West, who was kind enough to take me under her wing during my first few years of grad school. I would also like to thank my committee members, Professor Scott Crichlow, and Professor Trisha Phillips for serving as my committee members even at hardship. I would especially like to thank my peers Samantha Godbey and Sera Matthew. Our endless angry rants on weak status of women all over the world have added to the understanding of the problem I address in my Ph.D. thesis.

A special thanks to my family. Words cannot express how grateful I am to my parents, Sushil Prasad Dhungana and Mina Dhungana, and my grandparents, Gopal Prasad Acharya and Rama Acharya, for all of the sacrifices that they've made on my behalf. I am also grateful towards my sister, Kritika Dhungana, for always cheering for me even when I doubted myself. I would also like to appreciate my extended family for their support. Your encouragement was what sustained me thus far. I would also like to thank all of my friends who have been there for me in every major life moments. At the end I would like express appreciation to my beloved husband, Sanjay Adhikari who was always been my support. Thank you for being the voice of the reason in the moments when there was no one to address my doubts. 


\section{TABLE OF CONTENTS}

CHAPTER 1: INTRODUCTION

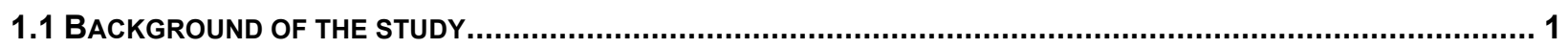

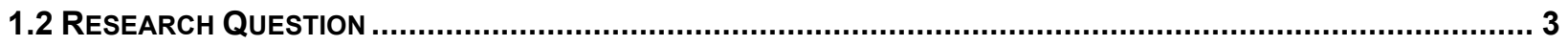

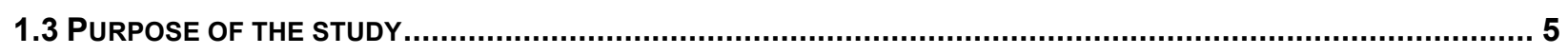

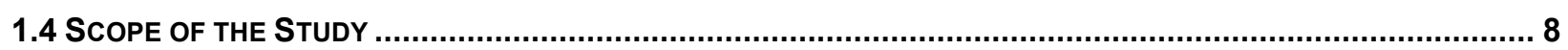

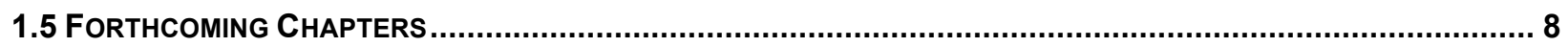

CHAPTER 2: THEORETICAL FOUNDATIONS OF DEVELOPMENT THEORY 11

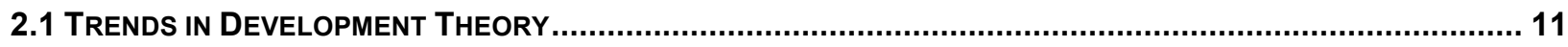

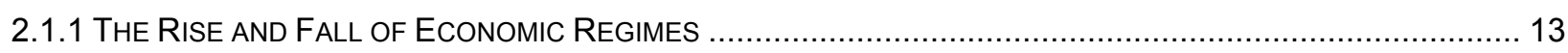

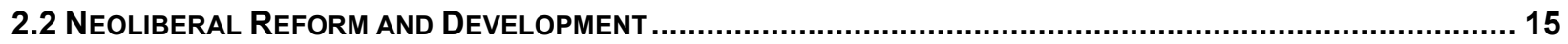

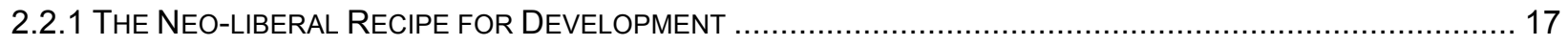

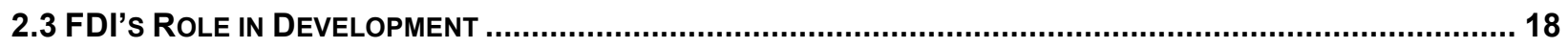

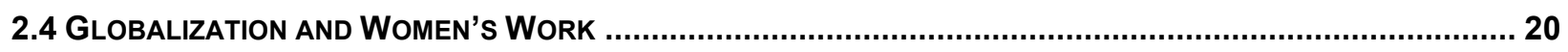

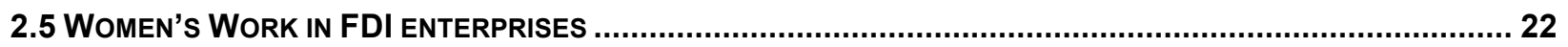

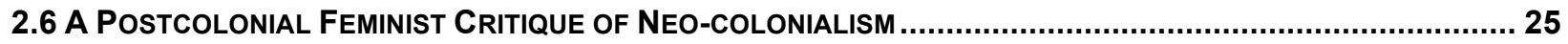

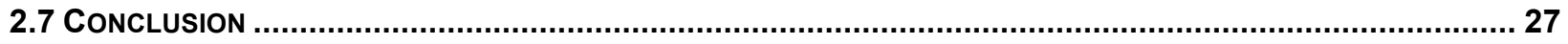

CHAPTER 3: WOMEN'S LABOR IN THE GLOBAL PRODUCTION

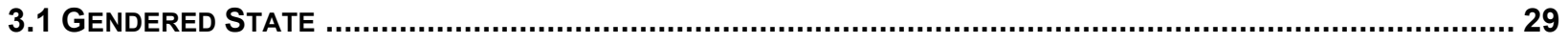

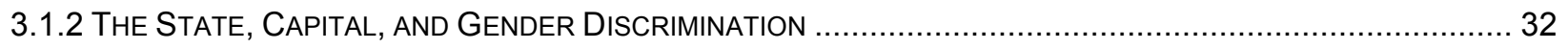

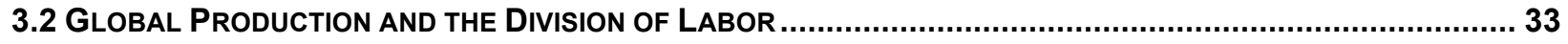

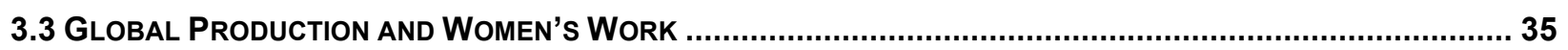

3.4 FACTORS INFLUENCING THE FORMATION OF GENDER IDENTITIES IN MODERN SOCIETIES .......................... 37

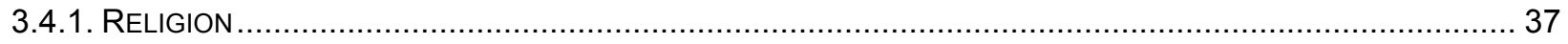

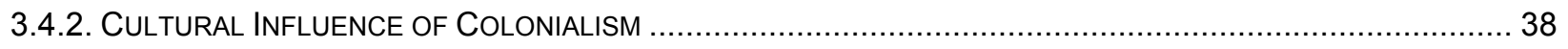

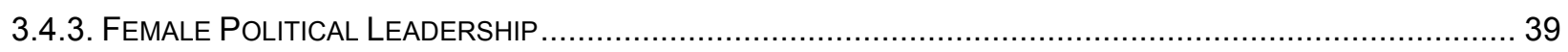

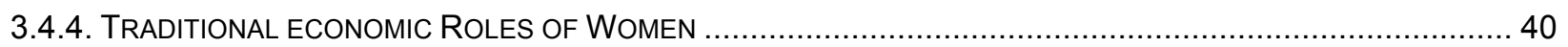

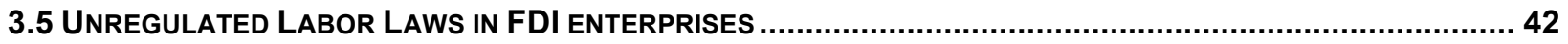

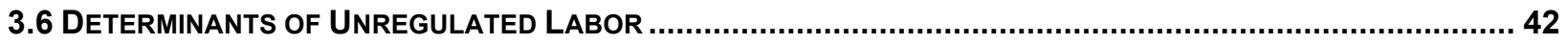

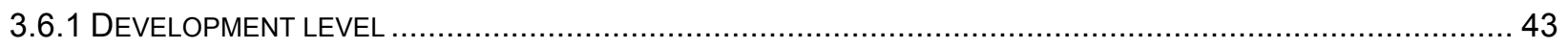

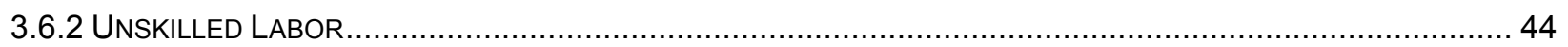

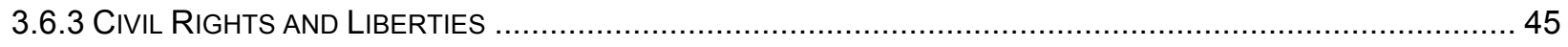

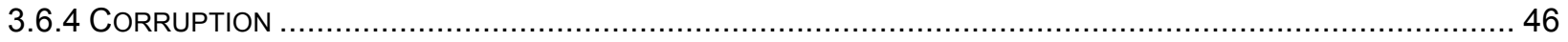

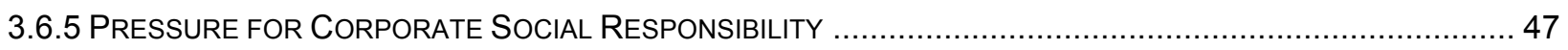




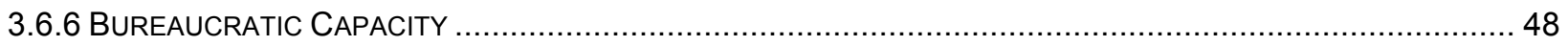

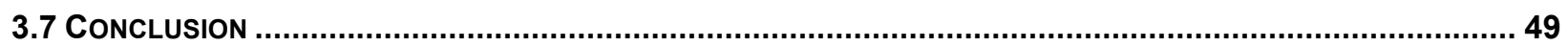

CHAPTER 4: CONDUCTING THE RESEARCH

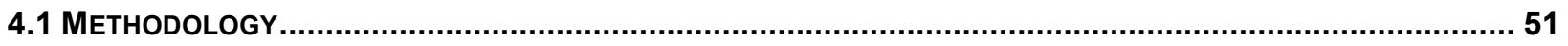

4.2 METHODS

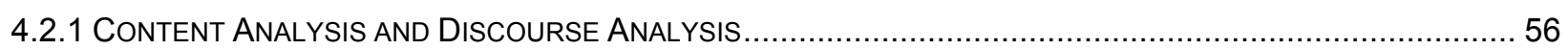

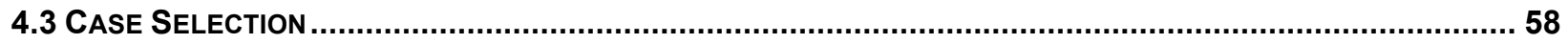

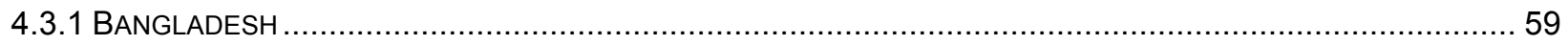

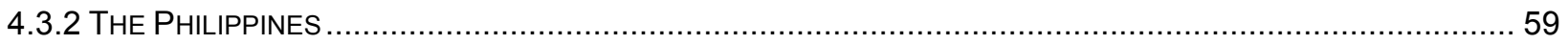

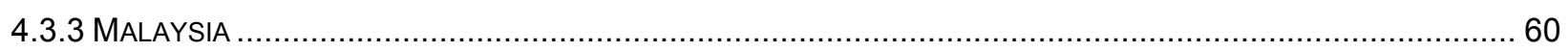

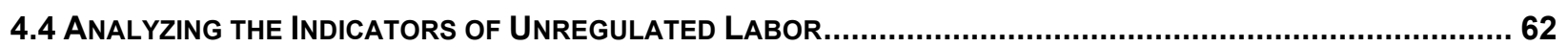

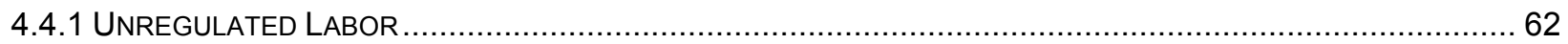

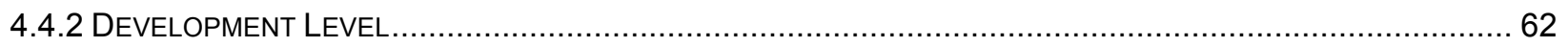

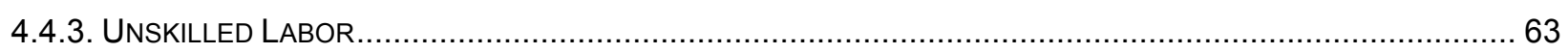

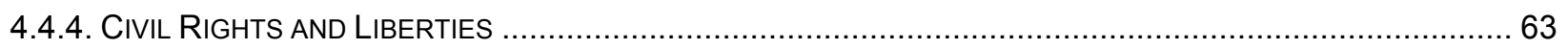

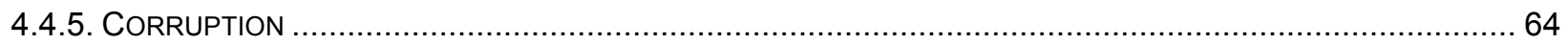

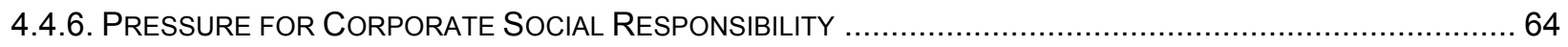

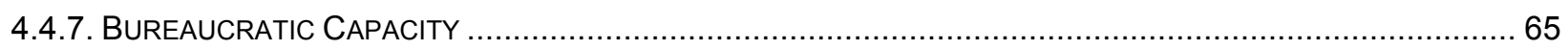

4.5 CONCLUSION

\begin{tabular}{lr} 
CHAPTER 5: BANGLADESH & 67 \\
\hline
\end{tabular}

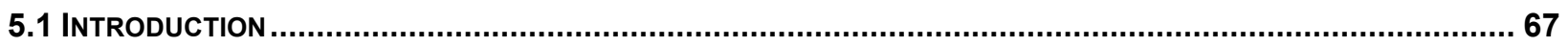

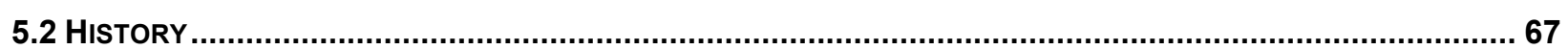

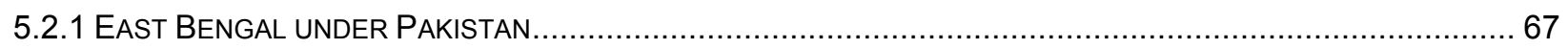

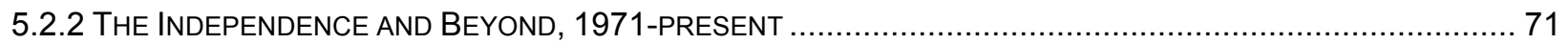

5.3 FACTORS INFLUENCING THE FORMATION OF GENDER IDENTITIES IN BANGLADESHI SOCIETY...................... 73

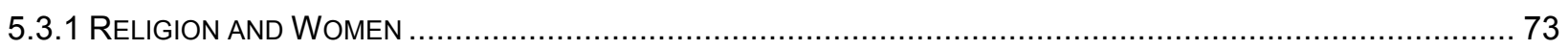

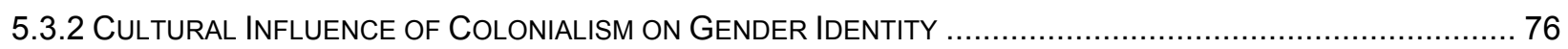

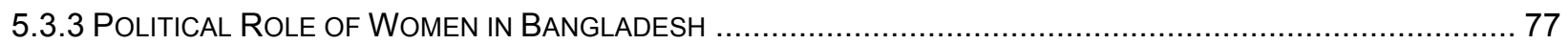

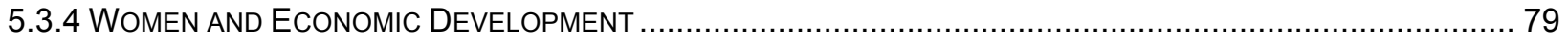

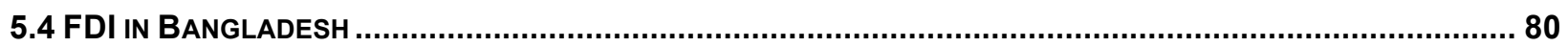

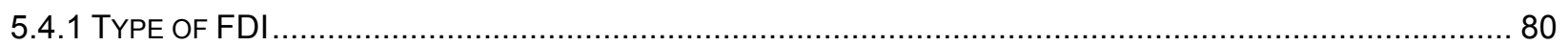

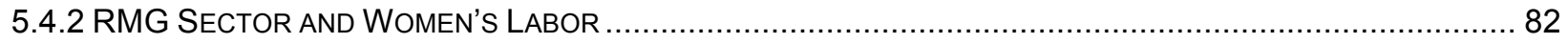

5.5 DETERMINANTS OF UNREGULATED FEMALE LABOR IN RMG SECTOR ................................................. 84

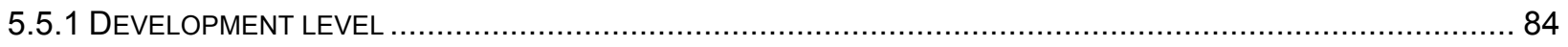

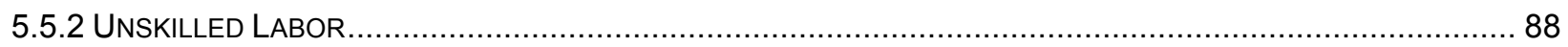




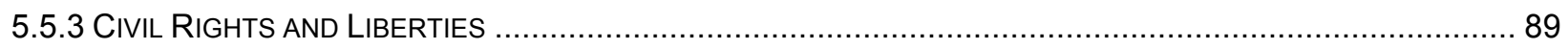

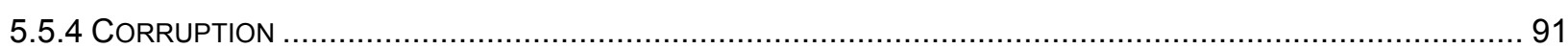

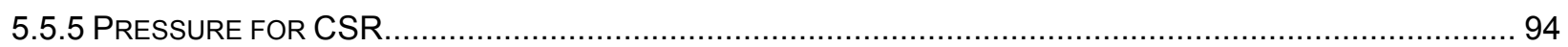

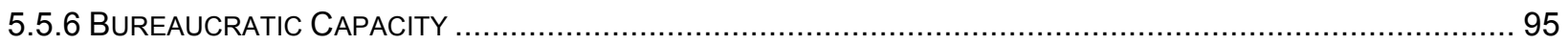

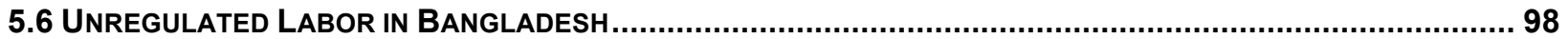

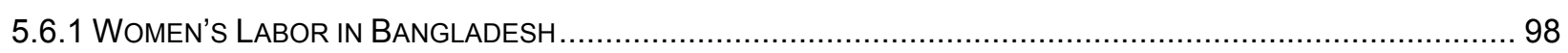

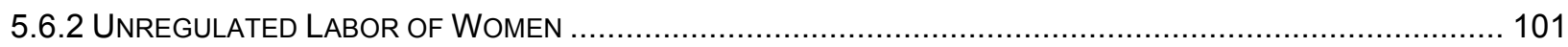

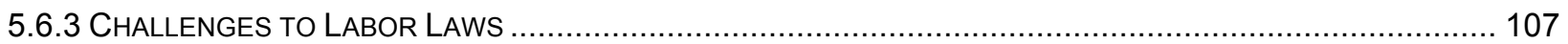

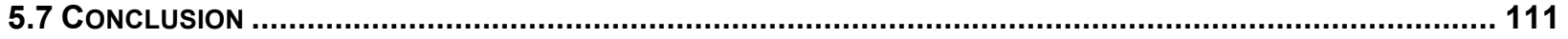

CHAPTER 6: THE PHILIPPINES 112

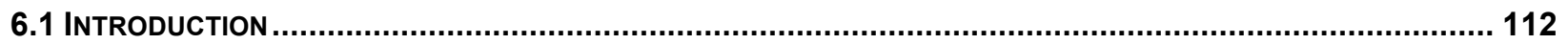

6.2 HISTORY

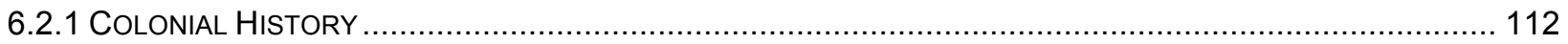

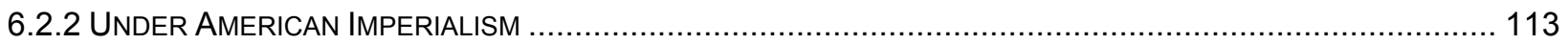

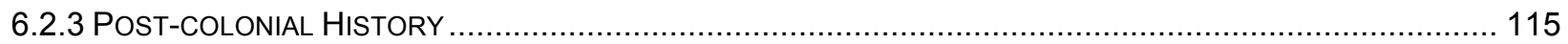

6.3 FACTORS INFLUENCING THE FORMATION OF GENDER IDENTITIES IN FILIPINO SOCIETY ............................ 117

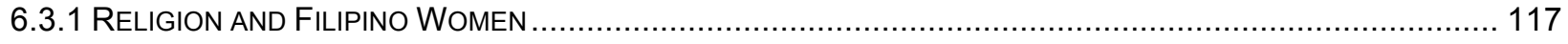

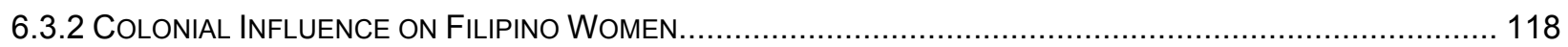

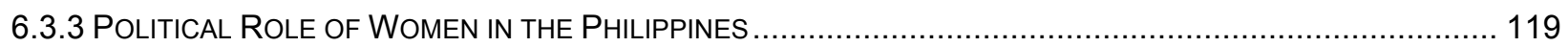

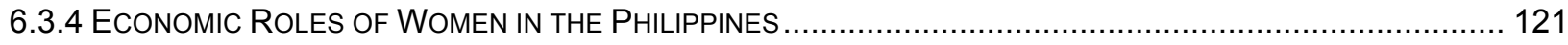

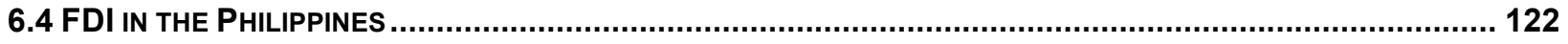

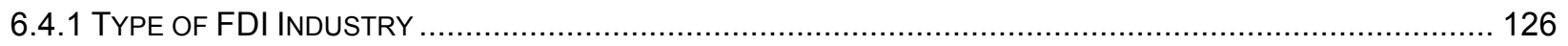

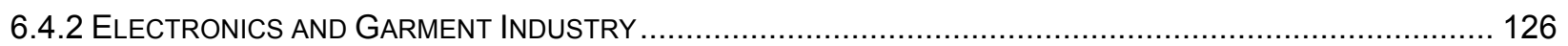

6.5 Determinants of UNRegulated Female LABOR IN THE PhILIPPINES............................................... 128

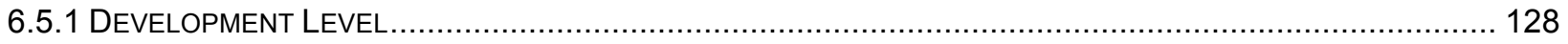

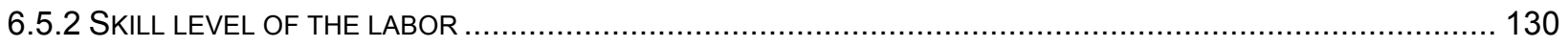

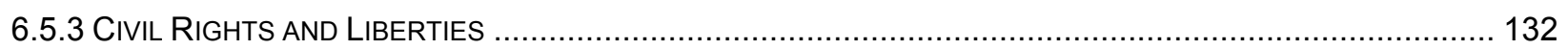

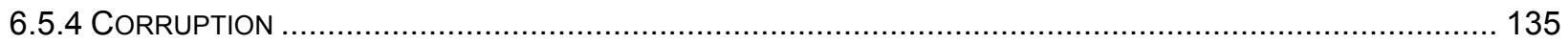

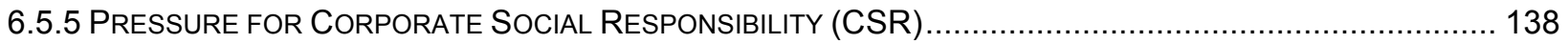

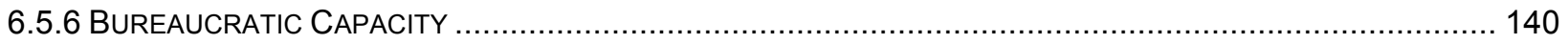

6.6 UNREGULATED LABOR: FEMALE LABOR IN EXPORT ORIENTED INDUSTRIES ........................................ 143

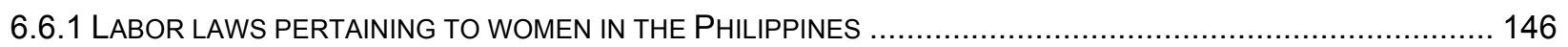

6.6.2 LABOR ACTIVISM AND WOMEN WORKERS IN THE PHILIPPINES................................................... 149

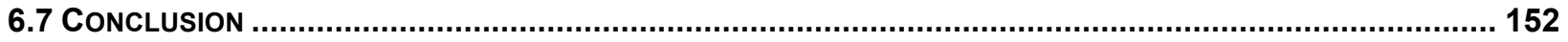

\begin{tabular}{lr} 
CHAPTER 7: MALAYSIA & 154 \\
\hline
\end{tabular} 


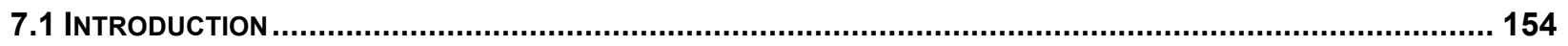

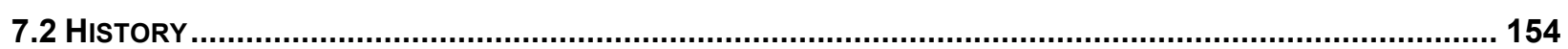

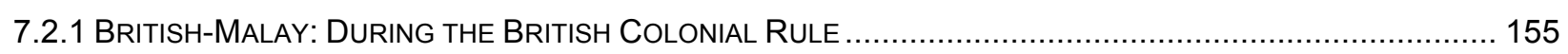

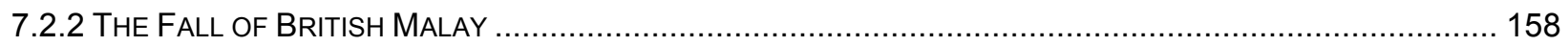

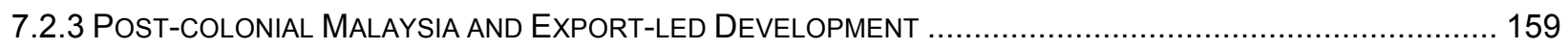

7.3 FACTORS INFLUENCING THE FORMATION OF GENDER IDENTITIES IN MALAYSIAN SOCIETY....................... 161

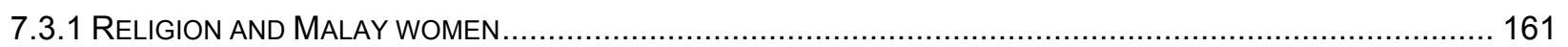

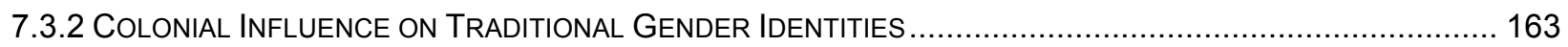

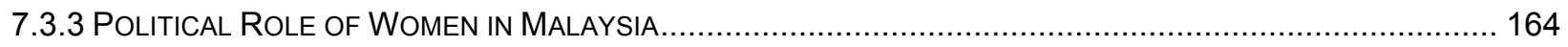

7.3.4 ECONOMIC ROLES OF MALAY WOMEN IN THE EXPORT-ORIENTEd FACTORIES.................................... 165

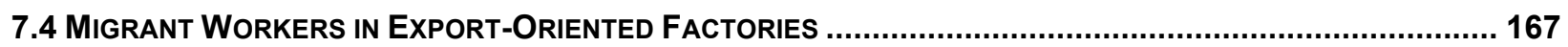

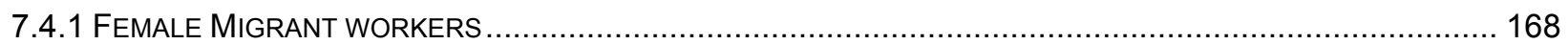

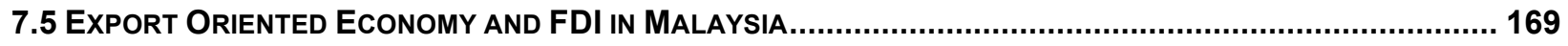

7.5.1TYPE OF FDI: ELECTRONICS AND ELECTRICAL (E\&E) PRODUCTS ................................................... 171

7.6 DETERMINANTS OF LESS REgULATION OF LABOR IN EXPORT-ORIENTED INDUSTRIES IN MALAYSIA ........... 173

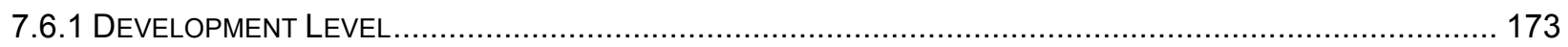

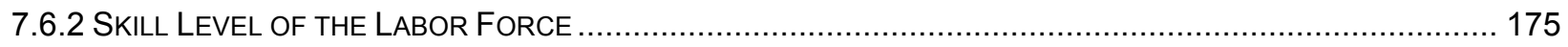

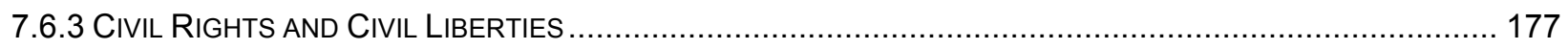

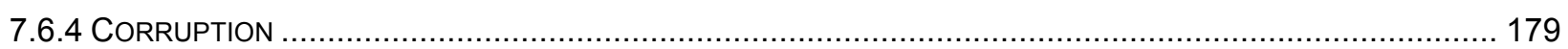

7.6.5 PRESSURE FOR CORPORATE SOCIAL RESPONSIBILITY (CSR) ................................................... 181

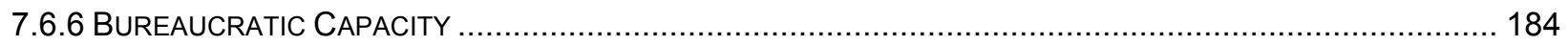

7.7 UNREgULATED LABOR: FeMALE AND MIGRANT LABOR IN MALAYSIA ............................................... 187

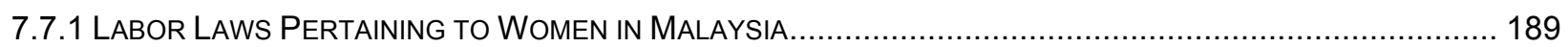

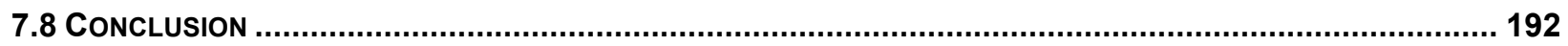

\begin{tabular}{lr} 
CHAPTER 8: CONCLUSION & 194 \\
\hline
\end{tabular}

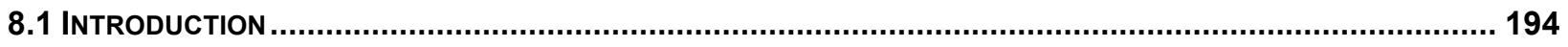

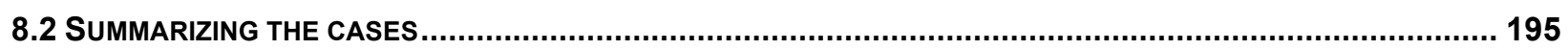

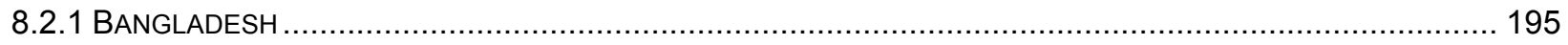

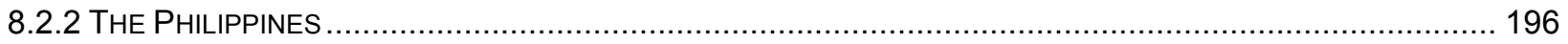

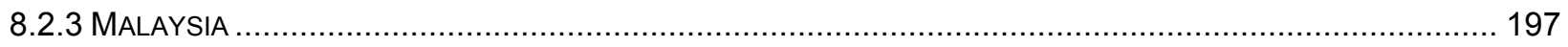

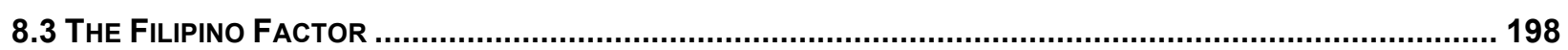

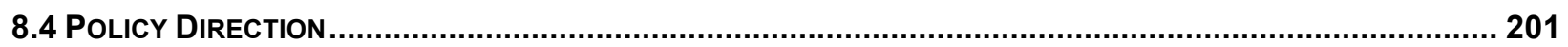

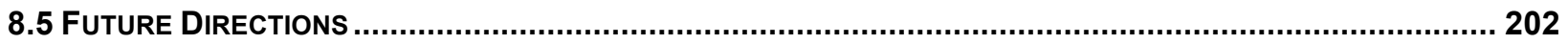

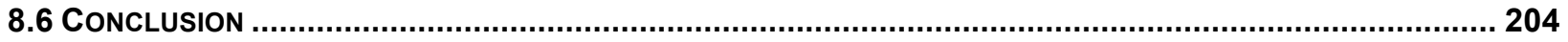

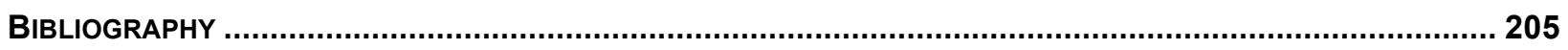




\section{LIST OF TABLES}

TABLE 1: APPLYING MILLS' METHOD OF AGREEMENT IN THE CASES 58

TABLE 2: DIFFERENCES AND SIMILARITIES IN THE SELECTED CASES 61

TABLE 3: EXEMPTION OF INCOME TAX PERTAINING TO INDUSTRIAL UNITS 87

TABLE 4: CIVIL LIBERTIES RATING, POLITICAL RIGHTS RATINGS, AND PRESS FREEDOM SCORE OF BANGLADESH, 2002-2012 90

TABLE 5: CORRUPTION PERCEPTION INDEX RANKINGS AND SCORES, 2001-2011 92

TABLE 6: TYPES OF CORRUPTION \& ACTORS INVOLVED, 2005

TABLE 7: EDUCATION LEVEL OF FEMALE RMG WORKERS IN CHITTAGONG METROPOLITAN AREA, $2010 \quad 99$

TABLE 8: GENDER DIFFERENTIALS IN WAGES IN RMG IN INDUSTRY, 200199

TABLE 9: GENDER DIVISION OF RMG JOBS (\% OF WORKERS) 106

TABLE 10: REPRODUCTIVE HEALTH CONDITION OF FEMALE WORKERS 110

TABLE 11: THE INCENTIVES OFFERED BY DIFFERENT EPZ AUTHORITIES 125

TABLE 12: VALUE ADDED TO INDUSTRY (\% OF GDP) 130

TABLE 13: CIVIL LIBERTIES RATINGS, POLITICAL RIGHTS RATINGS, AND PRESS FREEDOM SCORES IN THE PHILIPPINES, 2002-2012 133

TABLE 14: PERCEIVED LEVEL OF CORRUPTION OF PRESIDENTS IN THE PHILIPPINES, $2007 \quad 136$

TABLE 15: CORRUPTION PERCEPTION INDEX RANKINGS AND SCORES, 2001-2011 137

TABLE 16: RANKING OF THE ACTIVE ROLES PLAYED BY BUSINESS (BY SECTOR) 139

TABLE 17: FREQUENCY DISTRIBUTION OF ILLNESS AMONG FEMALE WORKERS IN ASSEMBLY LINE 145

TABLE 18: UNION MEMBERSHIP AMONG FEMALE WORKERS (BY SECTOR), 2012

TABLE 19: ETHNIC MAKE-UP OF MALAYSIA 158

TABLE 20: INCENTIVES THROUGH MIDA FOR FDI IN ELECTRICAL AND ELECTRONICS, PETROCHEMICALS AND OLEO-CHEMICALS, FOOD AND AGRO PROCESSING, AND BIOTECHNOLOGY 171

TABLE 21: MAIN INDUSTRIES WITH EXPORT-ORIENTED PROJECTS, 2013

TABLE 22: CIVIL LIBERTIES RATING, POLITICAL RIGHTS RATINGS, AND PRESS FREEDOM SCORE OF MALAYSIA, 2002-2013 178

TABLE 23: CORRUPTION PERCEPTION INDEX RANKINGS AND SCORE, 2001-2011 180

TABLE 24: SUMMARY OF DISCLOSURE IN MALAYSIAN CSR REPORTS, 2000 182

TABLE 25: MANAGEMENT'S ATTITUDES TOWARDS CSR IN MALAYSIA 183 


\section{LIST OF FIGURES}

FIGURE 1: MAP OF THE PARTITION OF INDIA, 1947

FIGURE 2: PERCENTAGE OF EMPLOYMENT IN GARMENT INDUSTRY BY SEX, 2001-2007 83

FIGURE 3: GDP GROWTH (ANNUAL \%), 1980-2010 (5 YEAR INCREMENT) 85

FIGURE 4: EXPORTS OF GOODS AND SERVICES (\% OF GDP), 1980-2010 (5 YEAR INCREMENT) 86

FIGURE 5: PERCEPTION ON POSSIBILITY OF PREVENTION OF FATAL FIRES, BY GENDER 109

FIGURE 6: MAP OF THE PHILIPPINES

FIGURE 7: FOREIGN DIRECT INVESTMENT, NET INFLOWS (\% OF GDP), 1980-2010 124

FIGURE 8: EMPLOYMENT IN TEXTILE, GARMENT, \& LEATHER INDUSTRIES, IN THOUSANDS, 19912009

FIGURE 9: GDP GROWTH (ANNUAL \%), 1980-2010 129

FIGURE 10: MALAYSIA UNDER BRITISH RULE 156

FIGURE 11: MAP OF MALAYSIA

FIGURE 12: PERCENTAGE OF FEMALE BY ETHNIC GROUP IN MANUFACTURING, $2012 \quad 167$

FIGURE 13: GLOBAL FDI INFLOWS IN US\$ BILLIONS 170

FIGURE 14: FOREIGN INVESTMENT IN APPROVED MANUFACTURING PROJECTS (MAJOR INDUSTRY), $2013 \quad 173$

FIGURE 15: GDP GROWTH (\% ANNUAL), 1980-2010 174

FIGURE 16: EXPORTS OF GOODS AND SERVICES (\% OF GDP), 1970-2012 175

FIGURE 17: NUMBER OF POOR HOUSEHOLDS BY RURAL/URBAN LOCATIONS, 1990-2009 (IN $\begin{array}{ll}\text { THOUSANDS) } & 176\end{array}$

FIGURE 18: PERCENTAGE OF FEMALE WORKERS BY INDUSTRY, 2012

FIGURE 19: PERCENTAGE OF MALE WORKERS BY INDUSTRY, 2012 


\section{LIST OF ABBREVIATIONS}

Armed Forces of the Philippines (AFP)

Asian Development Bank (ADB)

Awami League (AL)

Bangladesh Export Processing Zones Authority (BEPZA)

Bangladesh Garment Manufacturers and Export Association (BGMEA)

Bangladesh National Party (BNP)

Board of Investments (BOI)

Bureau of Labor and Employment Statistics (BLES)

Bureau of Workers with Special Concern (BWSC)

Business Protocol Outsourcing (BPO)

Cavite Special Economic Zone (CSEZ)

Central Intelligence Agency (CIA)

Communist Party of the Philippines (CPP)

Corporate Social Responsibility (CSR)

Corruption Perception Index (CPI)

Department of Labor and Employment (DOLE)

Electronic and Electrical (E\&E)

Employment Regulation Act of 1980 (ERA)

Export Processing Zones (EPZs)

Export Processing Zones Workers Association and Industrial Relations Act 2004 (EWAIRA)

Federated Malay States (FMS)

Foreign Direct Investment (FDI)

Free Industrial Zones (FIZ)

Free Trade Zones (FTZs)

General Agreement on Tariffs and Trade (GATT)

General Assembly Binding Women for Reforms, Integrity, Equality, Leadership, and Action (GABRIELA)

Generalized System of Preferences (GSP)

Gross Domestic Product (GDP)

Import Substitution Industrialization (ISI) 
Industrial Relations Act of 1967 (IRA)

Information Technology-Business Process Outsourcing (IT-BPO)

Institute for Global Labor and Human Rights (IGLHR)

Intergovernmental Organizations (IGOs)

International Labor Organization (ILO)

International Monetary Fund (IMF)

International Relations (IR)

International Trade Union Confederation (ITUC)

Kilusan ng Manggagawang Kababaihan (KMK)

Kilusang Mayo Uno (KMU)

Licensed Manufacturing Warehouse (LMWs)

Malayan People's Anti- Japanese Army (MPAJA)

Malaysian Investment Development Authority (MIDA)

Members of Parliament (MPs)

Multi-National Corporations (MNCs)

National Statistical Coordination Board (NSCB)

New Economic Policy (NEP)

New People's Army (NPA)

Newly Industrialized Countries (NICs)

Non-Governmental Organizations (NGOs)

Organization for Economic Co-operation and Development (OECD)

Philippine Commission of Women (PCW)

Philippines Economic Zone Authority (PEZA)

Promotion of Investment Act (PIA)

Ready-made Garment (RMG)

Special Economic Zones (SECs)

Structural Adjustment Policies (SAPs)

Subic Bay Freeport Zone (SBMA)

The Multifibre Agreement (MFA)

The United States (US)

Trade Unions Act of 1959 (TUA) 
Transnational Corporations (TNCs)

Transparency International (TI)

UNFPA (United Nations Population Fund)

WTO (World Trade Organization)

Women Industrial Workers Alliance (WIWA) 


\section{Chapter 1: Introduction}

\subsection{Background of the study}

Globalization has intensified trade relationships between states. It has made capital more mobile than ever before and with that mobility, capital is being invested in places that offer better incentives including tax breaks and lower cost of production. The need for lowering cost of production among states attracting capital investment has increased the demand for cheap labor. In order to fulfill that demand, the outlet that has been exhausted the most is the unskilled labor supply of developing countries, particularly that of women. Women workers are attractive mostly because they are inexpensive and at the same time perceived as passive, docile, and yet dexterous. The weaker position of women in the society has made women who work in low wage jobs largely unprotected. Such unprotected labor have resulted in events like factory fires in Bangladeshi garment factories, where hundreds of women workers perished due to lower health and safety regulations. These events shared an eerie similarity to the Triangle Shirtwaist Factory fire of 1911. The horrifying consequences of the incident in 1911 have led to stronger labor laws both in the United States and at the international level.

However, despite the enactments of such laws at the international level and in developed countries, developing countries have yet to make improvements in the protection of workers who find employment in the factories built by foreign direct investment (FDI). In fact, states entice FDI to enter their state through the promise to relax labor laws (among others). In the past three decades, women's economic roles have changed. It is not that they are seen solely as economic actors as they engage in work outside the home. But, because of the patriarchy within their culture, they are also expected to maintain a traditional role within the household. This means that they are mothers, wives, and daughters. They are torn between their jobs in FDI factories 
and their responsibilities to their families. These societal expectations along with basic biological facts make women, as a whole, more vulnerable than men as workers as well as citizens. So, in this project, I focus on how the interaction between states and foreign capital are amplified by cultural expectations of women's roles inside and outside the home. I expect, in places where cultural patriarchy continues to perpetuate, that women workers will not be protected via domestic labor laws.

Global leaders have unanimously established economic development as a priority since the end of the Second World War. The end of the Cold War led the dominant Western, liberal ideals of economic growth to influence the theoretical discussion on development. What followed was the introduction of trade liberalization policies under the leadership of the Bretton Woods Organizations. Under these policies, development is often measured in terms of industrial advancement of the state. This model allows the capitalist paradigm of development to dominate the policies drafted to assist the global development. The explosion of FDI is a result of such policies.

The Organization for Economic Co-operation and Development (OECD) defines FDI as "the category of international investment that reflects the objective of a resident entity in one economy to obtain a lasting interest in an enterprise resident in another economy" (OECD, 2008). FDI has been praised, as well as criticized, as a means to achieve economic growth for poorer countries. While FDI does lead to higher levels of wealth for the countries in question, scholars are also concerned about the effect it has on the country's citizenry. One factor that has enabled this attraction of FDI in the developing areas is the easy availability of cheap labor. The excess of unskilled labor in the markets of the developing areas have allowed FDI to establish manufacturing industries like apparel industries, food packaging industries etc., which does not 
require complicated know-how for operating at a line level. In these industries, the majority of low-wage labor is comprised of young female workers. Despite this majority, the macro level impact of FDI on social, political, and economic status of working-class women in the FDIdependent economies remains a mystery.

\subsection{Research Question}

In this dissertation I have two research questions: My first research question is to determine whether the interaction between states and FDI renders workers vulnerable and unprotected. Other scholars have shown that states have been willing to relax labor laws (and offer non labor-related incentives) in order to attract FDI. My hypothesis is that cultural patriarchy intensifies this relationship between states and FDI, and further weakens the labor laws. My second research question is to identify the causal factors that bring about change in the relationship between states and FDI, and minimize the influence of historical patriarchy. My hypothesis is that, in certain environments, cultural patriarchy has been mitigated by the rise of women's civic engagement. I show that grassroots movements and increased civic participation among women leads to states adopting labor laws that will specifically protect all women workers, especially the most vulnerable ones located in FDI industries.

Recently, there have been numerous efforts within the global communities in identifying the role of women in the development of a country. The feminist literature has been very active in highlighting the importance of women's work in agricultural and non-agricultural sectors of developing countries. This literature establishes that in many areas, especially Africa, women outnumber men in the agricultural sector (Quisumbing, 1996; Ellis 2005, 2007a, 2007b). However, limitations are still imposed on women's ability to enter the non-agriculture sector. Despite this, women in many developing countries have joined non-agricultural sectors for better 
wage opportunity and income security. FDI has also been established as a significant source of financial support for developing non-agricultural sectors. FDI transfers new technologies and skills, and also opens markets (Borenzstien et al., 1998; Lall, 2000; Moran, 2008; Adams, 2009). Nonetheless, there has not been much effort in studying how FDI affects women. The literature on women and FDI is concentrated in the definition of women's work and working conditions in FDI enterprises.

The literature establishes that governments in developing countries that seek to attract FDI tend to make their legislation favorable for FDI enterprises through tax breaks and relaxed labor and environmental laws (Harrison, 1995; Mabey \& McNally, 1999; Pigato, 2001; Li 2008). With this in mind, I am examining how state facilitates non-protection of women's labor in order to maintain its relationship with FDI. The mobility factor of FDI will allow FDI enterprises to be more powerful as it permits the Multinational Corporations (MNCs) to leave the area whenever the environment is not suitable for them to conduct business to their advantage. This takes away the power of laborers to bargain (Seguino, 2000; Braunstein \& Brenner, 2007). The literature argues that host countries (especially those in less developed countries) are reluctant in allowing the MNCs to control financial jurisdiction (Gilpin 2001). MNCs are prominent enterprises that hold both economic and political powers (Weiler, 2004). After the adoption of trade liberalization policies, MNCs are increasingly becoming influential on trade and economic sectors of developing countries. This influence of MNCs invades the authority of the government to regulate labor laws. Hence, I expect FDI to influence the government in developing countries to regulate labor laws.

FDI has been praised as an attempt to provide a window of opportunity for women to be a part of the developmental process. Host states often assert that FDI enterprises empower 
women by providing income opportunities; however, feminist scholars establish that by ignoring cultural and social roles of women, FDI dissuades women to be a part of the economic process (Moser, 1993; Elson \& Pearson, 2008). These scholars argue that FDI completely ignores reproductive roles, such as household chores, taking care of children etc., of women that are necessary for producing and maintaining the supply of future labor force. FDI's association with women empowerment is linked to provision of productive work, but it demands that women choose between reproductive and productive work. Considering this, I expect that FDI's association with women's empowerment is misleading as it completely neglects elements of cultural and social expectations of women's lives. Therefore, my research question focuses on how these expectations of women's societal roles allow for perpetuation of the non-protection as economic actors.

\subsection{Purpose of the study}

The impact of FDI on the economy of developing countries has been studied intensively. However, the literature has largely focused on macro-level measures of wealth and development. In doing so, the literature has not paid enough attention on women as workers of many FDI enterprises and their relationship with FDI as well as their civic involvement. This is my contribution to the literature. The general knowledge on women and FDI establishes that most of the FDI enterprises in low-income and lower-middle income countries employ women as core laborers in assembly lines. Feminist scholars like Mies (1998) and Elson and Pearson (2008) have also identified how the state advertises women as suitable employees for tediously uniform work in FDI enterprises.

The role of women as economic actors has been ignored for a long time. Time and again, women have been portrayed as passive actors in the process of economic development. This is 
magnified when considering women who work in low-wage jobs and live in a country where cultural patriarchy limits their civic participation. Because of this, there is a lack of political will in protecting unskilled labor, especially women. To assess this, I am using feminist methodology to examine the interplay between states, FDI, and cultural influences on how women workers remain unprotected by examining labor laws. I expect to find that in developing countries where women (in general) are affected by a historically patriarchal society, which therefore limits their political participation, their governments will not adopt or support policies that protect them. I expect to see a lack of laws related to maternity leave, family responsibilities, sick leave, time off due to familial circumstances, and, most specifically, laws against labor organizations that may support these types of legislation. States will do this in order to continue to be attractive to FDI, but there will be no consequences domestically because women are not politically active.

In this project, I am using gender analysis of labor policies adopted by developing states in South and South-east Asia to identify if legislation that protects women workers exists. Many other studies (Nash \& Fernandez-Kelley, 1983; Salzinger, 2003; Harley, 2007) have highlighted the role of women in the global production, but this study is different as it is trying to find women within the context of international relations (IR). Specifically, how does the state interact with foreign capital in order to keep low-wage women workers unprotected. IR, as a field, has overlooked the behavior of states as it pertains to its (human) labor employed in export-oriented economy, other than through the manipulation of laws and rules. In studying the role of women in global production, I am positioning this issue from its economic nature, where women's identification as workers are prioritized, to a political power driven status, where I seek to identify women's position as workers as well as citizens and their treatment by the state in its relationship with capital. Instead of looking at how poorly employers treat women as workers, I 
am interested in examining the role of the state as an intervening level of power where the state can reinforce societal patriarchy by perpetuating the economic oppression of poor women through lack of legislation protecting them and their jobs.

I examine how colonial policies have influenced each state's adoption of export-oriented economy in the post-colonial era. I am using a feminist lens in examining the relationship between states and FDI and how that affects women's status as vulnerable workers. Critical approaches to IR question the "inherently reductionist" view of the state, where it is assumed to be a unitary actor (Steans, 1998, p.108). Those who adopt critical or constructivist approaches define the state as something that is "made by the processes and the practices involved in constructing boundaries and identities between the 'inside' and the 'outside"' (Steans, 1998, p. 108). I am using this view of "the state" in exploring its behavior towards women as workers and citizens. Specifically, I am interested at how a state influenced by a patriarchal society is committed to protecting its most vulnerable worker: the low-wage woman worker. The feminist IR approach will allow me to use gender analysis to establish the power construct within the context of social, economic, and political relations where power is used to "the advantage of some and the disadvantage of others in human terms" (Youngs, 2000, p. 12). Gender analysis challenges the masculine ideologies that are predominant in IR that stress power. The assumptions based on these masculine ideologies produce incomplete analysis where the gendered bases of power plays are left undetermined (Youngs, 2000; Ackerly et. al, 2006; Ackerly \& True, 2010). Instead, I am studying one of the most vulnerable groups in society: lowwage women workers. The key to my employment of a feminist approach is to challenge the predominant androcentric views and to tease out how patriarchal society influences labor laws that affect women. 


\subsection{Scope of the Study}

Again, my research question focuses on the interaction between the state and FDI and how that affects the protection of women workers. Specifically, I am examining the role of the state influenced by the patriarchal society in perpetuating the non-protection of women workers employed by FDI industries in three countries: Bangladesh, the Philippines, and Malaysia. I chose these three cases, as they are all developmental states where the process of development is centrally coordinated by the state and driven by FDI. As mentioned before, IR scholars have moved away from using the terminology of the state to refer to a unitary actor. While it is clear

that the state is not unitary by any means, I use this term to refer to the agencies within that have had a large part in planning the development of the economy as well as those that can pass labor laws that can protect domestic labor. This marriage of the state and foreign investment along with the cultural influences facilitates the non-protection of women workers in these industries through the avoidance of passing legislation to protect women and families.

All of these cases are geographically located in South and South-East Asia and have cultural and societal similarities. The cases have their own developmental history and some have achieved more than others. The time frame for each case is different as well, but all of these states began their journey to economic development after independence from colonial regimes. I will thus be focusing on the post-independence era to track the development strategies adopted by each state.

\subsection{Forthcoming Chapters}

In the remaining chapters of my dissertation, I am trying to establish how the interaction between states and FDI allow for women's vulnerability as workers. This happens mainly through the absence of women's political participation and civic engagement. In chapter $2, \mathrm{I}$ 
discuss globalization and how that has made women more vulnerable to these treatments. This chapter shows how the growing interdependence is bolstered by international policies. This chapter introduces the phenomenon of feminization of labor and how this has been established to cater to the demands for unskilled labor and to lower the cost of production for the corporations. This chapter also introduces the concept of FDI and reviews the literature that establishes and counters the claim that FDI is a strong agent for development.

In chapter 3, I further the discussion on FDI and development by analyzing the role of FDI in the global division of labor. This section also reviews the literature that discusses how FDI uses the female labor as a means to reduce the cost of production. In this chapter, I discuss feminist theory in IR and try and situate this research within the larger literature of feminist IR. I highlight the role of gendered state and how that is perpetuated by capitalism.

In chapter 4, I provide a layout of my methodology and methods for this dissertation. I am using a feminist methodology for this research because the question I ask seeks to make the women workers in the global production visible. I am using comparative case studies to identify the effect of economic development on the state's protection of women workers in my cases.

The following chapters, 5, 6, and 7, present my case studies. I start with Bangladesh, followed by the Philippines and Malaysia. I begin with Bangladesh because Bangladesh is the newest country among the three cases to adopt export-oriented manufacturing as a development strategy. Bangladesh represents the economic status of the Philippines and Malaysia at the beginning of the adoption of the export-oriented economic policy. The final chapter, Chapter 8 , provides a concluding remark on the whole project. This chapter presents a brief summary of my findings and moves on to discuss my future projects. I conclude this chapter with a call for general consciousness on the issue of global gender inequality (both political and economic) and 
how this has been made more pervasive by the current capitalist system as well as the traditional patriarchal culture. 


\section{Chapter 2: Theoretical Foundations of Development Theory}

\subsection{Trends in Development Theory}

One of the early conceptual definitions of development establishes it as a tool constructed by the state to reduce the disorder caused by rapid economic growth in the nineteenth century (Cowen \& Shenton, 1995). Thus, development as a concept originated where the state was assigned the position of the principle actor (Gilpin, 2001). This state-centric view has often led actors to adopt mercantilist policies, whereby exports were encouraged and imports were restrained (LaHaye, 2008). Mercantilism is widely understood as a European economic practice in the time of absolutism. Mercantilism highlights active role of state in the economy (Viner, 1948; Heckscher, 1955). Within this system, the state adopted the policies of providing capital to new industries, exempted them from guild rules and taxes, instituting monopolies in local and colonial market, and incentivized successful producers through titles and pensions (LaHaye, 2008). In this approach, economic activities were not considered to be separate from state regulations; instead, it was viewed as a tool to increase state power. The mercantilist approach to international political economy was driven by national security and self-reliance. Mercantilism thus accentuated wealth consolidation in the domestic arena, and protectionism in the international arena. It emphasized trade with allies and former colonies to exert influence. During the mercantilist era, the sole goal of a state was to consolidate power in all forms (military, economic, and political).

Along with advances in technology and with discovery of other areas to invest in, liberalism took over mercantilism as the main trend in international political economy. Classical liberals challenged the mercantilist's idea of entrenched political interest in the market forces. Classical liberals advocated laissez-faire economics whereby there will be no intervention in the 
market. Unlike the mercantilists, liberals advocated free trade. They emphasized the idea of specialization. This school of thought stressed that the state should drive its energy towards efficient production. Adam Smith, father of modern economics, posited that foreign trade should be based on absolute advantage, whereby the countries in trade only sell products that they have absolute advantage on producing, and buy those that they cannot produce on their own. David Ricardo, another influential economist, took this idea one step further by introducing the concept of comparative advantage. Smith's concept of absolute advantage compares labor productivities across countries, while Ricardo's comparative advantage is determined by labor productivity ratios rather than absolute values of labor productivity (Crane \& Amawi, 1997).

The derivative of this school of thought gained popularity towards the end of the World War II. John Maynard Keynes, a British economist, challenged classical liberalism's promotion of hands-free economics. He advocated mixed economy, predominantly driven by the private sector with a moderate role of government and the public sector. Keynes' approach was marketoriented but it was redistributive. Keynes' success with New Deal made him one of the prominent economists during early post WWII era. Because of his noticeable role in the establishment of the Marshall Plan and the Bretton Woods system, Keynesianism has often been associated with the idea of international interdependence (Rapley, 2004).

The effect of international interdependence in political economy was also promoted and studied by another school of thought. Widely known as neo-liberalism, this school of thought emphasizes the situation of international interdependence and globalization. Neo-liberals argue that realists' assumptions do not consider the changing world conditions. The ease of communication and transportation has allowed capital to be more mobile today than ever. The concept of complex interdependence highlights such reliance on each other and argues that in the 
current world, states are connected through multiple channels, not just military (Keohane \& Nye, 2001). This approach recognizes the importance of transnational entities in driving political and economic forces of the modern world. This ideology situates the modern world along with actors and agendas of the new world that are interdependent on each other.

\subsubsection{The Rise and Fall of Economic Regimes}

The post-WWII era has often been recognized as the emergence of the New World Order.

With the defeat of totalitarian and fascist regimes, the allied groups were able to establish themselves as the protectors of the new regime. At this time, the development thought was not polarized as left and right. The success of Keynesian policies in battling depression made Keynesianism very popular among decision-makers. The war-ravaged Europe was in desperate need for financial assistance to rebuild it. With the Soviet Union getting stronger every day, the whole of Western Europe was vulnerable to totalitarian movement. To prevent Western Europe from falling under communism, the United States came up with a strategy, widely known as the Marshall Plan (Cowen, 1985; Payne \& Thakkar, 2012).

The adoption of Keynesian economics in Western Europe and the United States made postwar capitalism redistributive. Under this system, the government would strive for full employment, along with improved social benefits (Rapley, 2006). With resources being drained by lengthy war, the early post-WWII world was very vulnerable to another depression. It was to prevent that possibility that the allied forces met at the Bretton Woods Conference in the summer of 1944. This conference led to a system that established three major political-economic entities: International Monetary Fund (IMF), the World Bank, and the General Agreement on Tariffs and Trade (GATT). These institutions were designed to insure stability of the international trading system.

Along with the advent of these institutions, there was another shift in the world. In 1947, 
the Indian subcontinent gained its independence from the British, and the process of decolonization began. These newly independent countries were identified as the Third World. The term 'Third World' became popular among the political pundits and statesmen when the Cold War tensions were decreasing and as new independent sovereign states were being created in the 1960s and the early 1970s (Wolf-Phillips, 1987). This region had certain characteristics that were not identifiable to the First and Second World. They were emerging states and were struggling to figure out their place in the political world. They were also largely poor and mostly unindustrialized.

During this period of decolonization, the concept of dependency theory influenced much of the decolonized world. This theory highlighted the disconnected relationship between the 'center' (the developed countries), the 'periphery' (the developing countries), and inequality in terms of exchange between the regions. This movement was motivated to save national resources from Western Imperialism. Theotonio dos Santos defined dependency as "a situation in which a certain number of countries have their economy conditioned by the development and expansion of another...placing the dependent countries in a backward position exploited by the dominant countries" (Dos Santos, 1971, p. 226). The significance of this movement was that it identified the role of western imperialism in hindering the development of the decolonized state (Chilcote \& Johnson, 1983). This theory explained the underdevelopment phenomena by citing the dependency of the underdeveloped world on the developed world.

Asian countries, which were categorized as Third World countries, approached development through industrialization. Initially, the state-led development in these countries adopted the autarkic approaches, but for rapid economic growth, autarky was not sufficient. The strategy that most of the Third World adopted to develop economically was Import Substitution 
Industrialization (ISI). Instead of exporting raw materials and importing the finished goods, the countries would now produce the finished goods by themselves. However, because of characteristics like small domestic market, high cost of startup capital, unskilled labor, inability to exploit economies of scale, and declining terms of trade, ISI failed a as development strategy (Rapley, 2006).

\subsection{Neoliberal Reform and Development}

With globalization and technological advancement, the Third World (from now on South) ${ }^{1}$ was suddenly a new actor in global production. The global interdependence was increasing among the states along with asymmetrical interdependence. The bargaining relationships, in the context of dependency theory, between states have been defined on these pretexts: poor countries with fewer resources are weaker than the rich countries with more resources. Poor countries, unlike rich countries, are also less likely to have intense preferences as the power dynamics have always placed them in subordinate positions. The rich countries have the upper hand in the choices of resources. This led the rich and strong countries to build an attitude that is demanding with intense preferences. The idea of asymmetrical interdependence is derived from the argument that states with relaxed demands have an advantage over those with the more intense demands. The states with more intense demand have to sacrifice comparatively more to get what they want (Keohane \& Nye, 1977). This asymmetrical interdependence between the North and the South explains the Northern interest in the Southern development.

The Northern answer to Southern underdevelopment came in the form of neo-liberal reforms. This school of thought was driven by the assumption that human beings are rational beings who strive to maximize their utility (Rapley, 2004). The advocates of neo-liberal reform

\footnotetext{
${ }^{1}$ I am going to use the South and North as opposed to First World and Third World in the following paragraphs. I used the "First World" and "Third World" in the previous sections to highlight the significance of this divide within the context of the Cold War.
} 
argued that ISI was a failed attempt to increase economic growth because it was capital intensive, created few jobs, and trashed foreign exchange. The advocated solution was to shift to an export-oriented economy (Little et al., 1970; Balassa, 1986). The state actors in the developing world sought economic security. Such insurance came in the form of IMF-sponsored reform package full of structural adjustments.

The neo-liberal reform was furthered by another policy package widely known as Washington Consensus in 1989. The World Bank and the IMF formulated "one size fits all" development policies based on open markets and capitalism. These policies encouraged the idea of the Davos Man, representing the global, economic, and political elites across continents, who will achieve development by embracing free market spirit (Beneria, 2003). The Washington Consensus, formulated in the midst of the foreign debt crisis of late 1970s and early 1980s, attempted to mitigate the problem by implementing structural adjustment policies (SAPs). "Structural adjustment embodies the goals of neo-liberal theory: It places the market at the center stage, assigns the state a secondary role in development, and puts its faith in the potential of unfettered individual initiative, creativity, and ingenuity" (Rapley, 1997, p. 71). These packages become a typical way by which the neo-liberal policies (associated with Washington Consensus) were implemented. SAPs adopted strategies that were aiming to cut government costs. The consequence of adoption of such strategies was elimination of social policies that were oriented towards supporting poor people and the expansion of the income gap between the rich and the poor (Rai, 2002; Beneria, 2003; Visvanathan et al., 2008). Thus, it was mostly poor, women, and children of the developing countries who bore the brunt of this policy.

A major feminist criticism of SAPs maintains that these policies affect gender in both household and market dynamics. As a result of SAPs, women's household cost is increased with 
intensified domestic work, girls were more likely to be pulled out from schools over boys, and time inputs to obtain basic services for them and their family is increased. Similarly, market costs of SAPs are "increase in women's labor force participation" and "changes in the nature and conditions of their employment" (Beneria, 2003, p. 50). Based on capitalistic ideas, these policies suggest market-oriented solutions to the problem of underdevelopment. This "one size fits all" solution has been criticized for its ignorance on societal differences of different countries and dismissal of the social problems created by differences based on gender, class, caste, and race. These policies are suggested to impose western ideals of individuality, personality, and rationality on developing countries.

\subsubsection{The Neo-liberal Recipe for Development}

Neo-liberal theory identifies the role of economics in international political

development. This approach has been promoted as a mechanism for global trade and investment, which can enhance equal development (Shah, 2010). This view argues that the major problems of underdevelopment are tied to the domestic economic factors such as market imperfections, social and political rigidities, etc. of the developing countries (Spero \& Hart, 2009). The neoliberal idea of interdependence was legitimate. No matter how trivially, the North has always been dependent on the South. The North-South trade cycle has always had some elements of interdependence, but it has been asymmetrical.

During colonization, all the resources produced in peripheries were controlled and used by the core. This led them to control all the economic benefits from selling the resources and the products (Velasco, 2002). During decolonization, this practice became prevalent in slightly different forms. The peripheries controlled their resources but they did not have the ability to produce the finished good out of the raw material, so peripheries were exporting cheap unfinished raw materials to the core, and the core was exporting the expensive finished good to 
the periphery. The balance of trade was lopsided where the core was always the beneficiary. Dependency theory explains the current struggle of most of the developing countries. Today, the peripheries are more active in producing the finished product. However in present times, the core augments the value of idea (or brand), which is produced mostly in the core, but the labor used in producing the imagined product has been devalued to control the cost of production. The core, therefore, controls the markets for the products of developing countries along with its economic profit.

\subsection{FDI's Role in Development}

FDI has been identified as one of the effective means to pursue economic development. FDI is defined as "a form of international inter-firm cooperation that involves a significant equity stake in, or effective management control of, foreign enterprises" (De Mello1997, p. 4). Moran (2008) argues that FDI allows an entry point for development for poorer countries with excess unskilled labor through manufacturing and assembly of least-skilled-intensive products. This suggests that MNCs try to locate areas where there is abundance of unskilled labor to reduce the cost of production. Carkovic and Levine (2005) find that "while FDI flows may go hand in hand with economic success; they do not tend to exert an independent growth effect" (p. 221). Further, Lall (2000) posits that, while developing countries regard FDI as a necessary factor in development, it is very hard to measure if FDI induces economic growth. He argues that FDI can offer a variety of resources to developing countries like proprietary and non-proprietary assets comprised of capital, technology, skills and management, market access, and environment. However, he asserts that local firms in direct competition with foreign enterprises are discouraged by such competition, which leads them to avoid expensive trainings and processes that the firm needs to undertake to stay in the competition. 
In reviewing the literature, I found that there is no consensus on whether FDI causes development or development increases FDI. Many scholars maintain that characteristics of hoststates such as state-adopted trade policies, level of development of local financial markets, human capital, per capita income, the degree of openness in economy, and export propensities of FDI determines whether or not FDI will contribute to the economic growth of the country (Zhang, 2001; Hermes \& Lensik, 2003; Alfaro et al., 2004; Herzer et al., 2008). It can be argued that unless there are strong institutions in the recipient country that ensures the financial securities of the investment, FDI is a rare occurrence. FDI prefers stable political and economic environment, therefore they choose not to invest in areas that cannot offer financial securities (Schneider \& Frey, 1985; Asiedu, 2006; Busse \& Hefeker, 2007). This is one of the many reasons why most FDI circulates among the developed countries of the world. FDI's impact is "determined by the country's specific conditions in general and the policy environment in particular in terms of the ability to diversify, the level of absorption capacity, targeting of FDI, and opportunities for linkages between FDI and domestic investment" (Adams 2009, p. 178). Braunstein (2006) found that in 2001 and 2002, developed economies, as a group, received over $70 \%$ of world's FDI inflows.

While there has been much criticism among scholars about the efficiency of FDI to promote development, some argue that FDI is the most effective way to start the developmental process. Adams (2009) finds that FDI contributes to development in two ways: "augmentation of domestic capital and enhancement of efficiency through the transfer of new technology, marketing and managerial skills, innovation and best practices" (p. 178). While there is skepticism about FDIs ability to induce economic growth, one cannot ignore the positive effect of FDI. Nunnenkamp and Spatz (2004) suggest that market-seeking FDI can benefit host 
countries by increasing the level of competition in domestic market through introduction of new skills and technologies. They find that while the FDI induced growth is more visible in economies with favorable characteristics, it is only so because they attract more FDI than economies without favorable conditions. Despite this, many scholars have found that FDI poses a risk of crowding out domestic markets whereby FDI fails to contribute to capital formation in the local market, because foreign enterprises have superior resources and higher leverage (Weeks, 2003; Braunstein \& Epstein, 2004; Huang, 1998). Borensztein et al. (1998) found that FDI is one of the major channels for advancement of technology in developing areas, but only when the human capital in the country is skilled. Hence, human development and skilled labor are very important in effective use of FDI to reach development goals.

\subsection{Globalization and Women's Work}

The adopted policies of trade liberalization and free market expedited the process of globalization and interdependence. The world was smaller, not only in relation to products and markets, but also in labor. Suddenly, due to decolonization, there was a large pool of unskilled laborers in the new independent countries. Further, as a result of exploitative colonial policies, many people in these countries, whose market just opened up, were very poor and largely unemployed. As these countries embarked in the modernization process, they adopted neo-liberal policies, along with suggested austerity measures, to drive the economic development of the country. Deere et al. (2008) found that "structural adjustment policies are forcing families to absorb a greater share of the cost of survival as a result of cutbacks in social services, such as health and education, and the elimination or reduction of subsidies on food, transportation and utilities" (p. 267). This led to constant pressures from international organizations on developing on the states to join the race for development that was driven by strict capitalist measures. One of 
those measures was to open the borders for FDI and, in turn, utilize the unskilled, cheap labor of women.

The rapid growth in East and Southeast Asia has been partly due to the influx of cheap labor in export oriented industries, which has helped many women enter the public economic sphere where they were not able to during the era of colonialism. This phenomenon of the feminization of labor was widely adopted in developing countries that were planning economic growth via export-oriented economy. "Feminization was also encouraged by the widespread conviction among employers in East and Southeast Asia that female employees are more tractable and subservient to managerial authority, less prone to organize into unions, more willing to accept lower wages because of their own lower "reservation" and "aspiration", and easier to dismiss using life-cycle criteria such as marriage and childbirth" (Ghosh, 2009, p. 179). On top of that, technological advancement augmented the use of easily replaceable labor, which made feminization of labor more relevant (Moghdam, 1999; Beneria, 2003; Visvanthan et. al, 2008; Momsen, 2010).

The shift of women entering the labor market led to massive migration among women in search of better economic opportunities. The influx of export oriented industries and the preference of women workers have encouraged women from rural areas to migrate to urban areas (Oishi, 2005; Ghosh, 2009). This migration has also intensified women's economic vulnerabilities, as they have to start from virtually nothing in rapidly growing and expensive urban areas that arise around these FDI ventures. While such influx of industries may be presented as new opportunities for women, it has also, in a way, burdened them. Now it is almost expected of women to work outside of home to support their family. Also, there is no guarantee that working in these industries will provide stable income to the women. Lim (2008) suggests 
that manufacturing industries established by MNCs are "“footloose' because they are not bound to any particular location by a need for local markets or local input sources other than labour, which is abundantly available everywhere" (p. 218). This shows that working in such export industries that benefit from capital flight have made women more vulnerable to economic inconsistencies and informalization of labor.

\subsection{Women's Work in FDI enterprises}

Most labor employed in FDI factories is unskilled. It also happens to be relatively split between men and women. However, IR scholars have not attempted to gauge the impact of measures adopted by the state in light of FDI to reach economic growth on women in the developing countries. FDI allows it the mobility to leave the host economy if there were to be any resistance against the enterprise from the workers. FDI industries can use the unskilled labor of women for a very low cost with high demands (long working hours and bad working conditions). This leaves the workers (and especially women) at the whim of the FDI. While there has been increase in the literature on women and development in recent decades, the literature on FDI and how it affects women politically and economically is still lacking. Most of the literature on women and FDI focuses on the condition of women workers in the factories operated by FDI or the definition of women's work, not on the alliance between the state and FDI. The following paragraphs will discuss the literature on FDI and its effect on women.

When it comes to the role of FDI in increasing women's economic freedom, the literature is not conclusive. Scholars argue that women have gained economically from FDI with increased access to employment, which has assisted in narrowing the wage gap between men and women (Mehra \& Gammage,1999; Standing, 1999). Mehra and Gammage state "Sectoral trends in women's employment parallel the global trends and reflect improvements in employment 
patterns suggested by the broad shift from agricultural to nonagricultural employment" (1999, p. 537). An increase in women's participation in workforce is often linked to high net inflows of FDI. However, it could be that factors driving feminization of the labor force are also driving FDI (Braunstein 2006; Curd et al., 2007).

In her review of the literature, Braunstein $(2002 ; 2006)$ finds that usually the studies on FDI are not examined with a gender lens. Most of them tend to focus on small-scale case studies, which question if the employment in FDI-operated industries is good for women. My experience in gathering the literature on FDI and women has been similar to Braunstein's. Braunstein (2006) also discusses the literature on wage inequality and its relationship with FDI. She argues that while the literature on wage inequality and FDI is inconclusive, there exists a clear causal link: "First, FDI may affect labour demand. Second, spillover effects from potentially higherproductivity (and higher-paying) foreign enterprises could raise wages throughout the country. And lastly, because capital is internationally mobile and labour is not, FDI may enhance capital's bargaining power relative to labour, thereby lowering wage growth" (p. 10). The literature on wages in FDI enterprises has found that foreign owned factories are more likely to employ higher skilled labor and pay better (Lipsey \& Sjoholm 2001; Almeida 2004; Harrison \& Scorse 2004). There has been a structural shift in the wage structure (as it pertains to FDI) since the 1980s due to increasing global capital mobility (Paus \& Robinson, 1998). Mehmet and Tavakoli (2003) in their study of four Asian countries (China, Philippines, Thailand, and Singapore) found that the ease in mobility of the capital has made it easy for firms to relocate whenever there is demand for increase in wages. The wage inequality is one of the major tools to assess gender equity. The following paragraphs discuss the literature on gender equity as it pertains to FDI. 
Braunstein (2006) in "Foreign Direct Investment, Development, and Gender Equity" seeks to examine the relationship between gender inequalities and FDI: "The paper argues that there are ways to structure FDI policies from a gender-aware perspective, and that it is crucial to incorporate this perspective in struggles to link this type of FDI more closely with development" (p. v). Braunstein maintains that while FDI is no exception in discrimination of women when it comes to wages, the choice of working in FDI in comparison to local counterparts allows women to have access to better pay in better conditions. Artecona and Cunningham (2002), in examining the change in gender wage gap among maquiladoras of urban Mexico, find that:

"industries that are more protected in the domestic sphere (proxied by the concentration ratio), in the international sphere (proxied by the tariff rate) or both (the interactive term) have higher gender wage gap... Since these industries are protected and thus are likely to have excess profits, the gender wage gap may be partly explained by their ability to use their excess profits to pay men higher wages than women" (p. 15).

This shows that employing women in certain jobs will reduce costs for MNCs.

Economic growth in Asia has often been described as a result of readily available cheap labor of women (Bello \& Rosenfeld 1990; Seguino 1997a, 1997b; Cheng \& Hsiung 1998). Berik (2000) in studying the export-led growth of the Taiwanese economy finds that the economic status of women, in relation to men, did not improve despite increase in employment opportunities in manufacturing. Zhao (2001), in her case study of China, seeks to answer if FDI can influence wage structure in host countries. She finds that "facing high cost of skilled labor, domestic private enterprises of China often choose a technology to minimize the use of college graduates" (p. 18). This explains the preference of women workers over men, as women are less likely to be sent to school in China than men. The literature, however, is inconclusive when it comes to explaining gender inequality in wages as it pertains to gender in FDI enterprise. 


\subsection{A Postcolonial Feminist Critique of Neo-colonialism}

Historically, colonization has been linked with economic policies and it still prevails, to some extent, through globalization. Women are central to this phenomenon as the colonization we see today is based on the feminization of labor. Further, the colonial legacies of the developing countries which are prevalent in structural and institutional forms have allowed the rich of this world to increase their ability to have it all at the expenses of the cheap labor of the poor. On top of that, patriarchy and capitalism has worked hand in hand in degrading the work of women and targeting women as recruits for cheap labor. In the following paragraph, I will elaborate more on the phenomenon of neo-colonialism and I will be discussing post-colonial literature, particularly by post-colonial feminists, to bolster my arguments.

Colonialism has shaped the history of the world. The effects of colonialism are still persistent in the Global South. The colonial legacies have weakened political institution, which hampered the development process of these countries. As a result, the formerly colonized areas are dependent on the former colonial powers to assist them economically and politically. However, this has not been the case in all of the colonized spaces. In instances like New Zealand and the US we see that colonialism was more about resettling in the new land, making it similar to home politically, culturally, and socially (Acemoglu et. al, 2001).

Most of the 20th century was the period of formal decolonization, however, the process of decolonization never ended. The institutions established by the colonial powers still persist in the former colonized spaces, and where the colonial powers have established strong institutions that protects individual property rights and checks government power, countries have prospered in the modern economy, while the colonized states where the colonial powers established extractive institutions still struggle to maintain themselves in the modern economy (Acemoglu et 
al., 2001). Globalization has also opened other doors for the colonizers to continue their influence. Coined by the Ghanaian leader, Kwame Nkrumah, neo-colonialism is a system through which the colonizers have been able to control the economic and political policy of the colonized even after decolonization (Hoogevelt, 2001). Neo-colonialism, like colonialism, manifested the interest of the North on those of the South and uses the resources of the South to advance the interest of the North. This system has been able to utilize the colonial legacy to perpetuate the global division of labor, which in turn has resulted in supporting the system of neo-colonialism.

Postcolonial criticism provides a succinct understanding of the challenges of colonialism and neo-colonialism. Post-colonialism argues that many of the wrongs that we see in the world today can be attributed to the bloody history of colonialism, which was driven by the economic dominance of the South by the North. This critique is rooted in the non-western traditions of Marxism that grew in the course of anti-colonial struggles. It is unique, as it has successfully acknowledged other forms of discrimination based on gender, ethnicity, and class used by colonization to divide and rule colonized spaces and people. This critique incorporates voices that have been unheard by the bourgeoisie nationalism (Young, 2004). Postcolonial scholars (During, 2000; Mohanty, 2003; Krishnaswamy, 2004) have been apt in criticizing globalization as a form of re-colonization whereby the North is constantly dominating the South in economic and political context. The most vocal among these voices have been those of feminists. Feminism is a movement that has relentlessly challenged patriarchy. Postcolonial feminism is a part of this movement, which extends to challenge racist and Eurocentric views, which are being used today as a tool of capitalism and neo-colonialism. The colonial characteristics of the Western world still persist in its representation of itself as a liberator of the free world, through 
which it establishes itself as an ideal. In fact, its sole interest in the rest of the world has only been depicted in the economic interest it gains through maintenance of capitalist ideology in the world (Lim, 2008).

One way that the western world seeks to maintain capitalism has been through trade liberalization. FDI has been the prototype of trade liberalization policies. FDI has indeed opened new economic opportunities for the developing world. It has been the very source of technological knowledge in developing countries (Borenzstien et al., 1998; Lall, 2000; Moran, 2008; Adams, 2009). It has allowed domestic entrepreneurs and workers to learn the traits that make the export processing zone (EPZ) firms successful exporters. Madani states that "These traits may include managerial and production organizational skills, negotiations and marketing skills in dealing with foreign contractors, general business know-how and foreign contacts" (1999, p. 42). However, the skill training given to the workers are not helpful in developing work skills outside of the menial jobs they are doing in the enterprises (Kusago \& Tzannatos, 1998). Furthermore, the opportunities for economic advancement are also affected by the absence of job security. As already established, because FDI is mobile and is motivated by costeffective benefits, it can easily move whenever it finds a better option.

\subsection{Conclusion}

The literature on development trends establishes that Keynesianism has dominated the field of economic development since the end of WWII. The establishment of Bretton Woods organizations to drive the economic regime of the world proves that the growing interdependence is indeed a driving factor in the international political-economy scene. This interdependence today is much more integrated than it was at the advent of Bretton Woods organizations. The rising number of MNCs stands as an example of the growing 
interdependence. This chapter has established that multiple international policies are adopted to cater to the growing interdependence and its impact on division of labor. The next chapter delves into further explaining the phenomenon of global division of labor. In the following chapter, I will be focusing on feminist critique of neo-liberal economic reform in the definition of women's work and the use of women's labor in achieving the interest of the state and the capitalist entities. 


\section{Chapter 3: Women's Labor in the Global Production}

This chapter establishes the context in which women as workers are treated more vulnerable than men. Focusing on women in lower wage FDI-based work, I identify the role of women in global production and highlight the role of the state in gendering labor in global production. My research demonstrates ways in which patriarchy and foreign capital influence states' non-protection of women workers.

I begin my discussion with the concept of gendered state where I review the literature that establishes state as an entity that is heavily influenced by patriarchy. My discussion then moves to analysis of the interplay between state and foreign capital as well as its role in the gender division of labor using gender lens approach. Finally, I demonstrate the context in which the non-protection of women workers is perpetuated by the state to maintain its relationship with the foreign capital as enabled by the patriarchal society.

\subsection{Gendered State}

Gender is a socially constructed concept. Scott (1986) defines gender as a "constitutive element of social relationships based on perceived differences between the sexes, and gender is a primary of signifying relationships of power" (p.1067). Gender division of labor is based on these perceived differences between men and women. Chafetz (1991) wrote, "undergirding all systems of gender stratification is a gender-based division of labor, by which women are chiefly responsible for different tasks than are men" (177). These tasks are defined in terms of gender roles. For instance, any work with huge aspect of caring is considered women's work like child rearing and nursing.

Kimberly Crenshaw (1989) coined the term intersectionality to argue that the discourse on women of color and their experiences were being ignored by both feminists and anti racist 
scholars. "Intersectionality refers to the interaction between gender, race, and other categories of difference in individual lives, social practices, institutional arrangements, and cultural ideologies and the outcomes of these interactions in terms of power" (Davis 2008, p. 68). The disregard of intersectionality in the approach being used in development has resulted in a framework, which ignores experiences of women being employed in FDI enterprises like Export Processing Zones (EPZs). The presence of a "rational and industrial man" as a necessity to modernize has established elite entrepreneurial male, who had an access to education and wealth, as a major actor in the economic development process. Such emphasis has led to an androcentric view of the development process where women are invisible. In this study, I am shifting the focus to poor, rural, women who are central as workers of FDI industries. Considering the concept of intersectionality, I emphasize on the experiences of poor, rural women workers in FDI industries. These women are often the most vulnerable group as they are in the lowest rank in the power hierarchy (based on class, ethnicity, caste, urban/rural divide, and gender).

In an attempt to identify women in this interplay between state and non-state actors (FDI), I am relying on feminist IR approach to guide my research. I am interested in identifying women in the global politics. Feminist IR approach will allow me to do exactly that as this field is interested in finding "what does looking for women and gender in global politics tell us about how the world works?" (Tickner \& Sjoberg, 2011). As a field, mainstream IR focuses on the behavior of states and power relations among the states and non-state actors specifically on the great powers and their behavior (Tickner, 2006). Such focus has been particularly important for policy implications on foreign and national security policy. In this study, I am also interested on the behavior of states. My motivation to understand the behaviors of the states are in the context of finding why women are marginalized and disempowered in serving the capitalist interest of 
the states (Ackerly et al., 2006). My concern in state behavior is therefore driven by my interest in identifying the marginalized women workers of global production. In this chapter, I make an argument that state is a gendered entity and it operates along with the capital in adopting strategies that leads to women being disproportionately disadvantaged than men in global production. The following paragraph discusses the feminist IR literature on gendered state.

The field of IR began with the need to understand the "causes of war and suggest ways in which the relations between states could be organized according to principles which would sustain enduring peace" (Steans, 1998, p. 33). After this period of idealism, the field has introduced different theories including realism, liberalism, and constructivism. Realism as theory was most dominant till the end of Cold War. During this period, IR as a field mostly focused on the anarchic order of the international politics. In this order the state was an "autonomous entity" modeled on a "purposive individual" or a "sovereign man" (Steans, 1998, p. 46). In her analysis of gender bias in international relations, Rebecca Grant argues

The whole theoretical approach to international relations rests on the foundation of political concepts which it would be difficult to hold together coherently were it not for the trick of eliminating women from the prevailing definitions of man as the political actor (1991, p. 9).

This definition has led to construction of institutions that supports the interests of men and ignores the interests of women. The state, in this context, is one such institution. There is no consensus among feminist scholars when it comes to the idea of state as a completely patriarchal entity. While radical feminism defines state as a tool of patriarchy, liberal feminism adopts a rights based approach in defining the role of the state. In this view, the state is "a neutral arbiter between conflicting interests and a guarantor of individual rights" (Connell, 1990, p. 512). However, liberal feminism recognizes the state as a process rather than a thing and maintains that 
the process heavily influenced by masculine definition and control makes it a gendered entity. Socialist feminist, on the other hand, focuses on the role of the state in regulating gendered institutions like family and market (Connell, 1990; Steans 1998; McIntosh 2013). Despite the debate, it will be fair to suggest that patriarchal process influence state's function. With this conviction, Franzway (1986) maintains that the study of the role of the state is inevitable in the field of Feminism. I use this understanding of the gendered state throughout the rest of my dissertation.

\subsubsection{The State, Capital, and Gender Discrimination}

In this study, I examine how the gendered state cooperates with foreign capital by unregulating women's labor in low-wage sectors. Feminist scholars studying international politics have time and again highlighted the gender-hierarchical characteristics of international politics. They have argued for a "gender lens" approach that produces unbiased theories, which are essential for constructing balanced political decisions. "Feminists have argued that gender lenses are necessary in three ways: conceptually, for understanding the meanings of global politics; empirically, for seeing realities, understanding causes, and predicting outcomes; and normatively, for promoting positive change" (Tickner and Sjoberg 2011). In this study, I am using the gender lens in studying the global political economy to achieve all of these three goals. The feminist study of Global Political Economy (GPE) finds that our understanding of global political economy will be incomplete without the use of gender lens as gender is an essential factor in maintaining the global political economy.

IR feminists have been very influential in highlighting the gendered hierarchy in the global production. Their scholarship identifies "how feminized bodies are central to the workings of the global political economy through their gendered work in the labor market, in the reproductive sphere, and in the informal market" (McCracken, 2011, p. 210). In this study, I also 
seek to follow the Feminist IR approach to global political economy and highlight the use of female bodies in catering to the interests of the foreign capital and the state. Feminist research in GPE asks questions that identify women in the global production and highlight how gendered division of labor is used in the global production (Peterson, 2011). My intention in conducting this research is driven by similar motivations. Like other feminist scholars, I identify the gendered characteristics of the development process. As McIntosh (2013) argues, the state gets involved in patriarchal operations to guarantee robust social circumstances for capitalist production. McIntosh suggests that state supports institutionalization of patriarchal system like family and wage labor where women are discriminated in to support capitalist system. Feminist research (Ruggie, 1984; Smart, 1984) shows that state acts as a tool to carry on patriarchal system and in the process oppresses women. The interplay between the capital and the state and the common outcome of gender oppression is the subject of this research. The following section highlights the context in which women's labor are used by capital and the state.

\subsection{Global Production and the Division of Labor}

In the current globalized scenario, the division of labor has a new definition. The process of global restructuring heavily influenced the global division of labor. Since 1970s, this process of global restructuring has led to division of production where the developing economies are heavily based on manufacturing, and the developed economies are based on service. This division has increased the income gap between the developed countries and developing countries. The developed countries' labor market demands people with higher education and specialized skills. The workers in demand are required to use their knowledge. In the developing countries, the workers in demand are required to use physical labor, using their hands and feet. 
The global division of labor determines the type of FDI being invested in the host country. There are two types of FDI: horizontal and vertical. Horizontal FDI is determined by the market size of the country, as this type of FDI is seeking to cut cost on export expenses. Corporations produce similar commodities in various plants and service local markets through associate production rather than through export (Bjorvatn \& Eckel, 2001). On the other hand, vertical FDI is determined by cost effectiveness of production procedure. This type of FDI happens when production of a commodity is divided internationally to better achieve cost effectiveness (Bjorvatn \& Eckel, 2001; Kucera, 2002; Busse, 2003). Thus, vertical FDI is mostly found in developing countries.

The labor demands for vertical FDI comprises mostly of a cheap, unskilled, and laborintensive work force. As already established, many developing countries are abundant with unskilled labor. Moreover, because the developing countries are poor and trying hard to achieve economic development, they are also in need of financial investment. FDI has been recognized as one of the effective tools to initiate the process of economic development. This has created competition between developing host countries to try and receive more FDI from big MNCs, headquartered most of the time in developed countries. The mobility factor of FDI allows these enterprises to be more powerful, as it permits them to leave the host country whenever the environment is too hostile for them to conduct business to their advantage. This takes away the power of the laborers to bargain (Rodrick, 1998; Elliot \& Freeman, 2001; Mandle, 2003; Mutti, 2003). Developing countries are in constant need of capital to finance their economic development. The inability of the developing countries to invest in their own markets gives MNCs the upper hand as a prime investor and influences how the government will regulate labor laws. Taking the competitive market for FDI and its necessity in economic development of the 
country into account, the host government might be encouraged to contract labor rights to expand the capital from FDI.

\subsection{Global Production and Women's Work}

Jobs within FDI-funded facilities, identified as one of the income generating opportunities at a national level, has been touted as an attempt to include women in the public economic sphere. FDI has been associated to women empowerment as it allows for women to have increasing job opportunities for women (Braunstein, 2002). However, feminist scholars have argued that this process completely ignores different levels of work that women are expected to perform within the society (Enloe, 1990; Moser, 1993; Sharp, 2003). Traditionally, women's role in society is divided between reproductive and productive work. The reproductive role includes all the domestic chores to be performed and to bear and rear children required to guarantee the supply of the labor force, while the productive work entails income-generating work (Moser, 1993). In countering, FDI's association with women's economic empowerment, Sharp argues that,

...for many women, the issue of empowerment does not revolve around the ability to leave the home to be admitted into the labor force; for them their life-worlds have always spanned both public and private spaces (2003, p. 282).

While economic opportunities definitely help women to make their position stronger within the household, it also increases women's work burden, as women are now expected to engage in productive labor and at the same time meet the need to fulfill their reproductive roles in the society. The long and strenuous hours that are demanded by the jobs offered in FDI enterprises also have health effects, which limit the period for women to be able to work. Constant use of microscopes in electronic plants affects their eyesight, which leaves them unable to work at an early age. Further, continuous exposures to hazardous chemicals and lint in textile and garment 
factories also impact their health at an early age (Grossman 1979; Ehrenreich \& Fuentes 1981, 1983; Ward 1985). The patriarchal system manifests gender inequality in all sectors of life including health. Considering the pre-existing unequal system along with the financial challenges that comes with being poor it is likely that healthcare options are more limited for women than for men.

The discussion above establishes that the export-oriented development is supported by cheap female labor. FDI enterprises have allowed the poor, rural women from developing countries to escape domestic work and to migrate to towns and cities to contribute to the family's income. Such opportunities are linked to empowerment of these women as a first generation of women to break the tradition of domestic work. While such opportunities have provided these women a chance to gain financial independence it takes ways their agency as a laborer. Many of these women seek employment not just to add an income in the family income but also for financial independence within the household (Wolf, 2008). Such willingness of poor, rural women towards finding income generating employment opportunities to gain financial independence highlights the agency of women working in export-oriented factories in wanting to work for income. However, their "secondary status" in the labor market along with their position as laborers, which is immobile, challenges their agency (Lim, 1978, p. 11). The mobility of capital allows FDI to have the upper hand in bargaining with the state, while labor is not guaranteed any of these bargaining powers.

FDI enterprises are allowed to use the unskilled labor for a very low cost with high demands (long working hours and bad working conditions). FDI's characteristic as a capital allows them the mobility to leave the host economy if there were to be any resistance against the enterprise from the workers. Further, as women's productive roles clash with their reproductive 
roles (cultural and social values) it challenges their agency in pursing income-generating work. The following section discusses how gender identities and roles are constructed to bolster the patriarchal structure in which the state and the capital operate.

\subsection{Factors influencing the Formation of Gender Identities in Modern Societies}

\subsubsection{Religion}

Religion plays an important role in day-to-day life of millions of people around the world. Religion can be defined as "a set of ideas and practices that link to an authoritative source" (Bradley, 2011, p. 19). In the present context, religious identities are penetrating boundaries of national, racial, and ethnic identities. Considering this, it will be interesting to examine the effect of large-scale institutionalization of religion in gender equality. Raday (2003) argues, "Religions have codified custom into binding source books that predate the whole concept of gender equality and have both the legal and the institutional structures to enforce their principles" (p. 669). Such customs inhibit change and protect patriarchal culture and practices. It is within these customs that gender roles are created and public and private spheres are separated.

The recent events of religious extremism have intensely impacted global politics. The growing relevance of groups like ISIS and burgeoning of Christian extremist groups in Europe and America is changing the map of equality and tolerance in the global world. The institutionalization and highly politicized extremist movements could mean more restrictions on gender equality. In my case studies, I identify how religion intersects with gender identities. Specifically, the examination of the role of Islam as it pertains to women in society will be important in highlighting the success of gender and development approaches in Bangladesh and Malaysia. Similarly, examining Catholic culture in the Philippines will assist in identifying the religious context of gender equality in different cultures. 


\subsubsection{Cultural Influence of Colonialism}

Historically, colonization has been linked with economic domination of colonial spaces but colonization was also about influencing the culture of those societies. Colonial rule has had a profound impact on social structures that define gender roles in the colonized areas. Colonialism was partly justified, as a "civilizing mission" (Chatterjee, 1989, p. 622). Often times, the colonized subjects and culture were defined as barbaric, uncivilized, primitive and savage. The colonial authorities were established with the preconceived notion that the colonizers belonged to “a 'natural' community of common class interests, racial attributes, political affinities, and superior culture" (Stoler, 1989, p. 635). Culture was often used as a means of control by the colonizers, and it was in this context that colonizers justified their colonial actions. Dirks (1992) stated:

Cultural forms in newly classified 'traditional societies were reconstructed and transformed' by and through colonial technologies of conquest and rule, which created new categories and oppositions between colonizers and colonized, European and Asian, modern and traditional, West and East, even male and female (p. 4).

In this regard, the colonizers appointed themselves as the agents of change. The civilizing mission enforced cultural practices that aligned with European and Christian attributes. The cultural impact of colonialism defined the identities of the colonizers and the colonized.

The superior identity of the colonizers, their own definition, legitimized the control and authority over the 'weak' colonial subjects. The 'naturally superior' race was thus justified to be in a position to govern the weaker, other race. Driven by the desire to control, the colonial entities established political institutions that catered to their need to control and extract resources (Acemoglu et al., 2001). Acemoglu et al. (2001), find that colonies which suited the health of the Europeans allowed them to settle there, which then encouraged the establishment of institutions closer to home with protection of private property and checks on the powers of government. In 
colonies that had high European mortality rates the settlement was discouraged, and this allowed colonial powers to install authoritarian and absolutist states with an interest of facilitating the extraction of the resources. Colonialism has always been about economic interest. The idea to resettle in these newfound lands was driven by the economic opportunities presented in these regions, and the means were control and domination of the indigenous population. This interest was bolstered via cultural and social tools that the colonizers used to control the native population. The investigation on cultural influence of colonialism will enhance our understanding of the social structure that defines gender roles.

\subsubsection{Female Political Leadership}

Despite the dearth of female political leadership in the world, Asian women have had fair amount of success in securing positions of political leadership in their countries (Richter, 1991; Thompson, 2003; Flesecheberg, 2004; Jalalzai, 2004; Derichs et al., 2006). The first woman to be elected in the leadership position was Sirimavo Bandaranaike from Ceylon (present day SriLanka) in 1960. Since then, Asia has been remarkably successful in producing a number of influential female political leaders including Indira Gandhi, Benazir Bhutto, and Aung Sang Suu Ki. Asian countries producing influential female leaders have been more successful than egalitarian countries, despite never being associated with egalitarian values (Richter, 1991; Derichs et al., 2006).

The number of female leaders in politics in these countries has puzzled leadership scholars except when considering the importance of dynastic politics in Asian countries (Fraser, 1988; Richter, 1991; Thompson, 2003; Flesecheberg, 2004; Jalalzai, 2004; Derichs et al., 2006). With patriarchic elements in the background, it is quite apparent that women are only allowed the highest position of the country if they a part of a certain political dynasty. Richter (1991) posits that "the impact of gender-based public-private spheres, however, has been that women 
are accepted as behaving appropriately in politics when they are perceived as filling a political void created by the death or imprisonment of a male family member" (p. 526). With this in mind, I identify how dynastic politics have influenced my cases in production of female leaders in political context of each case. Further, I investigate if the female leaders in each of my cases have acted in influencing the definition of gender identities in their country, or if they have acted within the prescribed gender roles as a representative of the political cause of their family and class.

\subsubsection{Traditional economic Roles of Women}

For a long period of time, women were established as passive actors in the development process. Feminists have rigorously challenged this view. Feminist scholars argue that in studying the economics of development, women's domestic work is ignored and unaccounted for (Beneria, 2003). The recent attempts in incorporating women in the development literature have led to the understanding that women are an essential part of development (Charlton, 2008; Visvanathan et al., 2008).

Boserup (1990) was the first person to discuss how economic changes affected roles of women in the household and the society. She argues, "women's work, women's fertility, and women's role in the family and society at large are radically changed by economic development" (p. 14). She finds that increase in economic development leads to a larger share of goods that are being produced outside of the home for the family. This pushes women to join the workforce, as their domestic work will not support the family's needs. She also finds that in subsistence economies, where the "age-sex-race hierarchy" determines the job of a person within and outside of the household, paying men more than women for the same job highlights the superior status of men (p. 15). Boserup's discussion allows us to explain existing gender wage gap. 
Charlton (2008) outlines four clusters of issues that pertain to women and development: the role of ethical and moral choice of development, the structure of the international system in the late twentieth century, the influence and domination of western norms and institutions in development concepts and policies, and the political control of development. Charlton contends that the use of the term "development" is derived from "western European secular and scientific thought” (p. 7). She also argues that the history of colonization has strengthened the control that the West generates on the rest of the world. In discussing the structure of the international system, Charlton highlights the dependency of women in formal politics at the local, national, and international levels. Emphasizing the importance of political power, Charlton concludes, "development does not happen in a vacuum; it is subject to innumerable political and administrative influences, from the headman or cast leader of the smallest village to international agencies and multinational corporations" (p. 13). From this, it is clear that development is as much of a political phenomenon as it is an economic phenomenon.

Attempts at accounting for women's work in developing countries have shown that women are an important part of the economy through agriculture, domestic work, and recently, as employees in industries. The internationalization of development through FDI has also opened up avenues for women (mostly rural) in developing countries to gain economic independence (Inglehart and Norris, 2003). From Mexico to Bangladesh, poor, rural women from most developing societies are becoming a part of the new face of development. FDI enterprises have allowed them to escape rural domestic work to migrate to towns and cities and earn money for them and their families. It has allowed them to be the first generation of women to break the tradition of domestic work. In my cases studies, I examine what it costs women to have gained this new "economic empowerment." 


\subsection{Unregulated Labor Laws in FDI enterprises}

The outcome that I am interested in explaining via this research is unregulated labor laws in FDI enterprises, particularly those of women. I define unregulated labor laws as a phenomenon that happens when the state is not enforcing the labor laws guaranteed by a constitution or other state policies to protect its economic interest. For example: Bangladesh might choose to turn a blind eye towards complaints from workers working in a Nike factory about long hours in order to maintain a relationship with Nike, which ensures that Nike continues the investment in the Bangladeshi market. In this case, the state does not enforce the guaranteed rights of the laborers in order to maintain the relationship with FDI. It is important that I emphasize that I am interested in the non-protection of women workers, as they are the majority of the workforce in major export industries in all of my cases. $80 \%$ of the workforce in Bangladesh apparel industries is female (BGMEA, 2013). The Philippines and Malaysia both heavily export electronic integrated circuits and micro-assemblies. The majority of the labor in electronic industries for both countries is female. $69 \%$ of the workforce in Filipino electronic industries and $60 \%$ of the workforce in Malaysian electronic industries is female (LABORSTA, 2010).]

\subsection{Determinants of Unregulated Labor}

As stated previously, my expectation is that developing states are willing to relax labor laws (along with other incentives) not only to attract FDI to their country, but to keep them there. I am very much interested in the protection of women's labor within this context. I identify six determinants that make a state more prone to have an environment of unregulated labor. These include a state's development level, the population of unskilled labor, the protection of civil rights and liberties, the presence of corruption, pressure for corporate social 
responsibility, and, finally, bureaucratic capacity. By addressing each of these indicators, I am able to parse out the cultural and societal influences that allow the perpetuation of women to be less protected than men in the state's workforce.

\subsubsection{Development level}

Development level is one of the relevant factors that are different in my cases. The Philippines and Malaysia are primarily industry and service oriented economies, while Bangladesh is still an agricultural-based economy. Bangladesh is also the poorest country among the cases with the lowest level of female literacy rates (The World Bank, 2012). Considering that Bangladesh is one of the new countries that has recently adopted export-oriented development strategy, it is expected of Bangladesh to be more flexible, than the Philippines and Malaysia, regarding its labor and investment laws, to attract more FDI. Likewise, a theoretically relevant similarity among my cases is the number of women employed in major export industries. In the manufacturing of the major export products, in all three countries women are the majority of the workforce. FDI entities are usually associated to export industries, and the number of women employed in these industries may bolster my expectation that women are not necessarily empowered through employment in FDI industries.

Since Malaysia is more economically and politically stable than the other two cases, Malaysia has kept a good track record in attracting FDI. Malaysia has done well with exportoriented development and this has supported Malaysia to establish itself as one of the middleincome country. Malaysia, with its Vision 2020 plan, seeks to be a developed country by the year 2020 (Mohamed, 1991). With this plan, Malaysia is emphasizing not just on economic development but human development as well. The economic growth in Malaysia has changed its priority from sole economic interest to interest in social capital. With this in mind, it can be argued that as the country develops economically, it is more likely to introduce, enforce, and 
regulate laws that protect the labor of women. For the most part, this research is concerned with vertical FDI as the main argument highlights how the capital, bolstered by the host-state enacted policies, uses women's labor to cut the production cost.

\subsubsection{Unskilled Labor}

Unskilled labor has been one of the most cited reasons to justify the cheaper cost of production in developing countries. Women's labor has been a significant force in all aspects of economy, from agriculture to industry to services: "However... much of the work that women have done and continue to do is invisible, or is either assumed to be 'natural' or of little value" (Nisonoff, 2008, p. 177). This has been deemed true for the nature of the work that women are assigned in the EPZs. Jobs that are identified as 'women's work' are often categorized as 'unskilled,' whereas technically similar jobs that are identified as 'men's work' are recognized as being "skilled" (Phillips \& Taylor, 1980; Elson \& Pearson, 2008). Elson and Pearson (2008) claim that women's work is deemed unskilled because their training is "socially invisible, privatized, and the skills it produces are attributable to nature" (p. 193).

The concept I am most interested in is the degrading of women's labor where women's work is recognized to be unskilled. Skill is often identified as a socially constructed idea. It is held that certain jobs are defined as unskilled to control the labor employed to do that job (Wood, 1982). Women's labor has only been accepted in the society as a substitute labor. Women entered the labor force either when men were not available to work or when a new labor type was introduced (and was controlled by management). Beechey (1982) claims that women's labor is recognized as industrial reserve of labor that is to be used to substitute men's labor. She argues that this is the case because of these three terms:

(a) their labour power being paid for at a price below its value;

(b) their labour power having a lower value; 
(c) the existence of the family, and of women's dependency within the family, and the ideological assumptions which surround this, which enter into the determination of the value of female labour power (p. 69).

Enloe (1990), in Bananas, Beaches, and Bases, identifies the feminization of labor and in that process, the deskilling of female labor. In her study of the Levi Factory in the Philippines, she finds that women's work, primarily sewing, was assumed to be unskilled. Sewing was argued as something that women do "naturally" or "traditionally": "An operation that a person does 'naturally' is not a 'skill,' for a skill is something one has to be trained to do, for which one should then be rewarded" (Enloe, 1990, p. 162). Assuming skills like sewing as "natural" traits allows the management to identify it as unskilled. There is a fundamental flaw on assuming sewing as being untrained, as girls and women are trained by their mothers to sew. However, skills like sewing are devalued because women do it traditionally. Enloe also finds in her field research that many factories that employ women as seamstresses also employ men as cutters and pressers. These men are selected to run specialized machines like the zipper inserters and are paid more than women. Enloe's findings support my argument that skills like sewing are being feminized and identified as unskilled at the same time. This process of establishing women's work as unskilled is fundamental in explaining the lack of regulation of women's labor. With this in mind, it can thus be maintained that the higher concentration of unskilled female labor in the workforce leads to higher chances of unregulation of women's labor.

\subsubsection{Civil Rights and Liberties}

The status of the civil rights and liberties identify the true nature of democracy within the state. These rights have been established as basic tenants for human rights. The Universal Declaration of Human Rights serves to protect civil rights and liberties along with right to "life, liberty, and security of person" (United Nations, 2010). However, these rights including the discourse in human rights have ignored protection of women's rights. Everyday many people are 
subjected to violence, torture that sometimes result in death of a person just because of their gender. "The narrow definition of human rights, recognized by many in the West as solely matter of state violation of civil and political liberties, impedes consideration of women's rights" (Bunch, 1990, p. 488). The separation between the 'public' and 'private' spheres and association of violence against women/violation of women's rights with 'private' sphere allows the state to turn a blind eye towards such violations of women's rights (Bunch, 1990; Cook, 1993; Youngs, 2003). Despite these inadequacies in the rights discourse, it is very important to analyze the protection of civil rights and liberties in each case. Such analysis will allow me to gauge the status of citizens including women, not just as laborers, but also as citizens of the country. If political institutions were constantly attacking these rights, then it is likely that the governing bodies also do not take labor and women's rights seriously. Considering this, it can be asserted that the higher the protection of civil rights and liberties, the higher the protection of women's labor.

\subsubsection{Corruption}

Transparency International (TI) defines corruption as "the abuse of entrusted power for

personal gain.” TI categorizes corruption into: grand, petty, and political.

Grand corruption consists of acts committed at a high level of government that distort policies or the central functioning of the state, enabling leaders to benefit at the expense of the public good. Petty corruption refers to everyday abuse of entrusted power by low- and mid-level public officials in their interactions with ordinary citizens, who often are trying to access basic goods or services in places like hospitals, schools, police departments and other agencies. Political corruption is a manipulation of policies, institutions and rules of procedure in the allocation of resources and financing by political decision makers, who abuse their position to sustain their power, status and wealth. (Transparency International, 2014).

For the purpose of this study, I will be paying more attention to petty corruption and political corruption. I think it is important to pay attention to petty corruption because I am 
concerned about the implementation of policies. Usually, the people who are involved in guaranteeing the implementation of policies are low-and mid-level public officials. For instance, corruption among police provides a picture of trust among laborers and police. Anytime a crime is committed, the first post of complaint is to the police; if the police are open to bribery, then it is likely that crimes like harassment in the factory will not be reported. First of all, unlike workers, management will be able to pay a handsome bribe to the police to handle the case, as it is needed. Second, and more importantly, the level of trust among the victims in the police and their work will be very low.

I will also be paying attention to political corruption because in most of the developing countries, economic sectors are often associated with political elites. The people who control the government often control the market economy. Heavy political corruption will allow the manipulation of labor laws and their implementation to suit the interests of industrialists rather than the laborers. Further, research has established that corruption affects women differently than men (UNIFEM, 2010). This is especially true because women are less likely to have resources to offer as bribes to the public servants (UNIFEM, 2010). Thus, the country with the higher level of corruption will be less efficient in implementing labor laws that protect women.

\subsubsection{Pressure for Corporate Social Responsibility}

Corporate Social Responsibility (CSR) is an effort from the company to be socially responsible in producing and distributing the products. It is defined as "a company's commitment to minimizing or eliminating any harmful effects and maximizing its long-run beneficial impact on society" (Mohr et al., 2001, p. 47). The pressure for companies to adopt CSR has been increasing since the 1990s. These pressures have been initiated specifically through two channels. The first channel is through people, groups, concerned citizens, and Nongovernmental Organizations (NGOs). This pressure can be identified as organizational pressure 
as these pressures come from groups of people organizing to identify the irresponsibility of corporations in producing and distributing their products.

The second type of pressure directed through laws, standards, and policies is institutional pressure. This pressure is exerted via policies, international norms, standards, and laws. In current times, human rights have been identified as an integral part of advancing the state in the right direction. Most of the developed states have adopted human rights, and labor rights treaties and policies. Human rights are becoming a norm in the developed countries. While developing countries are still struggling to incorporate equality into their development agendas, MNCs that are headquartered in developed countries are being pressured by their government and other international institutions to normalize human rights and equality in operating their companies and factories. Keeping in mind that women workers are more disadvantaged in FDI enterprises than men, it can be argued that higher pressure of CSR will lead to a better protection of women's labor.

\subsubsection{Bureaucratic Capacity}

Good governance has time and again been associated with the capacity of the state in carrying out the outlined objectives of the government. According to Kaufman et al. (1999), governance is:

...the traditions and institutions by which authority in a country is exercised ... and ... includes the process by which governments are selected, monitored and replaced; the capacity of the government to effectively formulate and implement sound policies; and the respect of citizens and the state for the institutions that govern economic and social interactions among them (p. 1).

Governance requires different state actors and institutions to coherently work together to achieve the goal of the state. It entails the functioning and the legitimacy of the institutions of the state, their authority to formulate policy and make decisions on behalf of the larger population, and their capacity to implement the policies (Martin, 1991; Pierre, 2000). Capacity of the state is 
measured by the state's ability to function with authority in governing the state. Zafarullah and Rahman (2008) states:

A capable and effective state should have the power to monopolize the legitimate use of force, the potential capacity to extricate necessary resources from the society, shape national identity and mobilize consent, regulate society and the economy, maintain the internal coherence of state institutions and redistribute resources (p. 741).

The state capacity depends on the ability of the state to foster the institutional environment that involves political support and political will to achieve an outlined goal of the state. Further, the state also needs skilled staffs and resources to support the institutional and technical capacity of the state (Hood, 1983; Afifi et al., 2003). Since this research is concerned with treatment of women as both laborers and citizens, I am particularly interested in bureaucratic capacity building efforts in achieving gender equality. The adoption of MDGs by most of the developing countries and its emphasis on gender equality has led to introduction of various approaches to increase the bureaucratic capacity of the state in tackling gender inequality. The introduction, adoption, and investment in such measures will lead to better accommodation of women's social, economic, and political rights. Considering this, it can be argued that higher the investment in bureaucratic capacity to achieve gender equality, higher the protection of women's labor. In the following chapters, my assessment of the government's regulation of labor will be examined via the bureaucratic capacity of the state in implementing the policies.

\subsection{Conclusion}

This chapter outlined the globalized context in which the women's labor is used for the advantage of the state and the capital. The discussion in this chapter establishes how the global production is driven by the unregulated labor of women. The chapter also highlighted factors that have bolstered the operation of gendered norms in the society. I have elucidated the concept of 
unregulated labor and outlined its determinants. This chapter established the role the state plays along with the capital in economic oppression of women. In the following chapter, I will discuss the methodology and methods in conducting the case studies, along with a brief description of my cases. 


\section{Chapter 4: Conducting the Research}

\subsection{Methodology}

FDI has been established as a useful tool to initiate the process of economic development. The relationship between FDI and development has been understudied in the field of IR. In the global economic context FDI is used as a vehicle to operationalize the development goals of the state. Through FDI, states have created jobs, which have been associated with economic empowerment of poor, rural women. However, these jobs are offered to these women by devaluing their work and skills. The women who sew and embroider the textiles are paid less than men who cut and press the textiles, even though sewing and embroidering require more technical skill (Enloe, 1990). The jobs through FDI allows these women to help their children to go to school which helps the next generation to have a better income. However, these jobs do not help the poor, rural women workers in the FDI enterprises escape poverty. Another way of analyzing this would be to ask how does these jobs help the status of these women in the long run? Fontana (2003) asks "do the newly created jobs for women challenge gender stereotypes?"(p. 8) She finds that most of these jobs are developed by using these stereotypes and do not offer any opportunity to women to enter male-dominated sectors. She argues that these jobs do not offer long-term economic security to women.

Developmental and economic scholars have established FDI to be one of the best mechanisms to approach development. With this conviction along with adoption of neo-liberal economic policies, states are competing with each other in attracting FDI. Often times this is done by advertising the inexpensiveness and dexterity of the poor, rural women workers (Grossman, 1978; Mies, 1998). Considering the need for investment for economic development, it is more likely that developing states will attract more vertical FDI, which uses the devalued 
labor of poor, rural women to make it inexpensive. In order to keep up with the development requirements and keep attracting investment, developing countries are likely to neglect human rights, labor rights, and women's rights.

In identifying women in the interaction between state and non-state (FDI) actors, I am relying on feminist IR approach to guide my research. I am interested in identifying the interplay between the state and foreign capital in using labor of poor, rural women as resource to advance their economic interest. In this context, I am looking at state policies through a gender lens. Feminist IR provides the most suitable platform to conduct my research. Feminist IR provided a prominent voice during late 1980s and early 1990s when IR as a field was going through a period of transformation (Tickner \& Sjoberg, 2011). However, the area has fallen out of favor along with the larger feminist movement. This event has hindered the development of a more defined feminist IR methodology.

Feminists claim no "feminist way" of doing research (Reinharz \& Davidman, 1992, p. 243). Ackerly (2011), in elaborating feminist methodologies, maintains "feminism makes the use of any method more rigorous by being more broadly politically and theoretically informed" (p. 40). She furthers her argument by defining feminist methodologies as research approaches used by feminists that are cognizant of questions and theory that feminists use in better understanding the gendered hierarchy. Feminist scholars have successfully adopted different methods and tools to meet their research goals (Tickner, 2006). Feminist knowledge has developed from rooted skepticism of the conventional knowledge production process. Feminist IR grew into a subfield of IR by adopting a critical theoretical stand in understanding of the world politics. "Critical theory... looks to understand the world (and particularly its injustices) for the purpose of changing it for better" (Tickner \& Sjoberg, 2011, p. 10). Feminist IR challenges, rather than 
build on, such existing and conventional ways of knowledge production. In challenging these conventional knowledge production processes, feminist researches have introduced the concept of self-reflexivity, which has been vastly ignored by the conventional IR field. This concept "encourages the researcher to re-interrogate continually her own scholarship" (Ackerly et al., 2006. p. 4). This concept of self-reflexivity is developed as a response to androcentric research that places a value in neutrality. The adoption of this concept distinguishes feminist IR from nonfeminist IR.

Feminist IR also differs from conventional IR in that it asks different questions than conventional IR. Feminist scholarship is mostly interdisciplinary and focuses on exploring unequal gender hierarchies along with other power hierarchies, seeking various ways to challenge these hierarchies. Feminist IR situates the behavior of states as it pertains to women and other marginalized groups within the state: "Rather than uncritically assume the state as a given unit of analysis, feminists have investigated the constitutive features of 'gendered states"” (Tickner, 2006, p. 23). Feminist IR is interested mostly in understanding and explaining the disadvantaged positions of women in the global societies, and they seek to understand how international politics and global economy play a role in instituting, supporting, and re-enforcing this disadvantaged position.

While conventional IR relies on economics and natural sciences to depict the behavior of the states, feminist IR uses sociological analysis that focuses on individuals and the hierarchical social relations, where the lives of the individuals are situated. As Reinharz and David maintain, "making the invisible visible, bringing the margin to the center, rendering the trivial important, putting the spotlight on women as competent actors, understanding women as subjects in their own right rather than objects for men - all constitute to be elements of feminist research" (1992, 
p. 248). Feminist research suits my study because it challenges the normalized "androcentric or male biases" in the production of knowledge (Tickner, 2006, p. 20). Through this study, I also challenge the androcentric and masculine bias that establishes capitalism as "the natural order of life" (Chin, 1998, p. 17-18). I start my research by examining the lives of some of the most marginalized and disempowered women in the global context. This study is driven by the motivation to make the women workers in export-oriented industries more visible. I also identify other power hierarchies that marginalize certain groups in ensuring the success of capitalist regime in developmental states. My work focuses on demonstrating how poor, rural women in developing countries are influenced by the global economy and productions. Through this research, I hope to uncover the hierarchical and exploitative social structures that are instituted via state assistance for the foreign capital to achieve its goals.

\subsection{Methods}

FDI has been established as a development tool that allows the developing countries to "benefit from capital inflow, technology transfer, managerial know-how, market access, productivity spillover, and economic growth" (Li, 2009, p. 1099). These benefits have led to fierce competition between developing countries to attract more FDI. Along with competing for market investment, developing countries are also adopting the process towards democratization (Li \& Resnick, 2003). The installation of democratic values is only complete when states adopt policies that protect basic rights of its citizens. Scholars have time and again questioned how extractive and exploitative characters of MNCs affect state's protection of its citizens, particularly as workers (Evans, 1979; Smith et al., 1999). Rodrick (1998) suggests that competition to attract FDI among developing countries impact the status of human and labor rights negatively. This is more true with countries that are attracting labor-intensive capital 
(Mosley \& Uno, 2007). In such industries, a substantial amount of the investment is associated to the labor cost and cost cutting measures might lead to pressure for repression of labor rights (Elliot \& Freeman, 2001). Labor-intensive FDIs are also associated more with capital flight to seek out locations with more relaxed labor laws (Mandle, 2003; Mutti, 2003; Mosley \& Uno, 2007). The pressure to attract capital leads states to maintain a relationship with MNCs.

MNCs are immensely powerful entities and "inherently difficult (domestic) regulatory targets" (Weiler, 2004, p. 401). In his discussion of the impact of FDI in human rights, Weiler (2004) finds that developing countries that seek FDI are most likely to have ineffective rule of law. He suggests that "faced with competition, developing countries may relax or fail to enforce domestic regulatory standards - including human rights standards - to the detriment of the health and well-being of their citizens" (p. 433). While some have highlighted the negative impact of FDI on human rights and labor rights, others argue that FDI leads to economic growth, which assists the development capacity of the state (Borensztein et al., 1998; Moran, 2008; Adams, 2009). With the increase on the level of development, the need to attract labor-intensive FDIs will diminish. Economic growth will lead to higher education among the population, which will lead to production of skilled labor. Technological evolution will also increase. This will change the type of FDI being invested from labor-intensive to capital-intensive in the country (Bjorvatn \& Eckel, 2001; Kucera, 2002; Busse, 2003). Further, the increase in level of development also increases the standard of living among the people, which will lead to an increased understanding of political, social, and economic rights of the people.

With this increase in knowledge in civil rights and liberties there will be an increase in political pressure for the host government to protect these rights. Also, the rising economic activities in the country will make the country more noticeable in the global field. This notice 
can result in international pressure (via foreign governments, Intergovernmental Organizations, NGOs) for the host states to abide by international protocols for human rights. The host state will then have to succumb to such pressures and adopt measures to implement such protocols.

In order to gauge the discussed effects, I conduct case studies of three different countries: Bangladesh, the Philippines, and Malaysia. Considering that I am trying to explain an economic phenomenon, which is built on the exploitation of labor (mostly of poor, rural women), it is absolutely important for me to infer on historical approaches to the same phenomenon and how it still affects the way female labor is defined. I will also be using narrative analysis to assess historical events that might explain the lesser regulation of women's labor.

I conduct a qualitative analysis of each state in this study. I believe qualitative methods best suit my study, because it is a feminist inquiry that identifies women within the larger context of international political economy. Feminist scholars (Nielsen, 1990; Waring \& Steinem, 1998; Tickner, 2006) have argued that quantitative frameworks do not fit feminist studies, as women's experiences are usually not documented or analyzed by policy elites. They claim that standard measures of gender inequality, often collected by states, may conceal the relationships that may be important to understanding the gendered hierarchies in state operations. Considering that my study analyzes the gendered actions of the state, it is important that I deconstruct those concealed languages within the policies constructed by the state to understand the reality of women workers in each of these countries. My approach to this research is analyzing the contents of labor laws in each of my case study. The following section gives a brief description of content analysis and discourse analysis as methods and how I benefit from this approach.

\subsubsection{Content Analysis and Discourse Analysis}

Content Analysis is a popular method in qualitative studies. "Content analysis is a research technique for making replicable and valid inferences from data to their context" 
(Krippendorff, 1989, p. 403). Content analysis allows the researcher to interpret the data to produce an intense analysis of the data. The data for content analysis are usually texts that document "verbal discourses, written documents, and visual representation" (Krippendorf, 1989, p. 404). The use of content analysis helps to identify contextual meaning of the document along with hidden characteristics in the communicative languages (Hsieh and Shannon, 2005). Content analysis as a method is gaining ground in feminist research especially in exploratory and explanatory research (Ackerly and True, 2010). Content analysis suits my study as my research is also trying to explore as well as explain the relationship between capital and the state in using women's labor.

Content analysis usually involves identifying themes and concepts and analyzes the texts that address these themes and concepts. In this research, I am analyzing the labor laws of each country. Along with content analysis, I am also using discourse analysis to examine the behavior of the state in treatment of women as low-wage workers.

Discourse analysis seeks to analyze the meanings embedded in texts that reflect other discourses and indeed the broader discursive environment in which language constructs both meaning and power relations (Ackerly \& True, 2010, p. 208).

Using discourse analysis would allow me to identify the absence of gender lens in the state's measurements to protect labor. Further, in analyzing the discourse of these measures, I examine how these discourses are framing the concept of gender and constructing it at the institutional level (Hansen, 2006; Weldes, 2006). Discourse analysis suits my study because as Hansen (2006) suggest, applying discourse analysis in my comparative case studies would allow my cases to exemplify "constitutive theoretical propositions" (p. 11). Further, the use of discourse analysis enriches my adoption of feminist approach as it helps me to identify marginalized voices in the institutional treatment of women as workers (Ackerly \& True, 2010). 
I am particularly interested in analyzing the content and discourse of labor policies pertaining to women as laborers in FDI industries. In this process, I analyze documents that guarantee certain rights and protection to women as workers. I am interested in the language that surrounds the maternity benefit policies as it pertains to women as a part of the labor force. I also look at policies and laws that strengthen or weaken women's position as labor in FDI industries. Through this research, I am interested in identifying policy patterns that states adopt to relax labor laws. I rely on policy documents as my data in analyzing the content and context of use of female labor in the FDI industries by the state and the foreign capital.

\subsection{Case Selection}

Skocpol and Somers' (1985) macro-causal analysis is most suited for my study because it will allow me to develop a new explanation to the effect being studied in this project. This analysis allows me to investigate the problem by analyzing both theory and history in order to identify the causes of the outcome being studied in this project. In using this approach, I will be relying on nominal comparison, whereby I will be using Mills' Methods of Agreement (Skocpol $\&$ Somers, 1985) in selecting my cases. This selection method requires that all cases have a particular phenomenon in common. The goal of this method is to infer cause from other characteristics that are common (see table 1). The following discussion highlights my selection of cases based on the Mill's Methods of Agreement.

Table 1: Applying Mills' Method of Agreement in the Cases

\begin{tabular}{|c|c|c|c|}
\hline \multirow{2}{*}{\multicolumn{4}{|c|}{$\begin{array}{l}\text { Cause } \\
\text { Differences: Geography, Income Level, Religion, Female Literacy rates }\end{array}$}} \\
\hline & & & \\
\hline $\begin{array}{l}\text { Export Oriented Manufacturing as a } \\
\text { development approach }\end{array}$ & Yes & Yes & Yes \\
\hline $\begin{array}{l}\text { Majority of women labor in Export } \\
\text { Oriented Manufacturing Industries } \\
\text { (Unskilled) } \\
\text { Outcome }\end{array}$ & Yes & Yes & Yes \\
\hline Unregulated labor laws in FDI enterprises & Yes & Yes & Yes \\
\hline
\end{tabular}




\subsubsection{Bangladesh}

As one of the poorest countries in the world, Bangladesh has had its own struggle with famine and natural disasters. Bordering the Bay of Bengal, this country has been victimized time and again by massive floods. After secession from Pakistan in 1971, Bangladesh is still struggling to achieve political and economic stability. Although most of the economy is still driven by agriculture, the adoption of neo-liberal policies in the 1990s has allowed the manufacturing industry to burgeon in the economy (Asian Development Bank, 1998). With the economic opportunities that the recent increase in garment industries provides, more and more women are leaving the domestic sphere to participate in the national labor force. In the case of Bangladesh, the trade liberalization allowed FDI to introduce small-scale industries that opened doors for new opportunities. Bangladesh is a classic case where FDI invested garment industries uses the gendered division of labor to employ poor, rural, women who are mostly young and unmarried.

\subsubsection{The Philippines}

One of the most populous countries in the world, the Philippines is a middle-income country (The World Bank, 2013). The Philippines geared towards the development race in the early 1980s via adoption of unilateral investment and multilateral/ regional trade liberalization. However, the rapid rise in the population, along with the Asian economic crisis of the late 1990s, thwarted the Filipino development goals.

According to the Asian Development Bank (ADB), "A lack of opportunities at home has driven the long tradition in the Philippines of migration from rural to urban areas, especially by women, to find remunerative employment" (2008, p. xiv). The increased demand for earning opportunities forced the Filipino people to seek work elsewhere, making them more vulnerable in the global market. In these circumstances, many Filipino women migrated outside of the 
country to fulfill the need for cheap domestic and factory labor. In the past decade, the Filipino economy has seen better days than in the 1990s. This has increased economic activities in the country along with inflow of new FDI, particularly in the manufacturing and agroindustry. This investment has led to increased labor demand. Currently, women are the majority of the lowwage workforce in the export-oriented manufacturing in the Philippines (LABORSTA, 2010).

\subsubsection{Malaysia}

In the late 1960s, Malaysia competed with Newly Industrialized Countries (NICs) to achieve development through rapid expansion in manufacturing. Malaysian women have been an integral part of modern Malaysia, and both governmental and non-governmental forces recognize their role in the development. During the early adoption of neo-liberal policies in the 1970s and 1980s, "the industrial expansion had a profound effect on the pattern of employment and on the rural-urban migration, and drew unprecedented numbers of young, unmarried Malay women for the first time from villages into urban factories" (Ahmad, 1998, p. 22). This occupation structure is still valid for rural women who migrate to urban areas for better economic opportunity (Stivens, 2006).

Malaysia is also one of the countries that import unskilled labor to work in FDI enterprises. The recent economic growth, strongly purported by the export industry, has led to dearth of cheap labor to work in the manufacturing sector. This has led Malaysia to import labor from low-income country such as Bangladesh, Nepal, and Indonesia. The majority of the workers in major export industries (such as Electronic Integrated Circuits and Micro-assemblies) are migrant women workers (Piper 2006; ILO LABORSTA, 2010; Rudnick, 2009; Crinis, 2010). Table 2 highlights the differences and the similarities between my cases. 
Table 2: Differences and Similarities in the Selected Cases

\begin{tabular}{|c|c|c|c|}
\hline & Bangladesh & Philippines & Malaysia \\
\hline Religion & Islam & Catholicism & Islam \\
\hline $\begin{array}{l}\text { Geography } \\
\text { (None of the } \\
\text { countries are } \\
\text { land-locked) }\end{array}$ & Borders Bay of Bengal & $\begin{array}{l}\text { Archipelago, South China } \\
\text { Sea }\end{array}$ & $\begin{array}{l}\text { Southern area peninsula } \\
\text { bordering Thailand and } \\
\text { northern area is one third } \\
\text { of island Borneo, } \\
\text { bordering Indonesia and } \\
\text { Burma }\end{array}$ \\
\hline \multirow{4}{*}{$\begin{array}{l}\text { Economy }(G D P \\
\text { current US\$ } \\
2010)^{2}\end{array}$} & (Still Largely & (Largely export-oriented & \multirow{4}{*}{$\begin{array}{l}\text { Largely export-oriented } \\
\text { industry and service } \\
\text { based) } \\
\$ 247.53 \text { billion }\end{array}$} \\
\hline & Agricultural economy) & industry and service based) & \\
\hline & $\$ 100.36$ billion & $\$ 199.59$ billion & \\
\hline & & & \\
\hline Freedom & 3.5 & 3.5 & 4.0 \\
\hline \multicolumn{4}{|l|}{ Rating $^{3}$} \\
\hline \multicolumn{4}{|l|}{ of $G D P) 2010^{4}$} \\
\hline Major Exports & \multirow{4}{*}{$\begin{array}{l}\text { Apparel } \\
(80 \%)^{5}\end{array}$} & \multirow{4}{*}{$\begin{array}{l}\text { Electronic Integrated Circuits } \\
\text { and Micro-assemblies } \\
(69 \%)^{6}\end{array}$} & Electronic Integrated \\
\hline (Average & & & Circuits and Micro- \\
\hline Female & & & assemblies \\
\hline Workers, \%) & & & $(60 \%)^{7}$ \\
\hline \multirow{4}{*}{$\begin{array}{l}\text { Female Literacy } \\
\text { Rate } \\
\text { Women's } \\
\text { Political Rights }\end{array}$} & $52(2010)$ & $96(2008)$ & $91(2010)$ \\
\hline & & & \\
\hline & \multirow{2}{*}{$\begin{array}{l}\text { Guaranteed by law, } \\
\text { moderately prohibited } \\
\text { in practice }\end{array}$} & Guaranteed by law, & \multirow{2}{*}{$\begin{array}{l}\text { Guaranteed by law, } \\
\text { moderately prohibited in } \\
\text { practice }\end{array}$} \\
\hline & & $\begin{array}{l}\text { moderately prohibited in } \\
\text { practice }\end{array}$ & \\
\hline Women's & Some economic rights & Some economic rights of & Some economic rights of \\
\hline Economic & of women are & women are guaranteed under & women are guaranteed \\
\hline Rights $^{10}$ & guaranteed under law, & law, but these rights were not & under law, but these rights \\
\hline & $\begin{array}{l}\text { but these rights were } \\
\text { not effectively enforced }\end{array}$ & effectively entorced & $\begin{array}{l}\text { were not effectively } \\
\text { enforced }\end{array}$ \\
\hline
\end{tabular}

The discussion above shows that there are two common phenomena that drive all of my

cases. First and foremost, all my cases approached economic development via trade

liberalization. This led to expansion of export-oriented manufacturing in all of these countries.

\footnotetext{
${ }^{27}$ The World Bank

${ }^{3}$ Freedom House, 2010 Freedom in the World

${ }_{6}^{5}$ Bangladesh Garment Manufacturers and Exporters Association (BGMEA), 2009

${ }^{6}$ ILO LABORSTA (Averaged for 8 years from 2001-2008)

${ }^{7}$ ILO LABORSTA (Averaged for 8 years from 2001-2008)

${ }^{9}$ CIRI dataset

${ }^{10}$ CIRI dataset
} 
Second, all my cases rely on labor of young, unmarried, poor, rural women to drive the new export industries. Table 2 shows that majority of the workers in the major export industry of each country are female. I believe these three cases will give me a better picture of the impact of FDI on women workers, as all three cases have opened up economic opportunities for women after the adoption of trade liberalization policies. Further, the differences in each case will allow me to examine how these differences react with state, FDI, and low-wage women workers in FDI industries.

\subsection{Analyzing the Indicators of Unregulated Labor}

\subsubsection{Unregulated Labor}

The research on FDI and EPZs have shown that host countries often advertise themselves as suitable areas to invest in by stressing the weak implementation labor laws (Asia Monitor Resource Center, 1998). In the context of this project, I defined unregulated labor laws as labor laws that are either not legally strong enough or are weakly enforced by the state. In order to assess the unregulated labor laws, I use International Labor Organization's EPLEX and NATLEX database. EPLEX database records the employment protection legislative acts, and NATLEX records "national labor, social security, and human rights legislation" of different countries (ILO, 2014). Both of these databases provide a comprehensive record on labor laws in all of the cases I am studying.

\subsubsection{Development Level}

To examine the development level of each case, I will be using the indicator "Exports of Goods and Services" (\% GDP) from The World Bank Databank:

[this indicator] represents the value of all goods and other market services provided to the rest of the world. They include the value of merchandise, freight, insurance, transport, travel, royalties, license fees, and other services, such as communication, construction, financial, information, business, 
personal, and government services and exclude compensation of employees

and investment income (formerly called factor services) and transfer

payments (The World Bank, 2013).

This indicator will assist me in gauging the role of exports in the economic development of each country. I will also be using the indicator "GDP Growth Annual (\%)" to access the economic growth of the country.

\subsubsection{Unskilled Labor}

Unskilled labor has been often cited as a determining factor for cheap labor in developing host countries. In examining unskilled labor, I will be using the indicator Labor Force Participation Rate from the World Bank Data Bank. This indicator provides data for economically active people in production of goods and services that are ages 15 and older (The World Bank, 2013). This indicator will allow me to gauge number of women are employed in the formal sector of the country. Also, I will be using organizational documents, such as Country Gender Assessment published by the Asian Development Bank and labor reports produced by states' labor agencies to identify the economic sectors where women workers are mostly concentrated.

\subsubsection{Civil Rights and Liberties}

To assess the protection of civil rights and liberties, I will be using the Freedom in the World Report by the Freedom House. This report examines the protection of global political rights and civil liberties in different parts of the world (Freedom House, 2013). These reports look at civil rights violation of women and take that into account in calculating the scores for Civil Liberties. However, this organization uses the narrow definition of human rights that is "recognized by many in the West as solely a matter of state violation of civil and political liberties" (Bunch, 1990, p. 488). This definition does not include violation of women's rights that happens within the private sphere. While I recognize that this lack of data impedes many 
feminist researches including mine, the hidden nature of crimes against women, mostly associated with the public/private divide and lack of sensitivity training among data collectors, hinders the collection of data on violations of women's rights (Walker, 1989; Johnson 1995). I will also be using Annual Country Reports from U.S. Department of State. This report "covers internationally recognized individual, civil, political, and worker rights, as set forth in the Universal Declaration of Human Rights and other international agreements" (U.S. Department of State, 2009). This report allows me to examine the status of women's rights in each country.

\subsubsection{Corruption}

I will be relying on Transparency International's country reports and the Corruption Perception Index (CPI) to analyze the level of corruption in each country: "The Corruption Perceptions Index measures the perceived levels of public sector corruption worldwide" (Transparency International, 2014). Along with CPI, I will also be using various reports, such as Transparency in Corporate Reporting (2014), that are published by Transparency International. I will also be examining reports generated by organizations like Freedom House and the World Bank on the countries' corruption. Further, I will be using individual studies conducted by various scholars in studying the corruption of the country.

\subsubsection{Pressure for Corporate Social Responsibility}

In studying the pressure for CSR, I will mostly be focusing on organizational pressures. The institutional pressures are usually hollow as most of the time the state institutions in both home country and host country are more concerned about their capital gain than violations of workers rights. To identify organizational pressure, I use documents like reports, surveys, and interviews from NGOs, like Institute for Global Labor and Human Rights (IGLHR), Human Rights Watch, International Labor Rights Forum, and NGOs like Clean Clothes Campaign in 
Bangladesh, Federation of Free Workers Philippines, and Network of Actions for Migrants in Malaysia. I will also be using individual studies conducted by various scholars in studying the pressure of CSR in each country.

\subsubsection{Bureaucratic Capacity}

In order to assess bureaucratic capacity of each case, I will focus on bureaucratic capacity of the state to implement the enacted policies. I am particularly interested in studying the availability of qualified bureaucrats and dedicated civil servants. In measuring the states' bureaucratic capacity, I will be examining the following:

the existence of civil service academies for training and re-training of state employees, an association of a career in the civil service with financial security ... [and] ...a unified control and disciplinary system tackling rules violations committed by civil servants (Trezzini, 2001, p. 36).

I examine the status of the civil service agency by referring to scholarly research on civil service agencies of each country. I will also be assessing the effectiveness of civil service agencies through reports produced by international organizations, like Transparency International, United Nations, and the World Bank. To cater to purpose of this research, I will try to identify gender in the civil service agencies. In doing so, I will look at gender-mainstreaming documents produced by the state and other non-state agencies, and scholars.

\subsection{Conclusion}

In this chapter, I have outlined that I will be comparatively analyzing each case in the forthcoming chapters. I am using feminist IR to infer my research, as my research is interested in uncovering androcentric and patriarchal beliefs that influence global production. Although most of the feminist IR researches eschew the use of quantitative data collected by the state, as state's data are the product of the gendered institutions that the state fosters, I am using them with the 
conviction that these data will provide evidence of gender discrimination within the state. As I have already stated earlier, FDI and gender, as a subject of study, has been understudied in the field of political science. By tying the role of the government with fostering FDI in the particular country, I am studying the context in which economic development happens. I argue that economic oppression of poor, rural women provides a context for FDI induced economic growth. 


\section{Chapter 5: Bangladesh}

\subsection{Introduction}

Bangladesh is a classic case of a poverty-torn country that is advancing economically using FDI as a tool. Bangladesh is still a predominantly agricultural-based economy, but with the rising number of FDI operated factories, the industrial sector is slowly taking over (Central Intelligence Agency 2013b). Trade liberalization has allowed Bangladesh to open its doors to new opportunities. However, the gendered aspect of labor has very dominant preferences in FDI enterprises in Bangladesh. In the following paragraphs, I will present a comprehensive discussion on the gendered division of labor of the ready-made garment (RMG) sector in Bangladesh. In doing so, I am focusing on the post-independence period, specifically from 1980 onwards. My discussion highlights how Bangladesh fails to protect the labor of poor, rural women employed in the RMG sector. In this chapter, I am examining how Bangladesh allows poor treatment of female labor in export-oriented industries to cater FDI as capital.

\subsection{History}

The story of Bangladesh is contextualized by a long history of colonization, violence, and war. In reference to the history of Bangladesh, it is important to distinguish between the history of East Bengal and Bangladesh. Bangladesh became a country in 1971; prior to that, it was a part of Pakistan. The history of this area tells the story of inconsiderate division of colonized spaces by the colonial powers. In the following paragraphs, I will be focusing on post-independent economic policies of Bangladesh after the partition of India and Pakistan.

\subsubsection{East Bengal under Pakistan}

The partition of India and Pakistan in 1947 separated Bengal, the coastal region of the Bay of Bengal, by international borders. West Bengal was designated a part of India, and East Bengal, a part of Pakistan. The growing rift between the Hindus and the Muslims in India led to 
an idea of separating Muslims and Hindus territorially. A resolution adopted by the Muslim League in 1940 states that:

It is considered a view of this Session of the All India Muslim League that no constitutional plan would be workable in this country or acceptable to the Muslims unless it is designed on the following basic principles, viz., that geographically contiguous units are demarcated into regions... [and] that the areas in which the Muslims are numerically in a majority as in the North Western and Eastern Zones of the (British) India should be grouped to constitute 'independent states' in which the constituent units should be autonomous and sovereign. (Hassan, 1993, p.44)

This statement depicts the relevancy of the idea of carving a separate Muslim state. In East Bengal, this sentiment also had an economic reason. East Bengal was an agrarian society. The feudal system placed during early periods of colonization led to an unequal system of wealth distribution. Most of the zamindars, who were dictated to be the landowners during the early colonization periods, were high-caste Hindus. There was a huge revolt at the time against the landlord system directed by the Muslim peasantry.

On the issue of the division of Bengal, there was no consensus between the elite Hindus and the Muslims. The Muslim League was not so eager to divide Bengal; they wanted all of Bengal as a part of Pakistan. Instead, it was the Indian Congress Party, the ruling party in the post-independent India, which instituted the idea of the division of Bengal (Schendel, 2009). In the partition, the province of Bengal was divided into two parts. The largest chunk of the territory was designated to be under Pakistan's share and the rest of it was under India. After the partition, East Bengal came to be known as East Pakistan.

The partition led India to inherit all the colonial legacies, including political and economical institutions, but Pakistan had to start from nothing. The partition was built on the idea of establishing a state with a strong Muslim solidarity. However, such strong solidarities are only possible in areas without any social and cultural cleavages. The vast country of India in 
between East and West Pakistan, and the central government in West Pakistan had already initiated some social and cultural cleavages between East and West Pakistan.

Figure 1: Map of the Partition of India, 1947

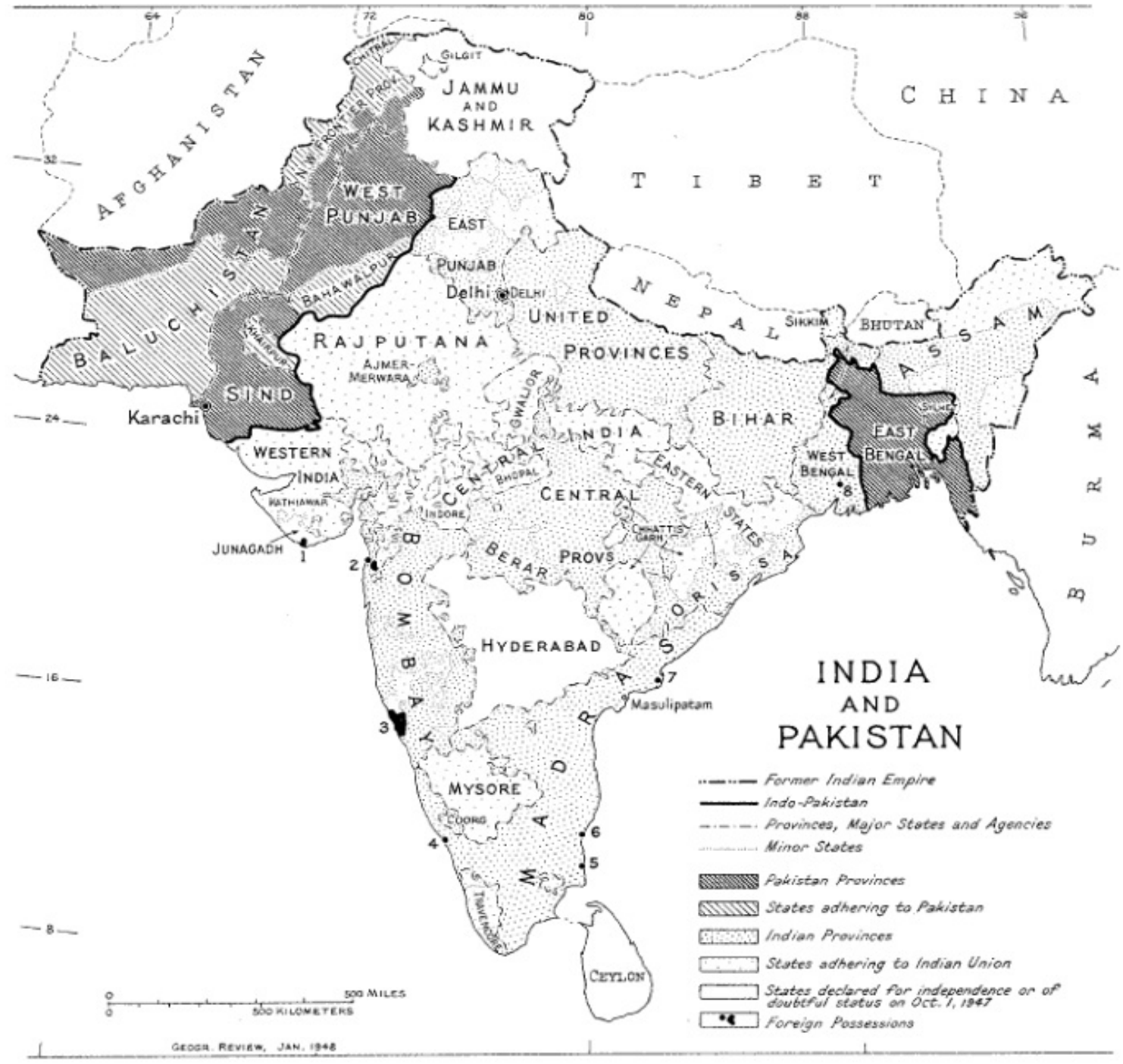

Ftc. t-Territorial structure of India and Pakistan. Boundaries: 1, Former Indian Empire; 2, Indo-Pakistan; 3. Provinces, Major States and Agencies; 4, Minor State; 5. Pakistan Provinces; 6, States adhering to Pakistan; 7, Indian Provinces; 8, States adhering to Indian Union; 9. States declared for independence or of doubtful status on October I, 1947; ro, Foreign Possessions: I, Diu, 2 , Damão. 3. Goa (Portuguese); 4. Mahé, 5. Karikal, 6, Pondichéri, 7, Yanaon, 8, Chandernagor (French).

Source: Spate, O.H. K. (January, 1948)

The new Pakistani political elites were really struggling with uniting the nation under religious solidarity. At the same time, they were failing miserably at not offending the identity of Bengali people in East Pakistan. Western Pakistani elites who migrated to Pakistan from India after the partition emphasized the Islamic culture, but Eastern Pakistanis did not resonate with 
such religiosity. For East Pakistanis, the separation was more about economic freedom from Hindu landlords. Eastern Pakistanis who used Bengali as a local dialect, therefore, were resentful when Urdu was established as the only state language of Pakistan: "Neglecting Bengali in this process spawned the feeling of distrust and discontent among the students and intelligentsia and political parties for East Pakistan" (Jabeen et al., 2010, p. 100). The use of Urdu, as authorized by the state, in government documents like currencies and official letterheads was not popular among Eastern Pakistanis (Zaheer, 1994; Jabeen et al., 2010). This resentment led to a bloody and violent riot between the students of Dhaka University and the police on February 21, 1952. The aftermath of the riot finally led to a path in establishing Bengali as a state language in 1956 (Jabeen et al., 2010). East Pakistanis regarded this neglect as a central government's bias towards one group. (Pasha, 1995)

Bangladesh experienced the political occupation continually until its independence from Pakistan in March 1971. Despite being a part of Pakistan, Bangladeshis were never culturally accepted in the country. The ruling class in Pakistan treated the people of Eastern Pakistan as second-class citizens time and again. In October 1958, the military coup took control of Pakistan under Ayub Khan (Ali, 2010). This coup led to the creation of the new elites in Pakistan: the military leaders and officers. After the coup, the military took control of Pakistan and established a dictatorial regime. East Pakistan was now under the rule of dictators who did not identify with East Pakistan. The government under Khan placed a provincial governor in East Pakistan to control the territory (Schendel, 2009). Under the military rule of Khan, East Pakistan was treated as a colony of Pakistan. The central government was becoming very unpopular and the desire for autonomy grew among the people of East Pakistan. 


\subsubsection{The Independence and Beyond, 1971-present}

For Bangladesh, independence came at a very heavy price. It was not until 1970 that Pakistan held its first national parliamentary election after the partition. The election results highlighted the difference between East and West Pakistan. The Awami League (AL) won momentously in East Pakistan, and the Pakistan People's Party won in West Pakistan. The AL was successful in winning $53 \%$ of the seats in the National Assembly. Yahya Khan, a military leader who served as a President of Pakistan, later canceled the parliamentary session before its creation. The failure of the leaders in the two wings of Pakistan to come to a consensus in the parliamentary election of 1970 led to a civil war (Ali, 2010). The civil unrest in Bangladesh led to a bloody war between India and Pakistan.

On April 17, 1971, the government of Bangladesh was formed under the leadership of Sheikh Mujibus Rahman. Bangladesh was now an independent country, however, the post-war era for Bangladesh was not as steady as expected. The democratically elected government was accused of enlarging the government (Sobhan, 2013). It was during this time that religious extremists took the opportunity to establish their ground in the politics of Bangladesh. The postindependence Bangladesh, under military regime, also tried to define Bangladeshi nationalism under the religious identity. The Bangladeshi National Party (BNP), led by Major Ziaur Rahman, defined Bangladeshi Nationalism as:

Religious belief and love for religion are a great and imperishable characteristics of the Bangladeshi nation ... the vast majority of our people are followers of Islam. The fact is well-reflected and manifest in our stable and liberal national life... (Bangladesh National Party, "Ghosanapatra" [Manifesto] as cited by Mohsin, 2013, p. 33)

This definition outlines that being Bangladeshi means being Muslim. Initially, under AL leadership, Bangladesh was going to be secular, where Hindus and Muslims would be an equal part of society. But as the party failed as leaders of the new government, the extremist forces 
took over to build a nation under one religion: Islam. The growing relevance of Islam in public life in Bangladesh had several implications in the lives of Bangladeshis. The Constitution established Islam as a state religion in Bangladesh in 1972. The growing strength of Islamist extremists had adversely impacted women of Bangladesh. The poor, rural women have often been used as a tool of Islamization in Bangladesh. Since the establishment of Islam as a state religion, rural clerics have made use of an extrajudicial system called salish (village arbitration) and fatwa (religious edict) to increase the implementation of sharia laws. Time and again, women are used as bait by the Islamic clerics to terrorize the population and instill fear of the consequences of not following Islam "properly."

Bangladesh has often been recognized as one of the up and coming industrialized developing countries, however, the conflict between the Western idea of development and the radical Islamic thought (which is gaining momentum in the Bangladeshi society) has placed the state in a dilemma where it is constantly struggling to choose between the developed state and religiosity. Bangladesh's attempts in industrialization have been supported by the policies enacted to attract FDI in the market. Along with these policies, Bangladesh also advertises cheap cost of production in the country. This low cost of production is bolstered by the availability of inexpensive and unskilled labor mostly of young, poor, rural women. To ensure this low cost, the Bangladeshi government regulates labor laws ineffectively. Such contraction of labor laws is disproportionately affecting Bangladeshi women who are majority of the labor force in the garment industry. Bangladesh is accruing a huge human cost in forms of unregulated labor of poor, rural women working in the garment industry. 


\subsection{Factors influencing the Formation of Gender Identities in Bangladeshi Society}

Today, Bangladesh is regularly depicted as a successful case of a country that has reduced poverty by adopting neo-liberal policies (Bangladesh Export Processing Zones Authority, 2010; Bangladesh Garment Manufacturers and Exporters Association, 2011). Often, the female faces that make these stories a success are hidden in the labels of our clothes. This project seeks to identify these women in the context of global production. In the following paragraphs, I discuss what influences gender identities in Bangladesh.

\subsubsection{Religion and Women}

The post-independence era has established Islam at the foundation of Bangladeshi identity. The establishment of Islam as a state religion in 1972 has resulted in increasing prevalence of Islam in the public life of Bangladesh. Islamic clergy are constantly trying to establish Islamic principles as a way of life and in trying to do so, the clergy has imposed sharia laws more frequently than before, and more often. Rural women are targeted, as they are the weakest members of the society, to instill terror in people. The number of fatwas issued on women surpassed those that were issued on men (Riaz, 2004). Most of the fatwas have been issued for the accusation of adultery. It is not uncommon for poor rural women to be arbitrarily accused of a wrongdoing and punished severely. In between 1993 and 2003, the local press and human rights organization have recorded at least 240 cases of female fatwa victims (Riaz, 2004).

The introduction of fundamentalism in public and political life in Bangladesh has indeed been detrimental to the women of Bangladesh. The organizations that have been set up to empower women are not immune to the wrath of religious extremism. NGOs are regularly attacked for their work in supporting women of Bangladesh. The patriarchal society in Bangladesh has reserved the domestic sphere for women. Women are supposed to be docile, 
weak, and submissive. The NGOs and grassroots organizations in Bangladesh are providing women with resources to empower themselves.

The NGOs (both international and local) have emphasized the importance of including women in development goals. By asking women to be a part of the economic society, NGOs are essentially telling women to ignore their purdah. To the mullahs (local clerics), this is a direct assault on their means of social control: the poor, rural women. The local clerics have time and again issued fatwas on women-oriented NGOs by declaring their work un-Islamic. Daily Inquilab, a newspaper controlled by the Islamists, published the fatwa against the NGOs. The allegations that were being publicized were as follows:

1. NGOs aided by "Jews and Christian conspirators" were wrecking the Islamic cultural values while threatening the independence of the country;

2. Foreign NGOs resembled the old East India Company, which once captured the Muslim empire in India and whose successors might now ruin Muslim sovereignty and Islamic culture in Bangladesh;

3. Numerous school of the Bangladesh Rural Advancement Committee (BRAC), an NGO specializing in education, were "spreading atheism" among people;

4. Western missionaries were converting people to Christianity under the pretext of helping the poor;

5. Unmarried women and men working together in the NGOs were engaged in extramarital sex;

6. By giving loans directly to wives and them chant certain mottos, NGOs were fuelling an anti-husband and anti-family mentality among women;

7. To create an "aggressively feminist" and "impure" society such as that of Europe and America, NGOs were forcing women to ride bicycles and motorcycles;

8. NGOs were preaching that "Islam was a religion of the illiterates," decrying purdah (seclusion) and degrading women by forcing them to parade before strange men (Riaz, 2004, p. 123).

Despite threats like these, women have responded really well to development projects in Bangladesh. Organizations such as Grameen Bank have been very successful in involving women in the productive economy of the country. 
However, the government's reliance on Islamic parties for electoral support has deteriorated once progressive agenda that was adopted by the state to bring women into the development process. In 1997, the newly elected AL government of Sheikh Hasina adopted the progressive National Women's Advancement Policy with an active collaboration of feminists and human rights group. However in 2004, this policy was changed without any consultation with the involved groups or open discussion in the Parliament. Contrary to the original document, this changed version denies women "equal rights to land, inheritance, assets, and control over acquired property." It has dropped "the provision to appoint a significant number of women to the Cabinet" (Siddiqui, 2006, p. 6). This version has also deleted "a clause calling for the appointment of women to the highest positions in judiciary, the diplomatic corps and key administrative bodies." As for the employment of women, "the new policy calls for efforts to employ women in appropriate professions." However, there is no clarity on what constitutes appropriate professions (Siddiqui, 2006, p. 6). The increasing Islamic extremism in the society has led the state to characterize women's rights as community or religious rights rather than individual rights. This has exacerbated the issue of gender-based discrimination in Bangladesh (Brandt \& Kaplan, 1996).

In Bangladesh, religion plays a big role in defining the status of men and women in the society. Islam determines the rights and obligations of the citizens. Along with the common law, a Muslim personal law that follows the principles of sharia also governs issues like property rights, succession, marriage, divorce, etc. These traditional laws and rules control, if not restrict, women from being as equal as men in the society. The rising religious fundamentalism is leading to more violence and inequality in the Bangladeshi society (Karlekar, 2005). The politics of religion in Bangladesh have made the society more religiously dogmatic, and this has led to a 
negative impact on the progressive goals of development that the state was once very active in adopting.

\subsubsection{Cultural Influence of Colonialism on Gender Identity}

Since Bangladesh was a part of colonial India, I will be focusing on colonial impact on gender identity of Indian women. Like women in most colonial spaces, Indian women were also objectified and perceived as exotic, while at the same time being victimized as subjects of their culture and religion (Chakravarti, 1989; Bannerji, 1995; Sen, 2001). The British colonial regime often branded Indian culture as "degenerate and barbaric" (Chatterjee, 1989). With such identification, the British regime took it upon them to civilize the Indian society. The treatment of women in Indian culture became a huge part of this task. It will be unfair to argue that Indian culture had no vices before the British, however the British did not do much except turn the tables in the game called patriarchy. The Indian tradition was indeed very patriarchal, but the British introduced new forms of patriarchy in the region. Chatterjee finds that this new patriarchy introduced intersectionality in the gender relations, where the "'new' woman was quite the reverse of the 'common' woman, who was coarse, vulgar, loud, quarrelsome, devoid of superior moral sense, sexually promiscuous, subjected to brutal physical oppression by males" (1989, p. 627). While male oppression of women was condemned, the idea of self-sacrifice tied to the culture of sati, where the widow self-immolated with the burning pyre of her husband, was commended as "feminine strength" (Sen, 2001, p. 32). Education for women was encouraged to instill the British values in them. The new Indian woman was to replicate Victorian-British women (Borthwick, 1984; Karlekar, 1991). While the British influence changed the anatomy of patriarchy in colonial India, some traditions endured, despite much effort by the British. One of them is the tradition of purdah. 
Traditionally, women in Bangladesh are guided by the concept of purdah. Purdah means curtain in Indo-Aryan language. The act of practicing purdah requires women to be secluded. It is practiced as a tool to limit the interactions between men and women (Papanek, 1973). This system has been established as a means for social control of women. This system was maintained because it was well suited for the agrarian culture of Bangladesh. Women's work was primarily situated within the domesticity of the house. Women were in charge of processing all crops, raising the livestock, providing food for the family, and the caring and rearing of the children. These were all work that did not require one to leave the household. Considering that Bangladesh is still an agricultural economy, these rules of purdah are still prevalent in Bangladeshi society.

This concept of purdah is essential in understanding the status of women in Bangladesh because this is one of such concepts that restrict women's rights to move freely. When women are not allowed to move freely, the economic opportunities for them diminish by a great level. Further, the women who choose to or have to work outside the home to support their families are stigmatized. This stigmatization is largely due to gendered division of labor within the household and the society. The role of earning money and supporting the family is not designated to the woman. Women's attempt in adopting these roles is often associated as attacks on masculinity. Such stigmatization makes women more vulnerable to violence. With such societal pressures, women often are left no choice but to follow purdah.

\subsubsection{Political Role of Women in Bangladesh}

From the time when Bangladesh earned its independence, women have assumed the role

of the Prime Minister more than men. Since the disposition of military rule in 1981, both Shiekh Hasina Wajid and Khalida Zia have acted as the head of the government and the head of the opposition party. In Bangladesh, the society is not only divided in public and private domains, "but also the stereotyped gender roles that assign women to the seclusion of the domestic sphere" 
(Chowdhury, 1994, p. 94). Considering such societal restrictions, it is indeed interesting that two women have consecutively held the most important office in the country in the last couple of decades.

The two female heads of state of Bangladeshi politics Sheikh Hasina Wajid and Khaleda Zia are also the daughter and the wife of the most influential male politicians in the country. Sheikh Hasina Wajid is the daughter of the Sheikh Mujibur Rahman, Bangladesh's first Prime Minister and party leader of AL who was assassinated in a coup in 1975. Begum Khaleda Zia is the wife of Ziaur Rahman, the military leader who was assassinated in another coup in 1981 . The fact that both female leaders of Bangladeshi politics belong to a prominent political family speaks to the fact that political dynasty might have allowed them access to the political front of the country.

Thompson (2003) finds that many times political leadership was forced on the women as there were no able or willing male heirs to fill the vacuum left by the deceased or ousted leaders. In the case of Sheikh Hasina Wajid, her father was assassinated along with his whole family. She was the only living representative of the family. Similarly, in the case of Khaleda Zia, she was involved because her son was too young at the time to assume political responsibilities and with the years of experience she has continued to exert influence as a party leader. Chowdhury suggests "the emergence of Sheik Hasina and Khaleda Zia in political leadership roles represents a paradox in a patriarchal culture that is best explained by their kinship linkages to male authority" (1994, p. 100). This statement seems true considering the low number of women represented in Bangladeshi Parliament. According to the most recent data on women in parliament, women only make up $19.4 \%$ of the assembly (Inter-parliamentary Union, 2014). The success of Sheikh Hasina and Khaleda Zia in controlling the major parties and the government 
does not translate into favorable policies for women or increase in female participation in politics (Jahan, 1987; Felschenberg, 2004). The cultural practices and gender hierarchies supported by the system of purdah still restrain women's interaction within the private sphere. Therefore, it will be valid to say that in the case of female political leaders in Bangladesh, the kinship ties trumps the gender identity of the female political leaders, which allows them the means to access resources like political platform.

\subsubsection{Women and Economic Development}

The discourses on women empowerment differ among the political actors in Bangladesh. Today, women's empowerment is a political term, and is often used in political agendas of women's rights groups, political parties, and foreign NGOs. Nazneen et al. (2010) study how different political actors are framing the concept of women's empowerment in advancing their interests in the Bangladeshi context. They find that women's organizations take a rights- based approach, where they emphasize women's rights within the human rights framework in addressing women's empowerment. The major political parties such as the AL, the Bangladesh National Party (BNP), and Jamaat-e-Islam, however, have varied uses of the concept "women's empowerment." The AL and the BNP use women's empowerment (narir khomotoyon), while the Jammat uses women's rights (narir ordhikar), whereby it defines women's rights under the sharia-based rights discourse (different from the development discourse). Differences within the discourses of the two centrist parties, $\mathrm{AL}$ and $\mathrm{BNP}$, show that the parties are competing to establish themselves as more progressive on women's issues than the other one. However, they seek to do so without risking the loss of support from the conservative groups by eschewing controversial issues, like reforming personal laws. The IGOs emphasize women's rights to financial independence. They are very vocal about women's rights to earn and work for them. In doing so, they highlight the integration of female labor in the market economy. 
With the advent of new technology and the mobility of capital, countries like Bangladesh are experiencing globalization as new members of the developing world. Bangladesh is one of the latest members participating in the rapid race for economic development. Bangladesh has been a fairly successful participant, so far. With the adoption of national and international policies to develop even faster, Bangladesh has had an influx of new economic opportunities. The introduction of the manufacturing industry in the late 80 s and early 90 s has increased investment in the Bangladeshi market, mostly in the textile industry (commonly known as garment industry in Bangladesh). This industry has opened new doors for poor, rural women who are young and unmarried. The abject poverty and new opportunities as seamstresses in the international textile company have led young, unmarried, poor, rural women of Bangladesh to ignore purdah and join the labor force in Bangladesh.

Bangladesh has only been a country since 1971; despite this, it has been remarkably fast in joining the development race. The rapid expansion of the export-oriented readymade garment industry has led to an influx of female labor in the market economy. This strategy of development is a direct result of the adoption of neo-liberal policies. Bangladesh, being a new member on the list of developing countries, kick started its development program with the adoption of economic liberalization policies in order to be eligible for much-needed foreign aid. Since then, the largest export industry in Bangladesh has been the ready-made garment (RMG) industry, which runs on labor of young, unmarried, poor, rural women of Bangladesh.

\subsection{FDI in Bangladesh}

\subsubsection{Type of FDI}

Bangladesh adopted the economic liberalization policies as early as the advent of the independent state. The necessary foreign assistance came at a time when Bangladesh had a pool of unemployed labor that was willing to work for pay. Initially, because of the traditional 
boundaries restricting women like purdah, Bangladesh's foreign investment entities employed men, but as the demand for cheaper and compliant labor grew, more women (mostly young, poor, rural, women) were encouraged to join the workforce(Kabeer and Mahmud, 2004). Numerous policies like the Foreign Private Investment (Promotion and Protection) Act of 1980, the Bangladesh Export Processing Zones Authority Act of 1980, and the New Industrial Policy of 1982 were established to attract more foreign investment in Bangladesh. All these policies were geared towards the establishment of strong manufacturing. The Industrial Policy of 2010 furthered this goal and proposed a combined strategy of economic growth through rapid industrialization. The state-guided manufacturing industry has indeed been successful for Bangladesh.

The laws introduced to bolster the manufacturing sector offered incentives to FDI and their enterprises. Some of these incentives allowed MNCs tax holidays for 5-10 years (The Dhaka Chamber of Commerce and Industry, 2000). These corporations were also guaranteed protection from nationalization and expropriation. Entrepreneurs, who were investing a minimum of $\$ 500,000$ USD or transferring $\$ 1,000,000$ USD to a recognized financial institution, were offered citizenship in the country. Export-oriented industries were offered tax exemption and duty-free imports of capital equipment. Foreign technicians employed in the industry were exempted for income tax for three years. EPZs were also incentivized with income tax exemption for 10 years, and they were also allowed $50 \%$ income tax rebate after 10 years. Raw materials and machineries were guaranteed duty free imports (The Dhaka Chamber of Commerce and Industry, 2000).

With such incentives along with available cheap labor of poor, rural women, FDIs were instantly attracted to Bangladesh. The incentives given to the FDI by the Bangladeshi 
government suggests that the investment was mainly directed towards establishing an exportoriented industry. FDI was primarily vertical FDI, whereby production of a commodity is divided internationally to better achieve cost effectiveness. This type of FDI is invested in producing labor-intensive intermediate products for consumption in high-income countries, and is oriented towards cutting cost of production (Bjorvatn \& Eckel, 2001; Kucera, 2002; Busse, 2003). The most cost-consuming element of the production is the labor; if one can save on the labor cost, then the cost of production will reduce significantly. It is with the goal to cut labor cost that MNCs like H\&M and Wal-Mart invest in countries like Bangladesh.

\subsubsection{RMG Sector and Women's Labor}

The industry that flourished after the economic liberalization was the RMG sector. Like everywhere else, this industry in Bangladesh used women's labor, mostly of young, unmarried, poor, rural women. Despite the sluggish industrial sector, the ready-made garment industry boomed in Bangladesh. Since its advent in the 1980s, the garment industry has been an important part of the Bangladeshi economy. The industry has created jobs and increased foreign exchange earnings (Khundker, 2002). The labor that sustains this industry is maintained through a pool of rural, poor, and unskilled women.

A 2001 study (Zohir, 2001) that surveyed 24 factories in a Bangladesh EPZ found that the average age of women working in the garment factories is 19 years old. The same study also found that $45 \%$ of female workers are unmarried and only $62 \%$ had above primary level education (Zohir, 2001). The employment in these industries has changed the gender relations within the household. The increase in garment industry has allowed women to work outside, increasing their bargaining power within the household; it has also made women vulnerable and less secure in the fluctuating global market. When it comes to wages in garment factories, the wages are low for both men and women, however, females are more likely to be employed to 
even lower paying jobs like helpers and operatives than men (Paul-Majumdar \& Begum, 2000; Yunnus \& Yamagata, 2012; Ahamed, 2013)

Figure 2: Percentage of employment in garment industry by sex, 2001-2007

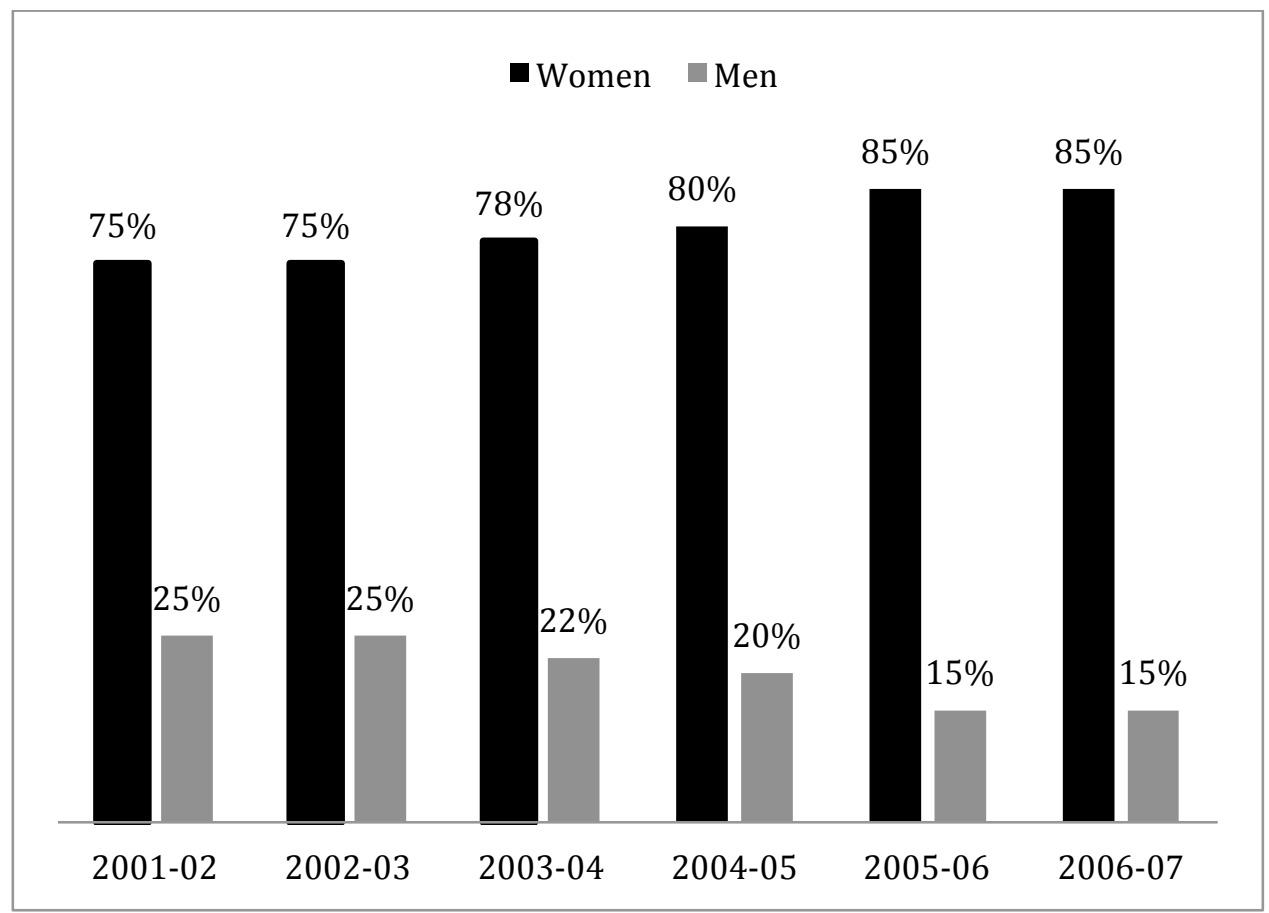

Source: Bangladesh Bureau of Statistics, 2008

It has been widely noted that the garment sector is a major industry in Bangladesh. The products of the garment industry account for $90 \%$ of the total export of Bangladesh. Despite such success and institutionalization, this sector offers contracts and benefits similar to that of an informal sector. The garment industry in Bangladesh boomed after East Asian clothing exporters were imposed export quotas (Kabeer \& Mahmud, 2004). In their study of the RMG industry in Bangladesh, Kabeer and Mahmud (2004) divide the garment factories in three tiers. The first tier includes factories that are directly connected to international markets, are technologically advanced, and have relatively skilled labor force. The second tier, like the first tier, has direct links to international buyers, but it is not established through FDI. Finally, the third tier is characterized by informal characteristics "made up of small low-grade factories which have no 
direct relationship to buyers or the capacity to open a Letter of Credit" (p. 144). They find that the majority of the factories are situated in the third tier. In the peak season, work from the first and the second tier are outsourced to the third tier.

In reviewing the employment procedures in the third tier factories, the authors find that the factories hire low skilled laborers and provide them with on-the-job training. The hours in these factories are long, and their hourly earnings are probably the lowest in the industry: "The availability of an apparently unlimited supply of female migrant labor willing and able to work the long hours demanded for little pay until it has to be replenished by fresh recruits from the countryside" (p. 146). This has allowed the employers to operate without changing their conditions. Kabeer and Mahmud (2004) also find that the access to employment in other sectors is not as easy as in the garment industries. They argue that while these jobs have allowed these women the financial security, increasing their bargaining power in the household, this is not a long-term solution to end female poverty. However, the state and FDI both seek to use labor of young, poor, migrant female workers to benefit economically. The strategy adopted by the state is to keep the labor cost low and loosely regulate labor laws to attract the capital in the country. In this strategy, the women workers in RMG sector are disproportionately disadvantaged than men. The following section highlights factors explaining the unregulated female labors in the RMG sector in Bangladesh.

\subsection{Determinants of Unregulated Female Labor in RMG sector}

\subsubsection{Development level}

Bangladesh has always been listed as one of the poorer countries in the world. The history of Bangladesh is that of dire hunger and poverty. The geographical structure of Bangladesh makes it one of the wettest areas in the entire world; agriculture is almost always threatened by flooding. The Bangladeshis are constantly struggling with the climate and its effect 
on their everyday lives. While the land is fertile, the produce is constantly in danger of being flooded during the monsoon season. In such a precarious climate, Bangladesh needed to figure out another way besides agriculture to support its economy. Though industrialization was introduced to the area during the British colonial period, it was not well established. After the introduction of the Export Processing Zones Authority Act of 1980, Bangladesh opened its market to foreign investment, and since then Bangladesh has expanded its industrial sector.

Figure 3: GDP Growth (Annual \%), 1980-2010 (5 year increment)

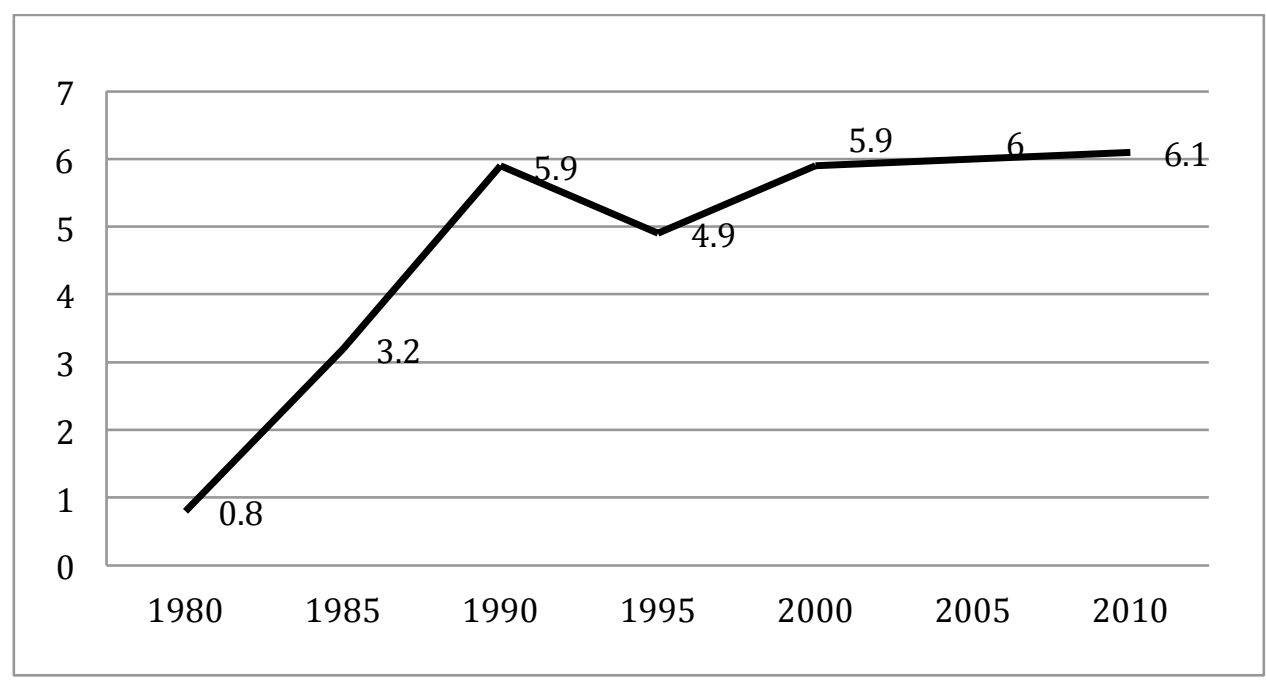

Source: The World Bank, 2013

The World Bank categorizes Bangladesh as a low-income country (The World Bank, 2013). With GNI (gross national income) per capita of $\$ 840$ in the year 2012, Bangladesh is taking small steps towards improvement but is still struggling to make ends meet. The majority of the population (77\%) still lives on less than $\$ 2$ a day. A decade ago, $21 \%$ of Bangladesh's GDP was agriculture and only $16 \%$ was manufacturing. Today the manufacturing has caught up with agriculture, and both of them contribute $18 \%$ to the economy. Another large sector of the income is personal remittances with $12 \%$ contribution to the GDP. Bangladesh has been doing well as an export-oriented manufacturing-driven economy (The World Bank, 2013). The figure 
below highlights the annual percentage of GDP growth from 1980 to 2010 . The growth rate bolsters the fact that Bangladesh is growing economically under the export-oriented economy. Manufacturing is a growing sector in Bangladesh. Most of the manufacturing sector is directed towards the production of export-oriented products. In 2012, 23\% of the GDP was via exports of goods and services. While FDI has been constant (contributing $1 \%$ of GDP) for the past ten years, it has been significant in the establishment of EPZs and garment sectors in the economy (The World Bank, 2013). The figure below outlines exports of goods and services as a percentage of GDP from 1980 to 2010 . The exports of good and services as a percentage of GDP have increased from $5.5 \%$ in 1980 to $18.4 \%$ in 2010 .

Figure 4: Exports of Goods and Services (\% of GDP), 1980-2010 (5 year increment)

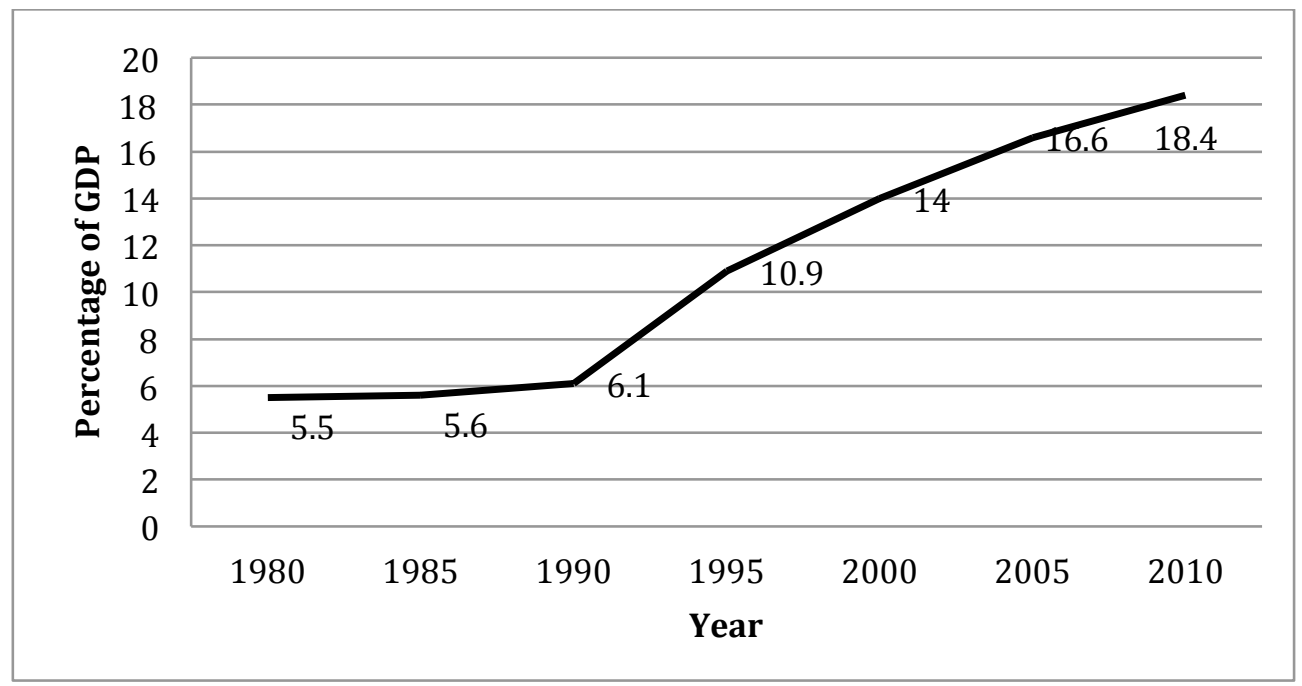

\section{Source: The World Bank, 2013}

Since its independence from Pakistan, Bangladesh has opened its market for all kinds of investment. In doing so, Bangladesh has introduced policies and laws to attract foreign investment. Some of these policies are the Foreign Private Investment (Promotion and Protection) Act of 1980, the Bangladesh Export Processing Zones Authority Act of 1980, and the new Industrial Policy of 1982. These policies offer various incentives to FDI including 5 to 10 
years of tax holiday; rationalization of import duties and tax; exemption of income tax for three years for the foreign employees of the industry, etc. The companies that sought to establish EPZs were given more incentives like income tax exemption for ten years, $50 \%$ income tax rebate on export earning, tax exemption on interests on foreign loans, duty free import of raw materials, etc. Bangladesh has successfully established itself as a good country to invest in.

Table 3: Exemption of Income Tax Pertaining to Industrial Units

\section{Tax Exemption Period}

$$
\begin{gathered}
1^{\text {st }} \text { and } 2^{\text {nd }} \text { year } \\
3^{\text {rd }} \text { and } 4^{\text {th }} \text { year } \\
5^{\text {th }} \text { Year }
\end{gathered}
$$

\section{Rate of Tax Exemption}

$100 \%$

$50 \%$

$25 \%$

\section{Source: BEPZA, 2010}

The World Bank has ranked Bangladesh 20th out of 187 countries for investment protection (BEPZA, 2010). Bangladesh structured its industrial sector to fit the export-oriented model. In 2012, exports accounted for 23\% of the economy of Bangladesh. The annual growth of export is also growing at an average of 12.5\% since last decade (The World Bank, 2013). Along with these policies, Bangladesh also started to advertise the suitable environment for foreign investment in the country. One of the strategies to attract foreign investment was by offering cheap labor.

Labor is a huge cost in producing any commodity. Labor is cheap, plenty, and young in Bangladesh. In a yearly report, BEPZA (2010) claimed that Bangladesh offers a competitive labor cost to foreign investors. On top of that, by exempting labor unions to operate in the EPZs, Bangladesh ensures hassle-free cheap labor. The control of political institutions and media by the garment industrialist also ensures loose implementations of labor laws. The intense need for market investment has allowed the Bangladeshi government and industrialists to keep the labor cheap. The only way to keep labor cheap is by having loose and weak labor laws that are rarely 
implemented. The weak labor laws in EPZs highlights the state's allowance of poor treatment of women workers in the EPZs. Thus, it will be safe to argue that Bangladesh is more worried about the competitive market of FDI than its female citizens whose labor is kept unregulated to attract FDI.

\subsubsection{Unskilled Labor}

Bangladesh, as a country, has had its own share of struggles. One of the most tenacious of those struggles has been the problem of poverty. Massive flooding time and again challenged the agricultural production of the country. Poverty has been a part of life for most of the Bangladeshis. Only $58 \%$ of the people can read and write. Of them, only $41 \%$ of females are literate. Women are increasingly becoming a visible part of the labor force in Bangladesh. The participation of women in labor force has increased from 57\% in 2001 to $60 \%$ in 2012 (The World Bank, 2013). Most of this rise can be attributed to the influx of the investment in the RMG sector of the Bangladeshi economy. Today, women make up $80 \%$ of the labor in the export-oriented apparel industry (BGMEA, 2013). Most of this labor is unskilled.

Marred with extreme Islamization and facets of strong patriarchal elements of the Indian sub-continent, Bangladesh is a society that devalues women. Violence against women is a major issue in Bangladesh. Women are constantly subject to violence because of their gender. The UNFPA (United Nations Population Fund) estimates that between 50 to $60 \%$ of women in Bangladesh have experienced some form of violence in their lives, be it rape, trafficking, acid attack, or assault, both domestic and public (Bangladesh Bureau of Statistics, 2013). Women are harassed in both private and public spheres. They are treated as second-class citizens. Most of the women who provide the labor in the EPZs are from rural areas, and are poor and unskilled. Most of the girls employed in EPZs are secondary school dropouts. Girls are also discouraged from attending school, as being "better educated" means marrying a educated man with a larger 
demand for dowry (Rao, 2012). Young women are often encouraged by their parents to join the garment factories to help fund their younger siblings' (usually males) education. Women are hired commonly in their early teens as apprentices. This pool of unskilled labor that is unaware of labor rights increases the chances of labor abuse, and thus, unregulation of labor laws.

The labor pool that is required for manufacturing industries in Bangladesh is unskilled labor. Most of the female labors are recruited to work on the assembly line as opposed to managers. Time and again, managers have cited their preference for female laborers for their docility. To keep the costs low, the manufacturing needs a labor force that is willing to work without any demands. It will suit the manufacturers if the workers are less aware of their rights as laborers. Thus, it will be fair to state that the majority of unskilled labor in the Bangladeshi labor force allows the state to keep the labor laws pertaining to women unregulated.

\subsubsection{Civil Rights and Liberties}

With its violent and tumultuous history, Bangladesh has struggled to ensure civil rights and liberties of its citizens. Bangladesh's democracy has been constantly threatened by military rule, growing Islamic extremism, and political violence. In such circumstances, the civilians have often had their rights denied to them. Problems like political polarization, weak rule of law, criminality within the government, and lack of bureaucratic transparency has been challenging government accountability repeatedly (U.S. Department of State, 2013). The growing Islamization has also led to attacks on civil rights and liberties of the people. People are discouraged and often threatened from adopting democratic practices, such as being a member of a political or social organization.

Journalism is constantly threatened and confronted by organized crime syndicates, political parties, and Islamic factions. The rights to assemble and associate are also attacked. Protestors have been targets of police violence (Freedom House, 2013; U.S. Department of State 
2013). It will be safe to assume that protecting labor rights is not on the agenda for most of the Bangladeshi authorities. Policies that ensure labor rights are already weak in Bangladesh; to make matters worse, labor union formation is challenged by a 30\% employee-approval requirement. Advocates of labor rights are constantly harassed by criminals, public officials, and entrepreneurs (Freedom House, 2013). Violence against women is a persistent problem. Issues like dowry violence, domestic violence, rape, acid attacks, and other violence against women are rarely effectively addressed by the bureaucracy.

\section{Table 4: Civil Liberties Rating, Political Rights Ratings, and Press Freedom Score of Bangladesh, 2002-2012}

$\begin{array}{cc}\text { Year } & \text { Civil Liberties ratings } \\ 2002 & 4 \\ 2003 & 4 \\ 2004 & 4 \\ 2005 & 4 \\ 2006 & 4 \\ 2007 & 4 \\ 2008 & 4 \\ 2009 & 4 \\ 2010 & 4 \\ 2011 & 4 \\ 2012 & 4\end{array}$

Political Rights Ratings
3
4
4
4
4
4
5
4
3
3
3

$\begin{gathered}\text { Press Freedom Score }(\mathbf{0}=\text { best, } \\ \mathbf{1 0 0}=\text { worst }) \\ 63 \\ 65 \\ 68 \\ 68 \\ 68 \\ 66 \\ 68 \\ 63 \\ 56 \\ 54 \\ 52\end{gathered}$

Source: Freedom House, 2013

A study conducted by UN in Asia and the Pacific surveyed 2,400 Bangladeshi men between ages of 18 and 49 in both urban and rural areas. The study found that more than $50 \%$ men were perpetrator of physical and/or sexual violence against women (UN, 2013). While there are laws enacted to protect violence against women, the prosecution rate of perpetrators of violence against women is very low (U.S. Department of State, 2013). The UN study also found that a vast majority of perpetrators of rape faced no legal penalties for their crime (UN, 2013). Sexual harassment is common in both public and private spaces, including in schools and workplaces, however because of the nature of the crime and the patriarchal culture, many incidents are underreported (U.S. Department of State, 2013). The U.S. Department of State's 
Country Report on Human Rights Practices reports violation of various labor rights in garment factories including unfair termination of employment, sexual harassment, and physical violence (2013).

In Bangladesh, women are treated by both the state and the MNCs as resources rather than citizens (Kabeer and Mahmud 2004). Bangladesh has inherited intense patriarchy from both Pakistan and India. When it comes to the role of women as laborers, they are being advertised and used as a cheap resource for rapid development of the state. In such a case,the Bangladeshi state is essentially allowing repression of women's rights as labor and as citizens to cater to the interest of the state and the capital. Thus, it will be fair to argue that women's labor is regulated less in countries like Bangladesh where the government is weakly imposing laws that protect civil rights and liberties.

\subsubsection{Corruption}

Corruption is a big problem in most of the developing countries, and Bangladesh is no exception. The public in Bangladesh establishes corruption as a "way of life"(Zakiuddin \& Haque, 1998, p. 1). The strong culture of patronage in Bangladesh bolsters the practice of corruption in the society. According to Transparency International, there are three types of corruption: grand, petty, and political. Bangladesh is a seasoned practitioner of all of these. In this case, I will be focusing first on petty corruption, and I will follow it with a discussion on political corruption.

A Transparency International report from 2012 finds that the justice and law enforcement sectors are the most corrupted sectors in Bangladesh. The major sources of the corruption are political influence, poor implementation of laws, lack of transparency, and inadequate accountability, among other things. The 2010 survey by Transparency International found that $80 \%$ of households that sought services from law enforcement agencies experienced corruption. 
The report also found that $68 \%$ of the households who sought help from the agency were forced to pay bribes (Transparency International, 2012c).

Police in Bangladesh have ranked as the highest bribe collectors in South Asia (Transparency International, 2011). A police station is the first place that a victim of any crime goes to report it. When police officers are asking people for bribes to register their complaints, then the victims, especially the ones who are poor, will try to avoid the extra expense by not reporting the crime at all. Also, the rampant bribe collection among the police suggests that they will work in favor of those who can pay a better amount. In the case of labor abuse, if a woman is harassed in the workplace by her employer and goes to the police to report the crime and seek justice, it is likely that she will fall victim to harassment by the police to pay the bribe. If the employer bribes the police, her complaint could never be filed or could be withdrawn easily.

Table 5: Corruption Perception Index Rankings and Scores, 2001-2011

$\begin{array}{cccc}\text { Year } & \text { Ranking } & \text { Score } & \text { No. Of Countries } \\ 2001 & 91 & 0.4 & 91 \\ 2002 & 102 & 1.2 & 102 \\ 2003 & 133 & 1.3 & 133 \\ 2004 & 145 & 1.5 & 145 \\ 2005 & 158 & 1.7 & 158 \\ 2006 & 156 & 2.0 & 163 \\ 2007 & 162 & 2.0 & 179 \\ 2008 & 147 & 2.1 & 180 \\ 2009 & 139 & 2.4 & 180 \\ 2010 & 134 & 2.4 & 178 \\ 2011 & 120 & 2.7 & 182\end{array}$

Source: Transparency International, 2012

Police are also often used in most of the South Asian countries as a tool of a ruling party. The ruling party uses police as a means of controlling public opposition in Bangladesh as well. Incentives, such as posting and promotions, are based on the loyalty to the ruling party rather than merit and efficiency (Islam, 2012). Police have been often used by the ruling party to control labor advocates and unions (U.S. Department of State, 2013). The rampant corruption in government institution like police affects the willingness of the victims to report the crime. The 
victims of labor abuses are less likely to go to the authorities when that only amounts to loss of time, money, and a job. When the crime is not accurately reported, the numbers won't show. This gives authorities a chance to bolster their argument that everything is controlled and wellgoverned with proper regulation of laws.

Along with petty corruption, political corruption is also widespread in Bangladesh. $62 \%$ of Bangladeshis perceive political parties to be corrupt entities, and $42 \%$ perceive Parliament to be a corrupt institution (Transparency International, 2012). Political parties have very weak checks and balances for the head of the party, who is responsible for decision-making on nominations and finances. Within the political system, a Bangladeshi executive holds great influence over the legislative branch (Hechler et al., 2011). This has led the political agenda of the institutions to cater to the interests of the executive. In the context of Bangladesh, the political rivalry between two major parties has been motivated by vengeance (Nazneen et al., 2010). Both leaders of the parties have driven their electoral agenda on vilifying the other side. The table below highlights the types of corruption in Bangladesh and actors involved in the corruption.

\section{Table 6: Types of Corruption \& Actors Involved, 2005}

$\begin{array}{cc}\text { Types of Corruption } & \text { Percentage } \\ \text { Abuse of Power } & 38.7 \\ \text { Bribery } & 21.0 \\ \text { Extortion } & 16.5 \\ \text { Fraud } & 7.8\end{array}$

$\begin{array}{cc}\text { Actors Involved } & \text { Percentage } \\ \text { Officers/Employees of Government } & 64.1 \\ \text { Officers/Employees of Private Sector } & 14.3 \\ \text { Elected Officials } & 8.1 \\ \text { Autonomous organizations and NGO } & 3.6 \\ \text { Political leaders/workers } & 4.7\end{array}$

Source: Transparency International Bangladesh, Corruption Database Report, 2006

Since political parties are very patrimonial, the current heads of the two major parties are from two prominent families of Bangladeshi history. One is a daughter of the founder of the nation, while the other is a wife of a celebrated military leader. The patronage network within 
the political realm has significantly weakened the institutions (Bertelsmann Stiftung, 2012). Although two of the most powerful persons in Bangladesh are women, this does not translate into more provisions that protect women and establish them as equal citizens. Instead, the rising Islamization and the reliance of political parties on religious groups in electoral politics have been detrimental to women in Bangladesh. Bearing this in mind, it can be argued that rampant corruption in Bangladesh explains the ineffective regulation of labor laws that protects women.

\subsubsection{Pressure for CSR}

Recognizing that poor states often fail to enact better laws to protect their own citizens, the international community has encouraged the adoption of CSR. Since the last couple of decades labor organizations, human rights organizations, and NGOs have been pressuring the MNCs to adopt policies of CSR. Such pressures come in two forms: Organizational pressures that are usually exerted by groups, and organizations that seek to identify corporate irresponsibility. The second type of pressures is institutional pressure that is exerted via policies, international norms, standards, and laws.

In Bangladesh, institutional pressures are like empty promises. The labor laws are already weak; most of them are there to appease international norms. On top of weak implementation, corrupt enforcement makes this type of pressure almost non-existent. Further, the institutional pressures are being targeted towards the state rather than the corporations. The suspension of Generalized System of Preferences (GSP) agreement by the United States with Bangladesh after the Tazreen incident in November 2012 shows that, at least in the case of Bangladesh, institutional pressures are being directed towards the state (Solidarity Center, 2014).

The organizational pressures are much larger in Bangladesh. The initiatives like Fair Trade Labor and Clean Clothes Campaign are constantly working on making the corporations involved in labor rights abuse more visible in the public eye. Organizations like Institute for 
Global Labor and Human Rights (IGLHR) and Solidarity Center are actively involved in making corporations like Gap and Wal-Mart take some responsibility of bad labor conditions in Bangladesh, and work towards eliminating labor abuse. These organizations do their best to increase public awareness on labor conditions in EPZs. Their goal is to increase consumer awareness, make consumers demand better treatment of labor, and put pressures on corporations for responsible actions. They have been fairly successful in increasing public awareness on poor treatment of women workers in RMG sector. The wide coverage of incidents like the collapse of Rana Plaza and the Tazreen factory fire by the media and these organizations have put Bangladesh on the map of countries with worst labor regulations. In Bangladesh, organizations' activism in identifying labor abuse of women in export-oriented industries and organizationally exerted pressure for CSR can lead to better regulation of labor laws enacted to protect women as workers.

\subsubsection{Bureaucratic Capacity}

Bangladesh's political background is tarnished with problems like patrimonial politics, corruption, and an overtly personalized political system. These problems have led to weak institutional authority that lacks accountability (Kochanek, 2000). In Bangladesh, the civil service is highly politicized where political interventions from incumbent politicians are regular. The existent merit-based personnel rules are regularly ignored in incentivizing the civil service. The people who have political connections are rewarded more often than those who are more competent (Zafarullah \& Rahman, 2008). The two major parties of Bangladesh have been accused of favoring their supporters in the bureaucracy while disdaining the supporters of the opposite party (Mukherjee, 2001; Zafarullah \& Siddiquee, 2001). This high politicization has resulted in incompetent bureaucrats who prioritize party loyalty over bureaucratic operations. 
Bureaucracy in Bangladesh also lacks relevant skills and knowledge. The bureaucratic ability is further hindered by lack of a clear job description that outlines rules, procedures, and knowledge required for the position, as well as duties and responsibilities of the position (Zafarullah \& Rahman, 2008). Corruption in bureaucracy has also impacted the political will of bureaucracy in implementing enacted policies (Kochanek 1993; Zafarullah \& Siddiquee, 2001). Zafarullah and Siddiqui (2001) find that the "spoils of corruption" are shared among different levels of officials and this impacts the implementation of policies at different levels of the organization (p. 477). The bureacratic capacity of the Bangladesh state has been continuously challenged by lack of political will, corruption, and highly politicization in the bureaucracy.

With the support of IGOs like ILO and the World Bank, Bangladesh has adopted various measures to tackle the problems related to labor. In the past decade, the government of Bangladesh, bolstered by ILO, has significantly reduced child labor from the garment industry. Much of the success of this reduction of child labor from garment industry has been associated to the introduction of the Child Labor Deterrence Act or the Harkin Bill. This bill sought to eliminate child labor by prohibiting imports of goods that used child labor (Harkin, 1999). However, according to a report published by ILO in 2012, the measures suggested by the bill are still not institutionalized by the state to absorb its full efficiency.

The mounting pressure on the Bangladeshi government to act on the labor issues resulted in the establishment of dual institutional measures: one government led and one private sector led. These institutions were specifically established to monitor labor conditions (Ahamed, 2013). The private led sector Bangladesh Garment Manufacturers and Export Association (BGMEA) has no established legal compliance framework to operate under. This lack of legal compliance made this institution unwilling to pursue the primary purpose of monitoring and enforcing labor 
laws in the member factories (War on Want, 2011). The primary institution that is responsible for enforcing labor laws and monitoring labor conditions is MOLE. In 2005, the government established a Compliance Monitoring Cell, which was charged with the responsibility of tracking the implementation of compliance of rules in the garment sector. This establishment has also failed to reach the ILO standards because of inadequate budget, inadequate training of staff, and inflexibility of established institutions (War on Want, 2011; Ahamed, 2013). Despite the strong support from IGOs like ILO and the World Bank, Bangladesh is still struggling to realize the goals of improvement of labor conditions in the country.

Like labor issues, gender equality has also struggled despite regular investment from IGOs like United Nations, Asian Development Bank (ADB) and the World Bank. The issue of gender equality in Bangladesh has been on the table for a long time. In 1997, the National Policy for Women's Advancement provided the government's commitment for gender equality. The government also introduced the Public Expenditure Support Facility Program in 2009. This program was designed to promote gender-inclusive growth. Through this program, the government formulated gender budget guidelines: "By 2011, 33 ministries had formulated budgets that disaggregated expenditures. About $30 \%$ of the entire budget consolidated across 33 ministries in 2010 was allocated for gender-related expenditures, of which $18.3 \%$ was for expenditures targeting women directly" (ADB, 2012). In 2011, the government introduced the National Women Development Policy to address gender based disparities and discriminations (ADB, 2012).

Further, the government has extended such commitments to gender equality in different sectors. Despite such vocal commitments in national policies, the government has yet to invest in building the needed capacity. The Country Gender Assessment Report produced by ADB (2010) 
finds that these commitments are usually "superficial" (p. 56). Time and again, bureaucratic challenges have been identified as a failure to realize the goals of improving labor and gender conditions in the country. The discussion above has established that Bangladesh is struggling to build bureaucratic capacity to better implement the enacted policies to protect labor and fight gender inequality in the country. These challenges explain the weak regulation of labor laws in Bangladesh.

\subsection{Unregulated Labor in Bangladesh}

\subsubsection{Women's Labor in Bangladesh}

The overwhelming presence of women as workers in Bangladesh's textile industry shows that this industry is clearly running on the concept of gender division of labor. Paul-Majumdar and Begum (2000) try to examine how employment of women in export-oriented industries exploits "comparative advantages of their disadvantage" (p. 1). They argue that the cheap labor of women has allowed the export-oriented industries, particularly the garment industry, to use female labor as a resource while providing economic opportunities for women. In the garment industry, there is a demand for skilled male workers and unskilled women workers (Paul-

Majumdar \& Begum, 2000; Zohir, 2001; Khundker, 2002; Mukhopadhyaya \& Chaudhuri, 2011). Paul-Majumdar and Begum (2000) find that as jobs in garment sectors become more technological and remunerative, more male employees are hired, and "female workers are ousted from that job and concentrated more and more in low-skilled jobs" (p. 10). Women are mostly employed as lower-level employees as junior sewing and knitting machine operators, and general sewing machine operators (Yunnus \& Yamagata, 2012). The recent influx of men in the industry with the production of knitwear can also be attributed to the belief that women are less capable of using the machinery to produce knitwear (Hossain, 2012). 
In a survey conducted by Chowdhury and Ullah (2010) in 29 garment factories in Chittagong Metropolitan area, they find that the majority of the women employed in the garment industry are primary school dropouts. The gender wage gap is insignificantly higher in exportoriented industries than in non-export oriented industries. In their study, Paul-Majumdar and Begum (2000) find that a female employee in an export-oriented garment factory earns only a little over half (58\%) of what a male employee would earn, while in non-export industries females earn $60 \%$ of male earnings.

Table 7: Education Level of Female RMG Workers in Chittagong Metropolitan Area, 2010

$\begin{array}{ccccccc}\begin{array}{c}\text { Level of } \\ \text { Education }\end{array} & \text { Illiterate } & \begin{array}{c}\text { Can Sign } \\ \text { Name Only }\end{array} & \text { Class I- V } & \text { Class VI-X } & \text { Above Class X } & \text { Total } \\ \text { Frequency } & 04 & 37 & 58 & 43 & 09 & 151 \\ & (0.265 \%) & (24.50 \%) & (38.41 \%) & (28.48 \%) & (05.96 \%) & (100 \%)\end{array}$

Source: Chowdhury and Ullah, 2010

Another study conducted in 2003 bolsters this finding, as they report that female workers are only paid $75 \%$ of what male workers earn in garment industries (Haque, 2003). The gender wage gap is also higher among the urban population (where most of the EPZs are situated) than among rural population (Ahmed \& Maitra, 2008). Table 8 highlights the gender wage disparity in the RMG industry. Though the data presented is more than a decade old, little has changed since then (Ahamed, 2013).

Table 8: Gender Differentials in Wages in RMG in Industry, 2001

Categories of Workers
Operator
Cutting Master
Ironer
Sewing Helper
Cutting Helper
Finishing Helper
Folder

Categories of Workers

older
Male Wages Tk/ per month

2,254

3,935

1,894

1,200

1,512

1,209

1,528
Female Wages Tk/per month

1,536

1,106

762

837

1,023

1,157 
Source: Ahamed, 2013

Note: US \$ 1= 77.6 Tk (as per the rate of June 10, 2014)

There are other factors that drive the widening of the gender wage gap in FDI-based economy. The literature above establishes that women in the Bangladeshi export-oriented garment factories are dominant in low skilled jobs, while the men control the high skilled jobs. It is important to note the control of managerial and skilled positions by males in the garment sector. This is mainly because of the degrading of women's skill to make their labor cheaper in the RMG sector. Women's labor has often been identified as substitute labor. This perception of second-class labor leads to degrading and labeling women's labor as unskilled. Elson and Pearson (2008) argue that this perception is an outcome of the reproductive roles of women. "This kind of gender subordination means that when a labour market develops, women, unlike men, are unable to take on fully the classic attributes of free wage labour" (p. 196). The informalization and feminization of the garment industry explain the large gender gap, along with the unregulation of labor as it pertains to women, in the garment industry.

A study from 2011 finds that gender wage differentials in garment factories were narrowed from 1983 to 1990, but increased from 1990 to 1997, mainly because more men were taking up high skilled jobs in the sector (Mukhopadhyaya \& Chaudhuri, 2011). The increase in use of technology has established the work as skilled. Wage associated with the job has also increased, along with the technology (Paul-Majumdar \& Begum, 2000). Most of the time, men are appointed for the labor that requires operating the larger and complicated machineries. These works are usually categorized as skilled, while the labor that does not require intensive training in the workplace, like sewing, are feminized and, thus categorized as unskilled (Enloe, 1990). To illustrate my point, I want to elaborate more on the example of sewing as a skill. 
In the Indian subcontinent, like every other occupation, the job of making clothes was also assigned by the caste. Usually, in the area, clothes making was a job of a man of a particular (lower) caste. That was the primary source of the income of the family of that caste. Thus, sewing was more of a family occupation than a woman's job. The feminization of sewing happened only after the introduction of mass production of ready-made garments. The western reservation of sewing as a women's job led the western investors to look for workers with particular female characteristics such as nimble fingers, docility, and naturally suited for monotonous, tedious, and repetitive jobs. This created a demand for women workers to work in that industry and with that demand the state started to advertise the female labor as it suits the interest of the investor. Further, the mass production of garments like any other products made the cost of labor in that particular industry cheaper.

The devaluation of women's work led to the creation of a pool of unskilled, inexpensive labor of poor, rural women who were ready to work in any condition. The desperate poverty led to a demand for work. The labor was not only cheap, but also it had no demands regarding the working conditions and pay as long as it was paid. With these "no strings attached deals," MNCs jumped into the opportunity to exploit this resource. The result was underpaid and overworked labor force that worked in dangerous working conditions. The two recent incidents pertaining to the RMG sector in Bangladesh: Tazreen factory fire of December 2012 and the collapse of Rana Plaza in April 2013 is the tip of the iceberg; such incidents are no anomaly to the workers in Bangladesh. The victims of both the incidents were mostly women.

\subsubsection{Unregulated Labor of Women}

Although large numbers of women in Bangladesh are employed in the RMG sector, the social value of female work has not increased at the rate of female employment. While this phenomenon is rare, it can be explained as an outcome of growing Islamic extremism. For most 
of the women in Bangladesh, joining the labor force meant getting out of the purdah. The idea of purdah has been re-emphasized with growing Islamization, which has made it more restrictive. Further, in Bangladeshi society, men of the household assume the traditional role of breadwinners. This role was often associated with machismo of the male members of the family. Considering this, women joining the workforce meant hurting the male machismo.

With the conservative Bangladeshi society in the backdrop, it is obvious to ask why there is such a large influx of women in the labor market, mostly in the RMG sector. Naila Kabeer (2000) asks the same questions in her study of women workers in RMG sector, and finds that the only reason employers are attracted to female labor is because unlike male employees, female employees are perceived to be less troublesome. The export industry, which prospers on the expense of the compliant labor force, hires the workers who are taught from their earliest days to be docile. The Bangladeshi society raises their daughters to be a compliant wife and a docile domestic worker. Considering this, despite financial needs, the family prefers the females to be confined within the walls of the household. Most of the female laborers in garment factories are poor, rural, young, and unmarried. The garment workers are often stigmatized and are called "dushito" (spoilt). It is not considered suitable for the women of respectable households (which are often identified along the lines of class and caste) to work in garment factories (Kibria, 1998; Rao, 2012). While conduction a focus group interview with young Bangladeshi men, Rao (2012) finds that men do not prefer girls who work in garment factories as their wives. The following statements were repeated more than once as justifications of their preference:

Women and men work together in garments, they come home late at night and this is not acceptable. People talk about their immorality. Working women have a different temperament. They don't care for their husbands. They can threaten to divorce their husband and live separately on trivial grounds as they are economically empowered. Therefore, men don't like marrying them. (Rao, 2012, p. 34) 
The social stigma attached to the job along with harassments and abuse, low pay, and long working hours, make the work in the garment factories a zero-sum game for the female workers in the garment industry in Bangladesh.

Such stigmatization works in the favor of the employers in degrading and devaluing women's work. This results in unregulated labor laws in the economic sector where women provide the majority of the labor. Bangladesh's government has detailed labor laws that protect the labor; however, they are rarely implemented. The following section will discuss the labor laws in Bangladesh as it pertains to the female labor being used in the EPZs.

\section{Maternity Benefits and Its Implementation}

Bangladesh is a new country that is struggling to create a democratic society supported by well-enforced rules and regulations. The Constitution of Bangladesh, which was drafted in 1972, guarantees freedom of association. Article 38 of the constitution guarantees the freedom of the citizens to association:

Every citizen shall have the right to form association or unions, subject to any reasonable restrictions imposed by law in the interests of the monetary or public order (ILO 2013a).

The Constitution also protects its citizen against forced labor under Article 34:

All forms of forced labour are prohibited and any contravention of this provision shall be an offence punishable in accordance with law (ILO, 2013a).

There are also other laws that have been enacted to protect the labor in the country. The 1977 Industrial Relations Rule Act prohibits unfair labor practices and discrimination of workers under labor unions. The Children's Act of 1974 eliminates child labor (ILO, 2013a).

Bangladeshi labor laws also address the issues related to women's labor. Chapter 4 of the Bangladesh Labor Act of 2006 (Act No. XLII of 2006) deals entirely with maternity benefits. 
This chapter discusses how employers are to treat pregnant women during the late pregnancy and early post-pregnancy period. The following paragraph discusses some of the sections of this chapter.

The chapter starts with employment prohibition of pregnant women in certain periods.

1) No employer shall knowingly employ a woman in his establishment during the eight weeks immediately following the day of her delivery.

2) No women shall work in any establishment during the eight weeks immediately following the day of delivery.

3) No employer shall employ any woman for doing any work which is of arduous nature or which involves long hours of standing or which is likely to adversely affect her health (Bangladesh Labor Act, 2006; ILO 2013a).

Section 50 of the Labor Act of 2006 also provides that if the employer dismisses the woman "within a period of six months and eight weeks after her delivery" she will still be entitled to her maternity benefits (ILO, 2013b). These provisions are established to protect women workers during their pregnancy. However, the implementations of these provisions are classified as ineffective and lousy (Kabeer, 2004; Institute for Global Labor and Human Rights, 2013). The lack of knowledge among the workers on their rights and benefits makes it easier for the factory owners and the government to keep the laws unimplemented. A study conducted in five garment factories found that only 40 out of 100 women were aware of maternity benefits and leave. The lack of trade union activism on issues like maternity leave also makes it a secondary problem (Hossain, 2012). Nevertheless, changes and improvements are occurring with every passing year (Kabeer \& Mahmud, 2004). A study conducted in an export-oriented manufacturing unit in MBM Garment Limited in Dhaka in 2009 finds that 70\% of the women who applied for maternity leave were granted maternity leave. When it comes to paying the maternity benefit, the study found that $23 \%$ of the women were paid no benefits and $24 \%$ were only paid one-month benefit (Hasan, 2009). 


\section{Export Processing Zones Workers Association and Industrial Relations Act, 2004 (EWAIRA)}

The most significant act pertaining to this study is the Export Processing Zones Workers Association and Industrial Relations Act of 2004 (EWAIRA). This act is preceded by the Export Processing Zones Authority Act of 1980 (Act No. XXXVI). This Act allows the government the authority to exempt a zone from operation of a certain law. According to this act:

The government may by notification in the official Gazette, exempt a Zone from the operation of all or any of the provisions of all or any of the following enactments or, direct that any such enactment or any provisions there of shall, in its application to a zone, be subject to such modification or amendments as may be specified therein... (ILO, 2013a).

The EWAIRA of 2004 amends the Act No. XXXVI by altering the name of the "workers association" to "workers welfare society." Section 5 of the EWAIRA enacts the formation of Workers Representation and Welfare Committee. It states that:

After commencement of this Act, the Executive Chairman or any other officer authorized by him in that behalf, shall require the employer and the workers in an industrial unit in a zone to constitute, in prescribed manner, a workers representation and welfare committee, hereinafter referred to as the committee (ILO, 2013a).

Even though RMG is a formal sector, labor unions are prohibited to operate in EPZs. This Act repeals the provision related to workers' representation. It also prohibits any contacts with NGOs (ILO, 2013a). By changing the name of the workers association to workers welfare society, this act is changing the dynamics of the relationship between the unions and the management in the zone. Also, by putting the Executive Director in charge of forming the committee of the workers' welfare association, it is allowing the company to choose its representative rather than a representative of a worker. This law is essentially curbing the powers of unions to unionize against the management. This law is a perfect example of the state's role in allowing the capital's exploitation of labor. 
A survey of workers in EPZs on the efficiency of unions controlling labor unrest in Bangladesh found that $50 \%$ of interviewed factory owners thought that labor unions are unnecessary. The same study also found that $30 \%$ of the laborers are pessimistic about labor unions (Tamanna, 2010). This shows that labor unions do not hold much leverage in this game field. The table below identifies that women are employed in certain jobs more often than men. Women also earn only $75 \%$ of what men earn for the same job. Women workers are also less likely to be aware of their rights and benefits because they are more likely to have less education than their male colleagues.

\section{Table 9: Gender Division of RMG Jobs (\% of workers)}

\begin{tabular}{ccccc} 
Job & \multicolumn{2}{c}{ EPZ } & \multicolumn{2}{c}{ Non-EPZ } \\
& Men & Women & Men & Women \\
Operator & 70 & 54.5 & 54.5 & 77.3 \\
Helper & 20 & 27.3 & - & 4.5 \\
Packer & - & - & - & 6.8 \\
Other & 10 & 18.2 & 45.5 & 11.4 \\
All & 100 & 100 & 100 & 100
\end{tabular}

Source: CPD/GATE survey, in Khatun, 2008

According to a survey conducted by the Alliance for Bangladesh Worker Safety (2014) in the garment industry, only $48 \%$ of women received schooling over the primary level, compared to $71 \%$ of male employees. This also puts women at risk more, as they are less likely to understand and handle health and safety issues.

While the Industrial Relations Act of 2004 might not be gendered in its language, I argue that it is gendered because of the area it is implemented in. The RMG sector in Bangladesh employs 1.7 million women (Ahmed, 2009). Women make up 80\% of the labor in the exportoriented apparel industry (BGMEA, 2013). The law that pertains to this particular industry directly affects women who are working in the garment industry. The Industrial Relations Act of 
2004 represses the bargaining power of women as workers in EPZs. While this law also affects males in the industry, their experience is different from that of women. Women are already at the lowest level in the hierarchy in the RMG sector, and this law takes away whatever negotiating authority they had with the state and FDI.

In a patriarchal society where women are confined to domestic duties, men do not share any responsibility in direct rearing and caring of children. A man's job is to provide for the family and anything outside of that falls into the women's job. In such context, men are very unlikely to need maternity benefits and less likely to need parental leave. They are also less likely to attend to most of parental duties like preparing food for children, taking care of children while they are home, or having to stay home if the children are unwell. Women are also more vulnerable as workers because they are more likely to be harassed in the workplace than men (Haque, 2003). The repeal of the bargaining power afforded by the unions puts working women at greater risk of losing their jobs. While much of this discrimination can be attributed to the Bangladeshi society and culture, the state and globalization is manipulating the lower status of women to increase their profit.

\subsubsection{Challenges to Labor Laws}

Labor is cheap in Bangladesh, and women's labor is even cheaper. Labor unions are already weak and women's labor issues rank among the least of their list of agendas. The challenge to the labor law mainly comes from unregulation of labor laws. The laws that are drafted to protect workers are also not sensitive to gender. It does not consider the cultural and social gender-based discrimination and how it can affect women as workers.

The ineffectiveness of the policies is often attributed to ineffectiveness in implementation of policies. A report prepared by the Committee on Foreign Relations in the United States Senate (2013) claims that there is a lack of political will in implementing labor policies and laws. It 
attributes this lack of will to political power that RMG factory owners hold in Bangladesh: "According to one Bangladesh government official, nearly every Member of Parliament has close ties to factory owners and may be direct owners themselves" (p. 4). BGMEA is one of the most powerful organizations in Bangladesh. Members of this group also control media in the country (Yardley, 2013). Business interests are also very powerful in Bangladesh's Parliament. Approximately $60 \%$ of members of parliament (MPs) are involved in industry or business. $10 \%$ of the MPs are direct owners of garment factories, while many others have indirect investment in the RMG sector (Yardley, 2013). This type of corruption and unregulation of laws was very much the case in the Rana Plaza collapse incident. Sohel Rana, the owner of Rana Plaza, was a local political figure associated with the ruling party AL (Bari, 2013). The large political clout of garment factory owners in Bangladesh has led to the lack of political will and interest to implement the labor laws effectively. The lack of political will in catering to women's rights could be because of fewer women representatives in the parliament. In the recent election of January 2014, only $19.8 \%$ of women were elected in the lower house (Inter-Parliamentary Union, 2014). The low number of women in the Parliament suggests that women are not being represented in the political arena.

Along with the lack of political will, another major problem with the laws is that they are not gender sensitive. Bangladeshi government encouraged women to join the labor force, but it did not consider the effect of social and cultural discrimination of women on women workers. Women are already at the lower strata in political, social, and economical life; this discrimination in everyday life has a profound effect on women's experience as workers. First, women are not afforded educational opportunities like men, so they are more likely to be employed in lower positions than men. The lack of accessibility to knowledge also has an effect on women's 
agency. Women in the RMG sector are often preferred employees for their docility. This docility could be a result of lack of access to education and awareness of their rights as citizens of Bangladesh. Women are less likely to comprehend their rights and benefits as workers and are more likely to be subjugated.

The lack of education among women workers also puts them at more health and safety risk than men. A survey in 28 RMG factories in Dhaka found that female workers had a harder time correctly identifying fire hazards than male workers (Alliance for Bangladesh Worker Safety, 2014). The same survey also found that $60 \%$ of male workers were trained in fire safety while only $52 \%$ of female workers were trained (Alliance for Bangladesh Worker Safety, 2014). The figure below highlights that women are also more pessimistic about the prevention of fatal fires.

Figure 5: Perception on Possibility of Prevention of Fatal Fires, By Gender

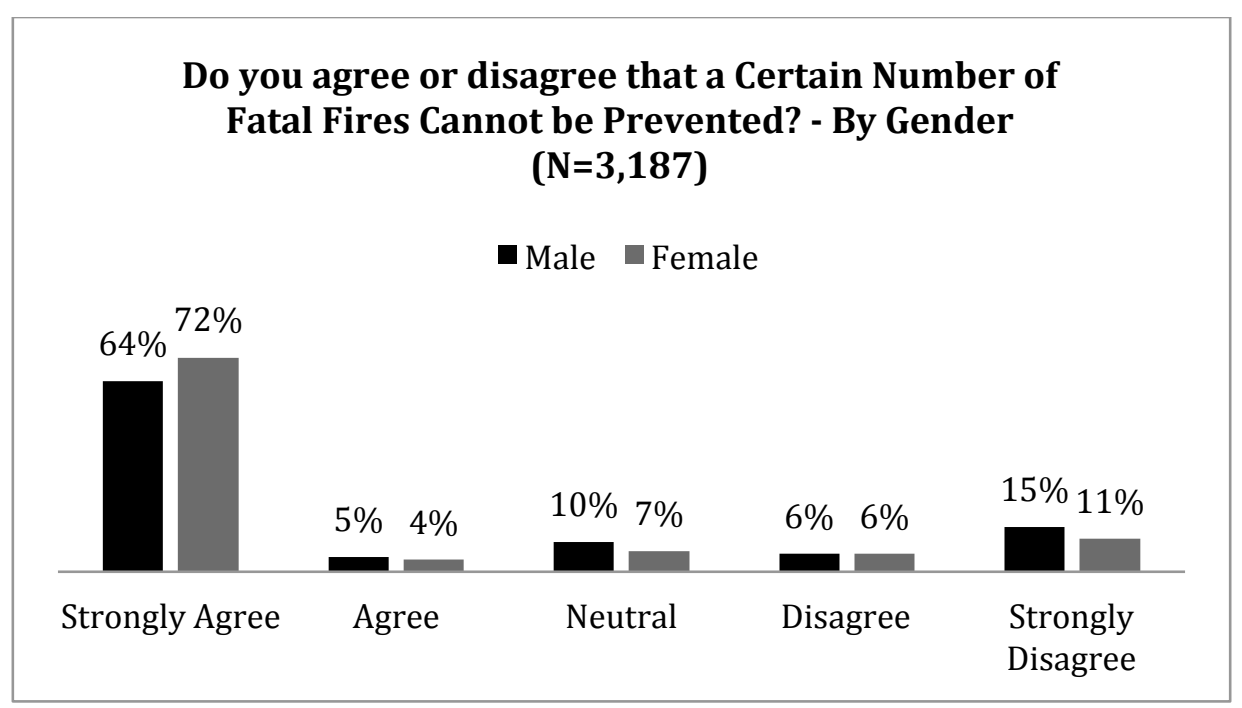

\section{Source: Alliance for Bangladesh Worker Safety, 2014}

It is clear from this discussion that social and cultural discrimination of women increases the vulnerability of women workers. In such circumstances, it is the state that must provide a safety net for women to have a safer working environment. The only policy that is in place to 
support working women is maternity leave and maternity benefits. Outside of that, the state does not even guarantee the employment protection of pregnant women. There is no provision within the maternity leave and maternity benefit policies that protects pregnant women from being fired (ILO, 2013b). Further, there is no provision of parental leave outside maternity leave.

Bangladesh has a patriarchal culture; the task of taking care of children falls under that of mothers. If a child is unwell, it is the mother who will have to take care of the child. Women are more likely to need parental leaves outside of maternity leaves to stay home to take care of their children than men; there is no provision under which women are protected from dismissal based on longer leave days.

Women also have different health needs than men. The tedious conditions of work in garment factories have a different impact on women than men. Women's health needs are completely ignored by the state and the industry. In a study conducted to understand how the working environment in garment factories are affecting female garment workers' health rights, Mridula and Khan (2009) find that 32\% of workers have respiratory problems, $28 \%$ have nausea and vomiting, $31 \%$ experience back pain, and $28 \%$ experience anemia. The table below highlights reproductive health conditions of the female workers in garment factories that were surveyed in this study. Some of these problems like excessive bleeding and extended periods can have serious effect in reproductive health.

\section{Table 10: Reproductive Health Condition of Female Workers}

$\begin{array}{ccc}\text { Problem } & \text { Yes } & \text { No } \\ \text { Excessive Bleeding during menstrual } & 67 \% & 33 \% \\ \text { cycle } & & \\ \text { Extended periods } & 32 \% & 68 \% \\ \text { More than 1 period in a month } & 21 \% & 79 \% \\ \text { Lower abdominal pain associated with } & 61 \% & 39 \% \\ \text { periods } & & 100 \%\end{array}$




\section{Source: Mridula and Khan, 2009}

\subsection{Conclusion}

Bangladesh has been classified as one of the new countries that are rapidly increasing its GDP with assistance of tools provided by FDI. In this process, Bangladesh has successfully increased the female labor force, comprising mostly of young, unmarried, poor, rural women, in the country. While I don't deny that the new financial opportunities afforded by the FDI to these women have allowed them to have some authority within the family structure, this opportunity is not enough for long-term gender equality.

In this chapter, I have highlighted how Bangladeshi women workers in the RMG sector are constantly struggling to gain respect socially, politically, and economically. The stigmatization of garment workers within the communities challenges their social status. The absence of unions in the EPZs takes away whatever bargaining power women workers have in the factory and challenges their political activism. Finally, the income they earn from strenuous work in the garment factory is hardly enough to make a living in the metropolitan areas where the factories are located. Bearing this in mind, it is highly questionable that women who are employed in the garment sector of Bangladesh are liberated because of opportunities provided to them in global production. In this chapter, I have discussed how FDI exploits women's labor in RMG sector. However, my analysis of exploitation of women's labor does not end at MNCs' treatment of women workers. I also identify the role of the state in allowing MNCs to mistreat women workers in the garment industry. The establishment of the Industrial Relation Act of 2004 by the Bangladeshi state strengthens the power of the capital and represses the bargaining power of the female labor in EPZs. By sanctioning this law, the Bangladeshi state is as much a culprit as MNCs in mistreatment of women workers in Bangladeshi RMG sector. 


\section{Chapter 6: The Philippines}

\subsection{Introduction}

The identity of the Philippines is rooted in its extensive history of colonization. Since the beginning of its existence, the Philippines has been identified as a subject of two different colonizers that are in no way similar to the culture of the land. With the introduction of Catholicism, the Spanish were successful in leaving a profound legacy that most Filipinos identify with even today. The U.S. imperialism also left a lasting legacy with the introduction of Western ideas of capitalism, democracy, and freedom. The Philippines adopted American capitalist entities and institutionalized them to build an export-oriented economy to suit the interest of capitalist entities that were investing in the country. In this adoption and institutionalization of capitalist policies, the Filipino state has time and again used female labor force as a resource for both the state and the MNCs. In furthering my discussion of the relationship between states, FDI, and the patriarchal culture, I highlight how women in the Philippines have been able to be civically engaged, and, in doing that, are able to better influence the adoption and implementation of laws that protect women workers.

\subsection{History}

\subsubsection{Colonial History}

Prior to the Spanish conquest, the area where the present Philippines is located was best described as "economic units with a system of subsistence agriculture which provided them with barely enough for their needs" (Constantino \& Constantino, 1975, p. 28). The Spanish colonial regime used force and wealth, along with the significant influence of the Catholic Church to control the area (Goodno, 1991). The Spanish occupation was driven by their desire to access the spice trade, to further Christian missionary efforts in Asia, and to use the Philippines as a base 
for the trade between China and Mexico (Goodno, 1991; Dolan, 1993). The Spanish economic interaction, as it pertains to the Philippines, was minimal. It was not until the early $18^{\text {th }}$ century, when the Great Britain started to colonize India, that the Philippines was forced to be a part of the world trade. The exposure to the world trade made Manila, the current capital of the Philippines, one of the busiest ports in the region. However, this new development was only afforded to the colonizers and the selected few residents of Manila, while the rest of the Philippines was still rural and had no access to modernization (Francisco \& Arriola, 1987). The Spanish control of the Philippines enjoyed its golden days until 1762. Spain suffered an irreparable damage to its reputation after its involvement in the Seven Years' War and defeat from the Britain. The Spanish controlled the Philippines as a base port for trading and paid no attention to local development of the area. The loss in the Seven Years' War ignited the native Filipinos resistance to the Spanish rule.

By the 1870 s, the resistance grew stronger and was gaining momentum among the native Filipinos. The strength of this resistance can be attributed to the American involvement in Spain's other colonial territories (Dolan, 1993). The Spanish-American War of 1898 rendered Spain as a weak enemy and America as a useful ally to the Filipino resistance. On August 13, 1898, Spain lost control over the Philippines. After this incident, the US changed its position from being an ally of the Philippines to another colonial occupier (Constantiono \& Constantino, 1975; Goodno, 1991; Dolan, 1993).

\subsubsection{Under American Imperialism}

United States President William McKinley established the First Philippine Commission in January 1899 to investigate the status of the Philippines and make recommendations on the country. The Second Commission was established a year later, headed by future US President William Howard Taft. This commission allowed legislative authority along with some executive 
powers to govern the Philippines (Dolan, 1993). President McKinley started the era of US imperialism under the rhetoric of 'benevolent assimilation' (Miller, 1982). In the one-year interval between the Spanish rule and American control, the relationship between Americans and Filipinos went downhill. Filipinos wanted a sovereign nation governed by the Philippines, but the Americans were not confident about the Filipinos' ability to run the country independently (Barrows, 1905). The American justification of the occupation was that they were preparing the Philippines for eventual independence.

\section{Figure 6: Map of the Philippines}

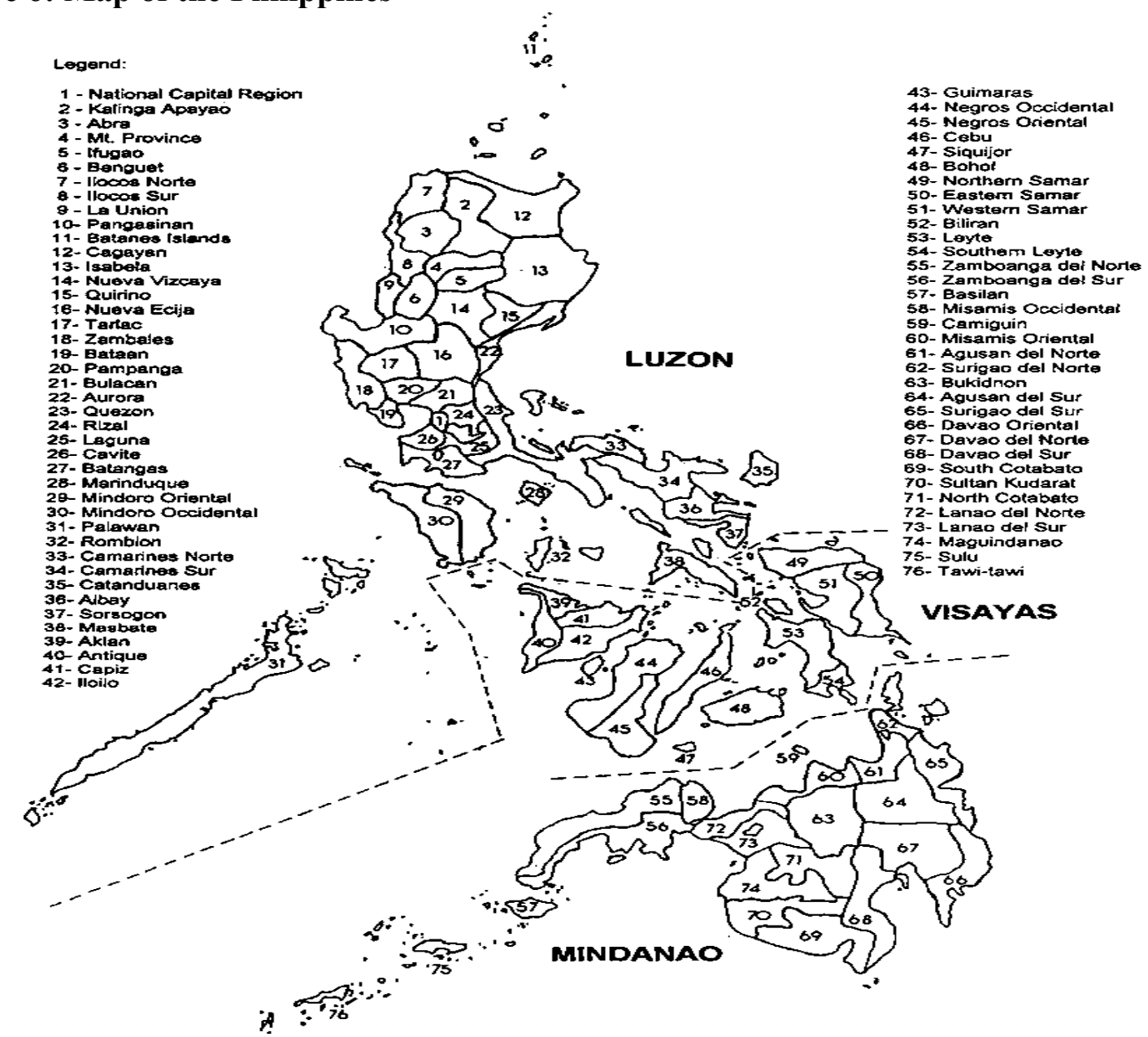

Source: Food and Agriculture Organization of the United Nations, 2014

Colonization is the pillar of capitalistic establishment. The very core of this concept is driven by capitalism. The period of American imperialism exposed the Philippines to plenty of 
capitalistic ventures. During this period, America formally and informally influenced its imperial subjects to cater to the interest of the US. Within the first decade of American control, the US had passed two policies that would allow for the Filipino products to enter the US markets. By 1939, Philippines was exporting $85 \%$ of its products and importing $65 \%$ of the products from the US (Dolan, 1993). The Philippines was becoming more and more dependent on the US.

\subsubsection{Post-colonial History}

The Philippines faced the wrath of the Second World War when Japan attacked the Philippines, following the attack on Pearl Harbor. Japan took control of Manila on January 2, 1942; however, only some territories were controlled. The Americans were not going to easily give up on the Philippines. The fighting in the territory continued until Japan's formal surrender. In this fight between two imperial powers, an estimated one million Filipinos were killed (Dolan, 1993).

By the end of the Second World War, most of the colonial powers were too weak to maintain the colonies. The US was successful in establishing itself as the systemic hegemon. The US, after the end of the Second World War, decided to grant the unsettled promise of independence to the Philippines. Filipino independence was guaranteed in the Tydings-McDuffie Act of 1936. Research indicates that this was mainly because of two reasons (Perlo 1951). First, the Filipino national liberation movement was gaining momentum and armed uprisings were increasing since the end of the First World War. The U.S. wanted to avoid a costly military intervention and maintain a good relationship with the Philippines: "The only hope of maintaining the Philippines as a stable military base for the operations of the United States imperialism in Asia, was to split the national liberation movement through granting formal independence" (Perlo, 1951, p. 21). Secondly, through this event, the U.S. was not relinquishing all forms of control in the Philippines. The Filipino economy was still to be controlled by the 
U.S. through the Bell Trade Act. The Philippines was independent on July $4^{\text {th }}, 1946$ (Dolan, 1993).

Despite independence, the Philippines was still very much economically dependent on the Unites States. The Bell Trade Act, passed by the U.S. Congress in 1946, maintained that "free trade be continued until 1954; thereafter, tariffs would be increased 5 percent annually until full amounts were reached in 1974" (Dolan, 1993, p. 43). This policy allowed the U.S. all the benefits of possessing a colonial space, economic as well as military, without the duties of maintaining domestic and administrative obligations (Jenkins, 1947). Filipino goods, on the other hand, were imposed absolute quotas. Further, the "parity" clause gave the U.S. citizens equal rights as Filipinos in using, owning, and operating resources, but these rights were not reciprocated to the Filipinos (Shalom, 1980). The Bell Trade Act was a U.S. sponsored mechanism to execute neo-colonialism in the Philippines. While the rhetoric used to justify this act depicted U.S. as an altruistic leader who was helping the Philippines to establish a stronger economy, critics have highlighted the inequality of the treaty where most of the benefits were secured by the U.S. (Legarda \& Garcia, 1966; Hess, 1996).

The neo-colonial economic dependence on the U.S. and its ultimate control over the archipelago via economic means was increasingly becoming unpopular in the area. After the untimely death of Magsaysay, the seventh President of the Philippines, Carlos Garcia took over the office of Presidency in 1957 and embraced a "Filipino First" policy in 1958. This policy was a result of frustration that Garcia had with the unsatisfactory level of economic assistance offered by the Eisenhower Administration. This policy called for more Filipino involvement in the home economy. The access to the American market and the already established export trade mechanism bolstered the development of the export-oriented economy of the Philippines 
(Cullather, 1994). The primary industrial objective of the Philippines, since the 1960s, has been the promotion of the export-oriented industry. The driving force for this type of industry has always been cheap labor: "Since the Philippines is abundant in labor, it takes this comparative advantage by opening its economy to the labor intensive operations of transnational capital” (Eviota, 1992, p. 80). Such industry thrived on the unskilled, inexpensive, and unregulated labor of poor, rural women.

\subsection{Factors influencing the Formation of Gender Identities in Filipino society}

Femininity in the Filipino society is influenced by the long Spanish colonial history. The pre-colonial Philippines was built on kinship ideology where economies were geared towards social use and to fulfill kinship obligations (Mananzan, 1987). In this section, I will discuss the factors influenced the construction of gender identities in the Filipino society.

\subsubsection{Religion and Filipino Women}

During the Spanish colonization, the institution of the Catholic Church in the Philippines introduced the concept of gender roles. The influence of Roman Catholicism on Filipino culture intensified patriarchy. Before that, in the pre-colonial society women held an equal position to men in the society. The Spanish colonization not only influenced political and economic activities in the islands, but social lives too. The colonial entity used different tools to "civilize" the indigenous population of the islands, one of such tools was a book called Urbana at Felisa, which advocated men and women to adopt the prescribed sets of sexual roles (Eviota, 1992). The introduction of Spanish culture redefined what it meant to be a woman in the Philippines:

The "new" Filipina (or female Indio) was now her father's meek daughter, her husband's faithful subject, the Church's obedient servant, and before her marriage, a chaste virgin who would yield only to her husband (and occasionally to the friar). But of course, like her peasant husband, she was also a slave like toiler who worked the rich man's and his descendants' land for pittance... (Maranan, 1987, p. 39) 
The introduction of Roman Catholicism as a religion encouraged monogamous marriage and chastity over equality. Before this, monogamy was not widely practiced in the Philippines. The institutionalization of property ownership and marriage led to the subordination of women. A Filipina now derives her identity from her father (before marriage) and her husband (after marriage). Such institutionalization gave men authority to control the conjugal property. Within the household, the roles of the male and female members of the family are divided by gender roles. The father of the household is metaphorically referenced to as 'the pillar of the home,' while the mother is referenced to as 'the light of the home.' The role of the father is to support the household via some kind of income and the role of mother is to care for the family. This role of the "light of the home" limits the social acceptance of female labor force participation in the society (Cheng, 1999). The duty of the women is defined in terms of their reproductive roles as a mother (Rodriguez, 2012). The women's role therefore is that of a nurturer confined within the domestic spheres.

\subsubsection{Colonial Influence on Filipino Women}

Throughout the first couple of years of Spanish rule, most of the Philippines (except some areas with Spanish population) made its livelihood from subsistence farming. The introduction of differential worth on gender identity by the Spanish led to inferior positions of women in society: "Women's productive work that came under the scope of colonial administration was valued differently from that of men" (Eviota, 1992, p. 46). The rapid industrial revolution in the Western hemisphere introduced new means and standards of economic activities; with this the definition of work changed. The differentiation of productive and reproductive work as well as the domestic and the public sphere marginalized women even further. 
Eviota (1992), in her discussion of the pre-colonial society (what we know as Philippines today), argues that the differential worth based on gender was non-existent in the pre-colonial society. It was colonial gender ideology that situated women at a lower position than men in the Filipino society. In the late eighteenth century during the Spanish occupation, the Philippines experienced the first impact of globalization. The Spanish instruction to produce cash crops for the exports connected the Philippines to the global market. At that time, the major exports of the Philippines were sugar, tobacco, and hemp. The tobacco monopoly was established in 1781 to raise revenues for the colony. Tobacco is a labor-intensive crop, and in its production, the gender roles were divided. The men were in charge of preparing the fields for planting, while the women (and children) were in charge of everything from planting to harvesting the tobacco and the actual production of the cigars (Eviota, 1992). Outside of the agricultural economy, women in the Philippines were already engaged in the market economy as domestic helpers, midwives, storekeepers, street vendors, seamstresses, and embroiderers (Honculada, 2012). The Filipino women were as much of a part of the Filipino economy as were Filipino men, but because of their lower gender status that was introduced under the Catholic Spain, women's work was always invisible.

\subsubsection{Political Role of Women in the Philippines}

The first female President of the Philippines was Corazon C. Aquino. After the assassination of her husband Benigno Aquino Jr., Corazon C. Aquino became the face of the opposition movement against the dictatorial regime of Ferdinand Marcos (Thompson, 2003). Corazon C. Aquino is often cited to be one of the most inexperienced politicians to have assumed the highest office in the country (Thompson 2003; Jalalzai 2004; Derichs et al., 2006). She, like her Bangladeshi counterpart, she was also "reluctantly drafted to run against" the oppressive regime (Richter, 1991, p. 535). As the first female leader of a very patriarchal 
Filipino culture, Aquino faced many challenges. During her administration, Aquino had to face six coup attempts from the military that was highly politicized during the Marcos regime. Her own vice-president, Salvador Laurel, has been noted to belittle her authority as a President because of her gender (Richter, 1991). Despite these challenges, Corazon Aquino is remembered as one of the cleanest Presidents in the culture where corruption has severely marred political lines.

Unlike the Bangladeshi female leaders, Corazon Aquino's administration has been influential in promoting women's political involvement. Her appointment of women in key political positions and in the delegation of the 1986 Constitutional Convention perhaps explains the institutional structure that supports female political involvement in the current Filipino context (Richter, 1991). According to Inter-parlimentary Union (2014), women represent 27.3\% of the Lower house and $25 \%$ of the Upper House of the Filipino parliament. Though the number is still low, it is better than most other countries in the region. The second female President of the Philippines, Gloria Macapagal Arroyo, was invited by Aquino to act as Assistant Secretary of the Department of Trade and Industry (Arroyo, 2014).

Like Aquino, Arroyo was also a member of an influential political family in the Philippines. Her father Diosdado Pangan Macapagal was the ninth President of the Philippines. Similar to her female predecessor, she also led an opposition movement against the incumbent President against corruption in 2001 (Thompson, 2003). The presidency of both female Presidents of the Philippines was significant in favoring policies directed towards women. It was under Arroyo's administration that the revolutionary policy known as Magna Carta of Women was adopted. This law is a wide-ranging women's rights law that seeks to "eliminate discrimination through the recognition, protection, fulfillment, and promotion of the rights of 
Filipino women, especially those belonging to marginalized sectors of the society" (Philippine Commission on Women, 2009). The role of female political leaders in the Philippines is very important in establishing a platform for political voice of women in the Philippines.

\subsubsection{Economic Roles of Women in the Philippines}

Women in the Philippines have always been a part of the market economy. Women have actively participated in economic activities during the colonial rule and post-colonization. Under American control, women's independent household works, like manufacturing clothes, were converted into wage labor. This decline in household work devalued women's position within the household as an earning member of the family to housewives. Women's labor was mostly unpaid within the household (Eviota, 1992). Women's diminishing financial status thus led them to be dependent on the men of the family and therefore more and more subordinate.

Women in the Philippines are as qualified as men when it comes to educational achievements. Of the female labor force, $37 \%$ has completed secondary education compared to $41 \%$ of the male labor force. More women have tertiary education at 35\% compared to men at 24\% (The World Bank, 2013). Despite this, the total percentage of women (between age 15-64) participating in the labor force is only $53 \%$, while for men the total is $81 \%$ (The World Bank, 2013). The occupations available to women are based on gender and culture stereotypes. Women are concentrated in industries like handicrafts, electronics, vending, domestic service, and sex tourism (Eviota, 1992; Roces, 2000). Women's strong educational background does not translate into equality in employment. A study found that male employees, both in managerial and non-managerial positions in manufacturing and construction sectors, were paid $18 \%$ more than women in 2003 (Cabegin, 2012). This wage gap can be attributed to the treatment of women workers as auxiliary labor in the labor force. 
The export-led growth made the Philippines more vulnerable to fluctuations in the world's economy. During the end of the 1970s and 1980s as the prices for Filipino commodities fell and the international recession imposed limitations on market growth, the balance of payment deficit degraded even more. To keep up in the world market, the Philippines ended up borrowing heavily from others. The impact of this economic failure on the Philippines was very extreme. By 1989 , an estimated $77 \%$ of the Filipino households could not meet their daily food needs; about one-third of the population was unemployed, and real wages continued to decline (Eviota, 1992). The experiences of women workers during this time were worse than male workers. They were often among the first to be laid off and last to be reabsorbed in the labor force. To generate the much needed income, many of them joined the informal sector and many migrated to another country (Chant \& McIlwaine, 1995). The other option was to work for EPZs in the city. The stories of Filipino women in the 1980s depict the story of women in the developing countries who were subjected to inconsiderate austerity measures imposed by the IMF and the World Bank.

\subsection{FDI in the Philippines}

The colonial rule introduced the Philippines to the export-oriented industrialization. The Bell Trade Act of 1946 was revised in 1955 via the Laurel-Langley Agreement. This agreement accorded the parity provisions to all the Americans. The introduction of the Bell Trade Act and the Laurel-Langley Agreement was the beginning of foreign investment in the Philippines after decolonization.

In the 1960s, under Carlos Garcia's administration, the Philippines adopted the "Filipino First" policy. The policy actively promoted the "Filipino business establishment" (Abinales \& Amoroso, 2005, p. 182). Under this policy, "domestic industries numbered about five thousand, 
the Filipino share of new investment rose to 88 percent... domestic consumer goods and production and secondary industries increased the urban work force" (Abinales \& Amoroso, 2005, p. 182). But this structure led to a protective system with overvalued currency, protective tariffs, and quantitative import restrictions.

The "Filipino First" policy was geared towards improving the living standards of a certain group of the society: the native Filipinos. This was also offending Chinese, American, and Chinese-Filipino businesses that were becoming more vocal about their grievances regarding the "Filipino-First" policy. The defeat of Carlos Garcia in the election of 1961 ended the "Filipino First" policy. The newly elected governments under Diosdado Macapagal promised to open the economy to the world trade, encourage foreign investment, and establish state-led development policies (Abinales \& Amoroso, 2005). Under the Macapagal Administration, the export-led economy was re-established in the Philippines. During this period, the Filipino economy geared towards developing an export industry based on manufacturing to start the economic development process. Production of garment and semi-conductor devices dominated the manufacturing industry (Eviota, 1992). These commodities were heavily dependent on imported raw materials and the only way to reduce cost in this industry was by cutting down on labor cost. Therefore, these industries relied on cheap and controlled labor of women.

The first and second oil price shock had a profound impact on the Filipino economy. During the same period, the Philippines also started to feel the jolt of other economic problems such as increasing debt, declining export, and low economic growth. The only option that the Philippines could afford was to accept loans offered by the IMF and the World Bank to stabilize the economy, which also meant accepting austerity measures, and specifically, the trade liberalization policies. Under the supervision of the World Bank, the Philippines adopted SAPs 
and enacted the Omnibus Investment Code of 1981 (PD, 1789) to incentivize investment in the country (Aldaba, 1994). Along with the Omnibus Investment Code of 1981, the Philippines furthered the advancement of FDI by legislating the Foreign Investment Act in June 1991 (Aldaba, 2008). These legislations were adopted to bolster the economic environment for attraction of FDI. The figure below charts the net inflow of FDI as a percentage of GDP, from 1980 to 2010. The FDI inflow pattern has been diverse in the past two decade with highs and lows corresponding with the market. This effect has been cited as an impact of increase in number of markets (in ASEAN countries) that have adopted more aggressive policies in attracting FDI (Manila Times, 2014).

Figure 7: Foreign Direct Investment, Net Inflows (\% of GDP), 1980-2010

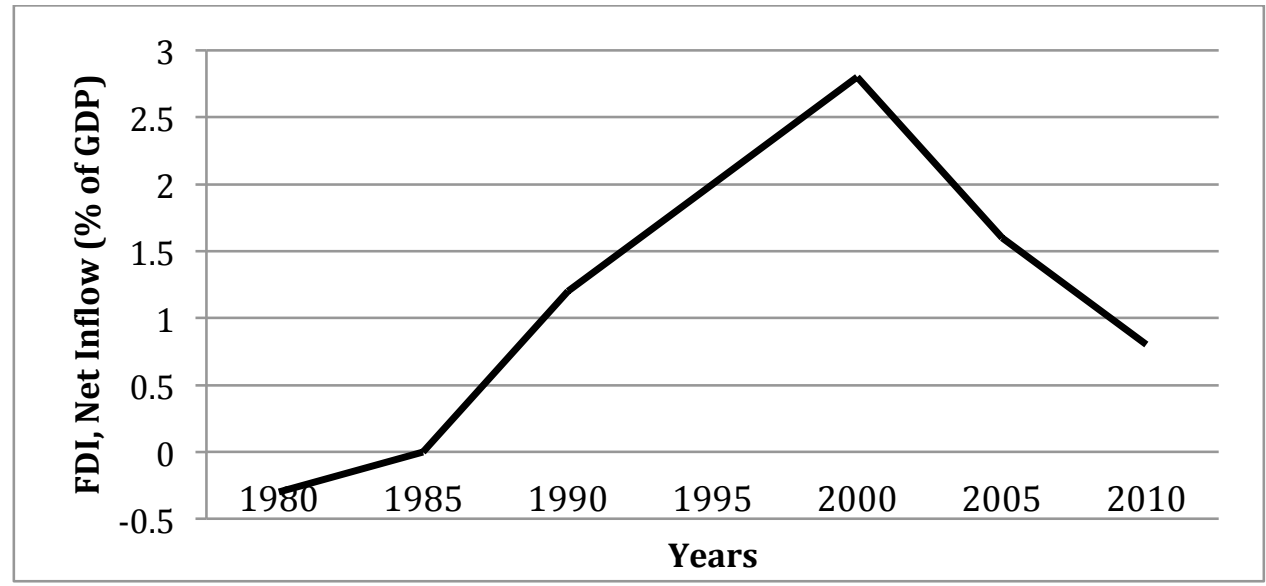

Source: The World Bank, 2013

The developing countries with export-oriented economies, like the Philippines, banked on foreign investments. To insure that MNCs invest in their countries, the state usually adopts an incentive-based approach to attract investment. The Philippines also adopted such an approach by offering tax incentives to foreign investment. In the Philippines, different bodies, mandated by the laws in management of EPZs, are authorized to offer the necessary incentives as it suits the authorized bodies.Tax exemptions are major incentives provided to attract and keep FDI. The 
Board of Investments (BOI) registered enterprises qualify for income tax holiday for four to six years. The non-pioneer projects qualified for four years of income tax holiday, and the pioneer projects and projects in less developed areas qualified for six years. The Philippines Economic Zone Authority (PEZA) offers investors incentives such as four to eight years of corporate tax exemption, tax credit for import substitution, additional deduction for training and labor expenses, etc. The following table highlights and compares the major incentives offered by these bodies.

\section{Investment Regimes \\ Income \\ Others \\ BOI OIC \\ 4-8 years ITH \\ After ITH, payment of the regular corporate tax rate of 35 percent of taxable income}

Table 11: The Incentives Offered by Different EPZ Authorities

Importation of raw Materials Tax credit and Supplies

Purchase of breeding stocks and genetic materials

Imported capital equipment, spare parts, materials and supplies

\section{Source: Adalba, 2008}

Tax exemption within 10 years from registration

Tax and duty exemption on spare parts
PEZA

4-8 years ITH

After ITH, exemption from national and local taxes, in lieu of this special rate of 5 percent tax on gross income

Tax and duty exemption

Tax and duty exemption

Tax and duty exemption
SBMA and CSEZ No ITH

5 percent of tax on gross income in lieu of all local and national taxes

Tax and duty exemption

Tax and duty exemption

Tax and duty exemption

FDI was one of the suggested tools to kick start the economic development process by the SAPs. For the investors, the Philippines was a good choice because, outside of the incentives offered explicitly for their investment, it also offered an abundant, literate (English speaking) labor force. English is an important part of high-school education in the Philippines and it is widely spoken and this facilitated the speed in training the workers (Chant \& McIlwaine, 1995). Most of the FDI invested in the Philippines was concentrated in the manufacturing sector. In 2002, about $50 \%$ of the incoming FDI was invested in manufacturing (Joint Foreign Chamber of 
Philippines, 2012). Since the adoption of the export-oriented economy, the Philippines have successfully established a strong manufacturing based industry.

\subsubsection{Type of FDI Industry}

The first EPZ established in the Philippines was in Bataan in 1971. After this, four other state-run EPZs were established in Mactan in 1978, Baguio in 1979, and Cavite in 1986 (Philippine Economic Zone Authority, 2014). In 1995, the Philippines adopted a more intense

campaign to attract more foreign investment - "restructuring, expanding, and privatizing its zone program" (Mckay, 2006, p. 46). Today there are 300 operating economic zones, out of which 66 are manufacturing economic zones and 17 are agro-industrial economic zones. Within these economic zones, there are a total of 1,284 export enterprises (Philippine Economic Zone Authority, 2014). The fastest growing sector in FDI currently has been in the Information Technology-Business Process Outsourcing (IT-BPO) sector. An estimate of US\$700 million was projected to be invested in the Philippines in the years 2010-2011(Joint Foreign Chamber of Philippines, 2012).

\subsubsection{Electronics and Garment Industry}

Manufacturing has been the top sector for FDI investment in the past decade. The electronics sector, which has an average annual investment of almost US\$700 million since the year 2000, had an estimated investment of US\$400 million in 2008 and US\$480 million in 2009 (Joint Foreign Chamber of Philippines, 2012). The electronics industries were established in the Philippines during the same time major electronic companies in the West were shifting their factories in the developing countries. By 1995, the sector established a strong foothold in the Philippines. Electronics is a prominent export industry in the Philippines with exports amounting to as much as US\$30 billion in 2010 (Joint Foreign Chamber of Philippines, 2012). 
The Philippines export industry in the beginning was concentrated mostly on garment exports. The Multifibre Agreement (MFA), a trade agreement created by World Trade Organization (WTO), which was regulated from 1974 to 2004 benefitted the Filipino export industry (War on Want, n.d.). The MFA used annual export quotas and assigned them to developing countries to control the growth of textile and garment imports by the developed countries. The regulation protected the involved firms from competition and thus increased investment in the garment sector.

Figure 8: Employment in Textile, Garment, \& Leather Industries, in thousands, 1991-2009

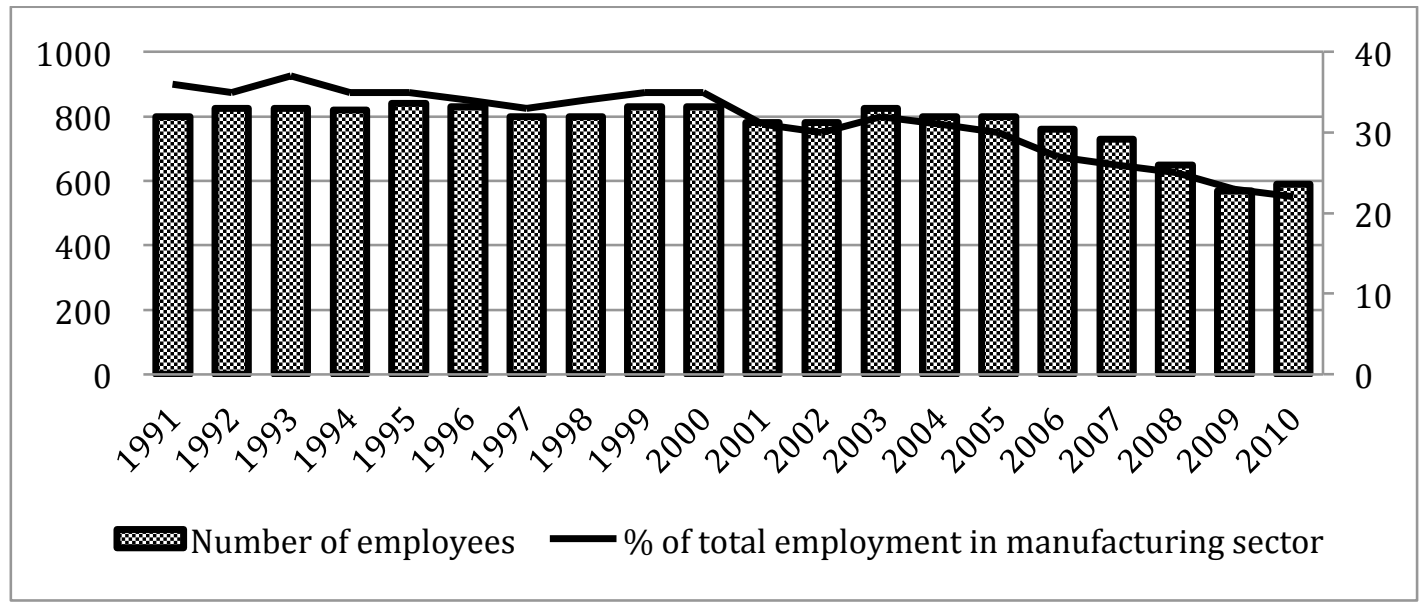

Source: Joint Foreign Chamber of the Philippines, 2012

The figure above highlights the employment in the textile/garment sector. The figure shows that the number of employees in garment/textile industries has been above average in the manufacturing sector. The end of MFA in 2005 increased the competition from other emerging contenders like Bangladesh, Cambodia, Vietnam, and China who were offering a much lower cost of production to the investors. Since the expiration of MFA, the Philippines have lost some 100,000-150,000 jobs in the garment sector (Joint Foreign Chamber of the Philippines, 2012). These job losses have particularly affected the young, poor women working in the apparel industry. With increased low cost opportunities elsewhere, many garment/textile industries have 
moved from the Philippines to other emerging markets. The impacts have been severe on women workers working in these factories. Women are majority of the workers in the garment/textile industry in the Philippines. They have been the preferred labor force as they are less expensive, more dexterous, and docile. With the increase in other emerging markets, the Philippines is struggling to attract investment in the export-oriented industries. In order to compete, the Philippines has to rely on strategies that will keep the cost of production low. One strategy that the Philippines has adopted is unregulated female labor. The following section highlights the determinants of less regulation of female labor in the Philippines.

\subsection{Determinants of Unregulated Female Labor in the Philippines}

\subsubsection{Development Level}

The Philippines' first exposure to globalization was during the Spanish colonization. At the time, the introduction to the global economy was not intended for the economic development of the Philippines. Instead, it was to suit the economic gains of the colonizers. All through the period of American imperialism, the U.S. government mostly controlled the Philippines' access to the global economy. During this time, the Philippines was introduced to ideas like freedom, democracy, and capitalism. It was in this time that the Philippines envisioned being a sovereign entity. Since the beginning of its independence (and before that), the Filipino economy was highly export-oriented. After its independence, the Philippines continued strengthening its national economy using exports. However, with the vulnerabilities that come with the exportoriented economies, Philippines has not fared that well under the system (Parreñas, 2005). The

two consecutive oil shocks of the late $20^{\text {th }}$ century affected the Philippines very harshly. With the high national debt, Philippines had no choice but to adopt SAPs suggested by the World Bank and the IMF. The implications of these policies have been harsh on Filipinos. The unemployment rate increased and the safety nets that were established help people in this hard time were failing 
because of the austerity measures adopted in SAPs. The Philippines was struggling and the poorest in the Philippines were bearing the brunt of this struggle.

Under the World Bank, the Philippines is categorized as one of the low-middle income countries. The reported GNI per capita for the year 2012 for the Philippines is US $\$ 2,500$. The chart below highlights the annual percent of GDP growth from 1980 to 2010 .

Figure 9: GDP Growth (Annual \%), 1980-2010

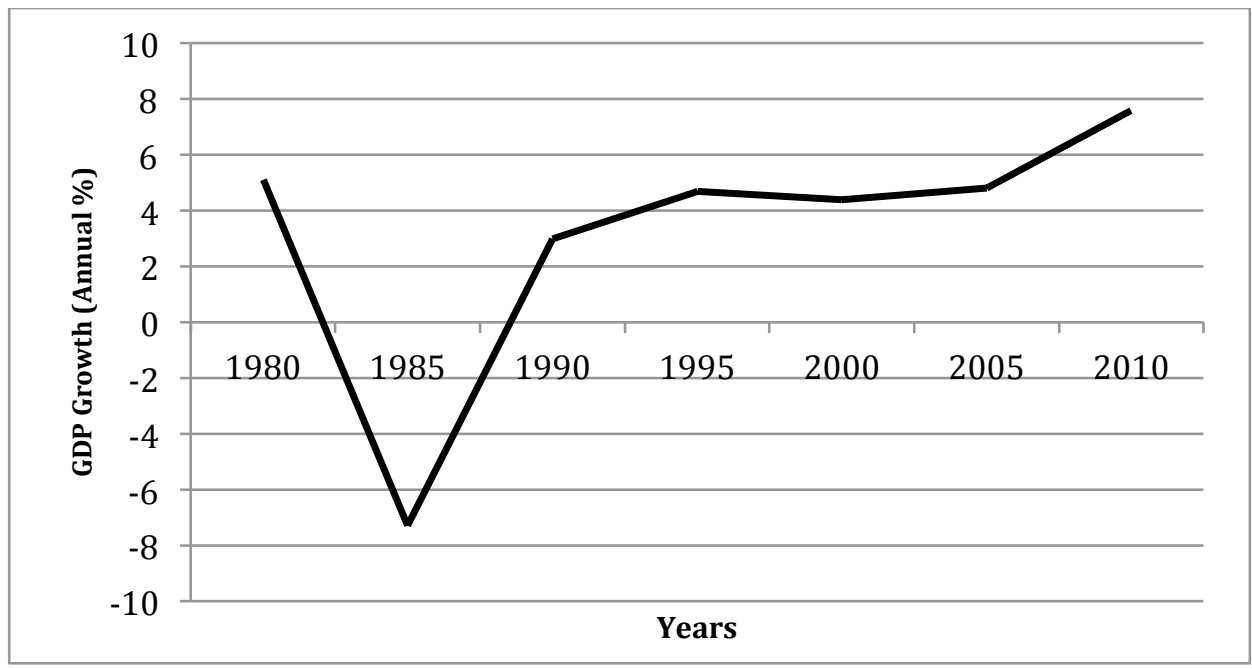

Source: The World Bank, 2013

The chart shows that the Filipino economy is growing since 1985. In present times, as the market has been improving, the Philippines is doing well under the export-oriented economy. With increase in number of MNCs, demand for cheap labor, and normality of global production, export-oriented economies are managing well in today's economy. While the country is moving rapidly towards its development goal, only a small group of people are benefitting from such rapid advancement. According to the World Bank, in 2009, 49.7\% of the income share is held by the highest $20 \%$ of the Philippines. A large proportion of the population, $41.5 \%$, is still living at $\$ 2$ a day. The export of goods and services (as percentage of GDP) has reduced from $51.4 \%$ in 2000 , to $30.08 \%$ in 2012 . The table below shows that in present time, the service industry is growing stronger, while manufacturing and agriculture have been more stagnant. 
Table 12: Value Added to Industry (\% of GDP)

$\begin{array}{ccccccccc}\text { Indicators } & \mathbf{2 0 0 5} & \mathbf{2 0 0 6} & \mathbf{2 0 0 7} & \mathbf{2 0 0 8} & \mathbf{2 0 0 9} & \mathbf{2 0 1 0} & \mathbf{2 0 1 1} & \mathbf{2 0 1 2} \\ \text { Agriculture } & 12.7 & 12.4 & 12.5 & 13.2 & 13.1 & 12.3 & 12.7 & 11.8 \\ \text { Manufacturing } & 24.1 & 23.6 & 22.7 & 22.8 & 21.3 & 21.4 & 21.1 & 20.5 \\ \text { Services } & 53.5 & 54.1 & 54.5 & 53.9 & 55.2 & 55.1 & 55.9 & 57.1\end{array}$

Source: The World Bank, 2013

Despite the early success, the Philippines has faced a failing economy since the 1990s. Since then, the high rates of unemployment and underemployment have maintained the pool of inexpensive labor in the Philippines. With such low performance of FDI in recent years, the Philippines is already considering adopting more aggressive tactics, like letting go of 60/40 ownership in FDI firms, in order to attract more FDI in the country. The 60/40 ownership rule, as stated in the Foreign Investment Act of 2014, provides that for a company to own land in the Philippines, it has to have 60\% Filipino ownership (Manila Times, 2014).. Further, considering that most women are unskilled workers and are employed in low paying jobs, feminization of poverty is very much a case in the Philippines. The lack of occupation opportunities for women has been associated with increasing number of poor women. The concentration of women in low paying jobs has increased their chances of being among the poorest people (Pearce, 1978; Bianchi, 1999). The increasing need for more FDI, the high unemployment and underemployment rates among women, along with the feminization of poverty has led the Filipino women to be desperately willing to work with minimum pay and benefits. Such desperation has allowed the state to keep the regulations that protects women as workers weak and unimplemented.

\subsubsection{Skill level of the labor}

Filipino struggles are usually tied with the financial crisis of the 1990s and its impact on the country. The export-oriented economy in the Philippines has hurled the country with all 
possible consequences of vulnerabilities that come with such an economy. In dealing with this struggle, the Philippines had to cope with harsh policies, widely known as SAPs, implemented via the IMF and the World Bank in order to deal with the economic crisis of the 1990s. Many Filipinos felt the impact of these policies. With deregulation, salaries went down and taxes increased. This led to an unstable labor market (Cheng, 1999). The failure of the market left many unemployed, forcing them to leave their homes and country to look for work elsewhere. With the assurance of the IMF and the World Bank, MNCs started investing in the Filipino economy as it improved. Most of the MNCs were concentrated on the retail industry and were there in search of cheap and unskilled labor that was willing to work without many demands. The MNCs hit the jackpot in the Philippines.

The Philippines has a growing manufacturing industry. Out of the total merchandise export, $82.63 \%$ was from the manufacturing industry in the year 2012 and exports account to $31 \%$ of the GDP (The World Bank, 2013). The export industry is a significant part of the Filipino economy. With the number of Special Economic Zones (SEZ) growing, labor, particularly female labor is in high demand in the Philippines. However, despite this rise in economic development, the Philippines is still failing to absorb its labor force in the economy. The $7 \%$ unemployment rate and the $7.2 \%$ underemployment rate are indeed disappointing. This has led to skilled labor being employed in areas that need unskilled labor.

Unlike Bangladesh, the labor in the Philippines is semi-skilled, where most of the members of the labor force are high school graduates. English is a well-spoken and well-known language in the Philippines, and most of the workers with mid-level school education can communicate and read and write in English. The workers usually comprehend the codes of conduct that are posted on the factory floors as required by law. The school enrollment for 
female at secondary level was $88 \%$ in the year 2009 (The World Bank, 2013). The female labor force is more skilled in the Philippines. However, high educational achievement does not translate to parity in the job market. Female labor participation is very low and women have higher rates of unemployment and underemployment when compared to men (Roces, 2000).

The labor in the Philippines is also very active and organized. Female labor is organized under Kilusan ng Manggagawang Kababaihan- Women Workers Movement (KMK) and GABRIELA (General Assembly Binding Women for Reforms, Integrity, Equality, Leadership, and Action). ${ }^{11}$ The high educational background and active labor organization that works to educate the workers about their rights has cultivated in successful labor activism. This has led to the establishment of good labor policies under the Philippines' government. However, because of the lack of political will among authorities, along with the association of militant labor organizations like KMK and Kilusang Mayo Uno (KMU) to terrorist organizations such as a communist group called New People's Army (NPA), has led to cracking down on labor organization and vilification of labor (Margold, 1995; Lacsamana, 2012). This has allowed the government to use an iron-fist to suppress the labor that is resisting the state's agenda of rapid development. Thus, it will be fair to argue that state's willingness to repress labor rights to appease the MNCs has made women's labor in FDI industries more vulnerable in the Philippines.

\subsubsection{Civil Rights and Liberties}

The Philippines is a well-established country that has modeled its constitution and the government like that of the U.S. As a colonial subject of the U.S., the Filipino outlook on governance was based on the American system. The idea of freedom and democracy that the Philippines learned from the U.S. created a space for strong civil society. The civil activism in

\footnotetext{
${ }^{11}$ Also named after Gabriela Silang, a woman revolutionary fighter against Spanish Colonialist
} 
the Philippines is robust and people don't hesitate to take to the streets if they are not pleased with the government. Trade unions are allowed and collective bargaining is common. However, for trade unions to register, they will have to represent $20 \%$ of the bargaining unit. Strikes and labor unrests happen often. The 1987 constitution guarantees the rights to life; prohibits torture and slavery and other civil rights like habeas corpus, freedom of religion, freedom of expression, and freedom of association, along with personal liberty and security. However, there are inconsistencies in the government's record of protecting the guaranteed rights and freedoms of the people (Dressel, 2011). The table below highlights the status of rights and freedom in the Philippines.

Table 13: Civil Liberties Ratings, Political Rights Ratings, and Press Freedom Scores in the Philippines, 2002-2012

\begin{tabular}{cccc} 
Year & $\begin{array}{c}\text { Civil Liberties } \\
\text { Rating }\end{array}$ & $\begin{array}{c}\text { Political Rights } \\
\text { Rating }\end{array}$ & $\begin{array}{c}\text { Press Freedom } \\
\text { (Scale: } \mathbf{0 =} \text { best, 100 } \\
=\text { worst) }\end{array}$ \\
2002 & 3 & 2 & 30 \\
2003 & 3 & 2 & 30 \\
2004 & 3 & 2 & 34 \\
2005 & 3 & 2 & 34 \\
2006 & 3 & 3 & 40 \\
2007 & 3 & 3 & 46 \\
2008 & 3 & 4 & 45 \\
2009 & 3 & 4 & 45 \\
2010 & 3 & 4 & 48 \\
2011 & 3 & 3 & 46 \\
2012 & 3 & 3 & 42 \\
\hline
\end{tabular}

Source: Freedom House, 2013

The Philippines' long struggle with the communist movement, widely known as the Communist Party of the Philippines (CPP) and its armed wing, the NPA (New People's Army) has led the government authority in the Philippines to allow the use of military tactics in dealing with the resistance. The 2002 declaration of the Philippines as the 'second front' in the war on terror intensified this crisis. The increased militarization and its use by the government to 
suppress any resistance (not just from NPA) have led to attack on civil rights and liberties of the Filipinos (Lacasamana, 2012).

The recent war on terror has led to increased restriction on civil freedom in the Philippines. The crisis against the NPA and the low rate of conviction of the perpetrators of extrajudicial killings makes the Philippines a dangerous place for those who resist the government. In such circumstances where basic rights and freedoms are curbed to cater to the national security interests, labor organizing and labor resistance will be heavily suppressed. The military branch of the Philippines widely known as Armed Forces of the Philippines (AFP) has been at the center of this crisis as an aggressor. Military personnel are often noted to group members of the leftists' organizations, labor unions, and party-list groups together with the NPA (Human Rights Watch, 2011). This has led to disappearances of hundreds of activists, labor leaders, journalists, and leftist party members (Freedom House, 2011; U.S. Department of State, 2013). Extrajudicial killings are common in dealing with the members of the resistance force. A number of labor leaders have been victims of extrajudicial killings in the Philippines (Freedom House, 2011; Human Rights Watch, 2011).

Women's rights groups like GABRIELA have also been targeted in this crisis. It has been noted that many women activists have been murdered, including some from GABRIELA. Women have often been "stripped naked and molested by military personnel. Sexual violence is used both as a form of torture and to create fear among women" (Permanent People's Tribunal, 2007, p. 14). When it comes to violence against women, domestic violence is a persistent problem in the Filipino society. Even though the law criminalizes such abuse, 9,687 cases of domestic violence against women and children were reported by August for the year of 2013 (U.S. Department of State, 2013). Country Reports on Human Rights find that sexual harassment 
in workplace is very common, however it is underreported by the victim because of the fear of termination of work (U.S. Department of State, 2013). Considering these evidences, it will be reasonable to suggest that despite robust civil activism, the Philippines has much to work on protecting the rights of its citizens.

\subsubsection{Corruption}

The Philippines is an electoral democracy that has been tarnished in the legacy of corruption and cronyism. The rampant and institutionalized corruption is a threat to the very foundation of its democracy. Such intense corruption is often characterized by dominance of elites in high positions in public and private enterprises, institutional weakness, a patronage system, weak political parties, and lack of political will in curbing corruption. Any political reforms in curbing the corruption are obstructed by the power of local clans and cronyism (Transparency International, 2011). Corruption in the Philippines is so intense that the grand and political corruption usually leads way for petty corruption.

The U.S. style presidential system has established a presidency with uncontested authority. Further, in state-led development, the executive branch of the government is very active in the economic planning of the country. This also increases the authority of the office and the individual in the office. With such unchallenged authority and access to power, presidents in the Philippines have often abused their power and are often accused of heavy corruption. As one scholar posits, "Truth to tell, it is widely perceived that corruption has footprints on the floors of every public office in the Philippines, including the Presidential Palace" (Obejas, 2009, p. 97).

The wide spread practice of patronage and nepotism have filled the political branches and the bureaucratic agencies with the campaigners of the ruling government. In such circumstances, the rule of law is often subject to the ruling administration. The judicial system is incompetent and inadequate and justice is more often a privilege than a right: "The poor have less far access 
to justice than the well connected, who work the system to their advantage" (Dressel, 2011, p.

531). The intense corruption is often attributed to the culture of utang na loob (debt of gratitude) (Dressel, 2011). The table below highlights the perceived level of corruption of the Presidents of the Philippines.

\section{Table 14: Perceived Level of Corruption of Presidents in the Philippines, 2007}

President

Gloria Macapagal-Arroyo (2001-present)

Joseph E. Estrada (1998-2001)

Fidel V. Ramos (1992-1998)

Corazon C. Aquino (1986-1992)

Ferdinand E. Marcos (1972-1986)
Percentage believing that the President was corrupt

42

16

5

1

35

Source: Quah, 2011

The Filipino culture values family and kinship ties, and this culture often leads to expectations from friends and families of the office holders to use some of his/her power for the good of the family and kin members. This culture has also led to Filipinos being tolerant towards corruption (Quah, 2013). Bribes are common practice in the Philippines. Businessmen are reported to pay "speedy money" to accelerate the applications processing for licenses and permits (De Guzman \& Reforma, 1988). Transparency International has regularly monitored the level of corruption in the Philippines. Under the Corruption Perception Index (CPI), the Philippines has constantly performed poorly.

The poor performance of the Philippines in the CPI can also be attributed to the lack of political will in curbing the corruption in the country. Ledivinia V. Carino (1994) highlights six instances of lack of political will in the Philippines that has allowed for such rampant corruption. She argues that the absence of proper monitoring and evaluation of the public policy official, the 
political elites incapability in differentiating between private and public interest, low rate of conviction among corrupted officials, inadequate enforcement of laws, inadequate funding and manpower allocated for anti-corruption measures, and a lack of political will in translating pronouncements in actions has allowed for weak governance and thus high corruption in the Philippines. The table below highlights the CPI scores and ranking of the Philippines since 2001.

Table 15: Corruption Perception Index Rankings and Scores, 2001-2011

$\begin{array}{cccc}\text { Year } & \text { Ranking } & \text { Score } & \text { No. of countries } \\ 2001 & 65^{\text {th }} & 2.9 & 91 \\ 2002 & 77^{\text {th }} & 2.6 & 102 \\ 2003 & 92^{\text {th }} & 2.5 & 133 \\ 2004 & 102^{\text {th }} & 2.5 & 146 \\ 2005 & 117^{\text {th }} & 2.5 & 159 \\ 2006 & 121^{\text {th }} & 2.5 & 163 \\ 2007 & 131^{\text {th }} & 2.5 & 180 \\ 2008 & 141^{\text {th }} & 2.3 & 180 \\ 2009 & 139^{\text {th }} & 2.4 & 180 \\ 2010 & 134^{\text {th }} & 2.4 & 178 \\ 2011 & 129^{\text {th }} & 2.6 & 182\end{array}$

Source: Transparency International, 2012

The poor performance of the Philippines in the CPI can also be attributed to the lack of political will in curbing the corruption in the country. Ledivinia V. Carino (1994) highlights six instances of lack of political will in the Philippines that has allowed for such rampant corruption. She argues that the absence of proper monitoring and evaluation of the public policy official, the political elites incapability in differentiating between private and public interest, low rate of conviction among corrupted officials, inadequate enforcement of laws, inadequate funding and manpower allocated for anti-corruption measures, and a lack of political will in translating pronouncements in actions has allowed for weak governance and thus high corruption in the Philippines.

Increase in corruption is often associated with income inequality: "As income inequality increases, the rich have more to lose through fair political, administrative, and judicial process. 
As inequality increases, the rich will also have greater resources that can be used to buy influence, both legally and illegally" (Jong-Sung \& Khagram, 2005, p. 138). With this in mind, it can be argued that poor women who work in export-oriented factories have less leverage over the political institutions established to protect them as workers. The crony capitalists who have the means to easily buy influence can repress women's labor, be it on the issue of unequal pay or sexual harassment, leading them to be more vulnerable in the labor market.

Such rampant corruption has a huge impact on civil society of the country. In the Philippines, this corruption means that civil activism might not lead to political reform. The nature of crony capitalism in the Philippines (Kang, 2002) further asserts that most of the public goods and services are only afforded to those with power and money (usually in the Philippines, people with money are people in power and vice versa). In such circumstances, the public policies and laws promising security to groups like labor unions, women workers, and other marginalized groups are less likely to be regulated and implemented. Thus, rampant corruption in the Philippines can lead to weaken the institutions established to protect women as workers.

\subsubsection{Pressure for Corporate Social Responsibility (CSR)}

The strong civil activism and religiosity in the Philippines also translates into the pressure for CSR. The idea of corporate citizenship is well-known among the public and is driven by the Catholic idea of 'for the good of...' A study conducted in 2005 found that $93 \%$ of the 166 business executives surveyed agreed, "good corporate citizenship improves corporate image and reputation" (Maximiano, 2005, p. 33). Despite such belief, the poor performance in these areas begs the question if the investment in the name of the CSR is driven by the corporate interest. By investing in areas like education, corporations are ensuring the supply of the skilled labor. Investment in other sectors like poverty, health care, and hunger may be driven by the Catholic idea of charity. The table below highlights the top areas where the businesses play the 
most active role in benefitting the cause. It must be noted that the table suggests that the least active areas are gender equality, cultural minorities, and AIDS.

\section{Table 16: Ranking of the Active Roles Played by Business (by sector)}

$\begin{array}{ccc}\text { Area } & \text { Mean response } & \text { Rank } \\ \text { Education } & 4.10 & 1 \\ \text { Poverty } & 3.92 & 2 \\ \text { Health Car } & 3.81 & 3 \\ \text { Hunger } & 3.61 & 4 \\ \text { Peace Advocacy } & 3.57 & 5 \\ \text { Human Rights } & 3.54 & 6 \\ \text { Development of Alternative energy } & 3.48 & 7 \\ \text { sources } & 3.42 & 8 \\ \text { Gender equality } & 3.05 & 9 \\ \text { Cultural minorities } & 2.93 & 10 \\ \text { Aids } & 3.54 & \\ \text { Average } & & \end{array}$

\section{Source: Maximiano, 2005}

Likewise, investment in areas like human rights and alternative energy might be driven by the effort to maintain a good image of the company. The low investment in AIDS can be attributed to its characterization as a sexually transmitted disease. The Department of Health of the Philippines reports that $96 \%$ of their AIDS victims are males, and only $4 \%$ are females. Among these instances, $3 \%$ of the infection was through homosexual contacts, and $36 \%$ was from heterosexual contacts (2012). The Philippines has a deeply religious society and these numbers do not appeal to the majority of the Filipinos who are Catholic. Considering this, the low rate of activism in the cause of AIDS among corporations is explainable

The lack of corporate investment in gender equality and minority issues gives a direction to my question: is CSR being used to bolster the interests of the corporations? While the data below cites the involvement of local corporations, I still think it adds to the understanding of the use of women's labor as resources in the Filipino culture. If the treatment of the women in the 
country lags behind in the number of issues among the local corporations, it will be certainly the case for the foreign companies, too.

The institutional pressure to adopt CSR in the Philippines is largely absent; however, with the enactment of policies like Magna Carta of Women, the Philippines is trying to maintain a good image in the global world. This initiation led by the Philippines shows that they are finally adopting post-materialist values. However, with state-led development that puts development goals over human rights and a strong culture of corruption that puts power and money over justice and equality, the Philippines' institutional pressures are very hollow and incompetent.

Nevertheless, despite a lack of corporate support in women's causes, corporations are constantly under pressures from local NGOs and women's organizations like GABRIELA and KMK to act on the issue of gender injustices in the society. Further, active alliances of these organizations with international NGOs like IGLHR and campaigns like Clean Clothes Campaign also increases the pressure for MNCs to act within the universal legal framework of labor and human rights. Such pressure will then make regulated labor laws within the interests of the MNCs, thus leading the MNCs to stress the government to keep the labor laws implemented and regulated. Thus, pressure for CSR might lead to protect women's labor in the Philippines.

\subsubsection{Bureaucratic Capacity}

Marred in political controversy and corruption, the Filipino Civil Service has time and again been identified as ineffective. The continuous reform efforts introduced by each administration since the fall of Marco regime left the Filipino Civil Service without any direction (Tjiptoherijanto, 2012). In 1987, the new Constitution created the Civil Service Commission (CSC) to recruit eligible public servants. The CSC was tasked to introduce merit-based recruitment, and promotion and capacity building of public servants. In 1995, CSC launched the 
Brightest for the Bureaucracy Program to launch recruit "exceptional individuals" in the civil service sector (De Leon, 2002, p. 11). This program was intended to increase bureaucratic capacity and also to promote the advantages of government jobs to more qualified candidates. Along with such capacity-building programs, the government also conducted gender sensitivity trainings to the civil servants. Further, the civil service sector also introduced guidelines and procedures on prosecution of sexual harassment cases in the civil service sector (De Leon, 2002).

The Filipino approach to gender equality has been driven by activism in the grassroots level. There is a huge influence of women's groups in gender mainstreaming policies adopted by the Filipino government. The Filipino government has been allocating 5\% of the government's national and local budget to gender and development issues formulated by the national agencies (Philippine Commission on Women, 2009). With pressure from groups like GABRIELA and KMK, the Philippines adopted the revolutionary policy called Magna Carta of Women to ensure the 'substantive' equality of men and women. Under this Act, the state pledges the following: ...provide the necessary mechanisms to enforce women's rights and adopt and undertake all legal measures necessary to foster and promote the equal opportunity for women to participate in and contribute to the development of the political, economic, social, and cultural realms (Philippine Commission on Women, 2009).

This act recognizes the economic, political, and socio-cultural realities that affect the current condition of women, and establishes the state's affirmation in promoting the role of women in the nation building process, and ensuring equality of both women and men. Under this act, women are entitled to a special leave benefit, where:

A woman employee having rendered continuous aggregate employment service of at least six (6) months for the last twelve (12) months shall be entitled to a special leave benefit of two (2) months with full pay based on her gross monthly compensation following surgery caused by gynecological disorders (Philippine Commission on Women, 2009). 
Under Section 22 of the Magna Carta of Women, the state ensures support and protection of women workers through:

a. Support services and gears to protect them from occupational and health hazards taking into account women's maternal functions;

b. Support services that will enable women to balance their family obligations and work responsibilities including, but not limited to, the establishment of day care centers and breast-feeding stations at the workplace, and providing maternity leave pursuant to the Labor Code and other pertinent laws;

c. Membership in unions regardless of status of employment and place of employment; (Philippine Commission on Women, 2009)

The law also established the Philippine Commission on Women (renamed from National Commission on the Role of Filipino Women), as the principal policy-making and directing body of women and gender equality affairs under the Office of the President. It authorizes the Philippine Commission of Women (PCW) to direct any government agency and institutions to report on the implementation of this act and capacitate the effective implication of this act.

The Philippines has also enacted various policies to incorporate women workers in the economy. The policies like Solo-parent Welfare Act and Early Childhood Care and Development Act supports the reproductive roles of women along with the productive roles (The World Bank, 2011). The World Economic Forum's Global Gender Gap Report (2013) ranked the Philippines 5th out of 136 countries: “The Global Gender Gap Report's Index assesses countries on how well they divide resources and opportunities amongst male and female populations, regardless of the overall levels of these resources" (Philippine Commission on Women, 2013). This shows that the Filipino's gender and development approach has been working in reducing gender discrimination in the country.

The labor legislation in the Philippines has been described as "more liberal than corporatist" as workers are ensured the rights to autonomously organize and bargain with the employers (Hutchinson \& Brown, 2001). The Filipino legal framework guarantees that workers 
have the right to membership in labor organizations. It also prohibits dismissal of laborers based on their membership in the labor organization (ILO, 2013a). The Filipino legislations have granted the 'economic unionism' via collective bargaining since the passage of the Industrial Peace Act of 1953. This act allowed for proliferation of local unions with official recognition (Wurfel, 1959).

Despite such robust efforts in addressing the need for gender equality at all levels of life, there are still shortcomings in the Filipino approach. Most of it is amounting in local governmental units from "technical difficulties and political issues in trying to allocate funds" (ADB, 2008, p. xx). The implementation of policies has also been noted to be slow and rather uneven (ADB, 2008). Nevertheless, the government has acknowledged the importance of gender equality in achieving the overall development of the country. The Philippines Development Plan 2011-2016 also commits to increasing gender equality in all sectors of Filipino society (The World Bank, 2013). The efforts of the Filipino government in addressing gender equality in the Filipino society are indeed commendable. The continued Filipino approach to include gender in governance has proven to have potential in protecting women's rights in the country.

\subsection{Unregulated labor: Female Labor in Export Oriented Industries}

The institution of SAPs in the Philippines bolstered the export-oriented approach with the introduction of foreign-owned MNCs in the Philippines. These policies were intended to absorb jobless men into the new factories established by the MNCs (Margold, 1995). However, these MNCs hired a large number of women (mostly young, poor, unskilled women) in the workforce. The MNCs plan on hiring women instead of men was not to give women an economic opportunity to empower themselves, in fact it was driven by their motivation to cut costs. While the regular pay did allow for some of these women to gain autonomy, these jobs are often 
comparable to those in the informal sectors: "workers' rights to organize and take collective action is suppressed, employment is insecure, the minimum wage is frequently waived, productivity quotas replicate the intensity of piece work, and labor is casualized through apprenticeship status" (Eviota, 2004, p. 56). The feminization of labor in the MNCs has propagated gender inequalities within the labor market for the women.

Female labor is the preferred labor in EPZs or SEZs. In the 1980s, $74 \%$ of the Filipino labor force in SEZs was women and remained the same until 1994 (Aggarwal, 2007). In the Philippines, 35\% of female workers are unskilled (Asian Development Bank, 2013). In 2009, $64 \%$ of the 660,600 workers employed in the SEZs were female. The proportion of female labor participation in the SEZs is no way representative of the overall female labor force participation. The proportion of women working in the SEZs is much higher than total female labor force participation rate.

Feminization of the labor force is the consequence of hiring practices based on gender stereotypes. Women, especially young women, are preferred because they are presumed to have nimble fingers, dexterity, and are assumed to be more suited for repetitive and boring work (Elson, 1983; Eviota, 1992; Chant \& McIlwaine, 1995; Roces, 2000). Youth is emphasized as young workers are expected to be more productive and have better health (particularly eyesight). The firms usually establish an educational requirement for the workers.

While the employment in EPZs presents a lengthy list of requirements to be fulfilled, these jobs offer no opportunity in learning new skills. The fact that most of the assembly line workers are only high school graduates limit the opportunities outside of factory work. Additionally, the punishing work hours and the responsibility of other household chores do not allow women to seek further education or training. The skills that women learn in assembly lines 
are also not easily transferable as the skills they learn are very specific and only suited to factory work (Pineda-Ofreneo, 1987; Eviota, 1992; Chant \& McIlwaine, 1995).

Another grave impact of factory employment is constant exposure of workers to occupational hazards. Women working in factory assembly lines often complain of back strain and headaches because of sitting for long hours and performing eye-straining tasks. While men also complain about these problems, they are not employed as much in the assembly lines (Yap, 1989; Chant \& McIlwaine, 1995). A baseline study conducted in 24 companies (most of them electronic manufacturing) in Philippines' EPZs with 500 workers (among them 88\% were female, $69.6 \%$ were single, $87.4 \%$ worked in production and assembly lines, and the mean age was 22.8 years old) found that women workers were exposed to "ergonomic hazards leading to exertion injury on the back (73.4\%), excessive work (66.7\%) and heat (66.0\%)" (Lu 2008: 336). The table below highlights the frequency distribution of illness among women workers in the factories.

Table 17: Frequency Distribution of Illness among Female Workers in Assembly Line

$\begin{array}{ccc}\text { Illness } & \boldsymbol{N} & \mathbf{\%} \\ \text { Headache } & 246 & 55.4 \\ \text { Cough and Cold } & 264 & 59.5 \\ \text { Gastrointestinal Problem } & 256 & 57.7 \\ \text { Musculoskeletal disorder } & 246 & 55.4 \\ \text { Tuberculosis } & 196 & 44.1 \\ \text { High Blood Pressure } & 186 & 41.9 \\ \text { Urinary Tract Infection } & 208 & 46.8 \\ \text { Arthritis } & 190 & 42.9 \\ \text { Skin allergy } & 207 & 46.6 \\ \text { Hearing problem } & 183 & 41.2 \\ \text { Visual Problem } & 236 & 53.2 \\ \text { Reproductive Problem } & 202 & 45.5 \\ \text { Physical exhaustion } & 247 & 55.6\end{array}$




\section{Source: Lu, 2008}

The study found that many women were suffering from headache and dizziness because of poor ventilation and dust. Women who were exposed to textile dusts and chemicals were identified to have a potential risk of pancreatic cancer. Other risks like esophageal cancer, pulmonary tuberculosis, stomach cancer, arthritis, and hypertension were also present when working in the factory environment. Problems like eyestrain were linked to dust. Dust causes irritation of eyes, and this is exacerbated by poor ventilation. Assembly line workers were more likely to be found tired than their supervisors. Continuous standing or sitting in poor posture strains muscles, causing pain and fatigue (Lu, 2008).

The job in the export-oriented factories has more negative outcomes than positive ones. The women who work in these factories are stuck in the dead-end jobs with no opportunities for upward mobility and no transferable skills; moreover, their pay is barely enough to support their family (Elson \& Pearson, 2008). Considering this, the claim that MNCs allows for economic opportunities for women to empower them is highly questionable. Instead, it will be fair to say that the feminization of labor in the FDI industries in the Philippines feeds off of gender stereotypes and uses these in exploiting young, poor, unskilled women workers.

\subsubsection{Labor laws pertaining to women in the Philippines}

The Philippines has shown considerable success in adopting Gender and Development (GAD) policies and gender mainstreaming strategies. Under the Philippine Development Plan (PDP) of 2011-2016, gender mainstreaming has been prioritized as a development goal (National Statistical Coordination Board, 2013). Gender mainstreaming involves the process of examining the implication of any planned actions, including policies for both men and women (United Nations, 2002). The adoption of laws like Magna Carta of Women has bolstered the gender mainstreaming approaches in the Philippines. 
However, with a more intensified and more insecure global market, the Philippines is struggling to maintain its well-being as an export-oriented economy. In such circumstances, it is eager to attract more foreign investment in the country, establish more SEZs, and promote investment opportunities advertising its skilled [female] labor force (especially on Business Protocol Outsourcing [BPO]). With this in mind, below I discuss how the Philippines intends to protect its workers and yet be able to market itself as a good place to invest (with low-cost labor being the most attractive point). I discuss Filipino labor regulation as it pertains to female workers. In this section, I will examine the state's actions in ensuring the protection of female workers. I will then divert the discussion from the state and look at various women's organizations that are working to resist the very ideas of capitalism, neoliberalism, and globalization. I intend to identify the agency of women in driving the resistance against the globalization.

The Philippines has introduced various laws to protect its women workers. The Labor Code (1989) includes some of these regulations (ILO, 2013a). Under Title III, Working Condition for Special Groups of Employees, Article 130 prohibits the work hours of women from ten o'clock at night to six o'clock in the morning in the industrial setting. Though this is in the book of government legal publications, privately published publications like "Guide to Philippines Employment Law," maintain that those who work between ten o' clock at night and six o'clock in the morning are entitled to different overtime rates. While this publication does not really specify the gender of the workers in discussing this law, it is catering to MNCs and implicitly suggesting that it is okay to employ people at night as long as you pay a mandated overtime rate (Torres, 2013). 
This provision was repealed by Republic Act No. 10151 (RA10151) that has been effective since July 12, 2011. This law applies to people "who are employed, permitted, or suffered to work at night during a period of seven consecutive hours, including the interval from 12 a.m. to 5:00 am" (Zerrudo et al., 2012). The Labor Code also ensures provision of proper seats for women during the work hours, separate restrooms for men and women, provision for a dressing room for women, and a nursery for working mothers. The law guarantees maternity leave for the women workers. Under Articles 133, the law states that:

a. Every employer shall grant to any pregnant woman employee who has rendered an aggregate service of at least six (6) months for the last twelve (12) months, maternity leave of at least two (2) weeks prior to the expected date of delivery and another four (4) weeks after normal delivery or abortion with full pay based on her regular or average weekly wages. The employer may require from any woman employee applying for maternity leave the production of a medical certificate stating that delivery will probably take place within two weeks.

b. The maternity leave shall be extended without pay on account of illness medically certified to arise out of the pregnancy, delivery, abortion or miscarriage, which renders the woman unfit for work, unless she has earned unused leave credits from which such extended leave may be charged.

c. The maternity leave provided in this Article shall be paid by the employer only for the first four (4) deliveries by a woman employee after the effectivity of this Code (ILO 2013a).

The maternity leave is guaranteed for 78 days for women who had a caesarean delivery. The employer is required to pay the full benefits within the 30 days from the filing of the maternity leave application. The Social Security System reimburses the full amount of the maternity benefit to the employer once adequate proof of such payment and legality is received (Torres, 2013). The Filipino legal framework also extends the protection of women workers to those who are victims of violence as well. Under Republic Act No. 9262, widely known as "Anti-violence Against Women and Their Children Act of 2004," women who are victims of violence are 
entitled to take paid leave of absence up to 10 days (Bureau of Workers with Special Concern, 2014).

The labor code also prohibits the discrimination based on sex in the workplace under Article 135 (1989). In prohibiting such discrimination, the law states that it is unlawful to do the following:

a. Payment of a lesser compensation, including wage, salary or other form of remuneration and fringe benefits, to a female employee as against a male employee, for work of equal value; and

b. Favoring a male employee over a female employee with respect to promotion, training opportunities, study and scholarship grants solely on account of their sexes (Department of Labor and Employment, 2013)

However, the data suggests otherwise. The estimated gender gap for annual earnings in 2012 for the Philippines was 40\% (Asian Development Bank, 2013). Despite the guarantee in the legal framework, women are still discriminated on equal pay. Further, because of assumed gender stereotypes, women are often only hired in low-level positions that pay less than mid-level and high-level positions that hire men.

\subsubsection{Labor Activism and Women Workers in the Philippines}

The Philippines has been a part of the globalized world since its independence. The trade conducted by the Spanish and the Americans in and throughout the Philippines gave it an exposure to some of the resources that the imperial and the colonial power used within the Filipino land. The American imperial rule, unlike Spanish colonial rule, was not intended to only extract from the Filipinos; Americans cultivated ideas like good governance and democracy and value for education among Filipinos. These ideas had a profound impact on the population of the Philippines.

The labor movement in the Philippines gained its ground during the Marcos regime in organizing against the regime. The KMU trade union center was established in 1980 to fight the 
Marcos Administration's resolution to contain growing labor activism in the country. KMU represented a social movement union (Lambert, 1990) that was committed to a policy outside of the workplace. By including alliances and extensive links as a part of their movement, social movement unionism also sought to influence other social and political movements. Under the social movement unionism, KMU organized strikes against nationalistic issues like militarization, IMF directives, and economic liberalization (Hutchinson \& Brown, 2001).

Under this social movement union of KMU, an organization that is solely devoted to women's issues is also established. Widely known as KMK (Kilusan ng Manggagawang Kababaihan- Women Workers Movement), this organization seeks to reconcile contradictions between the role of the women in the home and the workplace as well as the class difference between working class women and the Filipina middle-class women. KMK was established in 1984 with the Women Industrial Workers Alliance (WIWA) to organize and prioritize women workers and their issues in the social movement union (West, 1997). KMK, like KMU, extends its agenda beyond the labor issues and represents a feminist nationalistic movement.

Women workers in the Philippines addressed U.S. imperialism and the bankruptcy of Capitalism as the root cause of the economic and political crisis in the third world countries ... Simultaneous with this, the KMK asserts for greater democratic participation and involvement in various trade unions not as "contras" to presently male-dominated leadership but as partners ... This is a gigantic step towards liberating women from "house to bed" role[s] in the patriarchal-oriented Filipino family[s] (West, 1997, p. 79)

KMK has been an integral part of the liberal labor legislation as it pertains to women. It has vigorously promoted the idea for women-oriented workplace facilities and benefits. It advocated for insurance of full employment for women, equal pay for women, abolishment of piece rate system and forced overtime, protection for pregnant workers, maternity leave, and many other issues like parental leave and availability of child care centers (West, 1997). 
Another organization that has actively advocated for gender equality in the Philippines is GABRIELA. GABRIELA has often been identified as a militant coalition organization that organizes women's resistance to globalization in the Philippines (West 1997; Lindio-McGovern 2013). GABRIELA was founded as a feminist group for middle-class women. By 1987, GABRIELA was representing 100 women's organizations with a total of 28,000 members including groups like SAMAKANA (women's urban poor organization) and AMIHAN (national federation of peasant women). KMK is also a member of GABRIELA and is one of the largest groups alliancing with GABRIELA (West, 1997). GABRIELA actively conducts resistance to globalization by organizing women's groups, facilitating organization of grassroots women, generating awareness between its members and the larger public, and highlighting the influences of globalization in the Filipino society. It targets the state in practicing its resistance tactics. GABRIELA has been very active in increasing the participation of women in national politics, and has elected its members to the Congress (Lindio-McGovern, 2012). Organizations like KMK (the Women Worker's Movement) and GABRIELA have been fundamental in supporting the cause of Filipino women empowerment and the establishment of state institutions like the PCW. Despite the liberal labor policy and active labor unions, participation in the unions is low in the Philippines, and the picture is even grayer among women workers.

In SEZs, union organizing is made difficult by having government security forces stationed closely. The Department of Labor and Employment (DOLE) has been reported to ineffectively enforce the labor legislations in the SEZs. In treatment of the union members and intrusions by employers in issues, reports have been made of bias, "including replacement of trade unions by non-independent company unions, dismissals, and blacklisting of the activists" (International Trade Union Confederation, 2012). The total number of unionized labor is only 
$9.9 \%$ of the total employees. Of this, only 9 percent of total working women are unionized

members. In the manufacturing sector, only $13.3 \%$ of workers are unionized, and only $10.7 \%$ of female workers are unionized. The table below highlights the number and percentage of union members and female union members in each industry group.

Table 18: Union Membership among Female Workers (by sector), 2012

$\begin{array}{ccccc}\text { Major Industry group } & \begin{array}{c}\text { Total } \\ \text { Employees } \\ \text { All Industries }\end{array} & \begin{array}{c}\text { Total Female } \\ \text { Employees }\end{array} & \begin{array}{c}\text { Female Union } \\ \text { Membership }\end{array} & \text { Percent Share } \\ \text { Agriculture, Forestry and } & 169,738,771 & 1,490,011 & 134,193 & 9.0 \\ \text { Fishing } & 30,002 & 22,584 & 5,628 & 24.9 \\ \text { Mining and Quarrying } & 918,232 & 3,109 & 510 & 16.4 \\ \text { Manufacturing } & 186,005 & 397,579 & 42,412 & 10.7 \\ \text { Construction } & 111.485 & 12,1700 & 300 & 19.5 \\ \text { Public Health Activities } & 44,509 & 70,782 & 13,770 & 7.5 \\ \text { Arts, Entertainment, and } & 14,770 & 1,110 & 3.3 \\ \text { Recreation } & 200,904 & 81,090 & 2,663 & 30.7 \\ \text { Accommodation and Food } & 172,096 & 104,392 & 32,005 & \end{array}$

\section{Source: Bureau of Labor and Employment Statistics, 2013}

The low rate of unionization in spite of the high level of political and social activism is indeed mind-boggling. However, difficulties for organizing the labor in the Philippines have been attributed to the recurrent national economic crisis, high levels of unemployment and underemployment, and manufacturing decline ( Hutchinson \& Brown, 2001). Considering these numbers, it can be argued that the legal framework of the Philippines falls short in protecting its workers when faced with a lack of political will and the inability of the state to properly enforce the laws.

\subsection{Conclusion}

The Philippines is a seasoned actor in the world of export-oriented economies. The Philippines has often assumed the role of advisor to the newly emerging economies, like Bangladesh, that seek to use export-oriented economy as a tool of economic development. The 
Filipino export-oriented economy has long employed women as workers in the multi-national firms, producing anything from garments to electronic semi-conductors. Women (mostly young, unskilled, poor) have been the labor force behind the success of FDI in the Philippines. Despite this, women workers in FDI industries have not been receiving their due, neither from the state nor from the MNCs.

Nevertheless, because of active civil involvement, groups like KMK and GABRIELA have championed the cause of women workers and constantly pressure the Filipino government to take necessary actions to ensure gender equality. This has led to institutionalization of political reforms like Magna Carta for Women. The robust activism of the women workers, with the support of NGOs in advocating for gender equality in the Philippines, promises a better future for women. The recent efforts from state in adopting Gender and Development approach in various governance strategies is indeed commendable. Despite this there are still areas where gender inequality persists, for instance women still lag behind male workers in equal pay and in economic sectors outside of the export-oriented industries. Further, institutional problems within the state like intense corruption and lack of political will among the political elites to implement the reforms obstruct the state-adopted measures taken towards ensuring gender equality. 


\section{Chapter 7: Malaysia}

\subsection{Introduction}

Malaysia is a classic case of a colonized area where the British implemented the strategy of divide and rule to control its resources. The British colonized the area specifically to control trade and establish an export-oriented industry based on tin and rubber. Since its independence, Malaysia has used the economic model based on the export-oriented production to allow continued economic growth of the country. In the 1970s, within the decade of its independence, Malaysia introduced various policies to strengthen its export-oriented economy, and has since been successful in attracting FDI to drive its export-oriented economy. Women have been active participants in driving Malaysia's economic growth. In this chapter, I will highlight the role of women in Malaysia's economic success. I will also discuss how the status of the labor has changed in Malaysia since they gained economic success and Malaysia's necessary move to import migrant labor to maintain their export-oriented economy. I intend to show the role of the state in keeping the immigrant labor unregulated to appease the MNC's capital.

\subsection{History}

For thousands of years, Indian traders who frequented Malaysia as a trading destination influenced the area culturally with political, social, popular, and religious ideas. For the most part, Malaysia, especially the Malacca Strait, remained a commercial area burgeoning with different cultural influences including those from India, China, and the Arab world.

Portuguese occupation of the Malacca Strait in the sixteenth century forced the rulers of the area to flee and establish another state in the Southern tip of the archipelago. The Portuguese control of the area was driven by their mission to convert the native peoples to Christianity. The Dutch captured the Malacca from the Portuguese in 1641 (Seekins, 1985). They treated the area 
as an extended part of their occupation of the East Indies and regarded the area as a fortress to maintain their monopoly of trade of spice, pepper, and gold (Vreeland,1977).

The geographical area of the Malacca Strait spurred the British interest in the Malacca. The East India Company was in search for a base for ships on the India-China trade route and the strait was a suitable area to build such a base (Seekins, 1984; SarDesai et al., 1997). The British colonial era had the most profound influence in the building of the modern Malaysia. The following paragraphs highlight the British influence and how that has translated into what we know as Malaysia today.

\subsubsection{British-Malay: During the British Colonial Rule}

Before 1870, the British attitude towards the Malay states was that of non-interference, but the continuous dynastic disputes in Malaysia and its effect on regional trade of tin led the British to intervene. The Pangkor Treaty of 1874 between the British and the Sultan of Perak, which was later signed with the states of Selangor, Negeri Sembilan, and Pahang, legitimized the

British control over the area. This treaty also established a residential system, where the British would appoint one of their own as an advisor to the sultan on everything except religion and customs (Vreeland, 1977; Andaya \& Andaya, 1982; Seekins, 1984; SarDesai et al., 1997). Under the Pangkor Treaty, the British devised a strategy whereby they will control the Sultan (the most powerful political entity), and thus control the area.

The British controlled the administrative state in the Malaya from 1826 to 1946 . The British re-defined the Malaya monarchy to make it more comprehensible to them. The monarchs were presented the title of "Sultan" by Queen Victoria as a gift of partial sovereignty, whereby the British will only control the administrative and economic state and will not influence the culture and the religion of the area, and in exchange for a signature in the Pangkor Treaty (Gopinath, 1991). By the middle of the 1800s, the British-controlled area had successfully 
established the Strait Settlements and the Federated Malay States (FMS). The crucial areas of Malacca and Singapore were under the Strait settlements. The FMS included all the states that had signed the Pangkor Treaty (Selangor, Negri Sembilan, Perak, and Pahang).

\section{Figure 10: Malaysia under British Rule}

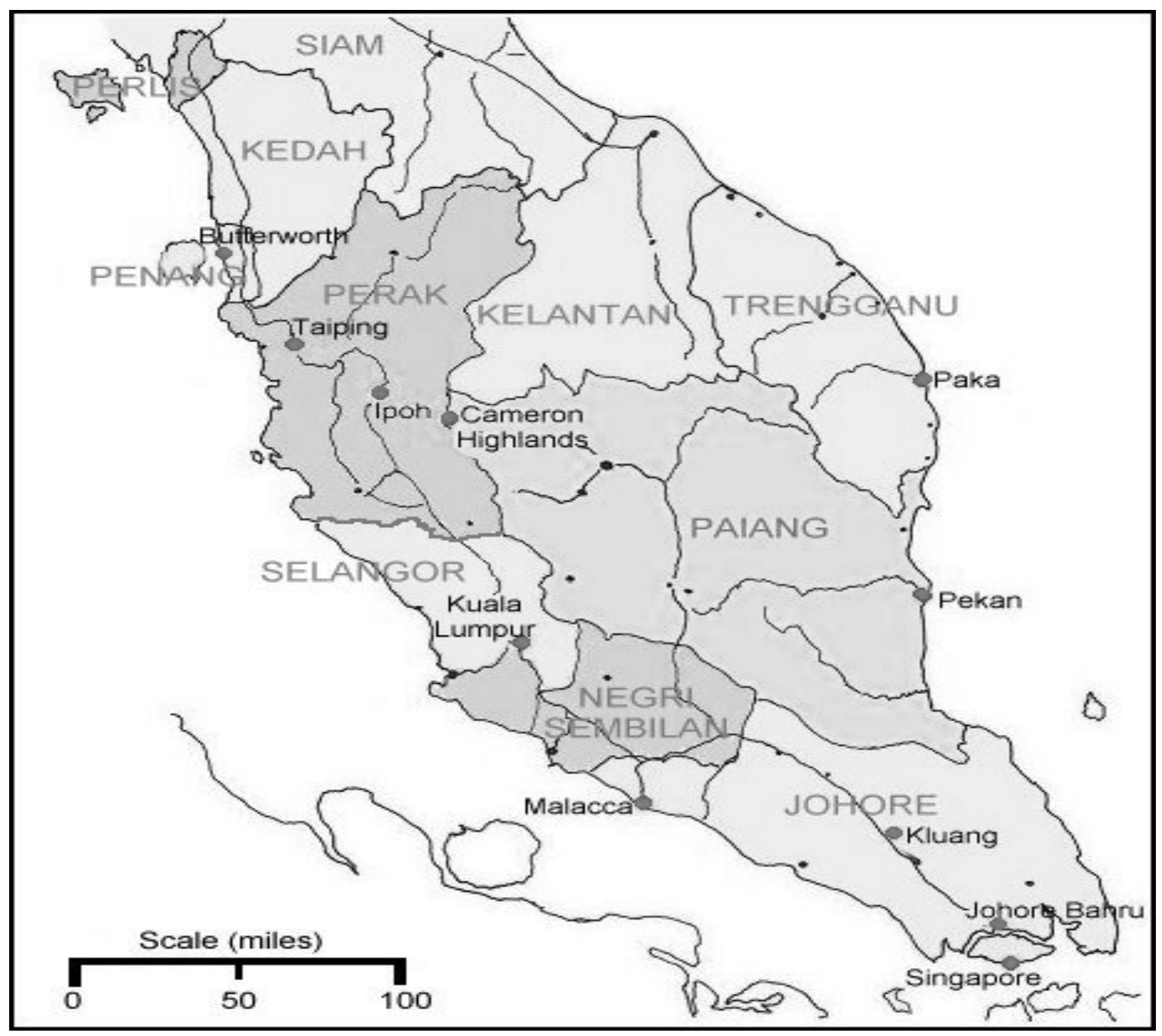

\section{Source: The Worcestershire Regiment, 2014}

The federation led a way to establish a central authority and vexed more power in the hands of appointed residents in each state. Through the establishment of the FMS, the British were successful in curtailing whatever power the regional government had and devising a new strategy of control. Malaysia as we know today is divided into two parts by the South China Sea, 
the peninsular part comprising the former federation of Malay and the island part comprising the states of Sabah and Sarawak in Borneo.

\section{Figure 11: Map of Malaysia}

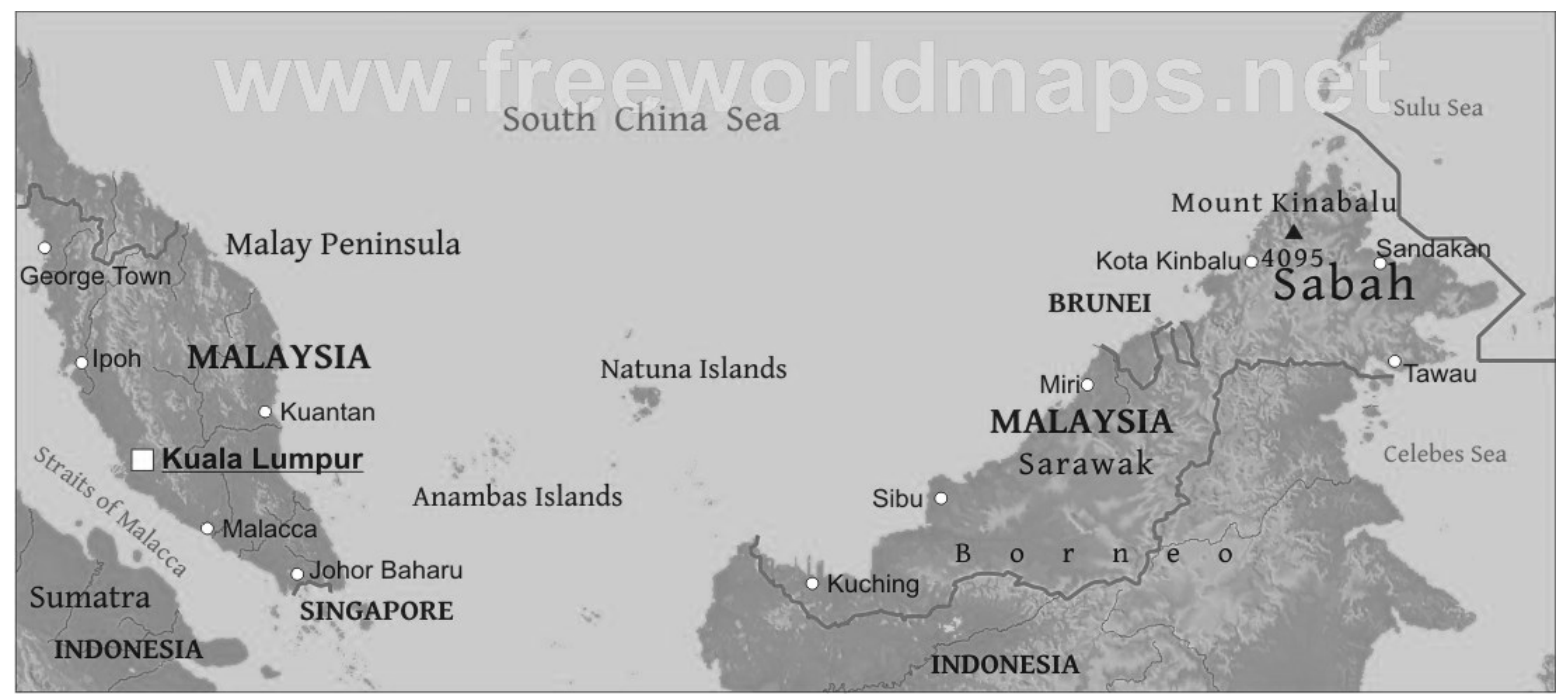

Source: Freeworldmaps.net

The economic interests of the British drove the British colonization of the Malay states.

To further this interest, the British wasted no time in establishing an export-oriented economy based on tin and rubber (Seekins, 1984). The British administration undertook significant changes that they regarded as necessary to facilitate the development of the export-oriented economy. One of the reasons that drove the British to interfere in the Malayan region was the frequent conflict between the Chinese secret societies and Malays, which was hampering the trade in the area. The British were very keen in maintaining the peace in the peninsula.

The first thing that the colonial rule offered was the security to the investors in the FMS. The British also established infrastructures like roads and railways to assist the development of the export-oriented economy. Another major change that the British instituted was the establishment of operative legal and administrative systems, including a Western-type land tenure system. This system encouraged Western plantation investors to invest and settle in the 
area. Along with the introduction of these administrative functions, the British government also facilitated the supply of labor needed for a successful export economy. The demand for the labor was met via unrestricted immigration from India, China, and Dutch East Indies (Carlson, 1975; Andaya \& Andaya, 1982; Seekins, 1984; Harper, 1999). Andaya and Andaya find that "the government's willingness to use its power to guarantee a ready and cheap source of labor was a strong inducement to private entrepreneurs to invest in the British Malaya" (1982, p. 208). Malaysia, because of its geographical structure, has always had a diverse population. The tin mines had always attracted Chinese to the area, as tins have always been useful in China for storing tea (Andaya \& Andaya 1982). The Indian settlement began after they migrated to the area with the British as indentured servants and farm workers in rubber plantations (Seekins, 1984). Today, the ethnic makeup of Malaysia is very diverse. The migrant population in Malaysia is also very significant, making up $8.2 \%$ of the total population (Central Intelligence Agency 2013a).

Table 19: Ethnic Make-up of Malaysia

\begin{tabular}{|c|c|}
\hline Ethnic Group & Percentage of Population \\
\hline Malay (Bhumiputras) & 50.1 \\
\hline Chinese & 22.6 \\
\hline Indians & 6.7 \\
\hline Indigenous & 11.8 \\
\hline Non-Citizens & 8.2 \\
\hline
\end{tabular}

Source: Central Intelligence Agency, 2013a

\subsubsection{The Fall of British Malay}

The end of the British control of Malaysia was a consequence of the British participation in the Second World War. The cost of World War II was challenging to imperial Britain and 
maintaining the colonial spaces was becoming expensive. On December 8, 1941, the Japanese invaded Malaysia. Under this occupation, the Chinese ethnic group was treated brutally (Andaya \& Andaya, 1982). The Japanese allied with the weak Malay monarchs to encourage Malay nationalism and suppress the ethnic Chinese in the area (Vreeland, 1977). The conflict created by this occupation between the Malays and the ethnic Chinese is still an issue in present-day Malaysia.

The harsh behavior of the Japanese towards the Chinese minority led to an active antiJapanese movement among the ethnic Chinese. With the support of Chinese communities in China and elsewhere as well as the British, the ethnic Chinese grouped under Malayan People's Anti-Japanese Army (MPAJA). During the Japanese occupation (1942-1945), the MPAJA grew to be an armed group that took over the regional government to maintain law and order. In early 1945, the British returned to the Malaysian territories, and by 1948 promised to grant self-rule to the Federation of Malaya (Vreeland, 1977; Andaya \& Andaya, 1982). The British government, however, was fearful of ethnic conflicts and insisted on a federation. In 1957, Singapore submitted a proposal to consolidate the Malay states. The Malays were not very pleased with it and objected to it based on the fear of Chinese domination within the proposed union. In 1963, Singapore seceded from the peninsular Malaysia and by mid-1965, Singapore became an independent and sovereign country (Vreeland, 1977; Seekins, 1984). Malaysia now embarked on a state-building campaign amidst the colonial influences on race relations, nationalism, and the export-oriented economy.

\subsubsection{Post-colonial Malaysia and Export-led Development}

The immediate problem surrounding the post-colonial Malaysia was that of racial tensions. The race riots of 1969 led to a realization among the Malaysian elites that ethnic compromise and accommodation were significant to the success of the new Malaysia. Keeping 
this in mind, the Malay-controlled government enacted the New Economic Policy (NEP) in the 1970s. The NEP had two goals: poverty elimination (regardless of race), and abolition of the system of identifying race as per the economic function [as instituted in British Malay] (Sundaram, 2004). During the colonial era, the British institutionalized race relations by identifying each ethnic group with certain occupations. Andaya and Anadaya suggest that "put crudely, the European was to govern, and administer the immigrant Chinese and Indian to labour in the extractive industries and commerce, and the Malays to till the fields" (1982, p. 222). The NEP sought to advance the position of the native Malays in the society. As a part of the "Look East” policy, Prime Minister Mahathir Mohamed openly rejected Western influence and welcomed Japan and South Korea as development examples for the country (Lim \& Fong, 1991; SarDesai et al., 1997). The "Look East" policy encouraged imitation of Japanese and Korean work habits and awarded major construction projects to Japanese and Korean firms (Bowie, 1991).

The NEP sought to increase the economic participation of the Malays. In doing so, the state diverted all its attention in increasing investment from the Malaysians. However, since the Malay entrepreneurial class was non-existent, the state apparatus that was established to encourage Malaysian investment had to seek the investment from foreign entities. Between 1970 and 1985, foreign investment was welcomed and encouraged only in export-oriented industries in Malaysia. The recession of the late 1980s forced the Malaysian government to rethink the import-substitution and restrictive foreign investment policies. This led to the introduction of the Promotion of Investment Act of 1986, which provides incentives for FDI in Malaysia (Lim \& Fong, 1991). Along with FDI incentives, Malaysia also offered an abundance of inexpensive labor to work in the FDI enterprises. 
The influx of FDI has been linked to employment generation in Malaysia. Malaysia's encouragement to have foreign investment concentrated in the export-oriented industries has indeed led to an increase in the number of people participating in the labor force. New opportunities in the electronics and semi-conductor industries were bringing a surge of new labor in Malaysia; most of these were inexpensive labor consisting of young, rural Malay women.

\subsection{Factors influencing the Formation of Gender Identities in Malaysian Society}

The diversity of Malaysian population also translates to diversity in culture. The customs outlining gender roles are very different from one ethnic group to another. For the purpose of this project, I will only be focusing on Malay women as they are the majority, mostly from rural areas, and were absorbed in the labor market in large numbers after the introduction of the export-oriented economy in Malaysia. Islamic laws and customs determine women's traditional role in the Malay society. The strong kinship culture, like that of the Philippines, also dictates that economic production should be directed towards the betterment of the family rather than oneself (Karim, 1992). Women have always been economically active in Malaysia, however, the definition of work (among women) has been changing since the inception of the export-oriented industrialization.

\subsubsection{Religion and Malay women}

The ethnic differences between the Chinese, Indians, and Malays led to differences in cultural practices. Although most Malaysians are Muslim, the Malaysian culture is very diverse because of the significant population of immigrants. The early history of Malaysia depicts it to be a mostly agricultural society where women were also involved in the economic production. The concept of adat, which means "customary practices" mostly adopted and understood by the Malays, is a pan-Asian concept influenced by Hinduism, Buddhism, and Confucianism (Juhary, 2011, p. 281). This concept is important in situating the position of women in the Malay society: 
"The most obvious characteristic of adat in the context of matters relating to land, economics, kinship, and marriage is its overall pervasive norm of 'bilaterality' of reducing hierarchical differences based on gender" (Karim, 1992, p. 5). The concept of adat is very much present among rural Malays in defining the gender roles even today.

In Malaysian context, women were never totally dependent on men for survival, although men traditionally enjoyed privileged positions from the religion and the customs. Malay interpretation of gender differentiation was more in terms of morality than biological make-up. The moral duty of the man was to be a guardian and protect the females within the household. Married women enjoyed more freedom than unmarried women. Unmarried women were confined within a short distance of home and were expected to keep their distance from kinsmen (Ong, 1990). The state-led development that targeted the Malay population absorbed a huge number of young, unmarried females into the workforce, and this challenged the customary practices in the Malay society.

The Islamic revival in Malaysia happened right after the government's adoption of stateled development based on the export industry. The increase in number of females in the labor market was challenging the economic roles of the men of the household (Sabbah, 1984). Further, the middle-class literate population also looked upon the modernization attempts as neo-colonial strategies. This assumption led to a popular movement called the dakwah movement. Dakwah, in Malay language, means missionary work in Islam (Oxford Islamic Studies Online, 2014). The dakwah movement spoke more to middle-class women than to the working-class women. The female university students were very much a part of this movement. The students identifying with this movement were adopting clothing choices that were more "Arabic" than Malaysian, like telekung (headscarves). Some even donned a hijab, signifying full purdah, a practice alien to 
historical Malay customs (Ong, 1990). Female dakwah lecturers also attacked working women for adopting consumerism promoted by factory work (Buang, 2002).

However, despite the Islamic revival, working class women were not affected as the new employment opportunities were allowing their households to earn much needed extra income. The customary practices and religion were promoting traditional virtues of young unmarried women as well as their obligations to the religion and duties to the custom. On the other hand, the modernization and rising value of monetary transactions encouraged economic ambition (Lie \& Lund, 1994). The appeal of modern society and the need for income led working-class Malay women to make the economically rational choice and take the opportunities provided by the export-led development.

\subsubsection{Colonial Influence on Traditional Gender Identities}

Traditionally, Malay women were part of the peasant class and were involved in the agricultural sector. Women who had access to land also cultivated vegetables and sold them at the local market. These rural women were also involved in processing fish for family consumption and sale; making handicrafts, women's clothing, and preparing food for sale; raising chicken and ducks for selling eggs and meat; and as street vendors and shop keepers (Firth, 1966; Strange, 1981). The introduction of the export-oriented economy based on manufacturing exposed rural Malay women to factory work.

Although British colonialists did not seek to influence the culture and tradition of the Malaysian state, their presence and economic policies influenced gender roles and identities within the household. The introduction of wage labor and Malaysia's participation in the international economy influenced the social and economic roles of women (Kaur, 1999). In her study of gender and labor relations in Malaysia, Kaur (1999) finds that the adoption of capitalist economy, under the colonial British government, led to the separation of labor by gender. In this 
separation of labor, women had no place within the capitalist market economy. The displacement of women from active labor force led to changing discourse on women's work. Crinis (2004) finds that "in the colonial records pertaining to labour Malay women are either invisible or regarded as part of the working family rather than as individual workers" (p. 34). The colonial discourse on women changed their role from active economic participant to an "institutionalized inactive reserve army of labour" (Kaur, 1999, p. 17). This degraded the position of women within and outside of household in the Malay society.

\subsubsection{Political Role of Women in Malaysia}

Unlike Bangladesh and the Philippines, Malaysia has yet to see its government headed by a woman. Despite rapid economic growth, Malaysia has been unsuccessful in incorporating women as equal citizens in the political realm of the country. The female representation in the politics does not add up to the level of economic development that Malaysia has achieved. Women occupy only $10.4 \%$ of the Lower House of the Parliament (Inter-Parliamentary Union, 2013). The most prominent female politician is Dr. Wan Azizah Wan Ismail. She is the head of the opposition party. Wan Azizah became the political voice of the opposition when her husband Anwar Ibrahim, the former Deputy Prime Minister of Malaysia, was arrested. After the arrest of her husband, "Wan Azizah has used her own as well as her husband's moral capital as an essential asset in her political strategizing and public image" (Derichs et. al, 2006, p. 246). In the hegemonic one-party system of Malaysia, Wan Azizah has been a prominent voice; however, her voice was given the political platform because of her kinship ties to her husband (Fleschenberg, 2004). Wan Azizah is a strong political personality who stood against the most powerful man in the Malaysia, former Prime Minister Mahathir Mohamed, using her morality and Islamic values. Like many of her South and South-east Asian counterparts, she, too, was forced into the political game. She took the role by making the injustice to her husband her cause (Derichs et al., 2006). 
Wan Azizah's style of politics is based on her religious faith, and she seeks to practice politics within the boundaries of her faith. In an interview, she identified herself to be a mother first, then a wife, and only then a citizen. Her politics are not vocal about changing the society and extending the rights and equality to the minority population (Derichs et al., 2006). Considering this, it will be fair to say that Malaysia still has a long journey to recognize and establish gender equality in all aspects of Malaysian society. Wan Azizah's choice to drive her politics by her faith perhaps explains the only context in which women are accepted in the political platform.

\subsubsection{Economic Roles of Malay Women in the Export-oriented Factories}

With the adoption of the NEP in the 1970s, the government sought to increase the participation of the rural Malays in the industrial sector. The huge amount of investment pouring in the country for the manufacturing of electronic and electrical $(\mathrm{E} \& \mathrm{E})$ industry and the textile industry quickly targeted the young Malay women as the preferred work force. The Malaysian state also took an active role in promoting women as a resource to the export industries. The quote below outlines the statement from a government-sponsored investment brochure intending to attract FDI by advertising female labor:

The manual dexterity of the Oriental female is famous the world over. Her hands are small and she works with extreme care. Who, therefore, could be better qualified by natured and inheritance to contribute to the efficiency of a production line than the Oriental girl? (Ehrenreich \& Fuentes, 1983, p. 16)

The export-oriented manufacturing was highly encouraged by the government, with benefits like $100 \%$ foreign equity investment. This was predominantly done to prompt rapid economic growth and mass employment of rural Malay workers in the urban-industrial sector (Lim \& Fong, 1991). The state identified this as a new opportunity to empower women but the trade and investment perspective purely drove its interest in women's empowerment (Mohammad \& $\mathrm{Ng}, 2013$ ). With new opportunities of earning income, women in rural Malaysia saw employment in EPZs as a 
potential way to contribute to the family income. Tying this opportunity to the duty of being a good daughter, young, rural Malay women made themselves available as laborers in the exportoriented factories. Lie and Lund (1994), in their study of foreign owned companies in one of the Free Industrial Zones (FIZs) of Malaysia, found that women initially only saw this prospect as temporary and as a venue to socialize with other girls of the same age. The reason behind this was because girls were expected to get married in their early twenties, and after that, only tend to the needs of their families.

The recruitment was completely based on the sex and age of the workers. It determined who would be hired for what kind of work. The young female workers were targeted as preferred workers and this led to feminization of labor in the electronic industry (Safa, 1983). By 1993, $75 \%$ of the total labor force in the electronic industry was female, and of that, $63 \%$ were Malay (Migration News, 1995).

Despite the increase in the female labor participation, mostly of young girls between age 16 and 25 (Daud, 1985), factory work was a highly disputed topic in Malaysia. Parents were often reluctant to allow their daughters to be the part of the workforce, as girls working in the factories were often accused of being immoral and sexually permissive (Ackerman, 1980; Daud, 1985; Wichterich, 1994). The industries' preference for young girls, the treatment of the factory job as a temporary work by young women, and the controversy related to being a women working in the factory, all tallied to make this preferred and cheap labor more scant. The chart below highlights the ethnic division among female workers in the manufacturing. The high demand for cheap labor led Malaysia to import migrant workers mostly from Indonesia, followed by Nepal, Bangladesh, and other South Asian and South-east Asian countries. 
Figure 12: Percentage of female by ethnic group in Manufacturing, 2012

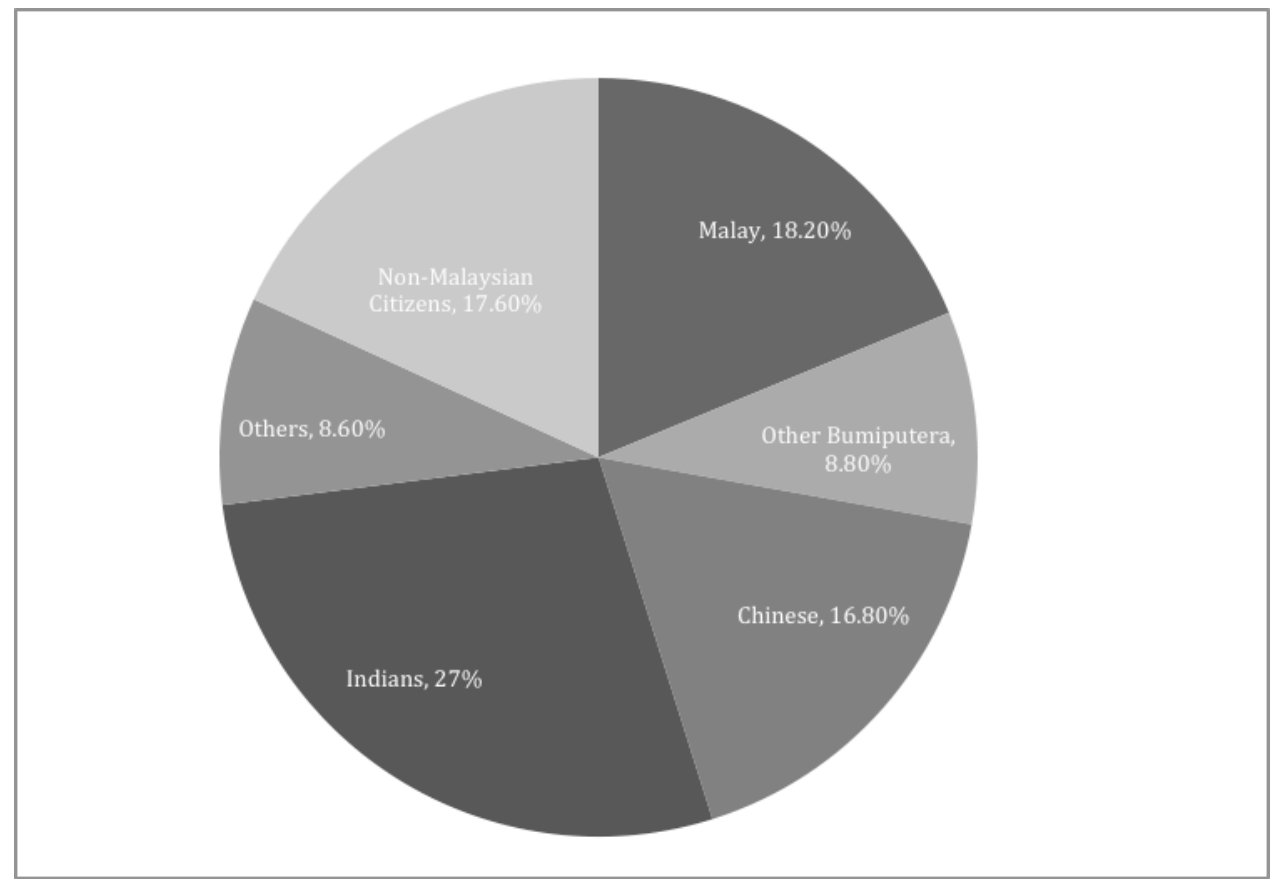

Source: Department of Statistics, Labor Force Survey 2012

\subsection{Migrant Workers in Export-Oriented Factories}

Importing labor is not a new phenomenon in Malaysia. The Chinese migrant labor force that migrated to Malaysia since before the colonization now makes a significant part of the Malaysian population. The Indian migrant labor force introduced by the British is also a substantial part of the Malaysian population today. With the increase in investment and rapid industrialization, Malaysia was in constant need of cheap labor as demanded by the exportoriented industries. As the country started to do better in the economy, it started to invest more in human development. This investment led to an increase in a more skilled and educated labor force that was not so cheap. By the 1990s, factory jobs were well paying with good working conditions. This was mainly because of decreasing labor reserve (Rudnick, 2009). The skilled labor was not fitting the need to be employed in the low level and low-paying jobs. This led to decreasing labor reserve of unskilled workers. The decreasing supply led to an increase in 
demand, and thus the cost of the labor increased in Malaysia. To address this demand for cheap labor, Malaysia started recruiting foreign labor.

\subsubsection{Female Migrant workers}

Malaysia's growth under the export-oriented economy was mostly built on manufacturing industry. The two major exports of Malaysia were clothing and electronic equipment. The garment industries were introduced in Malaysia after the adoption of export-oriented economy. Under the MFA, introduced in 1974, the Malaysian garment industry flourished. The MFA imposed quotas on the amount of textile and clothing products that the developing countries could export to the developed countries (World Trade Organization, 2014). By the end of the MFA in 2004, the industry's export amounted to US \$2.5 billion and was the sixth largest contributor to the total earning from manufactured exports (Crinis, 2010). The trade liberalization of the late 1990s and the termination of the MFA have resulted in increased competition in the garment industry. With this increased competition, Malaysia is constantly struggling to retain the investment in the sector. Some of the manufacturers have been able to retain the investment by using high levels of technology for top end sportswear industry. The government has also supported this initiative by the companies and has granted incentives like import concessions for inputs to the factories that are investing in cutting edge machinery and training (Crinis, 2010). However, this has not been enough and in order to keep the cost of production low for other factories, the government had to rely on the import of migrant workers in the sector.

Most of the male migrant workers in Malaysia are concentrated in the construction, agriculture, fisheries, and small manufacturing industries. Most of the female migrant workers are in care industry and domestic help industry. In the manufacturing sectors, the female migrant workers are concentrated in the garment industry (Piper, 2006). In 2011, Malaysia registered 
over 2.3 million migrant workers (War on Want, 2012). Over 50\% are undocumented and unaccounted migrant workers (Piper, 2006; Rudnick, 2009; Crinis, 2010). Almost 40\% of the migrant workers work in the manufacturing sector (War on Want, 2012). It is estimated that 300,000 migrant workers work in the electronics industry, in where $70-80 \%$ of the workers are women (Bormann et al., 2010). The garment industry also employs 68,000 migrants, where the majority are women (Malaysian Investment Development Authority, 2014). These numbers show that the Malaysian export industry, despite the economic advancement, is still driven by the availability of cheap labor of women workers. The only difference is that today, the female workers are now imported to bolster to the export-oriented economy and to ensure the inflow of FDI. The Malaysian state is thus, importing the cheap female labor from poorer countries to cater to the low labor cost demands from the MNCs.

\subsection{Export Oriented Economy and FDI in Malaysia}

The infrastructure for a successful export-oriented economy in Malaysia was built during the colonial rule. The British government's intention in colonizing the region was to support the growth of the British trade, and with this mission Malaysia was established to be an exportoriented economy. This strategy was adopted by post-colonial Malaysia and was bolstered by different policies enacted to support the growth of the export-oriented economy.

The enactment of NEP in 1970 initially tried to curb the dependency on export and encouraged import substitution (Salleh \& Meyanathan 1993; Rashia \& Shari, 2001). The export industries at the time were encouraged in export manufacturing-particularly in electronics and textiles. Between 1970 and 1985, the Malaysian state was more concerned about inequality among the economic participants in the society. The state had just decolonized and was struggling to build a national identity among the diverse population. Thus, the economic policies 
were geared towards this purpose (Lie \& Lund, 1994). The foreign investment policy at the time was only incentivizing the export-oriented industry. These industries were allowed $100 \%$ ownership, and those that were categorized as pioneer industries were exempted from corporate and development tax for five to ten years, depending on criteria like capital invested, jobs created, location, etc. (Lim \& Fong, 1991). The chart below highlights the FDI inflow in Malaysia since 2007.

Figure 13: Global FDI Inflows in US\$ Billions

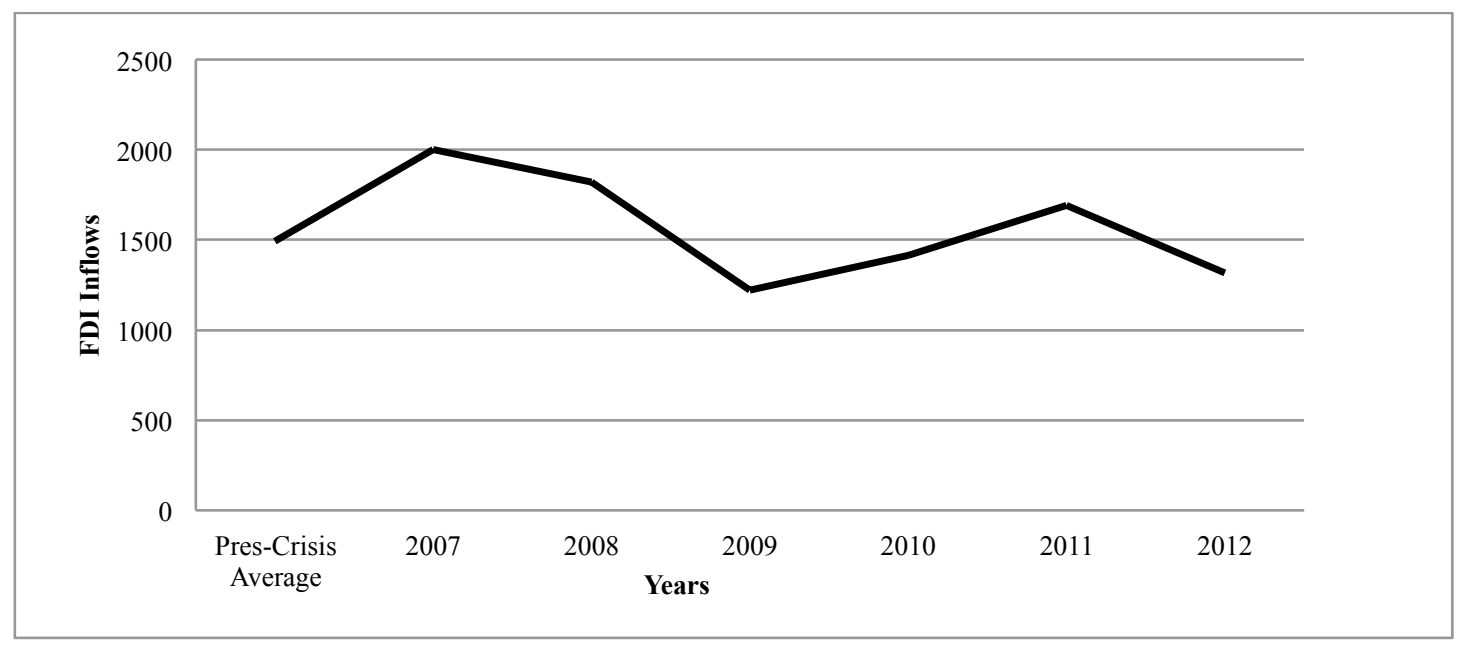

Source: MITI, Malaysia Investment Performance Report, 2014

The recession of the late 1980s led to government budget and balance of payment deficits and foreign investment and external borrowing declined. This led to a new policy, widely known as the Promotion of Investment Act (PIA) of 1986, which replaced the Investment Incentives Act of 1968. This policy exempted income and development tax for companies involved in manufacturing new products, or initiating modernization, expansion, and/or diversification of the manufacturing (Rasiah, 1995; Sundaram \& Gomez, 2000). Since the introduction of the PIA in 1986, export-oriented investment has dominated the economy. FDI has been an important part of Malaysia's economy since then. 
The industry that took a huge foothold in the Malaysian economy since the adoption of the PIA was E\&E. The table below highlights the incentives offered by the Malaysian Industrial Development Authority (MIDA) for FDI. The incentives granted by the PIA extend the pioneer status from the Investment Act of 1968, and it also allows Investment Tax Allowance (ITA) as per the status of the companies. These incentives are directed to attract FDI in the country.

Table 20: Incentives through MIDA for FDI in Electrical and Electronics, Petrochemicals and Oleo-chemicals, Food and Agro Processing, and Biotechnology

\begin{tabular}{|l|l|l|}
\hline Status & Pioneer Status & Investment Tax Allowance \\
\hline General & $\begin{array}{l}5 \text { years Pioneer } \\
\text { Status and tax } \\
\text { exemption at } 70 \% \\
\text { of statutory } \\
\text { income }\end{array}$ & $\begin{array}{l}60 \% \text { ITA on qualifying capital expenditure incurred within } 5 \\
\text { years and can be set off against } 70 \% \text { of statutory income }\end{array}$ \\
\hline $\begin{array}{l}\text { High Technology } \\
\text { Projects }\end{array}$ & $\begin{array}{l}5 \text { years Pioneer } \\
\text { Status and tax } \\
\text { exemption at } \\
100 \% \text { of statutory } \\
\text { income }\end{array}$ & $\begin{array}{l}60 \% \text { ITA for } 5 \text { years and can be set off against 100\% of } \\
\text { statutory income }\end{array}$ \\
\hline $\begin{array}{l}\text { Strategic and } \\
\text { Prepackaged }\end{array}$ & $\begin{array}{l}10 \text { years Pioneer } \\
\text { Status and tax } \\
\text { exemption at } \\
100 \% \text { of statutory } \\
\text { income }\end{array}$ & $\begin{array}{l}100 \% \text { ITA for } 5-10 \text { years and can be set off against } 100 \% \text { of } \\
\text { statutory income }\end{array}$ \\
\hline
\end{tabular}

Source: Iskander Regional Development Authority, 2014

\subsubsection{Type of FDI: Electronics and Electrical (E\&E) Products}

The Malaysian economy has depended on foreign investment for a long time in its development history. During the colonial times, the British structured the Malaysian economy to suit the interests of the British investors. The British and other foreign investors heavily invested in the rubber and tin industry in Malaysia. Post-colonization, after a failed attempt at import substitution, Malaysia geared towards a modern export-oriented economy to cover the deficits incurred during the period of import substitution.

The economic liberalization policies that Malaysia adopted during the 1970s led to the influx of FDI in the country. With the introduction of FIZs and Licensed Manufacturing 
Warehouses (LMWs), Malaysia provided the MNCs with incentives along with cheap labor and political stability, which was not very common in the region at the time (Lie \& Lund, 1994). Most of the investment that flooded the market was in the manufacturing of electronics. In present day too, E\&E industry attracts most investment.

Table 21: Main Industries with export-oriented projects, 2013

\begin{tabular}{|c|c|c|}
\hline Project & No. of projects & Total Investment (RM bil) \\
\hline E\&E & 60 & 7.4 \\
\hline Petroleum products including petrochemicals & 4 & 4.1 \\
\hline Basic Metal Products & 11 & 3.7 \\
\hline Scientific and measuring equipment & 14 & 1.0 \\
\hline Food manufacturing & 23 & 3.3 \\
\hline
\end{tabular}

Note: 1 US\$=3.21 RM

Source: Malaysian Investment Development Authority, 2013

In the 1970s, Malaysia became the world's largest exporter in the electronic industry and third largest producer of semiconductors. During this time the electronic industry in Malaysia grew at an average of $13.3 \%$ annually (Lim \& Fong, 1991). Today as well, the E\&E industry tops the chart when it comes to investment from FDI. Within the E\&E industry, most of the investment is invested on the production of electrical products, which includes household appliances and lighting equipment (Ipsos Business Consulting, 2012). According to the Ministry of International Trade and Industry (MITI), the E\&E sector employed 322,607 people in 2012.

The literature finds that rural Malay women were the preferred work force in Malaysian E\&E industries (Safa, 1983; Lim \& Fong, 1991; Lie \& Lund, 1994; Bormann et al., 2010). But as the economy has improved, the price of labor in Malaysia has also increased. This has led to dearth of cheap labor once supplied by rural Malay women. Women still make up approximately $70 \%$ of the workforce in the E\&E industry (Bormann et al., 2010). However, because of low wages, restriction on joining unions, and harsh working conditions, there is a high turnover rate among local employees. 
Figure 14: Foreign Investment in Approved manufacturing projects (major industry), 2013

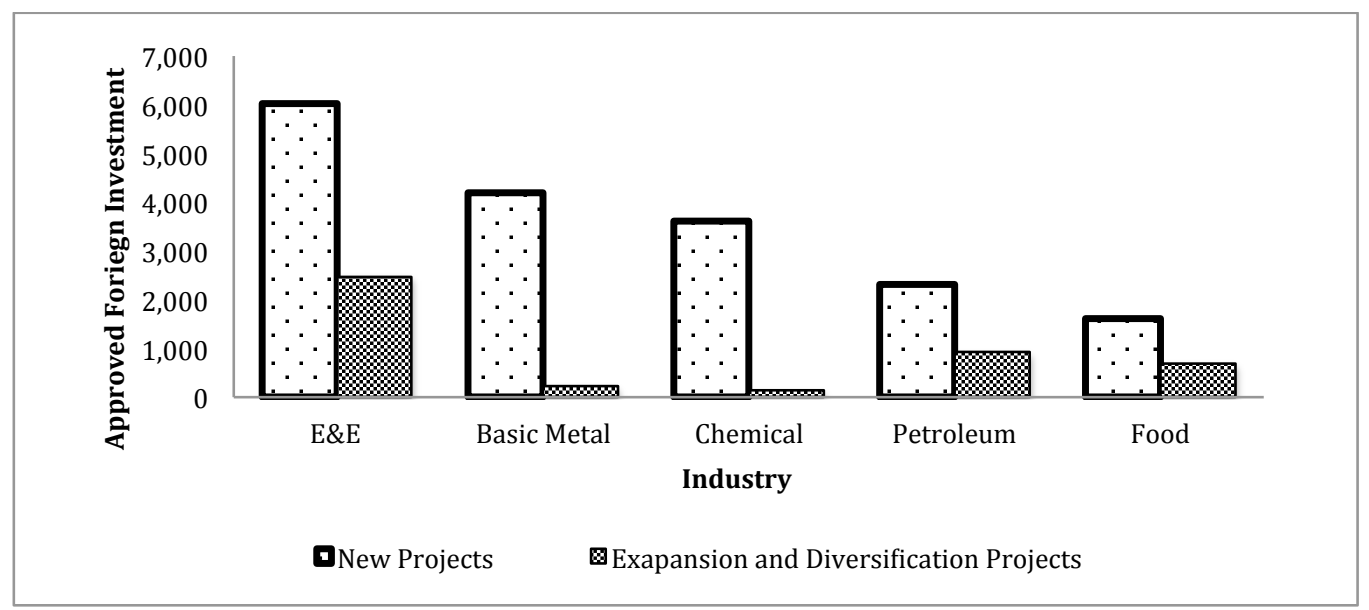

Source: MIDA Investment Performance Report, 2013

This has led the industry to employ more migrant workers in recent years (Bormann et al., 2010; Richard \& Henderson, 2009). Thus, the E\&E industry in Malaysia is flourishing on the unregulated labor of powerless female migrant workers. In order to maintain the low cost of labor, Malaysia adopted flexible labor policies that were barely regulated. The following section highlights factors explaining the ineffective labor regulation in Malaysia.

\subsection{Determinants of Less Regulation of Labor in Export-oriented industries in Malaysia}

\subsubsection{Development Level}

Malaysia's mission for rapid development has been aided by the institutionalization of the export-oriented economy. During the colonial era, the British government laid a solid foundation for the export-oriented economy. The British were able to convince many foreign investors to invest in the area by advertising the profits to be earned from the commodities, like tin and rubber. In order to attract more investment, the British also focused on building infrastructure such as railways and roadways. 
Malaysia's development in the post-colonial era has been based in the export-oriented economy that the British institutionalized; the only difference was instead of tin and rubber Malaysia was now seeking rapid development via heavy export-based industrialization. As Malaysia promoted itself to be a suitable environment for FDI, investment flooded the Malaysian market. Malaysia since then has established itself as one of the prominent choices for FDI.

Figure 15: GDP growth (\% Annual), 1980-2010

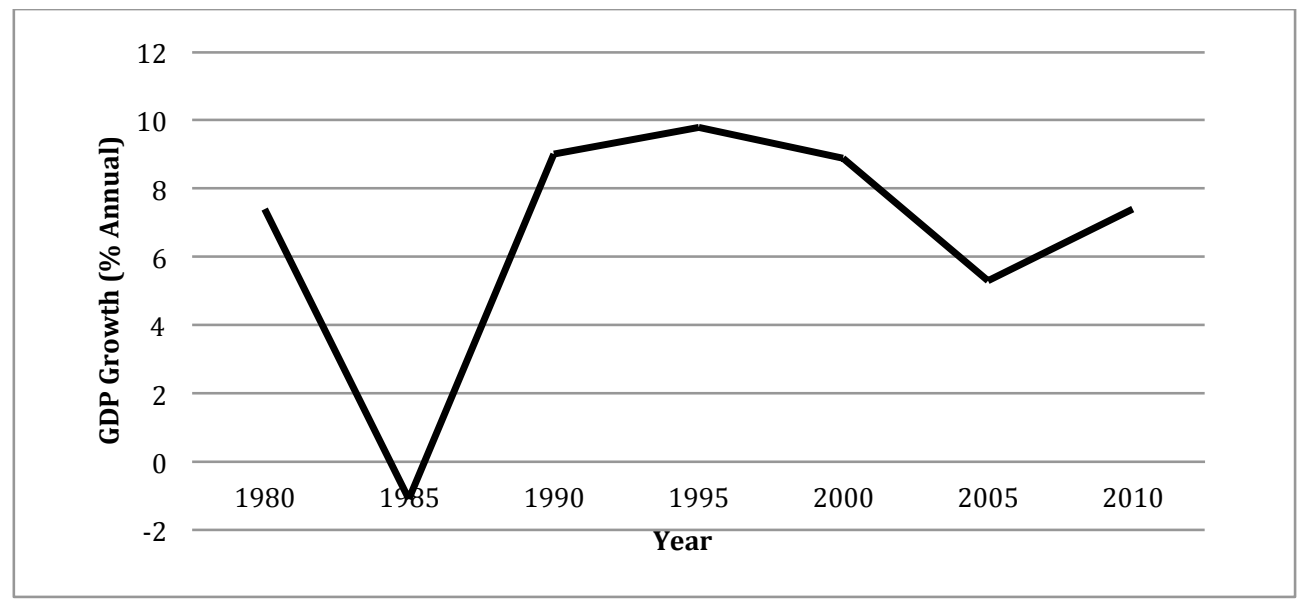

Source: The World Bank, 2013

FDI has played a significant role in driving the economic development in Malaysia. The solid economic performance has led Malaysia to successfully tackle the problem of poverty among its citizens. In 2009, the poverty gap in Malaysia, at \$2 a day, was only $0.2 \%$ (The World Bank, 2013). However, inequality in income persists in the Malaysian society. More than half $(51.5 \%)$ of the total income of the country is shared by the highest $20 \%$ of the population.

The figure below highlights the exports of good and services as a percentage of GDP for Malaysia. The figure clearly establishes that Malaysia is extremely dependent on export for achieving its development goal. The export of goods and services (as percentage of GDP) has reduced from $115.4 \%$ in 2004 , to $87.1 \%$ in 2012 . The exponential growth in the export-oriented economy, as well as the development of the country, has indeed been commendable in the case 
of Malaysia. Along with the achievement of economic development, Malaysia has invested in its human capital to produce a semi-skilled labor force.

Figure 16: Exports of goods and services (\% of GDP), 1970-2012

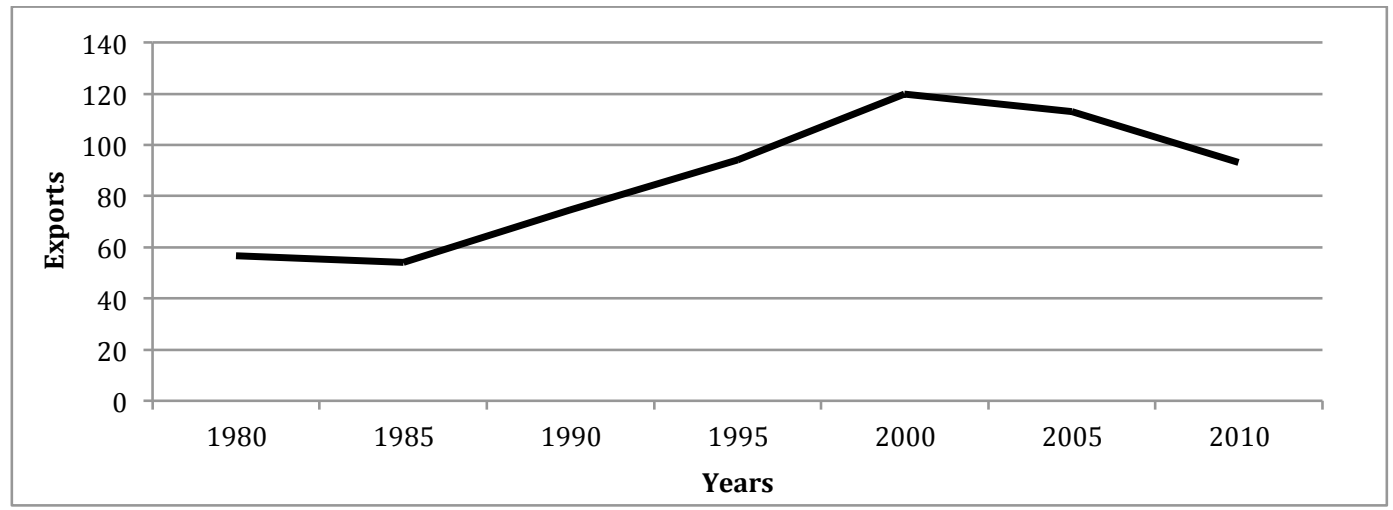

\section{Source: The World Bank, 2013}

With the production of a skilled and educated labor force, the wages in the country have increased, leading to a scarcity of cheap labor. This has led Malaysia to import immigrant labor to cater to the demand of cheap labor. The powerless immigrant labor is bound by restriction to unionize in their contracts, allowing Malaysia to keep their repressive union laws. Further, none of the labor protection policies are directed to the safety of the immigrants deliberately by the Malaysian state, including ILO’s protocol to protect migrant workers. It can thus be suggested that the Malaysian state, along with the MNCs, is an active participant in repressing economic rights of female workers in the export-oriented industries.

\subsubsection{Skill Level of the Labor Force}

Malaysia has been often exemplified as one of the success stories in the region. With increasing wealth and rising middle class, Malaysia has successfully achieved developmental goals like poverty elimination. The GDP has increased significantly since the country's attempt to develop. However, this rise in the middle-class has cost Malaysia its cheap female labor. 
The rise in GDP has also led to an increase in investment in other economic sectors like service, and wholesale and retail industry. Malaysians now have better economic and employment options than they used to. This has led to a high turnover rate among Malaysians working in the manufacturing industry. The rising number of middle class in the rural areas has led to the dearth of the cheap labor force, increasing the demand for low-cost labor.

Figure 17: Number of Poor households by rural/urban locations, 1990-2009 (in thousands)

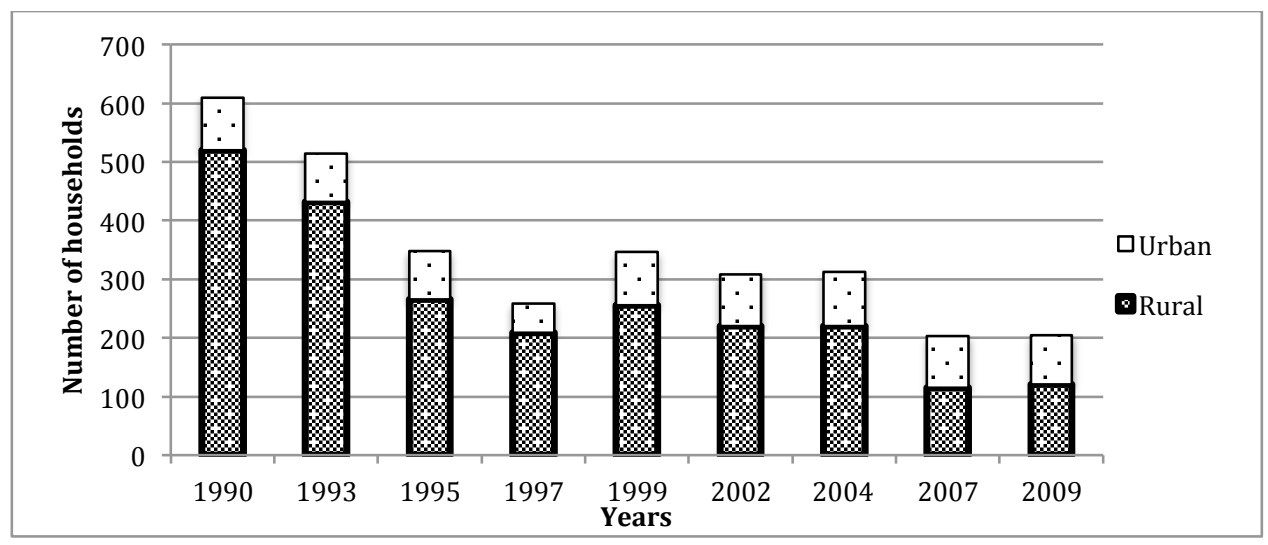

Source: United Nations Country Team Malaysia, 2011

Despite the rise in income of Malaysians, Malaysia still lacks a skilled labor force that is needed for the industries based in the country. Malaysia has been identified as one of the countries that are suffering from the "middle income trap" (Kanapathy \& Hazri, 2014). This condition refers to the risk that countries that achieved rapid economic growth via low-wage, low skilled labor, low value manufacturing, and export-oriented economy are facing as they stagnate at the middle-income level and fail to advance to upper income level. This has been partly because of the emigration of skilled labor force of Malaysia. With the historical and unequal preference for the ethnic Malay group, strengthened by the NEP, the skilled laborers of other ethnic groups are choosing to migrate to neighboring Singapore for better and more equal opportunities (Lim \& Fong, 1991; Kanapathy \& Hazri, 2014; Lee \& Ho, 2010). Moreover, the hostile immigration rules drafted mainly to control the unskilled labor supply from poorer 
countries has also led to diminish the pull factor for a skilled labor force. Malaysian citizens with foreign spouses face arbitrary and discriminating rules under the current immigration system. This has led many skilled workers to stay in other countries that they have migrated to (Lee \& Ho, 2010).

Despite this risk, Malaysia is more concerned currently about the lack of cheap labor in the country. The high turnover rates among the local workers, mostly female, in the exportoriented factories like electronics and garment are often associated with harsh working conditions and low pay (Lee \& Ho, 2010; War on Want, 2012). The state's concern in maintaining the supply of cheap labor of migrant workers has led to heavier restriction and weaker protection of workers in the export sector. Therefore, it will be fair to argue that despite the increase in the skill level of workers, the aggressive demand for cheap labor fulfilled by the imported labor has made it easier for the state to keep repressing labor and human rights of female migrant workers in the export-oriented industries.

\subsubsection{Civil Rights and Civil Liberties}

Malay culture is dictated by kinship values that are a significant part of the Asian culture. When it comes to the idea of freedom and liberties, Asian cultures have only been introduced to it via either colonization or normalization of these concepts in the international politics. Asian cultures value community over the individual, and this is very much the case in Malaysia (Yum 1988). This value has, in fact, led to a weaker working class in Malaysia. Since the communities in Malaysia are defined in terms of ethnic identities, the working class identity is more of an individual identity than a communal identity (Caspersz, 1998). Asian cultures also value economic development over political and civil rights (Manan, 1999). Malaysia is a classic example of this. Malaysia's political goals are determined via economic development goals. This has led to repressive laws that curtail personal liberties. 
The right to freedom of religion is constantly challenged in Malaysia. Practicing any other version of Islam outside of Sunni is not popular and is restricted. Practitioners of other religions are not easily permitted to build houses of worship, and the government retains the right to demolish them if they do not have the correct government permits. Academic freedom is restricted and teachers that engage in questioning the government or encourage such sentiments are subject to disciplinary actions. Formations of any civil organizations are subjected to the Societies Act of 1996, which can restrict the formation of any organization that questions the state's action. While there are a number of NGOs that operate in Malaysia, some international organizations are not allowed to operate officially via branch offices in Malaysia (Freedom House, 2013).

The table below highlights the freedom in Malaysia based on scores assigned by the Freedom House.

Table 22: Civil Liberties Rating, Political Rights Ratings, and Press Freedom Score of Malaysia, 2002-2012

\begin{tabular}{|c|c|c|c|}
\hline Years & $\begin{array}{c}\text { Civil Liberties } \\
\text { (1=best, } 7=\text { worst })\end{array}$ & $\begin{array}{c}\text { Political Rights } \\
\text { (1=best, } 7 \text { = worst })\end{array}$ & $\begin{array}{c}\text { Press Freedom } \\
\text { (0=best, 100=worst) }\end{array}$ \\
\hline 2002 & 5 & 5 & 71 \\
\hline 2003 & 5 & 5 & 69 \\
\hline 2004 & 4 & 5 & 69 \\
\hline 2005 & 4 & 4 & 65 \\
\hline 2006 & 4 & 4 & 68 \\
\hline 2007 & 4 & 4 & 65 \\
\hline 2008 & 4 & 4 & 65 \\
\hline 2009 & 4 & 4 & 64 \\
\hline 2010 & 4 & 4 & 64 \\
\hline 2011 & 4 & 4 & 63 \\
\hline 2012 & 4 & 4 & 71 \\
\hline
\end{tabular}

Source: Freedom House, 2013 
Freedom of the press is also highly restricted. Journalists are often subjected to arbitrary arrests or threats of legal actions. While physical harassment of journalists have not been an issue in Malaysia, it has been elsewhere:

several instances of physical harassment were noted in 2012, including attacks on two journalists in Penang who were covering a public protest against the construction of a rare-earth-metals plant in the state of Pahang by Australian mining company Lynas Corporation (Freedom House, 2013).

These scores in the table above highlight that during the past 10 years not much has changed when it comes to civil liberties, political rights, and the freedom of press despite the increase in wealth.

Violence against women is punishable by law, however, patriarchal mindsets in institutions like police force results in many such offences being not reported. Female Genital Mutilation is enforced on Muslim women by Fatwa Committee of the country's National Council of Islamic Religious Affairs (U.S. Department of State 2013). Malaysian women are minority in the labor force and most of the labor in manufacturing especially in textile and E\&E industry is provided by female migrant labor. Migrant workers are often exposed to forced labor through practices like confiscation of passport, withholding of wages, and debt obligation to employers and recruitment agents (U.S. Department Of State 2014). The Malaysian government relies on the cheap labor of female migrant workers in expanding its export-oriented economy and thus, shows no interest in enacting labor policies to protect the migrant labor. With such poor records in protecting the rights of its citizens, it is fair to submit that Malaysia's lack of regulation of female migrant labor in the export-oriented industry is not surprising.

\subsubsection{Corruption}

The kinship culture and advantageous status of Malays, as bolstered by the NEP, has led Malaysia to perform poorly in dealing with corruption: "Economic policies associated with the 
perceived need to maintain a balance between ethnic groups and to privilege ethnic Malays created wide scope of deal-making and feeding pervasive patronage system" (Kanapathy \& Hazri, 2014, p.16). The governing authorities adopt oligarchic policies whereby access to power is limited to only a certain groups of elites.

Corruption in Malaysia can be tied to enmeshed interests between corporate and public realms. The revolving door is an existent practice in Malaysia, whereby people are constantly switching work between public and private agencies. This also leads to more corrupt institutions, as it is more likely that people will use the public office to gain the private interests. This also allows for acts of corruption without impunity. Malaysia's record in tracking corruption has not been very good. The table below highlights the CPI of Malaysia; it gives us an idea of the level of corruption in the country. The CPI scores shows that Malaysia is not considered a country with clean records.

Table 23: Corruption Perception Index Rankings and Score, 2001-2011

\begin{tabular}{|c|c|c|c|}
\hline Year & Ranking & $\begin{array}{c}\text { Score } \\
\text { (0= highly corrupt } \\
\mathbf{1 0 =} \text { very clean })\end{array}$ & No. of Countries \\
\hline 2001 & 36 & 5.0 & 91 \\
\hline 2002 & 33 & 4.9 & 102 \\
\hline 2003 & 37 & 5.2 & 146 \\
\hline 2004 & 39 & 5.0 & 159 \\
\hline 2005 & 39 & 5.1 & 163 \\
\hline 2006 & 44 & 5.0 & 180 \\
\hline 2007 & 43 & 5.1 & 180 \\
\hline 2008 & 47 & 5.1 & 178 \\
\hline 2009 & 56 & 4.5 & 182 \\
\hline 2010 & 56 & 4.4 & 4.3 \\
\hline 2011 & 60 & & \\
\hline
\end{tabular}

Source: Transparency International, 2014 
The concentration of power in one executive for 22 years has strengthened the executive branch with unchallenged authority. The media is tightly controlled and any challenges to the executive are addressed with draconian measures (Kanapathy \& Hazri, 2014). Heavy corruption in government including in high-level offices have deterred numerous government led measures to curb corruption (Quah, 2006; Freedom House, 2013).

Malaysia is also one of the few countries that allow political parties to possess corporate enterprises (Transparency International, 2014). This provision increases the likelihood of grand corruption where corporate interests drive the political ambition of the leaders and representatives of the political parties. The loose regulation of labor along with repressive laws on unionizing and against migrant workers can be explained through these provisions that allow corporate interests a better and bigger platform to represent their political interests than the labor of the country.

\subsubsection{Pressure for Corporate Social Responsibility (CSR)}

Malaysia is one of the countries that has been doing relatively better economically when compared to other countries in the region. With this successful stature, Malaysia seeks to be an example of a success story for other developing countries in the region. This goal is motivated by the need to enhance the government's image in the global arena and gain admission to elite groups in the USA, European countries, and Japan for better access to economic resources and support for developmental programs, and to be a part of the global trend (Amran \& Devi, 2008). Thus, the Malaysian government is active in encouraging CSR among the corporations in Malaysia.

CSR in developed countries have often been attributed to legislations, media and social activism, consumer awareness, and politics (Deegan, 2002). In the case of Malaysia, a rising trend in practice of CSR has been noted since the beginning of the millennium. The companies 
actively report their CSR practices (KPMG, 2002; ACCA, 2002). The national government has associated the CSR practices with adoption of sustainable development practices (Amran \& Devi, 2008). While there is an increase in the publications of these CSR efforts by the company, it has been found that these are just references to general commitments and are declarative and narrative in nature (Nik Ahmad \& Sulaiman, 2004; Thompson \& Zakaria, 2004).

Table 24: Summary of Disclosure in Malaysian CSR Reports, 2000

\begin{tabular}{|l|l|l|l|l|}
\hline \multirow{2}{*}{ Characteristics } & \multicolumn{2}{|c|}{ Companies } & \multicolumn{2}{c|}{ Sentences } \\
\cline { 2 - 6 } & Number & Percentage & Number & Percentage \\
\hline Theme & 42 & 16 & 1,296 & 7 \\
\hline Environment & 2 & 1 & 39 & 1 \\
\hline Energy & 116 & 45 & 4,254 & 24 \\
\hline Products and consumers & 83 & 32 & 3,819 & 22 \\
\hline Community & 83 & & \\
\hline Employees and Human Resources & 27 & 11 & 770 & 4 \\
\hline H\&S & 211 & 82 & 7,142 & 40 \\
\hline Others & 238 & 93 & 7,192 & 45 \\
\hline Total & 13 & 5 & 348 & 2 \\
\hline General & & \multicolumn{5}{|l|}{} \\
\hline Total & \multicolumn{5}{|l|}{17,668} & 100 \\
\hline Evidence & 134 & 52 & 2,286 & 13 \\
\hline Monetary Quantification & 149 & 58 & 6,584 & 37 \\
\hline $\begin{array}{l}\text { Non-monetary } \\
\text { quantification }\end{array}$ & 138 & 54 & 8,798 & 50 \\
\hline Declarative & & & 17,668 & 100 \\
\hline Total & & & \\
\hline Source Thaps & \\
\hline
\end{tabular}

Source: Thompson and Zakaria, 2004

The table above highlights the disclosures made by the corporations in Malaysian CSR

Reports. It is clear from the table that "employees and human resources" tend to have more coverage in the reporting, followed by "products and services," and then "community." The table 
supports the claim that CSR is more than practical; the monetary contribution towards CSR is not significant. Nevertheless, CSR in Malaysia has been attributed to various factors. One study (Haniffa \& Cooke, 2002) found that institutional pressures like corporate governance structure influence the structure of CSR and it's reporting. The study finds that family-operated companies (with more family members on the board) are less likely to practice CSR. Further, they find that companies that have designated one of the executive directors as a chairperson are more likely to disclose their CSR than those with a chairperson outside of the executive directors (Haniffa \& Cooke, 2002).Abdul and Ibrahim (2002) examined the perspectives of executives and management on the ideas of CSR. They found that these perspectives were lacking and misleading. The table below highlights their findings.

Table 25: Management's Attitudes towards CSR in Malaysia

\begin{tabular}{|l|l|l|}
\hline Attitudes towards Corporate social Responsibility & $\begin{array}{l}\text { Agree 2001 } \\
\mathbf{( \% )}\end{array}$ & $\begin{array}{l}\text { Agree 1991 } \\
\mathbf{( \% )}\end{array}$ \\
\hline $\begin{array}{l}\text { Socially responsible corporate behavior can be in the best economic } \\
\text { interest of the shareholders }\end{array}$ & 62.1 & 82.6 \\
\hline $\begin{array}{l}\text { Efficient production of goods and services is no longer the only thing } \\
\text { society expects from the business }\end{array}$ & 53.5 & 72.7 \\
\hline $\begin{array}{l}\text { Corporations are social institutions and as such must live up to } \\
\text { society's standards }\end{array}$ & 56.6 & 68.2 \\
\hline $\begin{array}{l}\text { Business already has too much social power and should not engage in } \\
\text { social activities that might give it more }\end{array}$ & 33.8 & 55 \\
\hline $\begin{array}{l}\text { Business managers are trained to manage economic institutions } \\
\text { (companies) and not to work effectively on social issues }\end{array}$ & 35.9 & 51.9 \\
\hline $\begin{array}{l}\text { A company that ignores social responsibility can obtain a competitive } \\
\text { advantage over a company that does not }\end{array}$ & 42.9 & 70 \\
\hline
\end{tabular}

Source: Abdul and Ibrahim, 2002

While $82.6 \%$ of respondents agreed to the statement that "socially responsible corporate behavior can be in the best economic interest of the shareholder" in 1991 , only $62.1 \%$ agreed to 
it in 2001. To the statement that "efficient production of goods and services is no longer the only thing society expects from the business," only $53.5 \%$ agreed in 2001 as compared to $72.7 \%$ in 1991. This shows that executive and management attitudes are getting worse rather than better. However, the respondents to the negative attitude towards CSR, such as "business already has too much social power and should not engage in social activities that might give it more," are declining from 55\% agreement in 1991 to only $33.8 \%$ agreement in 2001 .

While there are not many studies conducted to study corporate attitudes of MNCs and their management, judging by the CSR culture in Malaysia, it will be fair to assume that MNCs also practice CSR to an equal extent of Malaysian corporations. However, considering that most of the immigrants and women working in the manufacturing sector (especially in $\mathrm{E} \& \mathrm{E}$ companies) are working for MNCs, MNCs might score lower in CSR practices than local corporations. It is clear that while the Malaysian state is adopting CSR vigorously and even advocating for it, there is space for improvement when it comes to implementations of CSR. Further, while the Malaysian state is claiming to create a more just economic society by 2020 and making businesses a part of this venture, it will not be able to reach this goal unless it starts to treat the migrant workers better and allow them to be a part of a more democratic culture; thus, more pressure for CSR might lead to stronger legislation for an effective regulation of labor.

\subsubsection{Bureaucratic Capacity}

Malaysia is one of the few countries in Asia that has been able to rise up quickly in the development ladder. Malaysia's record in development has been praised time and again in the international context (UN Country Team Malaysia, 2011). For Malaysia to reach the Vision 2020 goals of becoming a developed country by 2020, Malaysia must have a strong civil service. The history of Malaysian civil service is rooted in the colonial era. During the colonial era, the 
Malaysian Administrative Service (MAS) was established as a public service body. However, the recruitment of public servants during this time was exclusively offered to males and Malays with aristocratic backgrounds (Terzzini, 2001). This Malayaisation of public servants has skewed the system to favor ethnic Malays in public service. The government jobs are still occupied mostly by ethnic Malays at $87 \%$ (Tjiptohrtijanto, 2012). In 1978, there was an effort to bring about a systematic change in the recruitment process. This effort was applied by introducing a meritocratic approach to recruitment of public servants. Applicants for public jobs were required to pass an exam in order to be eligible for public service (Ahmad, 1980; Ismail, 1980).

Since this change, Malaysian civil service has emphasized the importance of ethical guidelines for the civil servants. The National Integrity Plan (NIP) also instructs the establishment of good governance via three goals: "a) effectively reducing corruption, malpractice and abuse of power; b) increasing efficiency and the public delivery system and overcoming bureaucratic red tape; c) enhancing corporate governance and business ethics" (Tjiptohrtijanto, 2012, p. 5). The Malaysian government has also introduced the Public Service Transformation Framework (PSTF) that focuses on transforming the current system and building better human capacity (United Nation Country Team Malaysia, 2011). Known widely as a Transform program, this framework is designed to meet the goals of Vision 2020 of a better civil service sector that is driven by citizen-centric service delivery. These recent changes in the Malaysian public sector shows that Malaysia is investing in building a better bureaucratic capacity to meet its goal of becoming a developed country by 2020 . However, since my focus is to identify gender in the development process, I am also interested in Malaysia's effort in including gender in better capacitating the civil service. 
Malaysia has been commended for its outstanding performance in the Millennium Development Goals (MDGs). Malaysia was very successful in reducing its poverty. The number of those living under a dollar day reduced from $17 \%$ of the population in 1990 to $4 \%$ in 2009 (United Nations Country Team Malaysia, 2011). Malaysia has also invested heavily on the education of its population and has achieved gender parity in education. Despite this equality, women's participation in the labor market is still very low (United Nations Country Team Malaysia, 2011). In 2000, the Malaysian government recognized the importance of gender mainstreaming and established a commitment to gender responsive budgeting. This commitment led to the establishment of the Ministry of Women and Family Development for promotion of gender equality and women's development in 2001 (Ministry of Women, Family, and Community Development, 2005). In 2003, the Malaysian government adopted gender responsive budgeting in five ministries (Sim, 2009). A year after the adoption of gender responsive budgeting, the government committed to increasing women in decision-making positions by at least $30 \%$ in the public sector (Sulaiman, 2007).

These guarantees by the government show that the Malaysian government is committed to bettering the status of women in the country. However, what do these guarantees mean to women involved in global production in Malaysia? Malaysia's refusal to adopt international migrant labor rights puts the women in the export industry in a vulnerable position. While Malaysia has invested in securing the rights of it's citizens and committed resource in building a better Malaysia, it has yet to take action in providing security to the thousands of migrant workers in the country. 


\subsection{Unregulated Labor: Female and Migrant Labor in Malaysia}

Female labor participation in Malaysia accounted for 38\% of the total labor force in 2012 (The World Bank, 2013). While the labor force participation is low among women, women make up a significant portion of the labor in the manufacturing sector. The charts below highlight the percentage of female and male workers by industry. The data from the charts below clearly shows that almost $50 \%$ of the workforce in the manufacturing industry and wholesale and retail trade are women.

Figure 18: Percentage of Female Workers by industry, 2012

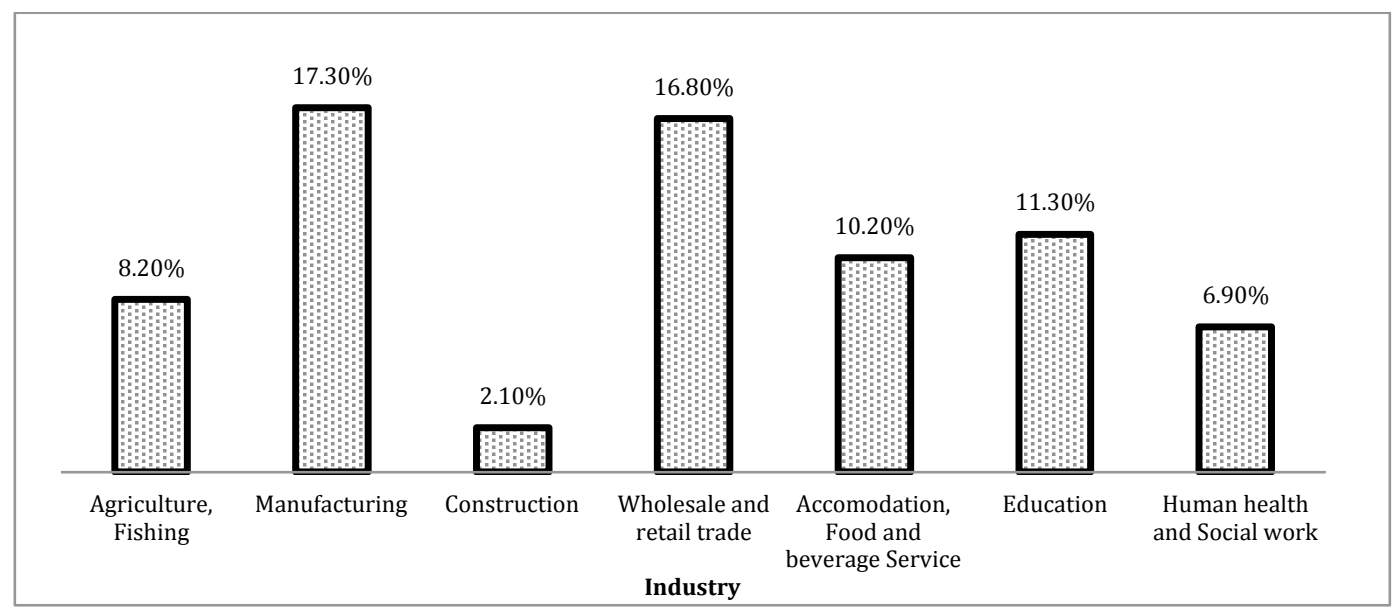

Source: Department of Statistics, 2012

Figure 19: Percentage of Male Workers by industry, 2012

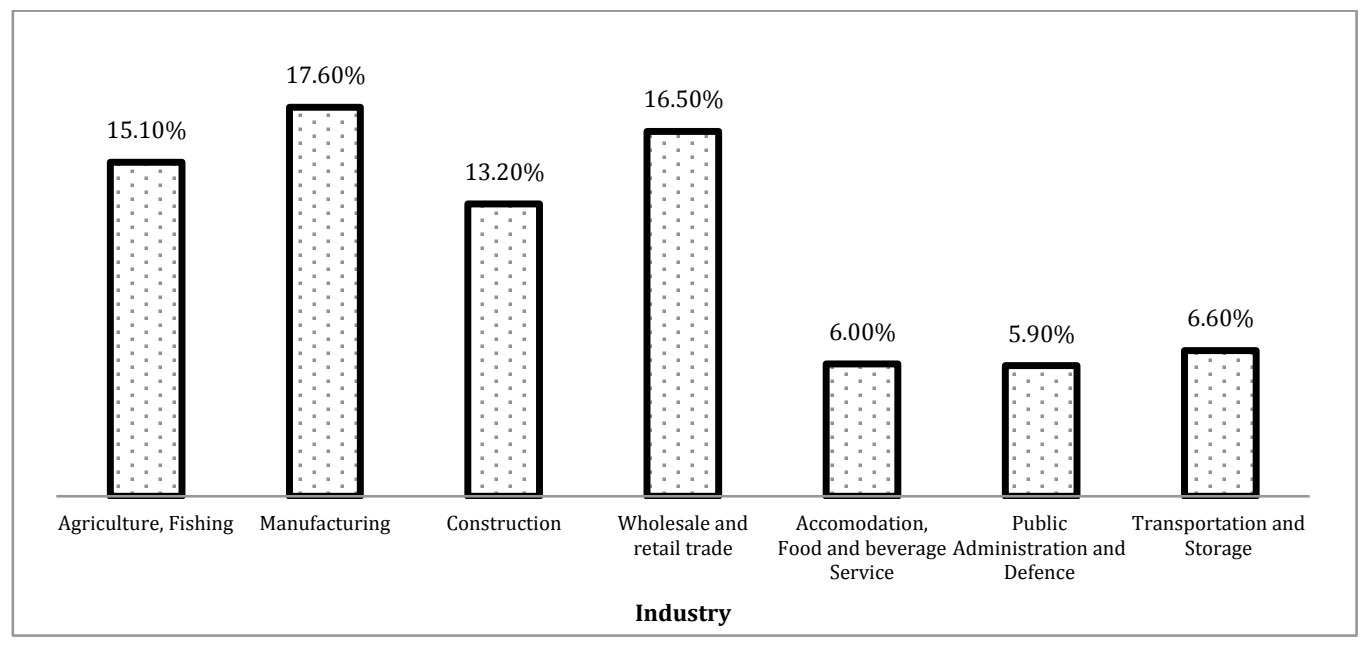

Source: Department of Statistics, 2012 
In the manufacturing industry, too, those that are export-oriented tend to employ more women than those that are producing products for the local markets (Lie \& Lund, 1994). In the beginning of the 1970s when Malaysia introduced FDI to support its export-oriented economy, most of the people employed in the factories were rural Malay women. Today, Malay women make $18.2 \%$ of the work force in the Malaysian manufacturing sector (Department of Statistics Malaysia, 2012). Non-Malaysian citizens also make up a significant number of workers in the manufacturing industry; in 2012, $17.6 \%$ of females employed in the manufacturing sector were migrant workers (Department of Statistics Malaysia, 2012).

The export-oriented economy of Malaysia flourished at a rapid pace because of the availability of cheap labor of docile and dexterous female workers, who were mostly young and from rural areas (Lim \& Fong, 1991; Lie \& Lund, 1994; Caspersz, 1998). As the country’s economy grew, the price of the labor in the country also increased. Under the watchful eyes of different IGOs and NGOs, Malaysia could no longer justify repressing its labor in the name of economic development (Crinis, 2010). This led to a struggle in retaining the FDI inflow by advertising cheap labor. In order to ensure that cheap labor was available, Malaysia started to recruit migrant labor in the export-oriented manufacturing sector. Most of these E\&E and garment industries employ migrant women. Out of nearly 300,000 employees in the E\&E industry, 70 to $80 \%$ are women; of these, a significant number are migrant women (Bormann et al., 2010; Department of Statistics, 2012).

The scarcity of cheap labor in Malaysia led to a huge demand among the export-oriented industries. Further, the demand grew as new state actors with better offers on labor cost started to compete with Malaysia for foreign investment (Rudnick, 2009). Garcés-Mascareñas (2007) outlines three characteristics used by the Malaysian immigration policy to control the labor. The 
first characteristic is labor circulation, whereby by restricting the immigrant to settle in the area, Malaysia is assuring the process of labor maintenance and renewals. The second characteristic is the limitation on mobility of migrants. The migrants in Malaysia are only allowed to work for the employer with whom they have signed their contract. They are required to leave the country once the contract ends. The third characteristic of the Malaysian strategy is to keep the labor powerless. Migrant workers bargaining powers are weakened by the dependence on their employers, who have the ability to terminate their contract and have them deported back to their countries. This three pronged approach adopted by Malaysia has made the migrant labor force extremely vulnerable. Considering that migrant women make up a significant number of the work force in the manufacturing industry, this approach makes migrant women workers more vulnerable as workers, because along with their migrant status, migrant women workers are also subjected to gender-based discrimination. The stereotypical assumption of docility and dexterity also make female workers more susceptible to repressive and demanding work environments.

\subsubsection{Labor Laws Pertaining to Women in Malaysia}

The Employment Act of 1955 outlines minimum standards for working conditions such

as work hours and maternity benefits. Under this Act, women are not allowed to work during the night. This section states that:

(1) Except in accordance with regulations made under this Act or any exemption granted under the proviso to this subsection no employer shall require any female employee to work in any industrial or agricultural undertaking between the hours of ten o'clock in the evening and five o'clock in the morning nor commence work for the day without having had a period of eleven consecutive hours free from such work: Provided that the Director General may, on application made to him in any particular case, exempt in writing any female employee or class of female employees from any restriction in this subsection, subject to any conditions he may impose.

(2) Any person --

(a) who is affected by any decision made or condition imposed under the proviso to subsection; and 
(b) who is dissatisfied with such decision or condition, may within thirty days of such decision or condition being communicated to him appeal in writing therefrom to the Minister.

(3) In deciding any appeal made to him under subsection (2), the Minister may make such decision or order thereon, including the alteration or removal of any condition imposed or the imposition of any further condition, as appears just and such decision or order shall be final (ILO, 2013).

However, this provision has been relaxed to enable cheaper female labor to operate in any hours of the day. Further, export-oriented manufacturing sectors, like the E\&E and garment sectors, are exempted under “approved undertakings" (Capersz, 1998, p. 273).

This Act also provides maternity protection and benefits for women workers. Under this section, it is stated that:

Every female employee shall be entitled to maternity leave for a period of not less than sixty consecutive days (also referred to in this Part as the eligible period) in respect of each confinement and, subject to this Part, she shall be entitled to receive from her employer a maternity allowance to be calculated or prescribed as provided in subsection (2) in respect of the eligible period (ILO, 2013)

Prior to the 2012 amendments, the maternity leave entitlements depended on the wages of the female workers. The amendments led to Section 44 A of the Employment Act to state, "maternity leave entitlements are now extended to all female employees, irrespective of their wage" (ILO 2013b). However, maternity leave does not yet meet the minimum standard of 90 days as required by the ILO.

The laws pertaining to women in Malaysia are only trying to meet minimum standards of working conditions. Perhaps the reason is the weak identification among the workers under the identity of working class. The Malaysian state has time and again politicized the ethnic identity of workers to support its export-oriented economy. Caspersz (1998) argues that the state employs indirect means, such as manipulations of private interests of workers, to keep the EPZ labor controlled. By encouraging nationalism among Malay workers, who make up most of the 
working class in the Malay society, the state strengthens the group's ethnic identity over that of their class identity.

The state also employs direct means like repressive union policies to control the labor. The Trade Unions Act of 1959 (TUA), the Industrial Relations Act of 1967 (IRA), and succeeding amendments have constantly repressed the rights of the workers to unionize: "These acts also allow for wide-ranging interference in union affairs by the director-general of the trade unions, who under the TUA, for instance has the right to refuse union registration" (Caspersz, 1998, p. 269-70). The Employment Act of 1955 and the Employment Regulation Act (ERA) of 1980 also restrict the bargaining rights of the workers in the pioneer industries for terms of employment more advantageous than that specified under the relevant acts. Under ERA, pioneer industries are also protected from "unreasonable demands" of a trade union (Caspersz, 1998, p. 270). The union's size and structure are also profoundly controlled via laws like TUA and the Societies Act of 1966. Trade union officers are not allowed to hold political office, which has led to weak political representation of the working class (SUARAM, 1998). The discussion in this paragraph has established that labor activism is very repressed in Malaysia via different means. While there are some avenues available to Malaysian workers for labor activism, there is no such provision for migrant workers.

Migrant workers are not entitled to any provisions that are provided by the government to protect the labor of its citizens. Migrant labor in Malaysia is reported to experience many labor rights violations, including withholding of passports, social and physical isolation, threats of deportation, physical and verbal abuse, withholding of pay, etc. (Crinis, 2004; Rudnick, 2009; War on Want, 2012). Migrant labor is essential for driving the export-oriented growth that Malaysia relies on, but there is no protection for the migrant labor in Malaysia. Migrant workers 
are also not protected from arbitrary dismissal and can be dismissed for any reasons, including pregnancy (Crinis, 2004). Further, the state employs other means to control the migrant labor in the country. The migrant workers are not allowed to marry the locals or bring their dependents and spouses. This curbs the migrant's opportunities to be a local in the area. The foreign labor in Malaysia is not entitled to any of the regulations and laws that are there to protect the workers. Malaysia has also constantly denied ratifying the International Convention on the Protection of All Migrants Workers and Members of their Families (Crinis, 2004; Piper, 2006; Rudnick, 2009). Malaysia has ensured that all means towards a possibility of naturalizing a migrant as a citizen is shut off completely. Further, it has also clearly established that their intention towards the migrant workers is nothing beyond the fulfillment of the supply of cheap labor.

\subsection{Conclusion}

Malaysia is a successful actor in the global economy. Malaysia seeks to be a role model for the developing countries and in the past has offered suggestions and advice to new exportoriented economies in the region. The success of Malaysia must be credited to the young rural Malay women workers who worked to establish the strong base for the E\&E industry, which is still the largest manufacturer of the export-oriented products in Malaysia. Today, with economic development and better work opportunities elsewhere, Malaysian women are getting smarter about their choices and leaving the industries that are not paying and protecting them enough. This has led to a huge turnover among local employees in Malaysian export industries. In order

to fill that gap in the labor force, MNCs are demanding the Malaysian state to import labor from poorer countries that are cheap as well as dexterous (Crinis, 2004; Piper, 2006). Malaysia has succumbed to this demand and has been importing labor from countries like Bangladesh, Indonesia, Nepal, and Myanmar. While most male migrant workers work in plantations, 
construction, and mining industries, most female workers work in export industries like electronic semiconductor and garment industries. Malaysia's export-oriented industry is, thus, still driven by female workers, but not Malaysian female workers.

Migrant workers in Malaysia are subjected to harassment, low pay, and the constant threat of deportation. They are not protected by any regulations that apply to Malaysian citizens. They can be subjected to dismissal on any ground, including pregnancy. The status of the female migrant worker is even vulnerable as she is exposed to discrimination imposed by the intersectionality of her immigrant and her gender identities. Further, the employment of migrant women in export-oriented enterprises based on her gender identity makes her more vulnerable to repressive work environment. Malaysia and MNCs treat the female migrant workers like a resource, which it has purchased from another state, to use to reach its economic goals. While Malaysia boasts about its goal to be a developed nation by 2020 , and claims to establish an economically just society, it has yet to do anything, including ratifying ILO's Convention on the Protection of the Rights of All Migrant Workers and Their Families, to protect the very workforce supporting its export-oriented economy. 


\section{Chapter 8: Conclusion}

\subsection{Introduction}

In this project, my research question goes beyond what the previous literature has considered, in that the interaction between states and FDI allows workers to remain vulnerable and unprotected. In order to attract FDI, states have been willing to relax labor laws (along with offering other non-labor-related incentives). However, I am expanding this literature to include a discussion about how cultural patriarchy intensifies this relationship, especially in relation to women workers. I expect that, in certain environments, cultural patriarchy has been mitigated by the rise of women's civic engagement. To gain a better understanding, I examined three Asian countries that are at different levels of development: Bangladesh, a newly industrializing country that has recently adopted the economic liberalization policies; the Philippines, a low-middle income country that adopted the liberalization policies in the shadow of US imperialism; and finally, Malaysia, the country that has benefitted most from an export-oriented economy since its time as a colony. I have highlighted how the gendered state allows for the use of women's labor as a resource by FDI through its unregulation. This research finds that this unregulated labor supports the continued repression of these women to suit capitalist interest of the FDI and the state within a patriarchal society.

In examining the role of the state in not protecting female labor in FDI industries, I used feminist IR approach. Feminist IR approach adopts a critical theoretical stand in understanding the global politics. Critical theory is a purpose driven methodology whereby it seeks to understand the problem and find a solution to address that problem (Tickner and Sjoberg, 2011). Feminist scholars studying international politics have time and again highlighted the genderhierarchical characteristics of international politics. My intention in conducting this research is 
driven by similar motivations. Like other feminist scholars, I have identified the gendered characteristics of the development process by examining the partnership between FDI and states in unregulating women's labor. The use of gender lens to examine the development process has enhanced the understanding of the concept of gendered state in my study. Feminist IR approach has undeniably enriched my study by allowing me to uncover androcentric practices at the institutional level of state operations.

Proponents of neo-liberal economics have identified export-led growth as the most effective model to ignite the process of economic development. For poor countries to establish a strong foundation for export-based economies, it is absolutely necessary to attract foreign investment. Considering that poor countries do not have the tax base to generate enough revenue to support local investment, they have to rely on other sources like FDI for market investment. To make their economy attractive, developing countries often depend on the export-oriented industries that are based on low-cost labor. Usually, to keep the labor cost low, the FDI industries tap into unused resources like large pools of unemployed and unskilled poor, rural women. Often, foreign firms and the host state claim that, by allowing these women to work in the newly established FDI industries, it is helping women to be financially independent and, thus, empowered. While this might be true for some women within certain spaces, most women workers are not empowered via the low income and repressive work environment offered by the export-led economy, supported by the state and the cultural patriarchy .

\subsection{Summarizing the cases}

\subsubsection{Bangladesh}

Among the cases I studied, Bangladesh is the weakest state, politically and economically, and also the latest state to adopt the export-led economic policies. Therefore, the Bangladeshi government is struggling to even ensure basic rights to its citizens, let alone labor rights to 
women. The rising Islamic extremism and its use of violence against women have also repressed the grassroots activism on gender equality. Further, the political instability that is driven by personal rivalry between the two party leaders, along with extreme corruption has led to weakened governance. This weakened governance has enfeebled the protection of rights and liberties of Bangladeshis, especially those who are marginalized in the society. The young, poor, rural women workers who work in the export-oriented garment industries are in constant danger of major occupational hazards, such as factory fires. While the mounting pressure on government and corporations to protect these women workers are forcing the state and the corporations to adopt more regulatory measures, what needs to happen is for the state to enforce these measures and protect women's labor. Until there is a political will to do so, we will not see the change in the vulnerability of women workers.

\subsubsection{The Philippines}

The history of authoritarian regime along with the financial crisis of 1997 led the Philippines into a severe economic crisis. In order to get back on track, the Philippines had no choice but to adopt the SAPs, as advised by the World Bank and the IMF. Since then, the Philippines have liberalized its economic policies to attract FDI to cater to its development needs. With discouraging unemployment rates after the crisis, the Philippines struggled to resume its export-led economy to reach the potential before the economic crisis of the late 1990s. This led the Philippines to export its labor. The phenomenon of exportation of labor is very much gendered in the Philippines. Women are more likely than men to migrate to other countries, such as Malaysia, Japan, Italy, and the U.S. Women are also the preferred labor in the export-oriented industries, primarily for their docility and submissiveness. But unlike in Bangladesh, women in the Philippines are politically active in voicing their grievances against the government policies that are repressive. 
The political activism in the Philippines has been strong since the Marcos era, and labor and women groups have been crucial in the resistance movement against Marcos. However, the Philippines has its share of problems when it comes to protecting the civil liberties and rights of its people. Further, a troublesome record of corruption has not helped the Philippines to establish a more developed society. Despite this, active involvement from groups like GABRIELA and KMK have been successful in advocating the interests of women in the Philippines and pressuring the state to adopt gender mainstreaming policies that bolster the cause of gender equality.

\subsubsection{Malaysia}

Malaysia's economic development is bolstered by its style of governance, whereby the state's policies are catered towards serving the developmental goal of the country. The Vision 2020, a plan set by long-term Prime Minister Mohamed to have Malaysia as a developed country by 2020, is a goal that the government of Malaysia is striving to achieve. Malaysia's development strategy is based on export, and so far this strategy has worked for Malaysia. The post-independence Malaysia adopted the already established export-oriented economy to further the economic development of the country. In attracting FDI, Malaysia relied on low-cost unskilled labor of poor, rural Malay women. Even today $70-80 \%$ of the labor in Malaysia's major export industry (the E\&E industry) is female.

Malaysia established its export empire based on low-cost labor. However, along with the development of the country, the wages increased and this rise led the labor cost to increase as well. Malaysia, in catering to the demand of low-cost labor, now relies on imported labor. The increasing middle-class in Malaysia has supported the Malaysian socio-political culture to adopt post-materialistic attitudes, such as sustainable development, and encouraging CSR practice. However, these attitudes are not extended to the migrant labor that makes up most of the labor in 
the export-oriented industries. When it comes to migrant labor, Malaysia assumes a very strict immigration policy that increases the vulnerability of migrant workers in the country. While Malaysia might have made its place economically, it has yet to exude the same energy when it comes to fixing its human rights record.

\subsection{The Filipino Factor}

In this research, I set out to identify the exploitation of female labor in the states adopting the export-oriented economies supported by FDI. The cases I have examined are all exportoriented economies that have structured their manufacturing sector to cater to the consumer markets in the developed countries. All of these cases rely on FDI to financially drive this manufacturing sector. Further, all of the examined cases employ female labor in the export oriented industries. It has been identified in the previous chapters that female labor, mostly young, poor, rural is the preferred labor because of their perceived docility, dexterity, and cost effectiveness. While all of the examined cases have enacted policies to protect women's labor, the Philippines has more exhaustive policies than both Bangladesh and Malaysia. So, why is the Philippines different than Bangladesh and Malaysia? I believe that the Philippines is different mainly because of a different colonial history.

The Filipino colonial history is different from that of both Bangladesh and Malaysia. While both Bangladesh (at the time, a part of India) and Malaysia were colonized by the British, the Philippines was colonized by the Spanish and then by the U.S. The colonial establishments and styles of the British were very different from that of the Spanish and the Americans. The British, in both India and Malaysia, devised and implemented a divide and rule strategy whereby they accentuated the identities of different groups. The British used the identity politics to strengthen their colonial rule. Bangladesh is a consequence of the divide and rule strategy 
employed by the British in the Indian subcontinent. By highlighting the differences between Muslim and Hindus, and by favoring one group over another, the British colonization created a rift between the Hindus and Muslims of the area. The assignment of the title of zamindars (landlords) to the Hindus while designating the majority of the Muslims as landless peasants resulted in the revolt that divided the Bengal in the first place. This rift is still very pervasive in the region.

Similarly, in Malaysia the British favored the elite Malays over the rural Malays and Chinese and Indian residents. The biased treatment towards the other groups deepened the ethnic segregation. This segregation took a toll on the Chinese population during the Japanese occupation. The British strategy of divide rule in Malaysia also resulted in a division of Malaysia and creation of Singapore. Further, after independence, the government enacted a policy called NEP, which sought to advance the positions of the Malays in the society. This prolonged the identity clash between Malays and the other ethnic groups in Malaysia.

This effect was non-existent in the Philippines, because unlike the British, the Spanish did not use divide and rule as a strategy to control the area. Instead, one of the missions of the Spanish in colonizing the area was to spread Christianity. Rather than perpetuating ethnic differences in the area, Spain sought to enforce a religious identity on the Filipinos. The Spanish were successful in eliminating ethnic identities and creating a religious identity that most of the Filipinos identify with even today. After the fall of the Spanish, the U.S. occupied the Philippines, driven by economic and military goals. Further, under the rhetoric of benevolent assimilation, the U.S. asserted that this occupation was temporary and promised eventual independence to the Philippines. While, the U.S. definitely gained more than the Philippines in this occupation, the Filipinos, under the U.S., were introduced and educated on ideas like 
democracy, freedom, civil rights, and liberties. This education had a profound impact on the Filipino civil activism.

The differences in this history can explain characteristics that the Philippines has that is absent in the other two cases. The first that the Philippines has is its strong national identity. This can be associated with the colonial history that eliminated the identical differences and unionized the population under one religious identity. In Bangladesh (considering that this is relatively a new country) people still relate to an enforced religious identity and the Bengali identity that they inherited from India. The Bangladeshis are still trying to figure out what it means to be a Bangladeshi. Similarly, in Malaysia the ethnic rift between the Chinese and Malays are still very pervasive at all levels of Malaysian life. The government time and again uses the identity politics to minimize the impact of other identities based on class and gender. In the absence of such a unifying identity, the elites are often justifying their political actions based on their own ethnic or religious identity.

The second characteristic is the robust civil activism in the Philippines, which is virtually non-existent in Bangladesh and Malaysia. With early exposure to ideas like democracy, civil rights and liberties, and freedom, the Philippines instituted an active civil society. While this was challenged by an almost 20-year-long dictatorship (instituted in the early years of the independent Philippines), it was this robust civil activism that led to the ousting of the powerful dictator. The civil engagement of the working class (labor unions) was significant in ending the authoritarian regime of the Marcos. This contribution is recognized in the Philippines. Along with the working class members, women had a prominent role in the resistance movement against the Marcos. Since then, women groups involved in the resistance have been provided a 
platform for a political voice. The robust civil activism in the country instilled by different groups explains the exhaustive policies adopted by the Philippines to ensure labor protection.

\subsection{Policy Directions}

In 2000, the United Nations introduced its Millennium Development Goals (MDG), which were to help the poorest of the poor countries set themselves on the road to development. While the countries I studied in this dissertation are not necessarily the poorest countries in the world, they are still considered developing. One of the main MDGs acknowledged the problem of gender discrimination and the promotion of gender equity and empowerment. Considering that my study concludes with the idea that women's civic engagement has led to the greater enforcement of policies in the Philippines when compared to Bangladesh and Malaysia.

The problem with this is that, again, cultural factors (specifically, a historic patriarchal society) are one of the main drivers on how states and FDI perpetrate the vulnerability of women workers. So, the question remains: How can we change a state's culture? While many of our expectations and desires surrounding women's rights and their political and economic participation has a Western bias, there is no way for us as scholars to prescribe a manner in which this can change. This has been one of the major critiques against development strategies in the post-World War II era: the West and its major international organizations does not consider the culture and society of a country when creating a roadmap for development. Therefore, studies like these can only inform NGO groups that may be able to help women's equality movements within states such as Bangladesh and Malaysia. The change itself needs to come from within, from with a grassroots momentum. In the past century, IR 
scholars (and specifically, development scholars) have seen that when change is implemented from the outside (or, in a way, forced), it does not take hold.

\subsection{Future Directions}

This research employs a feminist methodology to address an issue in international relations. In this study, I examined how states deal with other actors within the state (women workers, labor unions, NGOs) and those outside the state (MNCs) to reach its goal (development). I focused on women workers who work in FDI enterprises, and how they are not protected by the state so they can reach their development goals.

There are numerous studies conducted in regard to the use of women as resources for developmental goals; however, these studies have been mostly conducted within the fields of economics and geography. In this study, I have situated the problem within the political science field by highlighting the relationship between states, FDI, and patriarchal culture in nonprotection of women workers. The literature on women workers in FDI enterprises is gaining ground again after the two major incidents in Bangladesh: a factory fire (November 2012) and a factory building collapse (April 2013). I seek to add to this literature by specifically highlighting the role of the state in forming and nurturing this unequal relationship between the unskilled women workers and the FDI enterprises that employ them.

My short-term goal in furthering this research is to study the framing of the word "empowerment" as it relates to women workers in FDI enterprises. The fuzziness of the word and its use to further perpetuate gender discrimination is very evident in global production. To extend this research further, I plan to conduct a study with Nepali female migrant workers who worked in Malaysia and have returned to Nepal. I plan to employ qualitative methods like interview and focus group studies to understand how the Malaysian and the Nepali state used 
these women's labor to achieve its goals. I seek to identify the support system that encouraged women to own their agency within the system of the global production via different means of retaliation to the state's and FDI's means of control. It has been established in this research that migrant workers in Malaysia aren't allowed to unionize and express their grievances. Therefore, I specifically would like to understand what opportunities were granted to the female migrant workers to express their grievances, and ask: What were the sources of these opportunities? I seek to examine if there is any role that transnational feminist network play in supporting the female migrant workers in Malaysia. Further, I also want to extend this research to study the role of the state as a labor-exporting state and the relationship between the state importing the labor, the state exporting the labor, and FDI in using women as resources to cater to their economic interests.

The regional shifts in Asia, with dynamics of economic growth, have changed the power structure of the global economy. Asian countries are becoming more and more engaged in the global economy as a labor importing countries and as FDI investing countries. The present day trend in the global production usually follows this pattern: the American/ European MNC invests in middle-income country like Malaysia to produce a commodity, which is outsourced by the Malaysian company to a low-income country like Bangladesh. This trend is getting more and more pervasive with the increase in the cost of labor in the middle-income countries, like Malaysia. I seek to extend this study by examining the impact of such regional shifts on labor in low-income countries. Will this regional shift reduce the abuse of labor or will it further the exploitation? While the bad records that these emerging economies hold on human rights lead towards a future with further exploitations, the increasing consumer awareness and activism may force these MNCs to adopt a better CSR policy in ending such exploitation. 


\subsection{Conclusion}

In this study, I have identified how women workers are disproportionately disadvantaged when compared to men in FDI driven economy due to the patriarchal nature of the society. In studying the three cases, I find that states use the export-led economy as a development strategy. In this type of economy, states utilize the unprotected labor of poor, rural, unskilled women as means to attract FDI. The use of women's labor in achieving economic development is not a new phenomenon. Women's labor has been used in every industrializing country to cater to its industrial goal. But a century after the Triangle Shirtwaist Factory Fire of 1911 and normalization of many international laws and regulation protecting male and female workers, we still have incidences like the Tazreen Factory Fire of 2012, where hundreds of women died because of the same reasons as in the case of the century old incident of the Triangle Shirtwaist Factory Fire.

Despite this, employment of women workers in these factories has time and again been justified under the wide-ranging term “empowerment." I have effectively established that while states and MNCs often claim to "empower" women via the income opportunities that comes with being employed in export-oriented enterprises; it is not entirely true. First, the goal of FDI and the state is not to empower women; second and more importantly, they are employing women because women are much cheaper and easier to control than men. The use of women's labor based on their inexpensiveness and docility propagates a patriarchal culture that the state and FDI uses to cater to their economic demands. Considering this, I conclude this research with a request for general consciousness on the issue of global gender inequality, which is being perpetuated further by the current system of global production. 


\section{Bibliography}

Abdul, Zabid, and Saadiatul Ibrahim. 2002. "Executive and Management Attitudes towards Corporate Social Responsibility in Malaysia." Corporate Governance: The international journal of business in society 2(4): 10-16.

Abinales, Patricio N., and Donna J. Amoroso. 2005. State and Society in the Philippines. Rowman \& Littlefield Publishers.

ACCA. 2002. The State of Corporate Environment Reporting in Malaysia. London: Certified Accountants Educational Trust.

Acemoglu, Daron, Simon Johnson, and James A. Robinson. 2001. "The Colonial Origins of Comparative Development: An Empirical Investigation.” American Economic Review 91(5): 1369-1401.

Ackerly, Brooke. 2011. "Intelligence and Compassion, the Tools of Feminists: An Engagement with Catia Confrontini." In Feminism and International Relations: Conversations about Past, Presnt, and Future, eds. J. Ann Tickner and Laura Sjoberg. Routledge, 40-48.

Ackerly, Brooke A., Maria Stern, and Jacqui True. 2006. Feminist Methodologies for International Relations. Cambridge University Press.

Ackerly, Brooke, and Jacqui True. 2010. Doing Feminist Research in Political and Social Science. Palgrave Macmillan. http://arrow.monash.edu.au/vital/access/manager/Repository/monash:131264 (March 1, 2015).

Ackerman, S. 1980. "Cultural Process in Malay Industrialization.” University of Michigan.

Adams, Samuel. 2009. "Can Foreign Direct Investment (FDI) Help to Promote Growth in Africa?" African Journal of Business Management 3(5): 178-83.

Afifi, N.H., R. Busse, and A. Harding. 2003. "Regulation of Health Services.” In Private Participation in Health Service, eds. A. Harding and A.S. Preker. Washington D.C.: The World Bank, 219-334.

Aggarwal, Aradhna. 2007. Impact of Special Economic Zones on Employment, Poverty, and Human Development. Indian Council for Research on International Economic Relations New Delhi. http://www.democraciaycooperacion.net/IMG/pdf/1-working_paper_194.pdf (April 9, 2014).

Ahamed, Ferdous. 2013. “Improving Social Compliance in Bangladesh's Ready-Made Garment Industry." Labour and Management in Development 13. http://www.nla.gov.au/openpublish/index.php/lmd/article/view/2269 (March 8, 2015).

Ahmad, Aminah. 1998. "Country Briefing Paper: Women in Malaysia." Asian Development Bank.

Ahmad, Takiyuddin bin Shaari. 1980. "Recruitment and Selection in the Malaysian Public Service." In Asian Civil Services Techincal Papers, Recruitment and Selection, eds. Amara Raksasataya and Henrich Siedentopf. Bonn: Institute for International Partnership.

Ahmed, Nazneen. 2009. "Sustaining Ready-Made Garment Exports from Bangladesh.” Journal of Contemporary Asia 39(4): 597-618.

Ahmed, Salma, and Pushkar Maitra. 2010. "Gender Wage Discrimination in Rural and Urban Labour Markets of Bangladesh." Oxford Development Studies 38(1): 83-112. 
Aldaba, Rafaelita M. 2008. Assessing Competition in Philippine Markets. Philippine Institute for Development Studies. http://dirp3.pids.gov.ph/ris/dps/pidsdps0823.pdf (April 12, 2014).

Alfaro, Laura, Areendam Chanda, Sebnem Kalemli-Ozcan, and Selin Sayek. 2004. "FDI and Economic Growth: The Role of Local Financial Markets." Journal of International Economics 64(1): 89112.

Ali, S. Mahmud. 2010. Understanding Bangladesh. Columbia University Press.

Alliance for Bangladesh Worker Safety. 2014. Baseline Worker Survey Report. Alliance for Bangladesh Worker Safety.

Almeida, Rita. 2004. The Labor Market Effects of Foreign-Owned Firms. Rochester, NY: Social Science Research Network. SSRN Scholarly Paper. http://papers.ssrn.com/abstract=610345 (March 6, 2015).

Amran, Azlan, and S. Susela Devi. 2008. "The Impact of Government and Foreign Affiliate Influence on Corporate Social Reporting: The Case of Malaysia." Managerial Auditing Journal 23(4): 386404.

Andaya, Barbara Watson, and Leonard Y. Andaya. 1982. A History of Malaysia. University of Hawaii Press.

Arroyo, Gloria Macapagal. 2014. "Biography.” The Official Website of Gloria Macapagal Arroyo. http://www.macapagal.com/gma/index.php (December 8, 2014).

Artecona, Raquel, and Wendy Cunningham. 2002. Effects of Trade Liberalization on the Gender Wage Gap in Mexico. World bank.

Asia Monitor Resource Center. 1998. We in the Zone: Women Workers in Asia's Export Processing Zones. Asia Monitor Resource Center Ltd.

Asian Development Bank. 2008. Paradox and Promise in the Philippines: A Joint Country Gender Assessment. . Text. http://www.adb.org/documents/paradox-and-promise-philippines-jointcountry-gender-assessment (March 6, 2015).

_ 2010. "Country Gender Assessment: Bangladesh." Asian Development Bank. http://www.adb.org/documents/country-gender-assessment-bangladesh (March 9, 2014).

—_ 2012. "Gender Tool Kit: Public Sector Management." Asian Development Bank. http://www.adb.org/documents/gender-tool-kit-public-sector-management (March 9, 2014).

Asian Development Bank, Asian Development. 2013. Gender Equality in the Labor Market in the Philippines. Asian Development Bank. http://www.adb.org/publications/gender-equality-labormarket-philippines (March 9, 2015).

Asiedu, Elizabeth. 2006. "Foreign Direct Investment in Africa: The Role of Natural Resources, Market Size, Government Policy, Institutions and Political Instability." World Economy 29(1): 63-77.

Balassa, Bela. 1986. "Toward Renewed Economic Growth in Latin America." The International Executive 28(3): 29-31.

Bangladesh Bureau of Statistics. 2013. Report on Violence Against Women (VAW) Survey, 2011. 1ST edition. Bangladesh Bureau of Statistics. 
Bangladesh Export Processing Zones Authority (BEPZA). 2010. Annual Report 2008-2009. Bangladesh Export Processing Zones Authority (BEPZA).

- 2013. Information for Investors. Bangladesh Export Processing Zones Authority (BEPZA).

Bangladesh Garment Manufacturers and Exporters Association (BGMEA). 2011. "Industry Strengths." Bangladesh Garment Manufacturers and Exporters Association (BGMEA). http://www.bgmea.com.bd/home/about/Strengths (March 22, 2014).

- Factory Growth in BD. Bangladesh Garment Manufacturers and Exporters Association (BGMEA). http://www.bgmea.com.bd/chart_test/number_of_employment_in_garment (February $22,2013)$.

Bannerji, Himani. 1995. "Attired in Virtue: The Discourse on Shame (Lajja) and Clothing of the Bhadramahila in Colonial Bengal." In From the Seams of History: Essays on Indian Women, ed. Bharati Ray. Delhi: Oxford University Press.

Bari, Muhammad Abdul. "Bangladesh Factory Deaths: Deep-Rooted Corruption Behind a Human Tragedy." The Huffington Post UK. http://www.huffingtonpost.co.uk/muhammad-abdulbari/bangladesh-factory-deaths_b_3178559.html (March 17, 2014).

Barrows, David Prescott. 1905. A History of the Philippines... Amer. Bk. Company.

Beechey, Veronica. 1982. "The Sexual Division of Labour and the Labour Process: A Critical Assessment of Braverman." The degradation of work: 54-73.

Bello, W., and S. Rosenfeld. 1990. "Dragons in Distress: Asia’s Miracle Economies in Crisis." Penguin Books.

Benería, Lourdes. 2003. Gender, Development, and Globalization: Economics as If All People Mattered. Psychology Press.

Berg, Maxine. 1993. "Small Producer Capitalism in Eighteenth-Century England.” Business History 35(1): 17-39.

Berik, Günseli. 2000. "Mature Export-Led Growth and Gender Wage Inequality in Taiwan." Feminist Economics 6(3): 1-26.

Bertelsmann Stiftung. 2012. Bangladesh Country Report. Bertelsmann Stiftung. http://www.btiproject.org/reports/country-reports/aso/bgd/2012/index.nc (March 8, 2013).

Bianchi, Suzanne M. 1999. "Feminization and Juvenilization of Poverty: Trends, Relative Risks, Causes, and Consequences." Annual Review of Sociology: 307-33.

Bjorvatn, Kjetil, and Carsten Eckel. 2001. "Technology Sourcing and Strategic Foreign Direct Investment." Review of International Economics 14(4): 600-614.

Borensztein, E., J. De Gregorio, and J-W. Lee. 1998a. "How Does Foreign Direct Investment Affect Economic growth?1.” Journal of International Economics 45(1): 115-35.

— 1998b. "How Does Foreign Direct Investment Affect Economic growth?1." Journal of International Economics 45(1): 115-35. 
Bormann, Sarah, Pathma Krishnan, and Monika E. Neuner. 2010. Migration in a Digital Age: Migrant Workers in the Malaysian Electronics Industry; Case Studies on Jabil Circuit and Flextronics. WEED.

Borthwick, Meredith. 1984. The Changing Role of Women in Bengal, 1849-1905. Princeton University Press Princeton, NJ. http://press.princeton.edu/titles/165.html (March 8, 2015).

Boserup, Ester. 1990. "Economic Change and the Roles of Women.” In Persistent Inequalities, ed. Irene Tinker. Oxford University Press, 14-26. http://www.popline.org/node/384076 (March 10, 2015).

Bowie, Alasdair. 1991. Crossing the Industrial Divide: State, Society, and the Politics of Economic Transformation in Malaysia. Columbia University Press.

Bradley, Tamsin. 2011. Religion and Gender in the Developing World: Faith-Based Organizations and Feminism in India. I. B. Tauris.

Brandt, Michele, and Jeffrey A. Kaplan. 1996. "The Tension between Women's Rights and Religious Rights: Reservations to Cedaw by Egypt, Bangladesh and Tunisia." The Journal of Law and Religion: 105-42.

Braunstein, Elissa. 2006. Foreign Direct Investment, Development and Gender Equity: A Review of Research and Policy. UNRISD.

Braunstein, Elissa, and Mark Brenner. 2007. "Foreign Direct Investment and Gendered Wages in Urban China." Feminist Economics 13(3-4): 213-37.

Braunstein, Elissa, and Gerald Epstein. 2002. Bargaining Power and Foreign Direct Investment in China: Can 1.3 Billion Consumers Tame the Multinationals?. Rochester, NY: Social Science Research Network. SSRN Scholarly Paper. http://papers.ssrn.com/abstract=343540 (March 6, 2015).

Buang, Amriah. 2002. "Development and Factory Women: Negative Perceptions from a Malaysian Source Area." In Different Places, Different Voices: Gender and Development in Africa, Asia and Latin America, eds. Janet Henshall Momsen and Vivian Kinnaird. , 197-210.

Bunch, Charlotte. 1990. "Women's Rights as Human Rights: Toward a Re-Vision of Human Rights." Human Rights Quarterly: 486-98.

Bureau of Labor and Employment Statistics. 2013. Gender Statistics on Labor and Employment. Department of Labor and Employment -Philippines.

Bureau of Workers with Special Concern. 2010. "Women Workers Welfare Advocacy Program.” Bureau of Workers with Special Concern. http://www.bwsc.dole.gov.ph/women-workers-welfareadvocacy-program-w3ap/women-workers-welfare-advocacy-program (April 22, 2014).

Busse, Matthias. 2003. “Do Transnational Corporations Care About Labor Standards?” The Journal of Developing Areas: 39-57.

Busse, Matthias, and Hefeker Carsten. 2005. "Does Foreign Direct Investment Acccelerate Economic Growth?" In Does Foreign Direct Investment Promote Development?, ed. Theodore Moran. Washington D.C.: Institute for International Economics, 195-220.

Busse, Matthias, and Carsten Hefeker. 2007. "Political Risk, Institutions and Foreign Direct Investment." European Journal of Political Economy 23(2): 397-415. 
Cabegin, Emily Christi A. 2012. "Widening Gender Wage Gap in Economic Slowdown: The Philippine Case." http://ilera2012.wharton.upenn.edu/RefereedPapers/CabeginEmily\%20ILERA.pdf (April $23,2014)$.

Carino, Ledivinia V. 1994. "Enhancing Accountability in the Philippines: The Continuing Quest.” In Asian Civil Service Systems: Improving Efficiency and Productivity, ed. John P. Burns. Times Academic Press, 106-12.

Carlson, Sevinc. 1975. 25 Malaysia: Search for National Unity and Economic Growth. Sage Publications (CA).

Caspersz, Donella. 1998. "Globalization and Labour: A Case Study of EPZ Workers in Malaysia." Economic and industrial democracy 19(2): 253-86.

Central Intelligence Agency. 2013a. "East and South-East Asia: Malaysia." The World Factbook. https://www.cia.gov/library/publications/the-world-factbook/geos/my.html (May 10, 2013).

—_. 2013b. "East and South-East Asia: Philippines." The World Factbook. https://www.cia.gov/library/publications/the-world-factbook/geos/rp.html (April 20, 2013).

___ 2013c. "South Asia: Bangladesh.” The World Factbook. https://www.cia.gov/library/publications/the-world-factbook/geos/bg.html (April 12, 2013).

Chafetz, Janet S. 1991. "The Gender Division of Labor and the Reproduction of Female Disadvantage: Toward an Integrated Theory.” In Gender, Family, and Economy: The Triple Overlap, ed. Rae L. Blumberg. California: Sage.

Chakravarti, Uma. 1989. "Whatever Happened to the Vedic Dasi? Orientalism, Nationalism and a Script for the Past." Recasting women: Essays in colonial history: 27-87.

Charlton, Sue Allen. 2008. "Development as History and Process." In The Women, Gender, and Development Reader, eds. Nalini Visvanathan, Lynn Duggan, Nan Wiegersma, and Laurie Nisonoff. London: Zed Books Ltd., 7-13.

Chatterjee, Partha. 1989a. "Colonialism, Nationalism, and Colonialized Women: The Contest in India." American ethnologist 16(4): 622-33.

— 1989b. "Colonialism, Nationalism, and Colonialized Women: The Contest in India." American ethnologist 16(4): 622-33.

Cheng, Lucie. 1999. “Globalization and Women's Paid Labour in Asia.” International social science Journal 51(160): 217-28.

Chicote, R.H., and D.H. Johnson. 1983. Theories of Development: Mode of Production or Dependency? Beverly Hills: SAGE.

Chin, Christine B. N. 1998. In Service and Servitude: Foreign Female Domestic Workers and the Malaysian "Modernity” Project. Columbia University Press.

Chowdhury, Najma. 1994. "Bangladesh: Gender Issues and Politics in a Patriarchy." In Women and Politics Worldwide, eds. Barbara J. Nelson and Najma Chowdhury. New Haven, US: Yale University Press, 94-140.

http://journals.cambridge.org/production/action/cjoGetFulltext?fulltextid=6296664 (March 8, 2015). 
Chowdhury, Nazneen Jahan, and Md Hafu Ullah. 2010. "Socio-Economic Conditions of Female Garment Workers in Chittagong Metropolitan Area-an Empirical Study." Journal of Business and Technology (Dhaka) 5(2): 53-70.

Cingnarelli, David, and David L. Richards. "The Cingnarelli and Richards (CIRI) Human Rights Data Set." www.humanrightsdata.com (February 22, 2013).

Committee on Foreign Relations. 2013. Workers Safety and Labor Rights in Bangladesh's Garment Sector. Washington D.C.: United States Senate. Majority Staff Report. http://www.foreign.senate.gov/imo/media/doc/85633.pdf (March 4, 2013).

Connell, R. W. 1990. “The State, Gender, and Sexual Politics.” Theory and Society 19(5): 507-44.

Conradt, Kate. 2014. "Empowering Workers in Bangladesh Export Processing Zones." Solidarity Center. http://www.solidaritycenter.org/empowering-workers-in-bangladesh-export-processing-zones/ (April 22, 2014).

Constantino, Renato, and Letizia R. Constantino. 1975. A History of the Philippines. Monthly Review Press New York.

Cook, Rebecca J. 1993. “Women's International Human Rights Law: The Way Forward.” Human Rights Quarterly: 230-61.

Cowen, Michael, and Robert Shenton. 1995. “The Invention of Development.” In Power of Development, ed. Jonathan Crush. Routledge.

Cowen, Tyler. 1985. "The Marshall Plan: Myths and Realities." In U.S. Aid to the Developing World - A Free Market Agenda, ed. Doug Bandow. Heritage Foundation.

Crane, George T., and Abla Amawi. 1997. The Theoretical Evolution of International Political Economy: A Reader. Oxford University Press.

Crenshaw, Kimberle. 1989. "Demarginalizing the Intersection of Race and Sex: A Black Feminist Critique of Antidiscrimination Doctrine, Feminist Theory and Antiracist Politics." U. Chi. Legal $F .: 139$.

Crinis, Vicki. 2004. "The Silence and Fantasy of Women and Work." University of Wollongong. http://ro.uow.edu.au/theses/236.

—_. 2007. "Malaysia: Women, Labor Activism, and Unions." In Women and Labour Organizing in Asia: Diversity, Autonomy and Activism, eds. Kaye Broadbent and Michele Ford. Routledge, 50 65.

Cullather, Nick. 1994. Illusions of Influence: The Political Economy of United States-Philippines Relations, 1942-1960. Stanford University Press.

Curd, Alison, Amelia Julian, Adam Sabow, and Leigh Seligman. 2007. "The Impact of Foreign Direct Investment on Chinese Women." In Global Corporate Citizenship, eds. Anuradha Dayal-Gulati and Mark W. Finn. Northwestern University Press, 77-88.

Daud, Fatimah. 1985. “Minah Karan”: The Truth about Malaysian Factory Girls. Berita Publishing.

Davis, Kathy. 2008. "Intersectionality as Buzzword A Sociology of Science Perspective on What Makes a Feminist Theory Successful." Feminist theory 9(1): 67-85. 
Deegan, C. 2002. "Introduction: The Legitimizing Effect of Social and Environmental Disclosures--a Theoretical Foundation." Accounting, Auditing, and Accountability Journal 15(3): 282-311.

Deere, Carmen Diana, Helen Safa, and Peggy Antrobus. 2008. "Impact of Economic Crisis on Poor Women and Their Household." In The Women, Gender, and Development Reader, eds. Nalini Visvanathan, Lynn Duggan, Nan Wiegersma, and Laurie Nisonoff. London: Zed Books Ltd., 267-77.

Department of Labor and Employment. 2013. "Labor Codes of the Philippines." Deparment of Labor and Employment. http://www.dole.gov.ph/labor_codes (April 12, 2014).

Department of Statistics Malaysia. 2012. Labor Force Survey Report. Department of Statistics Malaysia. http://www.statistics.gov.my/portal/index.php?option=com_content\&id=1864\%3Alabour-forcesurvey-report-malaysia\&lang=en (April 5, 2014).

Derichs, Claudia, Andrea Fleschenberg, and Momoyo Hüstebeck. 2006. "Gendering Moral Capital: Morality as a Political Asset and Strategy of Top Female Politicians in Asia." Critical Asian Studies 38(3): 245-70.

Dirks, Nicholas B. 1992. Colonialism and Culture. University of Michigan Press.

Dolan, Ronald E. 1993. 550 Philippines: A Country Study. US Government Printing Office.

Dressel, Björn. 2011. “The Philippines: How Much Real Democracy?” International Political Science Review 32(5): 529-45.

During, Simon. 2000. "Postcolonialism and Globalization: Towards a Historicization of Their InterRelation." Cultural Studies 14(3-4): 385-404.

Ehrenreich, Barbara, and Annette Fuentes. 1981. "Life on the Global Assembly Line.” Ms. Magazine: 5371.

Elliott, Kimberly Ann, and Richard Freeman. 2001. White Hats or Don Quixotes? Human Rights Vigilantes in the Global Economy. National Bureau of Economic Research. Working Paper. http://www.nber.org/papers/w8102 (March 4, 2015).

Ellis, Amanda. 2007a. Gender and Economic Growth in Kenya: Unleashing the Power of Women. World Bank Publications.

—. 2007b. Gender and Economic Growth in Tanzania: Creating Opportunities for Women. World Bank Publications.

Ellis, Amanda, Claire Manuel, and C. Mark Blackden. 2005. Gender and Economic Growth in Uganda: Unleashing the Power of Women. World Bank Publications.

Elo, Satu, and Helvi Kyngäs. 2008. "The Qualitative Content Analysis Process.” Journal of Advanced Nursing 62(1): 107-15.

Elson, Diane. 1983. "Nimble Fingers and Other Fables." In Of Common Cloth: Women in the Global Textile Industry, eds. Wendy Chapkis and Cynthia H. Enloe. Transnational Institute, 5-13.

Elson, Diane, and Ruth Pearson. 2008. "The Subordination of Women and the International of Factory Production." In The Women, Gender, and Development Reader, eds. Nalini Visvanathan, Lynn Duggan, Laurie Nisonoff, and Nan Wiegersma. London: Zed Books Ltd., 191-203. 
Enloe, Cynthia. 1990. Bananas, Beaches and Bases: Making Feminist Sense of International Politics. Univ of California Press.

Evans, Peter B. 1979. Dependent Development: The Alliance of Multinational, State, and Local Capital in Brazil. Princeton University Press.

Eviota, Elizabeth U. 2004. "The Context of Gender and Globalization in the Philippines." In Women and Globalization, eds. Delia D. Aguilar and Anne E. Lacsamana. Humanity Books Amherst, NY, 52-67.

Eviota, Elizabeth U., and others. 1992. The Political Economy of Gender: Women and the Sexual Division of Labour in the Philippines. Zed Books.

Firth, Rosemary. 1966. Housekeeping Among Malay Peasants. London, The Athlone Press.

Fleschenberg, Andrea. 2004. "Asia's Women Politicians at the Top: Roaring Tigresses or Tame Kittens." In Women's Political Participation and Representation in Asia: Obstacles and Challenges, ed. Kazuki Iwanaga. NIAS Press, 23-54.

Fontana, Marzia. 2003. "The Gender Effects of Trade Liberalization in Developing Countries: A Review of the Literature." Discussion Papers in Economics (101).

Food and Agriculture Organization of the United Nations. "Map of the Philippines." Philippines -Map. http://www.fao.org/docrep/003/w6928e/w6928e01.gif (April 20, 2014).

Francisco, Mariel Nepomuceno, and Fe Maria C. Arriola. 1987. The History of the Burgis. GCF Books.

Franzway, Suzanne. 1986. "With Problems of Their Own: Femocrats and the Welfare State." Australian Feminist Studies 1(3): 45-57.

Fraser, Antonia. 1988. Warrior Queens. Knopf Doubleday Publishing Group.

Freedom House. 2011. Freedom in the World. Freedom House. $<$ http://www.freedomhouse.org/reports\#.U54_ypSwIqd $>$. (March 12, 2013).

__ 2012a. Freedom in the World. Freedom House.

$<$ http://www.freedomhouse.org/reports\#.U54_ypSwIqd $>$. (March 12, 2013).

— 2012b. Freedom on the Net. Freedom House. https://freedomhouse.org/report-types/freedomnet\#.VP3q6FPF8_M (March 12, 2013).

- 2013. Freedom in the World. Freedom House. http://www.freedomhouse.org/reporttypes/freedom-world\#.U5x5xZSwIqc (March 12, 2013).

Free World Maps. "Malaysia Physical Map." Free World Maps. http://www.freeworldmaps.net/asia/malaysia/malaysia-map-physical.jpg (May 4, 2014).

Fuentes, Annette, and Barbara Ehrenreich. 1983. Women in the Global Factory. South End Press.

Garcés-Mascareñas, Blanca. 2007. "Continuities and Discontinuities of Labour Migration Regulations in Malaysia. From Colonial Times to the Present." In Conference on Gender and Irregular Migration in a Global and Historical Perspective at Leiden University, The Netherlands,. 
Ghosh, Jayanti. 2009. "Informalization and Women's Workforce Participation: A Consideration of Recent Trends in Asia." In The Gendered Impacts of Liberalization: Towards "Embedded Liberalism"?, ed. Shahra Razavi. Routledge.

Gilpin, Robert. 2011. Global Political Economy: Understanding the International Economic Order. Princeton University Press.

Go, Julian, and Anne L. Foster, eds. 2003. The American Colonial State in the Philippines: Global Perspectives. Duke University Press.

Goodno, James B. 1991. The Philippines: Land of Broken Promises. Zed books London.

Gopinath, Aruna. 1991. Pahang, 1800-1933: A Political History. Kuala Lumpur.

Grant, Rebecca. 1991. "The Sources of Gender Bias in International Relations Theory." Gender and International Relations: 8-26.

Grossman, Rachael. 1979. Women's Place in the Integrated Circuit. New England Free Press.

Guhathakurta, Meghna, and Willem van Schendel. 2013. The Bangladesh Reader: History, Culture, Politics. Duke University Press.

De Guzman, Raul P., and Mila A. Reforma. 1988. Government and Politics of the Philippines. Oxford University Press, USA.

Haniffa, R. M., and T. E. Cooke. 2003. Culture, Corporate Governance and Disclosure in Malaysian Corporations. Rochester, NY: Social Science Research Network. SSRN Scholarly Paper. http://papers.ssrn.com/abstract=336822 (March 9, 2015).

Hansen, Lene. 2006. Security as Practice: Discourse Analysis and the Bosnian War. Routledge.

Haque, Tahmina. 2003. "A View Over Discrimination And Harassment Situation of Daily Unskilled Female Workers in Work Place in Bangladesh." Journal of Business Research 5. http://www.bdresearch.org.bd/home/attachments/article/328/A\%20View\%20Over\%20Discrimina tion\%20And\%20Harassment\%20Situation.pdf (March 8, 2014).

Harkin, Tom. 1999. "Text of S. 1551 (106th): Child Labor Deterrence Act of 1999 (Introduced Version)." GovTrack.us. https://www.govtrack.us/congress/bills/106/s1551/text (December 9, 2014).

Harley, Sharon. 2007. Women's Labor in the Global Economy: Speaking in Multiple Voices. Rutgers University Press.

Harper, Timothy Norman. 2001. The End of Empire and the Making of Malaya. Cambridge University Press.

Harrison, Ann. 1994. "The Role of Multinationals in Economic Development: The Benefits of FDI." The Columbia Journal of World Business 29(4): 6-11.

Harrison, Ann, and Jason Scorse. 2004. Moving Up or Moving Out? Anti-Sweatshop Activists and Labor Market Outcomes. National Bureau of Economic Research. Working Paper. http://www.nber.org/papers/w10492 (March 6, 2014).

Hasan, Mushirul. 1993. India's Partition: Process, Strategy and Mobilization. Oxford University Press, USA. 
Hassan, K. 2009. "Maternity Benefit for Women Worker in Bangladesh.” Bangladesh Institute of Management.

Hechler, Hannes, Gretta Fenner Zinkernagel, Lucy Koechlin, and Dominic Morris. 2011. "Can UNCAC Address Grand Corruption?" U4 Report 2011(2).

http://www.cmi.no/publications/publication/?4226=can-uncac-address-grand-corruption (Feb 8, 2013).

Heckscher, Eli F. 1955. 2 Mercantilism. Routledge.

Hermes, Niels, and Robert Lensink. 2003. "Foreign Direct Investment, Financial Development and Economic Growth.” The Journal of Development Studies 40(1): 142-63.

Hess, Gary R. 1996. "Negotiating National Identity: A Reexamination of US-Philippines Relations." Diplomatic History 20(2): 273-78.

Honculada, Jurgette. 2012. "Women Workers in Her-Story: Three Snapshots." Review of Women's Studies 13(2). http://journals.upd.edu.ph/index.php/rws/article/view/2932/2705 (January 9, 2015).

Hood, Christopher. 1983. "The Tools of Government. Chatham.” NJ: Chatham House.

Hoogvelt, Ankie. 2001. Globalization and the Postcolonial World: The New Political Economy of Development. JHU Press.

Hossain, Naomi. 2012. "Exports, Equity, and Empowerment: The Effects Of Readymade Garments Manufacturing Employment On Gender Equality In Bangladesh Bangladesh." https://openknowledge.worldbank.org/handle/10986/9100 (May 8, 2013).

Hossain, Naomi, Sohela Nazneen, and Maheen Sultan. 2011. "National Discourses on Women's Empowerment in Bangladesh: Continuities and Change.” IDS Working Papers: 1-41.

Hsieh, Hsiu-Fang, and Sarah E. Shannon. 2005. "Three Approaches to Qualitative Content Analysis." Qualitative health research 15(9): 1277-88.

Huang, Yasheng. 1998. FDI in China: An Asian Perspective. Institute of Southeast Asian Studies.

Human Rights Watch. 2011. World Report 2011. Human Rights Watch.

Hutchison, Jane, and Andrew Brown. 2001. Organising Labour in Globalising Asia. Psychology Press.

Inglehart, Ronald, and Pippa Norris. 2003. Rising Tide: Gender Equality and Cultural Change Around the World. Cambridge University Press.

Institute for Global Human Rights. "Gap and Old Navy in Bangladesh: Cheating the Poorest Workers in the World." www.globallabourrights.org. http://www.globallabourrights.org/reports/gap-and-oldnavy-in-bangladesh-cheating-the-poorest-workers-in-the-world (December 8, 2013).

International Labor Organization. 2010. "LABORSTA Internet.” International Labor Organization. http://laborsta.ilo.org/ (February 10, 2013).

2013. Country Profile: Bangladesh. Geneva: International Labor Organization. 
International Labor Organization (ILO). 2013a. "EPlex: Employment Protection Legislation Database." International Labor Organization. http://www.ilo.org/dyn/eplex/termmain.home?p_lang=en (June 21, 2013).

—_. 2013b. "NATLEX: Database of National Labour, Social Security and Related Human Rights Legislation." International Labor Organization. http://www.ilo.org/dyn/natlex/natlex4.home?p_lang=en (June 23, 2013).

International Trade Union Confederation. 2011. Report for the WTO General Council Review of the Trade Policies of Philippines (Geneva, 22 and 24 November 2011). http://www.ituccsi.org/report-for-the-wto-general-council,10084 (April 22, 2014).

Inter-Parliamentary Union. 2013. "Women in National Parliament." http://www.ipu.org/wmne/classif.htm (May 1, 2014).

—. 2014. "Women in National Parliament." http://www.ipu.org/wmn-e/classif.htm (May 1, 2014).

Ipsos Business Consulting. 2012. E\&E Sector Study on Supply-Demand of Talent in Malaysia. Ipsos Business Consulting.

Iskander Regional Development Authority. 2014. "Foreign Investment Overview." Iskander Malaysia. http://www.iskandarmalaysia.com.my/foreign-investment-overview (April 29, 2014).

Islam, Syful. 2012. "Small Businesses Pay Price in Bangladesh's Biggest Loan Scam." http://www.trust.org/item/20121002145200-hrwzm/ (April 8, 2014).

Ismail, Fauziah. 1980. "Training of Civil Servants in Malyasia." In Asian Civil Services Techincal Papers, Training in the Civil Service, eds. Amara Raksasataya and Henrich Siedentopf. Bonn: Institute for International Partnership.

Jabeen, Mussarat, Amir Ali Chandio, and Zarina Qasim. 2010. "Language Controversy: Impacts on National Politics and Secession of East Pakistan." South Asian Studies 25(1).

Jahan, Rounaq. 1987. “Women in South Asian Politics.” Third World Quarterly 9(3): 848-70.

Jalalzai, Farida. 2004. "Women Political Leaders: Past and Present.” Women \& Politics 26(3-4): 85-108.

Jenkins, Shirley. 1954. American Economic Policy toward the Philippines. Stanford University Press.

Johnson, Michael P. 1995. "Patriarchal Terrorism and Common Couple Violence: Two Forms of Violence against Women." Journal of Marriage and Family 57(2): 283-94.

Joint Foreign Chamber of Philippines. "Figures, Maps, and Tables." Arangkada Philippines. http://www.investphilippines.info/arangkada/figures-maps-and-tables/ (May 23, 2014).

Jong-Sung, You, and Sanjeev Khagram. 2005. "A Comparative Study of Inequality and Corruption." American Sociological Review 70(1): 136-57.

Juhary, Jowati Binti. 2011. "Abstraction and Concreteness in Customary Practices in Malysia: A Preliminary Understanding." International Journal of Humanities and Social Science 1(17): 28185.

Kabeer, Naila. 1998. “'Money Can’t Buy Me Love'? Re-Evaluating Gender, Credit and Empowerment in Rural Bangladesh.” Discussion Paper-Institute of Development Studies, University of Sussex 
(United Kingdom). http://agris.fao.org/agris-search/search.do?recordID=GB1999011278 (December 8, 2012).

2004. “Globalization, Labor Standards, and Women's Rights: Dilemmas of Collective (in) Action in an Interdependent World." Feminist Economics 10(1): 3-35.

Kabeer, Naila, and Simeen Mahmud. 2004. "Rags, Riches and Women Workers: Export-Oriented Garment Manufacturing in Bangladesh." Chains of fortune: Linking women producers and workers with global markets: 133-64.

Kanapathy, Vijayakumari, and Herizal Hazri. 2014. "Case Study from Malaysia." In Middle-Income Trap: Economic Myth, Political Reality, ed. Adam Burke. San Francisco, CA: The Asia Foundation, 18-22. http://asiafoundation.org/resources/pdfs/MiddleIncomeTrap.pdf (February $23,2013)$.

Kang, David C. 2002. Crony Capitalism: Corruption and Development in South Korea and the Philippines. Cambridge University Press.

Karim, Wazir-Jahan Begum. 1992. Women and Culture: Between Malay Adat and Islam. Westview Pr.

Karlekar, Hiranmay. 2005. Bangladesh: The next Afghanistan? Sage.

Karlekar, Malavika. 1991. Voices from within: Early Personal Narratives of Bengali Women. Oxford University Press New Delhi. http://indianmedicine.eldoc.ub.rug.nl/root/K5/363k/.

Kaufmann, Daniel, Aart Kraay, and Pablo Zoido-Lobaton. 1999. "Governance Matters.” The World Bank (2196).

Kaur, A. 1994. “A Historical Analysis of Women's Economic Participation in Development.” In Readings on Women in Development, ed. J. Arrifin. Population Studies Unit, University of Malaya.

Keohane, Robert Owen, and Joseph S. Nye. 1977. Power and Interdependence. Longman.

Khatun, Fahmida. 2008. Gender and Trade Liberalisation in Bangladesh: The Case of the Readymade Garments. Centre for Policy Dialogue.

Khundker, Nasreen. 2002. "Globalisation, Competitiveness and Job Quality in the Garment Industry in Bangladesh.” In Bangladesh, Economic and Social Challenges of Globalisation, eds. Muhammed Muqtada, Andréa Menefee Singh, and Mohammed Ali Rashid. University Press, 61-82.

Kibria, Nazli. 1998. Becoming a Garments Worker: The Mobilization of Women into the Garments Factories of Bangladesh. United Nations Research Institute for Social Development New York.

Kochanek, Stanley A. 1993. Patron-Client Politics and Business in Bangladesh. Sage Publications. 2000. "Governance, Patronage Politics, and Democratic Transition in Bangladesh." Asian Survey: $530-50$.

KPMG. 2002. International Survey on Corporate Sustainability Reporting. KPMG.

Krippendorff, Klaus. 1989. "Content Analysis.” International encyclopedia of communication 1: 403-7. http://repository.upenn.edu/asc_papers/226 (February 22, 2015). 
Krishnaswamy, Revathi. 2002. "The Criticism of Culture and the Culture of Criticism: At the Intersection of Postcolonialism and Globalization Theory." Diacritics 32(2): 106-26.

Kristof, Nicholas D., and Sheryl WuDunn. 2009. Half the Sky: Turning Oppression Into Opportunity for Women Worldwide. Vintage Books.

Kucera, David. 2002. “Core Labour Standards and Foreign Direct Investment.” International Labour Review 141(1-2): 31-69.

Kuhn, Annette, and AnnMarie Wolpe. 2013. Feminism and Materialism (RLE Feminist Theory): Women and Modes of Production. Routledge.

Kusago, Takayoshi, and Zafiris Tzannatos. 1998. Export Processing Zones: A Review in Need of Update. Social Protection Group, Human Development Network, The World Bank.

Lacsamana, Anne E. 2012. Revolutionizing Feminism: The Philippine Women's Movement in the Age of Terror. Paradigm Publishers.

LaHaye, Laura. "Mercantalism." The Concise Encyclopedia of Economics. http://www.econlib.org/library/Enc/Mercantalism.html (June 10, 2013).

Lall, Sanjaya. 2000. FDI and the Development: Research Issues in the Emerging Context. Center for International Economic Studies.

Lambert, Rob. 1990. "Kilusang Mayo Uno \& the Rise of Social Movement Unionism in the Philippines." Labour \& Industry: a journal of the social and economic relations of work 3(2-3): 258-80.

Lee, Daniel, and Richard Ho. 2010. Labor Shortage Issues Forum Report. Penang Institute.

Legarda, Benito Jr., and Garcia. 1966. "Economic Collaboration: The Trading Relationship.” In The United States and the Philippines, ed. Frank H. Golay. Prentice-Hall, 132-34.

De Leon, Ms Corazon Alma G. 2002. "REFORMS IN THE CIVIL SERVICE THE PHILIPPINE EXPERIENCE." In 4th Global Forum on Reinventing Government: Partnerships for Development and Democracy. UN Public Administration Programme. Marrakech, December, $11-13$.

http://reformthereformers.org/download/papers/Reforms\%20in $\% 20$ the $\% 20$ civil $\% 20$ service $\% 20$ th e\%20philippine\%20experience.pdf (January 9, 2015).

Levidow, Les. 1996. "Women Who Make the Chips.” Contributions in Sociology 118: 43-56.

Lewis, David. 2011. Bangladesh: Politics, Economy and Civil Society. Cambridge University Press.

Lie, Merete, and Ragnhild Lund. 1994. Renegotiating Local Values: Working Women and Foreign Industry in Malaysia. Routledge.

Lim, Linda. 1978. Women Workers in Multinational Corporations: The Case of the Electronics Industry in Malaysia and Singapore. Women's Studies Program, University of Michigan.

Lim, Linda YC, and Eng Fong Pang. 1991. "Foreign Direct Investment and Industrialisation in Malaysia, Singapore, Taiwan, and Thailand." http://ink.library.smu.edu.sg/lkcsb_research/240/ (February 9, 2014). 
Lim, Sung-Hoon. 2008. "How Investment Promotion Affects Attracting Foreign Direct Investment: Analytical Argument and Empirical Analyses.” International Business Review 17(1): 39-53.

Lindio-McGovern, Ligaya. 2013. Globalization, Labor Export and Resistance: A Study of Filipino Migrant Domestic Workers in Global Cities. Routledge.

Lipsey, Robert E., and Fredrik Sjoholm. 2001. Foreign Direct Investment and Wages in Indonesian Manufacturing. National Bureau of Economic Research. Working Paper. http://www.nber.org/papers/w8299 (March 7, 2013).

Li, Quan. 2009. "Democracy, Autocracy, and Expropriation of Foreign Direct Investment." Comparative Political Studies 42(8): 1098-1127.

Li, Quan, and Adam Resnick. 2003. "Reversal of Fortunes: Democratic Institutions and Foreign Direct Investment Inflows to Developing Countries.” International Organization 57(01): 175-211.

Little, Ian, Tibor Scitovsky, and Maurice Scott. 1970. "Industry and Trade in Some Developing Countries.” http://agris.fao.org/agris-search/search.do?recordID=US201300467290 (June 3, 2012).

Lu, Jinky Leilanie. 2008. "Occupational Hazards and Illnesses of Filipino Women Workers in Export Processing Zones.” International Journal of Occupational Safety and Ergonomics 14(3): 333-42.

Mabey, Nick, and McNally Richard. 1998. Foreign Direct Investment and the Environment. World Wildlife Foundation.

Madani, Dorsati. 1999. A Review of the Role and Impact of Export Processing Zones. World Bank Publications.

Malaysia Development Authority (MIDA). 2014. "Industries in Malaysia: Textiles and Apparel Industry.” Malaysian Development Authority. http://www.mida.gov.my (May 2, 2014).

Malaysian Investment Development Authority. 2013. Malaysia Investment Performance Report: Shifting into High Gear. Malaysian Investment Development Authority. http://www.mida.gov.my/env3/uploads/PerformanceReport/2013/IPR2013 (May 22, 2014).

Manan, Wan A. 1999. "A Nation in Distress: Human Rights, Authoritarianism, and Asian Values in Malaysia." SOJOURN: Journal of Social Issues in Southeast Asia: 359-81.

Manazan, Mary John Sr. 1987. "The Filipino Women: Before and After the Spanish Conquest of the Philippines.” In Essays on Filipino Women, ed. Mary John Manazan. Manila: St. Scholastica's College, 7-36.

Mandle, Jay R. 2003. Globalization and the Poor. Cambridge University Press.

Maranan, Aida. 1987. “Do Women Really Hold up Half the Sky?” In Essays on Filipino Women, ed. Mary John Manazan. Manila: St. Scholastica’s College, 38-39.

Margold, Jane A. 1995. "Narratives of Masculinity and Transnational Migration: Filipino Workers in the Middle East." In Bewitching Women, Pious Men: Gender and Body Politics in Southeast Asia, eds. Aihwa Ong and Michael G. Peletz. Univ of California Press, 274-98.

Martin, Denis-Constant. 1991. "The Cultural Dimensions of Governance." WORLD BANK ECONOMIC REVIEW: 325-41. 
Maskus, Keith Eugene, and Jill A. Holman. 1997. Should Core Labor Standards Be Imposed through International Trade Policy?. World Bank Publications.

Maximiano, Jose Mario B. 2005. "The State of Corporate Social Responsibility in the Philippines." In , 28-30. https://130.220.1.110/Documents/EASS/HRI/GIG/maximiano.pdf (March 9, 2013).

McCracken, Angela. 2011. "Beauty and the Quinceañera: Reproductive, Prouctive, and Virtual Dimension of the Global Political Economy of Beauty." In Feminism and International Relations: Conversations about Past, Presnt, and Future, eds. J. Ann Tickner and Laura Sjoberg. Routledge, 194-211.

McIntosh, Mary. 2013. "The State and the Oppression of Women." Feminism and materialism 255.

McKay, Steven C. 2006. "The Squeaky Wheel's Dilemma: New Forms of Labor Organizing in the Philippines.” Labor Studies Journal 30(4): 41-63.

Mehmet, Ozay, and Akbar Tavakoli. 2003. "Does Foreign Direct Investment Cause a Race to the Bottom?" Journal of the Asia Pacific Economy 8(2): 133-56.

Mehra, Rekha, and Sarah Gammage. 1999. "Trends, Countertrends, and Gaps in Women's Employment." World Development 27(3): 533-50.

De Mello, Luiz R. 1997. "Foreign Direct Investment in Developing Countries and Growth: A Selective Survey." The Journal of Development Studies 34(1): 1-34.

Mellström, Ulf. 2009. "The Intersection of Gender, Race and Cultural Boundaries, or Why Is Computer Science in Malaysia Dominated by Women?" Social Studies of Science 39(6): 885-907.

Mercado-Aldaba, Rafaelita A. 1994. Foreign Direct Investment in the Philippines: A Reassessment. Philippine Institute for Development Studies. http://pdf.usaid.gov/pdf_docs/PNABX021.pdf (July 9, 2013).

Mies, Maria. 1998. Patriarchy and Accumulation On A World Scale: Women in the International Division of Labour. Palgrave Macmillan.

Migration News. 1995. "Malaysian Reliance on Foreign Workers.” Migration News, University of California, Davis 2.

Miller, Stuart Creighton. 1982. Benevolent Assimilation: The American Conquest of the Philippines, 1899-1903. Yale University Press.

Minerals Council of Australia. 2013. It's Not Just a Program. Minerals Council of Australia.

Ministry of Women, Family, and Community Development. 2005. Gender Budgeting in Malaysia. Kuala Lumpur: Ministry of Women, Family, and Community Development. http://www.kpwkm.gov.my/documents/10156/253b1b03-da26-44fc-b1e3-e8259383906c (October 23, 2014).

Moghdam, Valentine M. 1999. "Gender and Globalization: Female Labor and Women's Mobilization." Journal of World Systems Research 2: 367-85.

Mohamad, Maznah, and Cecilia Ng. 2013. Feminism and the Women's Movement in Malaysia: An Unsung (r) Evolution. Routledge. 
Mohamed, Mahathir. 1991. "Malaysia: The Way Forward (Vision 2020).” Kuala Lumpur, National Printing Department.

Mohr, Lois A., Deborah J. Webb, and Katherine E. Harris. 2001. "Do Consumers Expect Companies to Be Socially Responsible? The Impact of Corporate Social Responsibility on Buying Behavior." Journal of Consumer Affairs 35(1): 45-72.

Mohsin, Amena. 2013. "The Two Meanings of 'Bangladeshi."” In The Bangladesh Reader: History, Culture, Politics, eds. Meghna Guhathakurta and Willem van Schendel. Duke University Press, 332-33.

Momsen, Janet Henshall. 2010. Gender and Development. 2nd ed. Psychology Press.

Moran, Theodore. 2008. "Foreign Direct Investment and Development." In The White House and the World: The Global Development, ed. Nancy Birdsall. Washington D.C.: Center for Global Development, 121-40.

Moser, Caroline. 1993. Gender Planning and Development: Theory, Practice and Training. Routledge.

Mosley, Layna, and Saika Uno. 2007. "Racing to the Bottom or Climbing to the Top? Economic Globalization and Collective Labor Rights." Comparative Political Studies 40(8): 923-48.

Mridula, Shakila Matin, and Khosrun Afrin Khan. 2009. Working Conditions and Reproductive Health Status of Female Garments Workers of Bangladesh. Bangladesh Occupational Safety, Health and Environment Foundation. http://amrc.org.hk/content/working-conditions-and-reproductivehealth-status-female-garments-workers-bangladesh (October 18, 2013).

Mukherjee, Ranjana. 2001. Bangladesh: The Experience and Perceptions of Public Officials. World Bank Publications.

Mukhopadhyay, Ujjaini, and Sarbajit Chaudhuri. 2011. "Economic Liberalization, Gender Wage Inequality and Welfare-A Theoretical Analysis." http://mpra.ub.uni-muenchen.de/32954/ (November 8, 2013).

Mutti, John H. 2003. Foreign Direct Investment and Tax Competition. Peterson Institute.

Nash, June C., and María Patricia Fernández-Kelly. 1983. Women, Men, and the International Division of Labor. SUNY Press.

National Statistics Coordination Board. 2014. "Indicators Produced and Compiled by NSCB." Philippine Statistics Authority- National Statistics Coordination Board. http://www.nscb.gov.ph/stattables/ (April 22, 2014).

Nielsen, Joyce M. 1990. Feminist Research Methods: Exemplary Readings In The Social Sciences. New edition edition. ed. * EDITOR. Boulder: Westview Press.

Nik Ahmad, Nazli, and Maliah Sulaiman. 2004. "Environment Disclosure in Malaysia Annual Reports: A Legitimacy Theory Perspective." International Journal of Commerce and Management 14(1): 44-58.

Nisonoff, Laurie. 2008. "Introduction to Part 3.” In The Women, Gender, and Development Reader, eds. Nalini Visvanathan, Lynn Duggan, Nan Wiegersma, and Laurie Nisonoff. London: Zed Books Ltd., 177-90. 
Nunnenkamp, Peter, and Julius Spatz. 2004. Foreign Direct Investment and Economic Growth in Developing Countries: How Relevant Are Host-Country and Industry Characteristics?. Rochester, NY: Social Science Research Network. SSRN Scholarly Paper. http://papers.ssrn.com/abstract=425260 (November 6, 2012).

Obejas, Joselito DR. "Wiping Away the Footprints of Corruption in the Philippines." In Resource Material Series, UNADEI, 97-122.

Oishi, Nana. 2005. Women in Motion: Globalization, State Policies, and Labor Migration in Asia. Stanford University Press.

Ong, Aihwa. 1987. Spirits of Resistance and Capitalist Discipline: Factory Women in Malaysia. Suny Press.

1990. "State versus Islam: Malay Families, Women's Bodies, and the Body Politic in Malaysia." American Ethnologist 17(2): 258-76.

Organisation for Economic Co-operation and Development. "Foreign Direct Investment." Glossary of Foreign Direct Investment Terms and Definition. http://www.oecd.org/investment/investmentfordevelopment/2487495.pdf (May 23, 2013).

Oxford Islamic Studies Online. 2014. "Dakwah (Malysia)." Oxford Islamic Studies Online. http://www.oxfordislamicstudies.com/article/opr/t125/e480?_hi=0\&_pos=13 (May 25, 2014).

Papanek, Hanna. 1973. "Purdah: Separate Worlds and Symbolic Shelter." Comparative Studies in Society and History 15(03): 289-325.

Parreñas, Rhacel Salazar. 2005. Children of Global Migration: Transnational Families and Gendered Woes. Stanford University Press.

Pasha, Ahmed Sahuja. 1995. Pakistan: A Political Studies. Lahore: Sang-e-meel Publications.

Paul-Majumdar, Pratima, and Anwara Begum. 2000. "The Gender Imbalances in Export Oriented Industries: A Case of the Ready Made Garment Industry in Bangladesh.” The World Bank.

Payne, Angela R., and Bharat S. Thakkar. 2012. "The Marshall Plan-Global Strategy and Foreign Humanitarian Aid.” GLOBALIZATION-APPROACHES TO DIVERSITY: 133.

Pearce, Diana. 1978. “The Feminization of Poverty: Women.” Work. http://socialworkers.org/feminizationofpoverty/presentations/pearce/Pearce_The $\% 20$ Feminizatio n\%20of\%20Poverty_1978\%20original\%20article.pdf.

Perlo, Victor. 1951. American Imperialism. International publishers.

Permanent People's Tribunal. 2007. Verdict: Indicting the U.S. Backed Arroyo Regime and Its Accomplices for Human Rights Violatio, Economic Plunder and Transgression of the Filipino People's Sovereignty. http://philippinetribunal.org/index.php?option=com docman\&Task=cat_view\&grid=43\&Itemid=53 (April 23, 2014).

Peterson, V. Spike. 2011. "Femininity: Culture, Ideology, and Political Economy." In Feminism and International Relations: Conversations about Past, Presnt, and Future, eds. J. Ann Tickner and Laura Sjoberg. Routledge, 212-20. 
Philippine Commission on Women. 2013. "Philippines Is Asia's Best Performer in Closing Gender Gap, Ranks 5th in the World." Philippine Commission on Women. http://www.pcw.gov.ph/article/philippines-asia\%E2\%80\%99s-best-performer-closing-gendergap-ranks-5th-world (March 4, 2014).

Philippine Economic Zone Authority (PEZA). 2014. “Operating Economic Zones." Philippine Economic Zone Authority. http://www.peza.gov.ph/index.php/economic-zones/list-of-economic-zones (April 22, 2014).

Phillipine Commission on Women. 2009. "Republic Act 9710: Magna Carta of Women." Phillipine Commission on Women. http://www.pcw.gov.ph/law/republic-act-9710 (April 26, 2014).

Phillips, Anne, and Barbara Taylor. 1980a. "Sex and Skill: Notes towards a Feminist Economics." Feminist Review 6(1): 79-88.

1980b. "Sex and Skill: Notes towards a Feminist Economics." Feminist Review 6(1): 79-88.

Phillips, Richard, and Jeffrey Henderson. 2009. "Global Production Networks and Industrial Upgrading: Negative Lessons from Malaysian Electronics.” Austrian Journal for Development Studies 25(2): $38-61$.

Pierre, Jon. 2000. Debating Governance: Authority, Steering, and Democracy. Oxford University Press. OUP Catalogue. http://econpapers.repec.org/bookchap/oxpobooks/9780198297727.htm (March 8, 2014).

Pigato, Miria. 2001. “The Foreign Direct Investment Environment in Africa.” In World Bank.

Pineda-Ofreneo, Rosalinda. 1987. "Women in the Electronics Industry in the Philippines." Technology and Gender: Women's Work in Asia, Women's Studies Unit, University of the Philippines/Malaysia Social Science Association, Diliman/Kuala Lumpur: 92-106.

Piper, Nicola. 2006a. "Migrant Worker Activism in Singapore and Malaysia: Freedom of Association and the Role of the State." Asian and Pacific migration journal 15(3): 359-80.

_ 2006b. "Migrant Worker Activism in Singapore and Malaysia: Freedom of Association and the Role of the State." Asian and Pacific migration journal 15(3): 359-80.

Quah, Jon ST. 2006. “Curbing Asian Corruption: An Impossible Dream?” CURRENT HISTORY-NEW YORK THEN PHILADELPHIA- 105(690): 176.

— 2013. "Curbing Corruption in the Philippines: Is This an Impossible Dream?" Philippine Journal of Public Administration 54(1-2): 1-43.

Quisumbing, Agnes R. 1996. "Male-Female Differences in Agricultural Productivity: Methodological Issues and Empirical Evidence." World Development 24(10): 1579-95.

Quisumbing, Torres. 2013. Guide to Philippine Employment Law: An Overview of Employment Laws for the Private Sector. Baker McKenzie. http://www.bakermckenzie.com/files/Publication/6e2edcc4648a-458f-8995-e862e90192f0/Presentation/PublicationAttachment/40c18d0d-1c55-4e07-9a144ccfbf9152ed/bk_manila_guideemploymentlawv2_2013.pdf (April 28, 2014).

Raday, Frances. 2003. “Culture, Religion, and Gender.” Int'l J. Const. L. 1: 663. 
Rahman, Syed Tayyeb-ur. 1985. Global Geo-Strategy of Bangladesh, OIC and Islamic Ummah. Islamic Foundation Bangladesh.

Rai, Shirin M. 2002. Gender and the Political Economy of Development: From Nationalism to Globalization. John Wiley \& Sons.

Rao, Nitya. 2012. "Breadwinners and Homemakers: Migration and Changing Conjugal Expectations in Rural Bangladesh." Journal of Development Studies 48(1): 26-40.

Rapley, John. 1997. Understanding Development: Theory And Practice In The Third World. Routledge.

—_ 2004. Globalization and Inequality: Neoliberalism's Downward Spiral. Lynne Rienner Publishers.

Rasiah, Rajah. 1995. "Labour and Industrialization in Malaysia." Journal of Contemporary Asia 25(1): 73-92.

Rasiah, R., and I. Shari. 2001. "Market, Government and Malaysia's New Economic Policy." Cambridge Journal of Economics 25(1): 57-78.

Reinharz, Shulamit, and Lynn Davidman. 1992. viii Feminist Methods in Social Research. New York, NY, US: Oxford University Press.

Riaz, Ali. 2004. God Willing: The Politics of Islamism in Bangladesh. Rowman \& Littlefield.

Richter, Linda K. 1991. "Exploring Theories of Female Leadership in South and Southeast Asia." Pacific Affairs 6: 524-40.

Roces, Mina. 2000. "Negotiating Modernities: Filipino Women 1970-2000.” In Women in Asia: Tradition, Modernity, and Globalisation, eds. Louise P. Edwards and Mina Roces. University of Michigan Press, 112-38.

Rodriguez, Luz Lopez. 2012. "Patriarchy and Women's Subordination in the Philippines." Review of Women's Studies 1(1). http://journals.upd.edu.ph/index.php/rws/article/view/3248/3046 (January 9, 2014).

Rodrik, Dani. 1998. “Has Globalization Gone Too Far?” Challenge 41(2): 81-94.

Del Rosario, Rosario. 1985. Life on the Assembly Line: An Alternative Philippine Report on Women Industrial Workers. Philippine Women's Research Collective.

Rosemblatt, Karin Alejandra. 2000. Gendered Compromises: Political Cultures and the State in Chile, 1920-1950. Univ of North Carolina Press.

Rudnick, Anja. 2009. Working Gendered Boundaries: Temporary Migration Experiences of Bangladeshi Women in the Malaysian Export Industry from a Multi-Sited Perspective. Amsterdam University Press.

Ruggie, Mary. 1984. The State and Working Women: A Comparative Study of Britain and Sweden. Princeton University Press.

Sabbah, Fatna Aït. 1984. Woman in the Muslim Unconscious. Pergamon.

Sadka, Emily. 1968. The Protected Malay States 1874-1893. Kuala Lumpur. 
Safa, Helen. 1983. "Women, Production, and Reproduction in Industrial Capitalism: A Comparison of Brazilian and U.S. Factory Workers." In Women, Men, and the International Division of Labor, eds. María Patricia Fernández-Kelly and June C. Nash. SUNY Press, 95-116.

Salleh, Ismail Mohd, and Saha Dhevan Meyanathan. 1993. Malaysia: Growth, Equity, and Structural Transformation. World Bank Publications.

Salzinger, Leslie. 2003. Genders in Production: Making Workers in Mexico's Global Factories. University of California Press.

Dos Santos, Theotonio. 1971. “The Structure for Dependence.” In Readings in US Imperialism, eds. K.T. Fann and Donald C. Hodges. Boston: Porter Sargent.

SarDesai, Damodar Ramaji, Ira D. Sasowsky, and Carol M. Wicks. 1997. Southeast Asia: Past and Present. Westview Press Boulder.

Van Schendel, Willem. 2009. A History of Bangladesh. Cambridge University Press Cambridge.

Schneider, Friedrich, and Bruno S Frey. 1985. "Economic and Political Determinants of Foreign Direct Investment." World Development 13(2): 161-75.

Scott, Joan W. 1986. "Gender: A Useful Category of Historical Analysis.” The American Historical Review 91(5): 1053-75.

Seekins, Donald M. 1984. "Historical Setting.” In Malaysia, a Country Study, ed. Frederica M. Bunge. http://agris.fao.org/agris-search/search.do?recordID=US201300635463 (January 9, 2013).

Seguino, S. 2000. "The Effects of Structural Change and Economic Liberalisation on Gender Wage Differentials in South Korea and Taiwan." Cambridge Journal of Economics 24(4): 437-59.

Segunio, Stephanie. 1997. "Export-Led Growth and the Presistence of Gender Inequality in the Newly Industrialized Countries." In Economic Dimensions of Gender Inequality: A Global Perspective, eds. Janet M. Rives and Mahmood Yousefi. Greenwood Publishing Group, 11-33.

Sen, Indrani. 2001. "Devoted Wife/Sensuous Bibi: Colonial Constructions of the Indian Woman, 18601900.” Indian Journal of Gender Studies 8(1): 1-22.

Shah, Anup. 2010. "A Primer on Neoliberalism.” http://www.globalissues.org/article/39/a-primer-onneoliberalism. https://saylor.longsight.com/handle/1/13161 (March 3, 2012).

Shalom, Stephen R. 1980. "Philippine Acceptance of the Bell Trade Act of 1946: A Study of Manipulatory Democracy.” The Pacific Historical Review: 499-517.

Sharp, Joanne P. 2003. "Feminist and Postcolonial Engagements." A companion to political geography: 59.

Siddiqi, Dina M. 2006. "In the Name of Islam? Gender, Politics and Women's Rights in Bangladesh." Harvard Asia Quarterly 10(1): 4-14.

Sim, Hew Cheng. 2009. "Globalisation and Its Challenges to Gender Mainstreaming in Malaysia." Akademika 86(1): 123-29.

Skocpol, Theda, and Margaret Somers. 1980. "The Uses of Comparative History in Macrosocial Inquiry." Comparative studies in society and history 22(02): 174-97. 
Smart, Carol. 1984. The Ties That Bind (Routledge Revivals): Law, Marriage and the Reproduction of Patriarchal Relations. Routledge.

Smith, Jackie, Melissa Bolyard, and Anna Ippolito. 1999. "Human Rights and the Global Economy: A Response to Meyer." Human Rights Quarterly 21(1): 207-19.

Sobhan, Salma. 2013. "Perceptions of Cultural Identity." In The Bangladesh Reader: History, Culture, Politics, eds. Meghna Guhathakurta and Willem van Schendel. Duke University Press, 303-10.

Spate, Oskar Hermann Khristian. 1948. "The Partition of India and the Prospects of Pakistan.” Geographical Review: 5-29.

Spero, Joan Edelman, and Jeffrey Hart. 2009. The Politics of International Economic Relations. Cengage Learning.

Standing, Guy. 1999. "Global Feminization through Flexible Labor: A Theme Revisited." World development 27(3): 583-602.

Steans, Jill. 2013. Gender and International Relations. John Wiley \& Sons.

Stivens, Maila. 2006. "Introduction: Gender Politics and the Remaining of Human Rights in the AsiaPacific." In Human Rights and Gender Politics: Asia-Pacific Perspectives, eds. Anne-Marie Hilsdon, Martha Macintyre, Vera Mackie, and Maila Stivens. Routledge, 1-36.

Stoler, Ann L. 1989. "Making Empire Respectable: The Politics of Race and Sexual Morality in 20thCentury Colonial Cultures." American Ethnologist 16(4): 634-60.

Strange, Heather. 1981a. "Rural Malay Women in Tradition and Transition." http://www.popline.org/node/426028 (March 9, 2015). 1981b. Rural Malay Women in Tradition and Transition. New York, NY, US: Praeger Publishers. http://www.popline.org/node/426028 (March 9, 2015).

SUARAM. 1998. The Non-State Sector: Rise of Human Rights Activism. SUARAM.

Sulaiman, Norhayati. 2007. "Gender Mainstreaming in Malaysia.” In Kuala Lumpur.

Sundaram, Jomo Kwame. 2004. The New Economic Policy and Interethnic Relations in Malaysia. United Nations Research Institute for Social Development.

Sundaram, Jomo Kwame, and Edmund T. Gomez. 2000. “The Malaysian Development Dilemma.” In Rents, Rent-Seeking and Economic Development: Theory and Evidence in Asia, eds. Mushtaq H. Khan and Jomo Kwame Sundaram. Cambridge University Press, 274-303.

Talpade Mohanty, Chandra. 2003. "Under Western Eyes Revisited: Feminist Solidarity through Anticapitalist Struggles." Signs 28(2): 499-535.

Tamanna, Urmi. 2010. "Labor Unrest in Bangladesh RMG Sector: Does Actice Labor in Union Reduce the Risk of Labor Unrest in RMG Sector?" BRAC University. http://dspace.bracu.ac.bd/bitstream/handle/10361/2087/Labor\%20Unrest $\% 20 \mathrm{in} \% 20$ Bangladesh\% 20RMG\%20Sector.pdf? sequence=1 (April 18, 2014).

The Dhaka Chamber of Commerce and Industry. 2000. Economic Policy Paper on Foreign Investment Protection Policies and Anti-Expropriation Measures. Dhaka: The Dhaka Chamber of Commerce 
and Industry. http://www.dhakachamber.com/economic_policy/Foreign_Investment_protec.pdf (April 24, 2014).

The Manila Times Online, (first). "Amend the Constitution to Attract More FDI?"

http://www.manilatimes.net/amend-the-constitution-to-attract-more-fdi/89109/ (April 19, 2014).

The Worcestershire Regiment. "Malaya and the Emergency (1950-52)." The Worcestershire Regiment. $<\mathrm{http}: / / w w w . w o r c e s t e r s h i r e r e g i m e n t . c o m / h \_m a l a y a 1 . p h p>$. (May 15, 2014).

The World Bank. 2011. Fostering Women's Economic Empowerment Through Special Economic Zones. The World Bank. http://herproject.org/downloads/sez-and-women-global.pdf (April 25, 2014).

—. 2013. "World Development Indicators."

http://databank.worldbank.org/data/views/reports/tableview.aspx?isshared=true (March 8, 2013).

Thompson, Grahame. 1998. Economic Dynamism in the Asia-Pacific: The Growth of Integration and Competitiveness. Psychology Press.

Thompson, Mark R. 2003. "Female Leadership of Democratic Transitions in Asia." Pacific Affairs 75(4): 535-55.

Thompson, Paul, and Zarina Zakaria. 2004. "Corporate Social Responsibility Reporting in Malaysia." Journal of Corporate Citizenship 2004(13): 125-36.

Tickner, J. Ann. 2006. "Feminist Meets International Relations: Some Methodological Issues.” In Feminist Methodologies for International Relations, eds. Brooke A. Ackerly, Maria Stern, and Jacqui True. Cambridge University Press, 19-41.

Tickner, J. Ann, and Laura Sjoberg. 2011. Feminism and International Relations: Conversations about the Past, Present and Future. Routledge.

Tjiptoherijanto, Prijono. 2012a. Civil Service Reform in Malaysia: Commitment and Consistency. Faculty of Economics, University of Indonesia. Working Papers in Economics and Business. http://econpapers.repec.org/paper/lpewpecbs/201204.htm (December 9, 2014).

—_ 2012b. Civil Service Reform in The Philippines: Building Strong Governance. Faculty of Economics, University of Indonesia. http://econ.fe.ui.ac.id/uploads/201202.pdf (December 19, 2014).

Transparency International. 2011. APEC Public Procurement Transparency Standards in the Philippines: A Work in Progress. USA: Transparency International. http://www.transparencyusa.org/documents/PhilippinesAPECProcurementStandardsFinal.pdf (April 27, 2014).

_ 2012a. "Corruption Perception Index." http://www.transparency.org/research/cpi/overview (March 8, 2014).

—_ 2012b. "How Corrupt Is Your Country?” http://www.transparency.org/cpi2012 (March 8, 2014).

—_ 2012c. "Overview of Corruption and Anti-Corruption in Bangladesh." U4. http://www.u4.no/publications/overview-of-corruption-and-anti-corruption-in-bangladesh/ (March 8, 2014).

2014a. "FAQs on Corruption." Transparency International.

http://www.transparency.org/whoweare/organisation/faqs_on_corruption/2/ (January 10, 2014). 
__ 2014b. "Transparency in Corporate Reporting: Assessing the World's Largest Companies (2014)." Issuu.

http://issuu.com/transparencyinternational/docs/2014_transparencyincorporatereporti (March 8, 2014).

Trezzini, Bruno. 2001. “Institutional Foundations of Malaysia’s State Capacity." Asian Journal of Public Administration 23(1): 33-63.

UN. 2013. Why Do Some Men Use Violence Against Women and How Can We Prevent It?. New York, NY, US: United Nations.

UNIFEM. 2010. Who Answers to Women? Gender and Accountability, Progress of the World's Women Report 2008. New York, NY, US: United Nations. file:///Users/ritudhungana/Desktop/Corruption-accountability-and-gender.pdf (August 5, 2014).

United Nations. 2002. Gender Mainstreaming: An Overview. New York, NY, US: United Nations: Office of the Speical Adviser on Gender Issues and Advancement of Women. http://www.un.org/womenwatch/osagi/pdf/e65237.pdf (April 29, 2014).

United Nations Country Team, Malaysia. 2011. Malaysia: The Millennium Development Goals at 2010. Kuala Lumpur: United Nations.

U.S. Department of State. 2013. "Country Reports on Human Rights Practices for 2013.” http://www.state.gov/j/drl/rls/hrrpt/humanrightsreport/index.htm (August 10, 2014).

U.S. Department Of State. 2014. "Trafficking in Persons Report 2014.” http://www.state.gov/j/tip/rls/tiprpt/2014/index.htm (August 10, 2014).

U.S. Department Of State. The Office of Website Management. 2009. "Human Rights Reports." http://www.state.gov/j/drl/rls/hrrpt/ (August 8, 2014).

Velasco, Andres. 2002. "Dependency Theory." Foreign Policy: 44-45.

Viner, Jacob. 1948. "Power versus Plenty as Objectives of Foreign Policy in the Seventeenth and Eighteenth Centuries." World Politics 1(01): 1-29.

Visvanathan, Nalini, Lynn Duggan, and Laurie Nisonoff. 2005. The Women, Gender and Development Reader. Zubaan.

Vreeland, Nena. 1977. Area Handbook for Malaysia: Research Completed June 1976. American University, Foreign Area Studies.

Walker, Lenore E. 1989. "Psychology and Violence against Women.” American Psychologist 44(4): 695702.

Ward, Kathryn B. 1985. Women Workers and Global Restructuring. Cornell University Press.

Waring, Marilyn, and Gloria Steinem. 1988. If Women Counted: A New Feminist Economics. Harper \& Row San Francisco. http://www.roiw.org/1992/237.pdf (January 8, 2015).

War on Want. 2011. Stitched Up: Women Workers in the Bangladeshi Garment Sector. London: War on Want. 
—_. "The Multi Fibre Agreement." http://www.waronwant.org/component/content/article/22sweatshops-/10553 (April 22, 2015).

- 2012. Restricted Rights: Migrant Women Workers in Thailand, Cambodia and Malaysia. War on Want. http://www.waronwant.org/overseas-work/sweatshops-and-plantations/hide/inform/17518restricted-rights-migrant-women-workers-in-thailand-cambodia-and-malaysia (March 9, 2014).

Weeks, John. 2003. "Exports, Foreign Investment and Growth in Latin America: Scepticism by Way of Simulation.” In New York University, New York, NY: Center for Economic Policy Analysis.

Weiler, Todd. 2004. "Balancing Human Rights and Investor Protection: A New Approach for a Different Legal Order.” Boston College International and Comparative Law Review 27: 429.

Weldes, Jutta. 2006. "High Politics and Low Data: Globalization Discourses and Popular Culture." Interpretation and method: empirical research methods and the interpretive turn: 176-86.

West, Lois A. 1997. Militant Labor in the Philippines. Temple University Press.

Wichterich, Christa. 2000. The Globalized Woman: Reports from a Future of Inequality. Spinifex Press.

Wolf, Diane L. 2008. "Daughters, Decisions and Dominations: An Empirical and Conceptual Critiqie of Household Strategies." In The Women, Gender, and Development Reader, eds. Nalini Visvanathan, Lynn Duggan, Laurie Nisonoff, and Nan Wiegersma. London: Zed Books Ltd., $118-32$.

Wolf-Phillips, Leslie. 1987. "Why Third World'?: Origin, Definition and Usage.” Third World Quarterly 9(4): 1311-27.

Wood, Stephen. 1982. The Transformation of Work?: Skill, Flexibility and the Labour Process. Taylor \& Francis.

World Trade Organization. 2014. "Textiles Monitoring Body (TMB): The Agreement on Textiles and Clothing." World Trade Organization. https://www.wto.org/english/tratop_e/texti_e/texintro_e.htm (May 12, 2014).

Wren, Colin, and Jonathan Jones. 2012. "FDI Location across British Regions and Agglomerative Forces: A Markov Analysis.” Spatial Economic Analysis 7(2): 265-86.

Wurfel, David. 1959. "Trade Union Development and Labor Relations Policy in the Philippines." Industrial and Labor Relations Review: 582-608.

Yap, Stacey GH. 1989. 24 Gather Your Strength, Sisters: The Emerging Role of Chinese Women Community Workers. AMS Press.

Yardley, Jim. 2013. "Garment Trade Wields Power in Bangladesh.” The New York Times. http://www.nytimes.com/2013/07/25/world/asia/garment-trade-wields-power-in-bangladesh.html (March 8, 2014).

Yodanis, Carrie L. 2004. "Gender Inequality, Violence Against Women, and Fear A Cross-National Test of the Feminist Theory of Violence Against Women." Journal of Interpersonal Violence 19(6): 655-75.

Young, Robert. 2004. White Mythologies: Writing History and the West. Psychology Press. 
Youngs, Gillian, ed. 1999. Political Economy, Power and the Body. Basingstoke: Palgrave Macmillan. http://www.palgraveconnect.com/doifinder/10.1057/9780333983904 (January 5, 2015).

_ 2003. "Private Pain/public Peace: Women's Rights as Human Rights and Amnesty International's Report on Violence against Women." Signs 28(4). http://www.jstor.org/stable/10.1086/368325 (February 8, 2015).

Yum, June Ock. 1988. "The Impact of Confucianism on Interpersonal Relationships and Communication Patterns in East Asia." Communication Monographs 55(4): 374-88.

Yunus, Mohammad, and Tatsufumi Yamagata. 2012. "The Garment Industry in Bangladesh." Dynamics of the Garment Industry in Low-Income Countries: Experience of Asia and Africa. IDE-JETRO Interim Report.<http://www. ide. go.jp/Japanese/Publish/Download/Report/2011/2011_410. html $>$ (accessed on December 18, 2012). http://www.ide.go.jp/Japanese/Publish/Download/Report/2011/pdf/410_ch6.pdf (March 8, 2014).

Zafarullah, Habib, and Redwanur Rahman. 2008. "The Impaired State: Assessing State Capacity and Governance in Bangladesh.” International Journal of Public Sector Management 21(7): 739-52.

Zafarullah, Habib, and Noore Alam Siddiquee. 2001. "Dissecting Public Sector Corruption in Bangladesh: Issues and Problems of Control." Public Organization Review 1(4): 465-86.

Zaheer, Hasan. 1994. The Separation of East Pakistan: The Rise and Realization of Bengali Muslim Nationalism. Oxford University Press Karachi.

Zain, M.M. 1999. "Corporate Social Reporting in Malaysia: The Current State of the Art and Future Prospect." University of Sheffield.

Zerrudo, Robert Gill, Catherine Franco, and Torres Quisumbing. "Prohibition on Night Work by Women Repealed." International Labor and Employment Law Committee Newsletter.

Zhang, Kevin Honglin. 2001. "Does Foreign Direct Investment Promote Economic Growth? Evidence from East Asia and Latin America." Contemporary Economic Policy 19(2): 175-85.

Zohir, Salma Chaudhuri. 2001. "Social Impact of the Growth of Garment Industry in Bangladesh." The Bangladesh Development Studies: 41-80. 